\title{
Innovative optical techniques for intraoperative anatomical guidance : surgical navigation beyond the limits of the human eye
}

Citation for published version (APA):

Schols, R. M. (2014). Innovative optical techniques for intraoperative anatomical guidance : surgical navigation beyond the limits of the human eye. [Doctoral Thesis, Maastricht University]. Maastricht University. https://doi.org/10.26481/dis.20141219rs

Document status and date:

Published: 01/01/2014

DOI:

10.26481/dis.20141219rs

Document Version:

Publisher's PDF, also known as Version of record

Please check the document version of this publication:

- A submitted manuscript is the version of the article upon submission and before peer-review. There can be important differences between the submitted version and the official published version of record.

People interested in the research are advised to contact the author for the final version of the publication, or visit the DOI to the publisher's website.

- The final author version and the galley proof are versions of the publication after peer review.

- The final published version features the final layout of the paper including the volume, issue and page numbers.

Link to publication

\footnotetext{
General rights rights.

- You may freely distribute the URL identifying the publication in the public portal. please follow below link for the End User Agreement:

www.umlib.nl/taverne-license

Take down policy

If you believe that this document breaches copyright please contact us at:

repository@maastrichtuniversity.nl

providing details and we will investigate your claim.
}

Copyright and moral rights for the publications made accessible in the public portal are retained by the authors and/or other copyright owners and it is a condition of accessing publications that users recognise and abide by the legal requirements associated with these

- Users may download and print one copy of any publication from the public portal for the purpose of private study or research.

- You may not further distribute the material or use it for any profit-making activity or commercial gain

If the publication is distributed under the terms of Article $25 \mathrm{fa}$ of the Dutch Copyright Act, indicated by the "Taverne" license above, 


\section{INNOVATIVE OPTICAL TECHNIQUES FOR}

\section{INTRAOPERATIVE ANATOMICAL GUIDANCE}

Surgical navigation beyond the limits of the human eye 
Copyright (C) 2014 by R.M. Schols. All rights reserved.

ISBN/EAN: 978-90-822614-4-8

Cover illustration: Nadine de Burlette, Grafische Dienstverlening MUMC+ Thesis layout: Tiny Wouters

Printed by: Grafische Dienstverlening MUMC+

The author of this thesis was funded by the van ' $t$ Hoff Program for Medical Photonics, a shared innovation program coordinated by the Netherlands Organization for Applied Scientific Research-TNO. Furthermore funding was provided by NUTRIM, School for Nutrition, Toxicology and Metabolism of Maastricht University and the Department of Surgery of Maastricht University Medical Center.

Reproduction of this thesis was kindly and unconditionally supported by KARL STORZ GMBH \& Co. KG, European Photonics Industry Consortium (EPIC), IPC Neurobrain, Stichting Pelerin, Stöpler Instrumenten \& Apparaten B.V., which is gratefully acknowledged. 


\section{INNOVATIVE OPTICAL TECHNIQUES FOR}

\section{INTRAOPERATIVE ANATOMICAL GUIDANCE}

Surgical navigation beyond the limits of the human eye

PROEFSCHRIFT

Ter verkrijging van de graad van doctor

aan de Universiteit Maastricht, op gezag van de Rector Magnificus, Prof. dr. L.L.G. Soete, volgens het besluit van het College van Decanen,

in het openbaar te verdedigen

op vrijdag 19 december 2014 om 12.00 uur

door

\section{Rutger Merlijn Schols}

geboren op 25 april 1987

te Maastricht 
Promotores

Prof. dr. L.P.S. Stassen

Prof. dr. N.D. Bouvy

\section{Copromotor}

Dr. Ing. F.P. Wieringa (van 't Hoff Program on Medical Photonics, TNO)

\section{Beoordelingscommissie}

Prof. dr. J.G. Maessen (voorzitter)

Prof. dr. H.J. Bonjer (VU medisch centrum)

Prof. dr. I.A.M.J. Broeders (Universiteit Twente)

Prof. dr. R.R.W.J. van der Hulst

Prof. dr. J.P. Kooman 


\section{Table of Contents}

Chapter 1 General introduction and outline of the thesis $\quad 7$

Chapter 2 Advanced intraoperative imaging methods for laparoscopic $\quad 17$ anatomy navigation: an overview

PART I NEAR-INFRARED FLUORESCENCE-GUIDED LAPAROSCOPY $\quad 35$

Chapter 3 Fluorescence cholangiography during laparoscopic cholecystectomy: 37 a feasibility study on early biliary tract delineation

Chapter 4 Combined vascular and biliary fluorescence imaging in laparoscopic cholecystectomy

Chapter 5 Near-infrared fluorescence laparoscopy of the cystic duct and 65 artery in pigs: performance of a preclinical dye

Chapter 6 Application of a new dye for near-infrared fluorescence laparoscopy of the ureters: demonstration in a pig model

PART II DIFFUSE REFLECTANCE SPECTROSCOPY DURING SURGERY

Chapter 7 Multispectral characterization of tissues encountered during laparoscopic colorectal surgery

Chapter 8 Automated spectroscopic tissue classification in colorectal surgery

Chapter 9 Differentiation between nerve and adipose tissue using wide-band $(350-1830 \mathrm{~nm})$ in vivo diffuse reflectance spectroscopy

Chapter 10 Parathyroid differentiation during thyroid and parathyroid surgery by spectroscopy (350-1830 nm)

Chapter 11 Summary, discussion and future perspectives

Nederlandse samenvatting

Valorization addendum

List of publications

Awards

Dankwoord 



\section{Chapter 1}

General introduction and outline of the thesis 
Chapter 1 


\section{Background}

Patient safety and procedural efficiency are constant points of concern in modern health care. In surgery, this particularly accounts for minimally invasive surgery. The Dutch Health Care Inspectorate has drawn attention to safety in its report, "Risks of minimally invasive surgery underestimated", of November $2007^{1}$. To improve safety and efficiency, and to reduce costs, specially organized surgery programs are designed to conduct e.g. laparoscopic inguinal hernia, gallbladder and colorectal surgery in highvolume.

The laparoscopic operation technique has allowed surgeons to conduct traditional open surgical procedures in a minimally invasive way. Benefits of laparoscopy to the patient include reduced postoperative pain, increased postoperative comfort, reduced risk of wound infection, reduced hospital stay and a quicker return to normal physical activities $^{2,3}$. Yet, in addition to its advantages, laparoscopic surgery also has some drawbacks. These consist of challenging eye-hand coordination, absence of tactile feedback, small two-dimensional field of view (in contrast to three-dimensional human eye representation) thereby lacking orientation points that open surgery offers. Nevertheless the laparoscopic technique is widely applied nowadays.

For all kinds of surgical procedures (open or laparoscopic) it is of great importance to distinguish vital anatomy, e.g. nerves, ureters, bile ducts and arteries. Discrimination of vital structures, when challenging, can impose increased risks with severe complications, such as vascular injury, ureter lesion, bile duct injury and nerve damage. An optical tool that can identify vital structures and enhance the contrast of these structures from surrounding fatty or connective tissues, or detect hidden structures (e.g. covered under a layer of fatty tissue) will offer preservation of these structures ${ }^{4}$. Innovative optical imaging and spectroscopy techniques enabling real-time enhanced surgical guidance have emerged in the last decade and are subject of research worldwide ${ }^{5}$.

\section{Towards optical enhancement of anatomical landmarks in surgery}

Innovative optical techniques can offer a roadmap to improve intraoperative identification and characterization of tissues. This would be of great interest for surgery in general, but especially for minimally invasive procedures, when a surgeon lacks spatial perception from direct sight and haptic feedback from direct touch. Two of 
these optical techniques are near-infrared fluorescence imaging and diffuse reflectance spectroscopy.

\section{Near-infrared fluorescence imaging [using exogenous contrasts]}

Near-infrared fluorescence imaging is based on the introduction of exogenous contrasts. Fluorescent visualization of tissues can be obtained after administration of a near-infrared dye or fluorophore (i.e. an exogenous contrast agent with fluorescent characteristics) in combination with a dedicated imaging system, which is sensitive in the invisible near-infrared (NIR) light spectrum (wavelength range 700-900 nm).

The great advantage of NIR light over visible light is an increased tissue penetration depth, at present up to 10 millimeters. No additional radiological support is needed and no ionizing radiation is involved. NIR fluorophores provide the possibility of tissuespecific visualization in relation to surrounding tissues: e.g. delineation of vital anatomical structures from their surroundings or under a layer of fatty tissue ${ }^{6}$, or tumor demarcation from healthy tissue ${ }^{7}$. Route and timing of administration are factors that influence contrast between the target tissue and the background tissue.

Over the past years the NIR fluorescence technique has been introduced for several clinical applications for both anatomical imaging and tumor imaging ${ }^{8-11}$. Fluorescence imaging systems for clinical and preclinical research purposes are already available for open $^{9,12}$, laparoscopic ${ }^{8}$, and robotic surgery ${ }^{13}$.

Currently only indocyanine green (ICG, $800 \mathrm{~nm}$ fluorophore ${ }^{14}$ ) and methylene blue (MB, $700 \mathrm{~nm}$ fluorophore ${ }^{15}$ ) are approved by the Food and Drug Administration (FDA) and clinically available for fluorescence imaging. ICG is rapidly and exclusively excreted into bile, making it useful for biliary imaging ${ }^{6} . M B$ is renally cleared and therefore also useful for ureter imaging ${ }^{16}$.

Other NIR dyes are being developed, but not yet FDA cleared for clinical use. For example, CW800-CA (a carboxylate of NIR fluorophore IRDye ${ }^{\circledR} 800 \mathrm{CW}$, LI-COR, Lincoln, Nebraska ${ }^{14}$ ) is a relatively new fluorophore, which like ICG also has $800 \mathrm{~nm}$ fluorescent capabilities. It has equal low risk of toxicity as ICG and incorporates favourable characteristics for fluorescence imaging of vital anatomy. The most advantageous characteristic of CW800-CA is its increased hydrophilicity, resulting in improved secretion into bile and earlier fluorescence illumination of the bile ducts. Furthermore it is both hepatically and renally cleared, increasing its clinical applicability: e.g. not only bile duct imaging, but also ureteral detection ${ }^{14,15}$. 


\section{Diffuse reflectance spectroscopy [using endogenous contrasts]}

Diffuse reflectance spectroscopy concerns a technique that does not require preprocedural administration of a contrast agent. Instead, it relies on the endogenous spectral properties of tissue; i.e. intrinsically present natural reflectance signature of tissue.

The visible range for man is less than $1 \%$ of the entire light spectrum. Human color vision is trichromatic: the eye has three cone types for blue, green and red light (Figure 1.1). In contrast, multispectral and hyperspectral cameras can cover a wide-band spectral range; they are polychromatic, providing an abundance of color bands using not only wavelengths within the detection range of the human eye (range 380-700 nm) but also within the invisible ultraviolet (range 10-380 $\mathrm{mm}$ ), near-infrared (range $700-1000 \mathrm{~nm}$ ) and infrared (>1000 nm) spectrum to depict tissue structures.

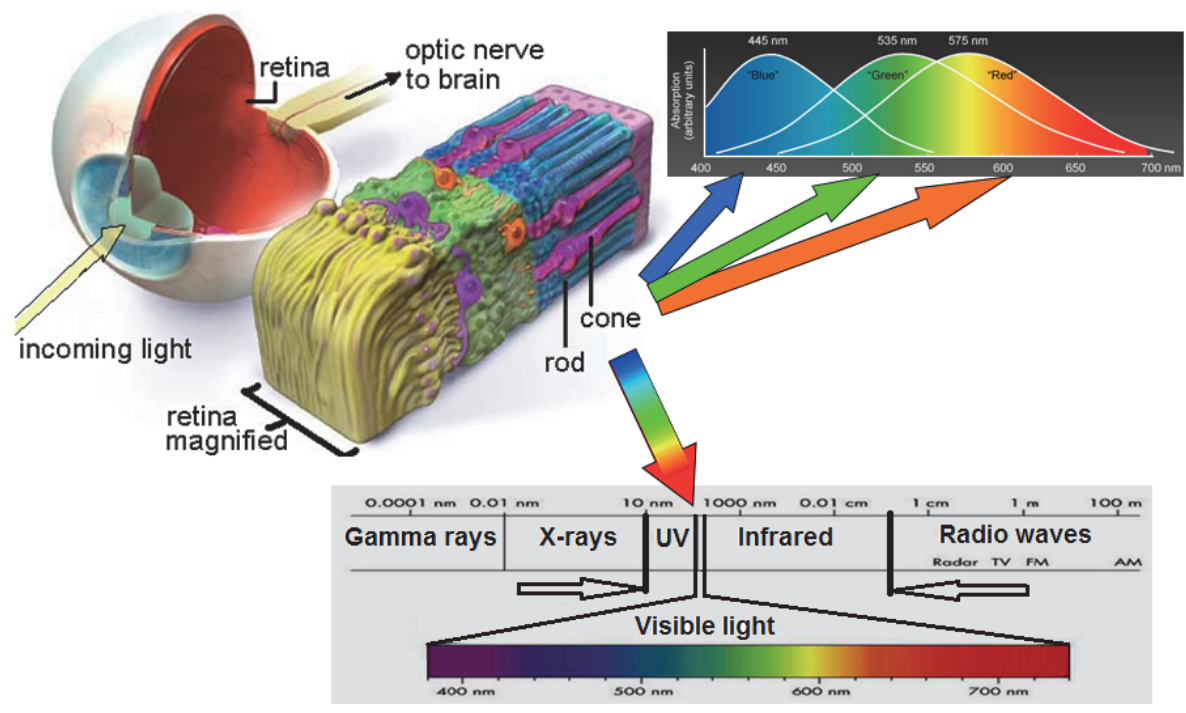

Figure 1.1 Detection of light by the human eye in relation to the entire light spectrum. The boundaries of the optical area and those of the invisible ultraviolet and infrared are marked. The human eye contains only three cones for red, green and blue. Yet, with these three receptor types, the experienced observer can discern millions of color shades within the narrow visible region. Nevertheless the visible range of men is less than $1 \%$ of the entire light spectrum. [Figure reused from: Wieringa FP. From Satellite to Surgery: A vision on surgical multispectral imaging. Intraoperative multispectral imaging workshop, Paris 2011 Dec 17] 
Aerospace science utilizes this by combining multi- and hyperspectral camera technology with pre-acquired "reference spectra" recorded on the earth surface. In terms of satellite images, this has provided spectacular insights for discovering places of interest for e.g. agricultural purposes ${ }^{17,18}$, archeology and forensics ${ }^{19}$, as well as military and homeland security applications ${ }^{20}$.

Using diffuse reflectance spectroscopy the "reference spectra" of human tissues can be mapped. By analyzing these spectra for distinctive endogenous tissue contrasts, the aforementioned "aerospace approach" can ultimately be translated to enable multi- or hyperspectrally enhanced surgical imaging. Medical applications of such imaging technology have potential to facilitate image-guided surgery ${ }^{21}$, in terms of anatomical imaging and tumor imaging. They have, for example, been investigated for contrast enhancement of coronary arteries during open heart surgery ${ }^{22}$, for intraoperative enhancement of bile ducts ${ }^{23}$, for intraoperative assessment of tissue oxygen saturation $^{24,25}$ and for intraoperative tumor detection ${ }^{26}$.

Endogenous tissue contrasts, such as oxygenated hemoglobin can be applied to measure oxygenation of tissues ${ }^{24}$. Furthermore, endogenous tissue contrast can also enable automated tissue classification for tissue-specific image-enhancement, thereby providing opportunities to improve the visual acuity of medical specialists. 


\section{Outline of the thesis}

This thesis is divided into two parts and describes both preclinical and clinical studies regarding two innovative optical techniques for application during surgery. Preceding the reports of these studies, a systematic review of the literature is given (Chapter 2), providing an overview of and an introduction to a variety of advanced intraoperative optical techniques, with special focus on minimally invasive surgery.

In Part I near-infrared fluorescence imaging after administration of a contrast agent is investigated. This concerns an already clinically available technique. Initially, the clinical feasibility of near-infrared fluorescence imaging using indocyanine green was studied during laparoscopic cholecystectomy: as a method for real-time intraoperative cholangiography (Chapter 3), and for concomitant extra-hepatic bile duct and arterial visualization (Chapter 4). In the scope of optimization of the technique at the level of the administered near-infrared fluorophore, the performance of a preclinical dye was tested in a pig model for two clinically relevant applications: extra-hepatic bile duct and arterial delineation during laparoscopic cholecystectomy (Chapter 5) and ureteral guidance during laparoscopic surgery (Chapter 6).

Part II focuses on wide-band diffuse reflectance spectroscopy. Regarding this technique experiments were performed on a more developmental level to enable future multi- or hyperspectrally enhanced surgical imaging. In Chapter 7, the potential of diffuse reflectance spectroscopy for automated tissue classification is explored on freshly extirpated human colorectal specimens. Chapter $\mathbf{8}$ describes in vivo classification results of spectroscopic measurements, collected during colorectal surgery, providing differentiation of ureter and artery from surrounding adipose tissue. In Chapter 9, automated nerve classification in relation to adipose tissue is explored using in vivo spectral data acquired during thyroid and parathyroid surgery, as well as during carpal tunnel release procedures. With the future goal of intraoperative optical detection of the parathyroid glands, Chapter 10 then focuses on in vivo spectroscopy performed during thyroid and parathyroid surgery.

Chapter 11 summarizes the main results and contributions as presented in this thesis; it depicts future perspectives and implications for further experimental research and clinical applications. 


\section{References}

1. Stassen LP, Bemelman WA, Meijerink J (2010) Risks of minimally invasive surgery underestimated: a report of the Dutch Health Care Inspectorate. Surg Endosc 24:495-498

2. Schwenk W, Haase O, Neudecker J, Muller JM (2005) Short term benefits for laparoscopic colorectal resection. Cochrane Database Syst Rev:CD003145

3. Sauerland S, Walgenbach M, Habermalz B, Seiler CM, Miserez M (2011) Laparoscopic versus open surgical techniques for ventral or incisional hernia repair. Cochrane Database Syst Rev:CD007781

4. Koninckx PR, Stepanian A, Adamyan L, Ussia A, Donnez J, Wattiez A (2013) The digital operating room and the surgeon. Gynecological Surgery 10:57-62

5. Schols RM, Bouvy ND, van Dam RM, Stassen LP (2013) Advanced intraoperative imaging methods for laparoscopic anatomy navigation: an overview. Surg Endosc 27:1851-1859

6. Ishizawa T, Bandai Y, Ijichi M, Kaneko J, Hasegawa K, Kokudo N (2010) Fluorescent cholangiography illuminating the biliary tree during laparoscopic cholecystectomy. Br J Surg 97:1369-1377

7. Ishizawa T, Fukushima N, Shibahara J, Masuda K, Tamura S, Aoki T, Hasegawa K, Beck Y, Fukayama M, Kokudo N (2009) Real-time identification of liver cancers by using indocyanine green fluorescent imaging. Cancer 115:2491-2504

8. Ankersmit M, van der Pas MH, van Dam DA, Meijerink WJ (2011) Near infrared fluorescence lymphatic laparoscopy of the colon and mesocolon. Colorectal Dis 13 Suppl 7:70-73

9. Mieog JS, Troyan SL, Hutteman M, Donohoe KJ, van der Vorst JR, Stockdale A, Liefers GJ, Choi HS, Gibbs-Strauss SL, Putter H, Gioux S, Kuppen PJ, Ashitate Y, Lowik CW, Smit VT, Oketokoun R, Ngo LH, van de Velde CJ, Frangioni JV, Vahrmeijer AL (2011) Toward optimization of imaging system and lymphatic tracer for near-infrared fluorescent sentinel lymph node mapping in breast cancer. Ann Surg Oncol 18:2483-2491

10. van der Vorst JR, Hutteman M, Gaarenstroom KN, Peters AA, Mieog JS, Schaafsma BE, Kuppen PJ, Frangioni JV, van de Velde CJ, Vahrmeijer AL (2011) Optimization of near-infrared fluorescent sentinel lymph node mapping in cervical cancer patients. Int J Gynecol Cancer 21:1472-1478

11. Hutteman M, van der Vorst JR, Gaarenstroom KN, Peters AA, Mieog JS, Schaafsma BE, Lowik CW, Frangioni JV, van de Velde CJ, Vahrmeijer AL (2012) Optimization of near-infrared fluorescent sentinel lymph node mapping for vulvar cancer. Am J Obstet Gynecol 206:89 e81-85

12. Themelis G, Yoo JS, Soh KS, Schulz R, Ntziachristos V (2009) Real-time intraoperative fluorescence imaging system using light-absorption correction. J Biomed Opt 14:064012

13. Spinoglio G, Priora F, Bianchi PP, Lucido FS, Licciardello A, Maglione V, Grosso F, Quarati R, Ravazzoni F, Lenti LM (2012) Real-time near-infrared (NIR) fluorescent cholangiography in single-site robotic cholecystectomy (SSRC): a single-institutional prospective study. Surg Endosc 27:2156-62

14. Tanaka E, Choi HS, Humblet V, Ohnishi S, Laurence RG, Frangioni JV (2008) Real-time intraoperative assessment of the extrahepatic bile ducts in rats and pigs using invisible near-infrared fluorescent light. Surgery 144:39-48

15. Tanaka E, Ohnishi S, Laurence RG, Choi HS, Humblet V, Frangioni JV (2007) Real-time intraoperative ureteral guidance using invisible near-infrared fluorescence. J Urol 178:2197-2202

16. Matsui A, Tanaka E, Choi HS, Kianzad V, Gioux S, Lomnes SJ, Frangioni JV (2010) Real-time, nearinfrared, fluorescence-guided identification of the ureters using methylene blue. Surgery 148:78-86

17. Huang W, Lamb DW, Niu Z, Zhang Y, Liu L, Wang L (2007) Identification of yellow rust in wheat using insitu spectral reflectance measurements and airborne hyperspectral imaging. Precision Agriculture 8:187-197

18. Hively WD, McCarty GW, Reeves JB, Lang MW, Oesterling RA, Delwiche SR (2011) Use of Airborne Hyperspectral Imagery toMap Soil Properties in Tilled Agricultural Fields. Applied and Environmental Soil Science 2011:Article ID 358193

19. Alsberg BK, Rosvold J (2014) Rapid Localization of Bone Fragments on Surfaces using Back-Projection and Hyperspectral Imaging. Journal of forensic sciences 59:474-480

20. Yuen PWT, Richardson M (2010) An introduction to hyperspectral imaging and its application for security, surveillance and target acquisition. The Imaging Science Journal 58:241-253 
21. Lu G, Fei B (2014) Medical hyperspectral imaging: a review. J Biomed Opt 19:10901

22. Wieringa FP, Mastik F, Duncker DJ, Bogers AJ (2006) Contrast enhancement of coronary arteries in cardiac surgery: a new multispectral stereoscopic camera technique. Eurolntervention : journal of EuroPCR in collaboration with the Working Group on Interventional Cardiology of the European Society of Cardiology 2:389-394

23. Zuzak KJ, Naik SC, Alexandrakis G, Hawkins D, Behbehani K, Livingston E (2008) Intraoperative bile duct visualization using near-infrared hyperspectral video imaging. Am J Surg 195:491-497

24. Holzer MS, Best SL, Jackson N, Thapa A, Raj GV, Cadeddu JA, Zuzak KJ (2011) Assessment of renal oxygenation during partial nephrectomy using hyperspectral imaging. J Urol 186:400-404

25. Olweny EO, Faddegon S, Best SL, Jackson N, Wehner EF, Tan YK, Zuzak KJ, Cadeddu JA (2013) Renal oxygenation during robot-assisted laparoscopic partial nephrectomy: characterization using laparoscopic digital light processing hyperspectral imaging. J Endourol 27:265-269

26. Panasyuk SV, Yang S, Faller DV, Ngo D, Lew RA, Freeman JE, Rogers AE (2007) Medical hyperspectral imaging to facilitate residual tumor identification during surgery. Cancer Biol Ther 6:439-446 


\section{Chapter 2}

Advanced intraoperative imaging methods for laparoscopic anatomy navigation: an overview

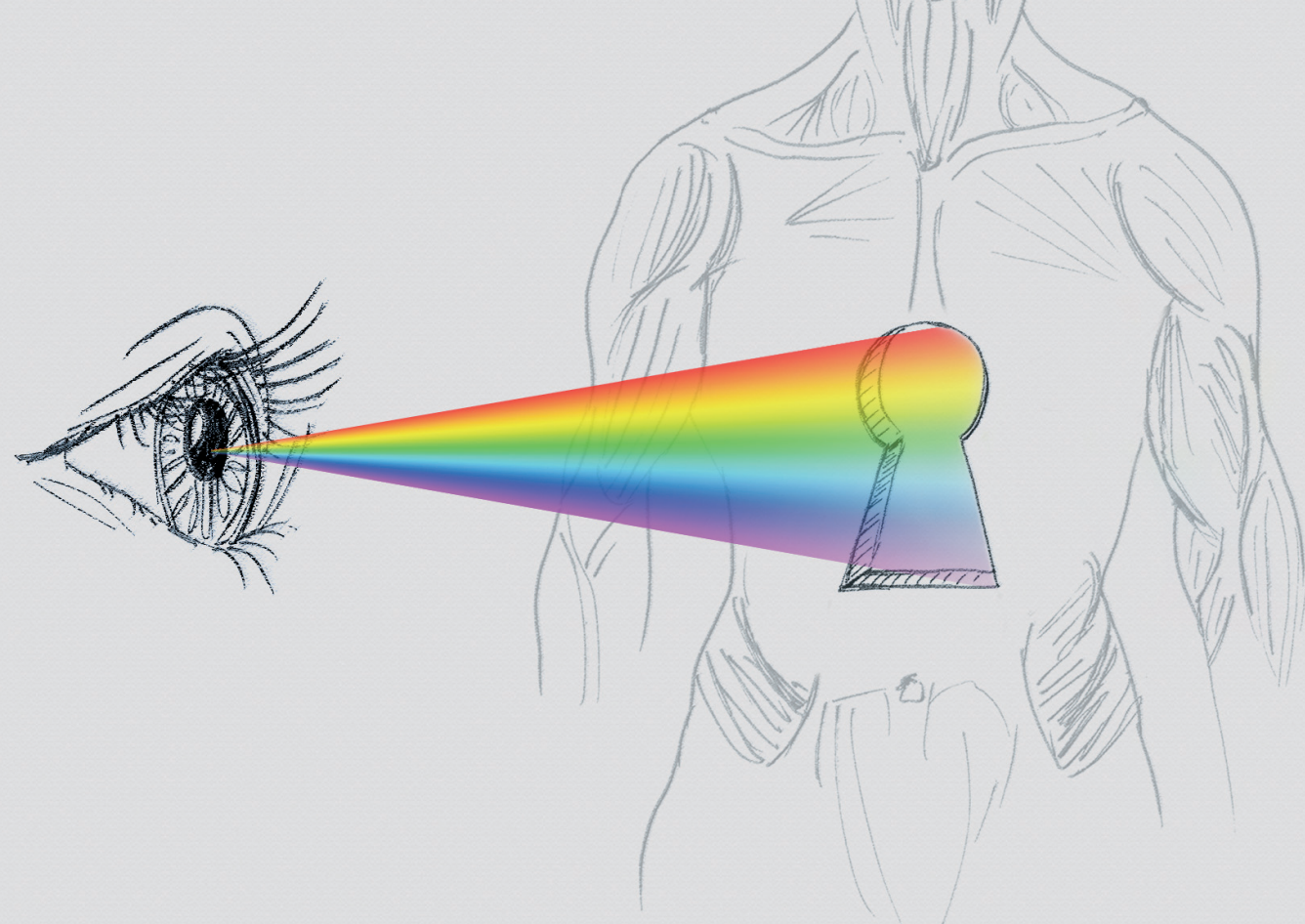

Schols RM, Bouvy ND, van Dam RM, Stassen LP Surgical Endoscopy 2013;27:1851-1859 


\begin{abstract}
Introduction

Safety and efficiency are important topics in minimally invasive surgery. Apart from its advantages, laparoscopic surgery has some drawbacks. These consist of 2D-imaging, challenging eye-hand coordination and absence of tactile feedback. Enhanced imaging with earlier and clearer identification of essential tissue types can overcome part of these disadvantages. Research groups worldwide are investigating new technologies for image-guided surgery purposes. This review article gives an overview of current developments in surgical optical imaging for improved anatomical identification and physiological tissue characterization during laparoscopic gastrointestinal surgery.
\end{abstract}

\title{
Methods
}

A systematic literature search in the PubMed database was conducted. Eligible studies reported on any kind of novel optical imaging technique applied for anatomical identification or physiological tissue characterization in laparoscopic gastrointestinal surgery. Gynecologic and urologic procedures were also included, whenever vascular, nerve, ureter or lymph node imaging was concerned.

\section{Results}

Various surgical imaging techniques were identified for enhanced intraoperative visualization of essential tissue types (i.e. blood vessel, bile duct, ureter, nerve, lymph node) and for tissue characterization purposes, such as assessment of blood perfusion. An overview is given of both preclinical and clinical experiences and the potential added value for intraoperative anatomical localization and characterization during laparoscopy.

\section{Conclusion}

Implementation of new optical imaging methods during laparoscopic gastrointestinal surgery can improve intraoperative anatomy navigation. This may lead to increased patient safety (preventing iatrogenic functional tissue injury) and procedural efficiency (shorter operating time). Near-infrared fluorescence imaging seems to possess the greatest potential for implementation in clinical practice in the near future. 


\section{Introduction}

The laparoscopic operation technique has allowed surgeons to conduct traditional open surgical procedures in a minimally invasive way. Benefits of laparoscopy to the patient have been shown in terms of reduced postoperative pain, increased postoperative comfort, lower risk of wound infection, shorter hospital stay and a quicker return to normal physical activities ${ }^{1,2}$. A limited field of view, 2D-imaging, different eye-hand coordination and the inability to achieve tactile feedback are limitations of laparoscopic surgery. Yet the laparoscopic technique is widely applied nowadays.

Increasing attention is arising in society for the safety of laparoscopic surgery. The Dutch Health Care Inspectorate has drawn attention to this in its report, "Risks of minimally invasive surgery underestimated", of November $2007^{3}$. Besides safety for the patient, procedural efficiency is a constant point of concern in modern healthcare. Specially organized surgery programs are designed for inguinal hernia and gallbladder operations to improve efficiency and safety, and to save money. Colorectal surgery is the latest form of high-volume surgery, in which the laparoscopic technique has now widely been introduced. It is an advanced procedure that requires a high level of skills in endoscopic surgery. Differentiating specific anatomical structures requires time and risks are involved in this process.

Vascular injury, ureter lesion, bile duct injury and nerve damage are complications that may occur during laparoscopic gastrointestinal surgery due to anatomical misinterpretation. Earlier and clearer identification of critical structures (i.e. blood vessel, bile duct, ureter, nerve, lymph node) might help to prevent these injuries.

New optical imaging techniques for real-time enhanced surgical guidance have emerged and are subject of research worldwide. The implementation of intraoperative imaging methods could be of great assistance to the (inexperienced) surgeon and it could help to improve the safety and efficiency of laparoscopic high-volume surgery.

The aim of this article is to give an overview of the latest developments in optical imaging techniques for enhanced anatomical identification and physiological characterization during laparoscopic gastrointestinal surgery.

\section{Methods}

A systematic literature search was performed using the PubMed database. The following generic terms were applied: 'laparoscopic surgery', 'optical imaging techniques', 'anatomy identification' and 'tissue characterization'. See Supplement for a detailed search strategy. 
The search was limited to articles published from 1975-2012 in the English, German and Dutch language. Initially, the titles and abstracts of the retrieved articles were screened. Secondly, the full text of potentially appropriate articles was printed and read. Reference lists were cross-checked for additional eligible papers. Figure 2.1 shows a flowchart of the article selection. Studies were eligible if they reported on novel optical imaging methods in laparoscopic gastrointestinal surgery, but also gynecologic and urologic procedures were included. Studies were excluded if they did not report on anatomical identification or tissue characterization using new optical imaging techniques, described a study protocol, or could not be retrieved in full length. First, the literature search and study selection was conducted by two authors (R.M.S. and L.P.S.) independently. After discussion, consensus was reached on the final inclusion for this review.

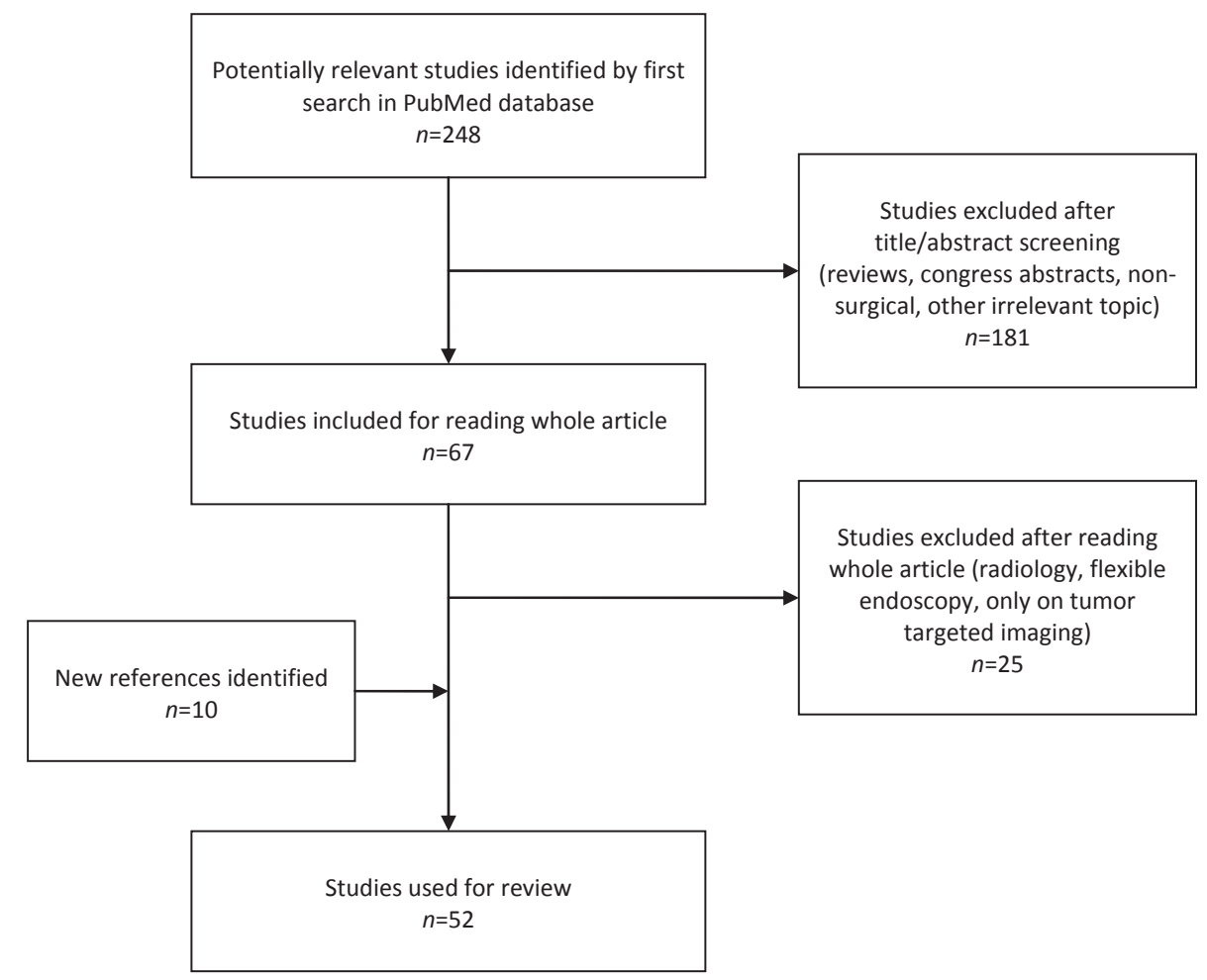

Figure 2.1 Flowchart for selection of articles 


\section{Results}

Based on the literature search six general optical imaging modalities, with potential clinical value for future implementation in laparoscopic gastrointestinal surgery, were distinguished. We give an overview of the current capabilities of these modalities with respect to intraoperative differentiation and localization of specific anatomical structures, and regarding potential for real-time physiological tissue assessment. A brief summary is presented in Table 2.1 .

\section{Infrared ray imaging}

Infrared (IR) imaging also referred to as thermography, measures and displays temperature differences and changes of tissues. After cold saline injection differentiation of vital anatomical structures can be provided using a laparoscopic infrared imaging system, with an assumed maximum tissue penetration of at least $5 \mathrm{~mm}^{4}$.

In laparoscopic animal studies it was shown ${ }^{5}$ that IR-imaging can facilitate the identification of the ureter and the assessment of organ perfusion. Subsequently, the clinical utility was assessed ${ }^{4,6}$. Using IR-laparoscopy vessel identification, assessment of organ perfusion, and transperitoneal localization of the ureter can be obtained.

The use of an infrared ureteral stent ${ }^{7}$ is a more invasive way of infrared identification of the ureter in laparoscopic procedures.

Based on the evaluation of intraoperative infrared cholangiography performed in open ${ }^{8}$ and laparoscopic ${ }^{9}$ surgical experiments with porcine models, IR-imaging was suggested as a feasible alternative to the traditional intraoperative cholangiography (IOC).

Infrared ray laparoscopy for sentinel lymph node (SLN) mapping has been studied during laparoscopy-assisted colectomy in patients with colorectal cancer ${ }^{10}$. In these patients saline was injected near the tumor before indocyanine green was injected. Regional lymph nodes and lymph vessels could be clearly visualized, which was not possible by conventional laparoscopy. Furthermore, the feasibility of using an infrared ray electronic endoscopic system with ICG injection has shown great potential for sentinel node navigation surgery in gastric cancer ${ }^{11,12}$. 


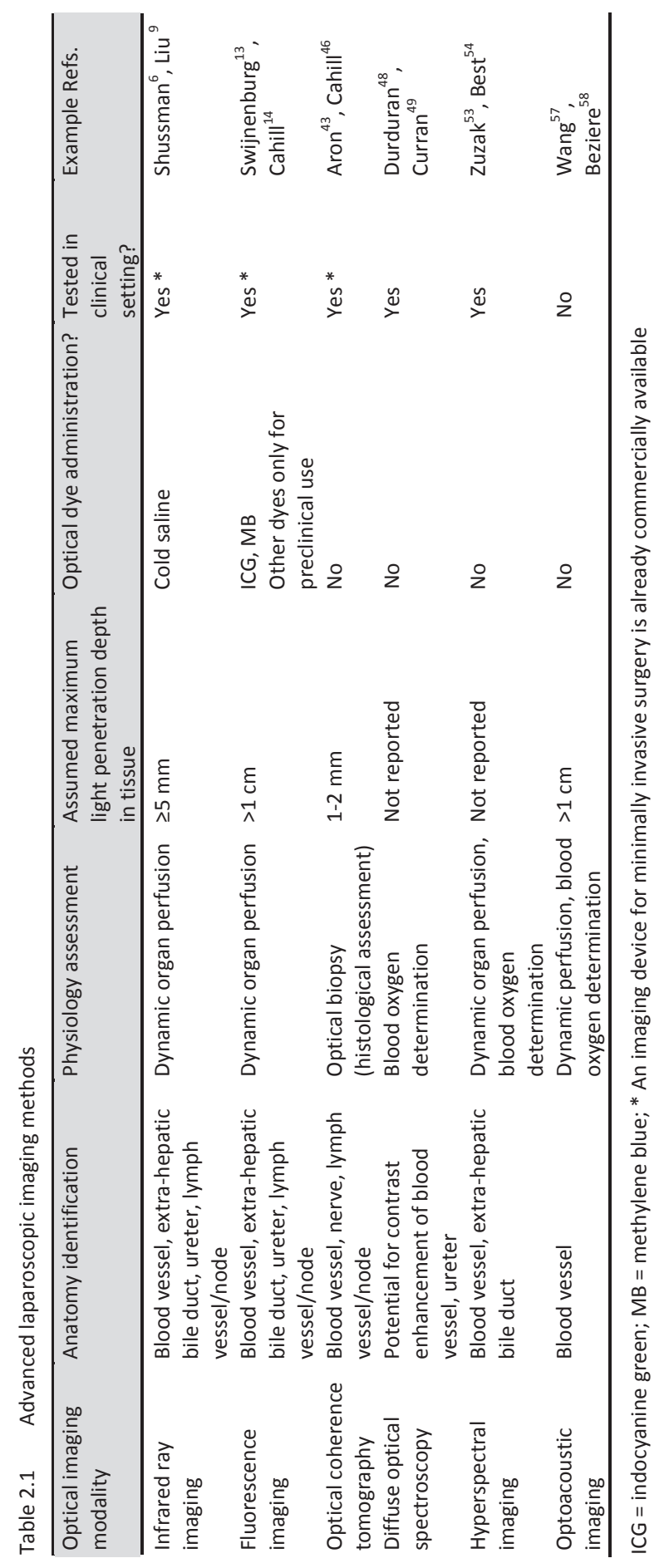




\section{Fluorescence imaging}

Using dedicated laparoscopic fluorescence imaging systems a preoperatively or intraoperatively administered optical dye with fluorescence properties is detectable during laparoscopy (see summary in Table 2.2). Intraoperative fluorescence imaging has been widely investigated for identification of vital anatomical structures, such as blood vessels, extra-hepatic bile ducts and ureters, but also for the detection of sentinel lymph nodes ${ }^{13,14}$. Structures are detectable at depths of one centimeter. A disadvantage of fluorescence-guided real-time visualization concerns the high costs of both the fluorescent dye and the required camera system.

Fluorescence properties of bile acid have been investigated for enhanced visualization of the biliary tract during laparoscopic surgery in mice ${ }^{15}$ and rabbits ${ }^{16}$. Mohsen et al. ${ }^{17}$ showed that intraoperative intravenous fluorescein injection and ultraviolet excitation facilitated identification of the extra-hepatic biliary anatomy during laparoscopic cholecystectomy.

The near-infrared fluorescence cholangiography (NIRFC) technique after local or intravenous administration of indocyanine green (ICG) has been evaluated in various animal models ${ }^{18-21}$ and in open, laparoscopic, and single-incision laparoscopic cholecystectomy ${ }^{20,22-24}$. Promising results were presented for successful intraoperative identification of the common bile duct and the cystic duct, compared to conventional laparoscopic imaging. Another clinical study showed that the NIRFC technique provides significantly earlier identification of the extra-hepatic bile ducts during dissection of Calot's triangle ${ }^{25}$. Real-time simultaneous imaging of the hepatic and cystic arteries can also be obtained ${ }^{26,27}$.

Next to ICG, methylene blue (MB) is another clinically available contrast agent, which appeared suitable for fluorescence imaging in the aforementioned situations ${ }^{21,26}$.

High sensitivity visualization of the ureters, which is desirable during laparoscopic colorectal surgery, can be provided with a near-infrared (NIR) fluorescence imaging system after intravenous injection of $\mathrm{MB}^{28}$ or the new optical dye CW800-CA, which is not yet FDA approved for clinical use ${ }^{29}$. Notably, CW800-CA seems to have favorable characteristics compared to $\mathrm{ICG}^{30}$, as its fluorescence intensity is supposed to be many times stronger, resulting in better visibility in adipose tissue.

In laparoscopic colorectal surgery it is shown that near-infrared ICG fluorescence imaging can allow rapid confirmation of lymphatic drainage and sentinel node identification in the mesocolon ${ }^{30,31}$. The concept has been described earlier in a goat model $^{32}$ : after percutaneous injection of ICG immediate bright fluorescence visualization is obtained of the efferent draining lymph vessels in the mesocolon. 


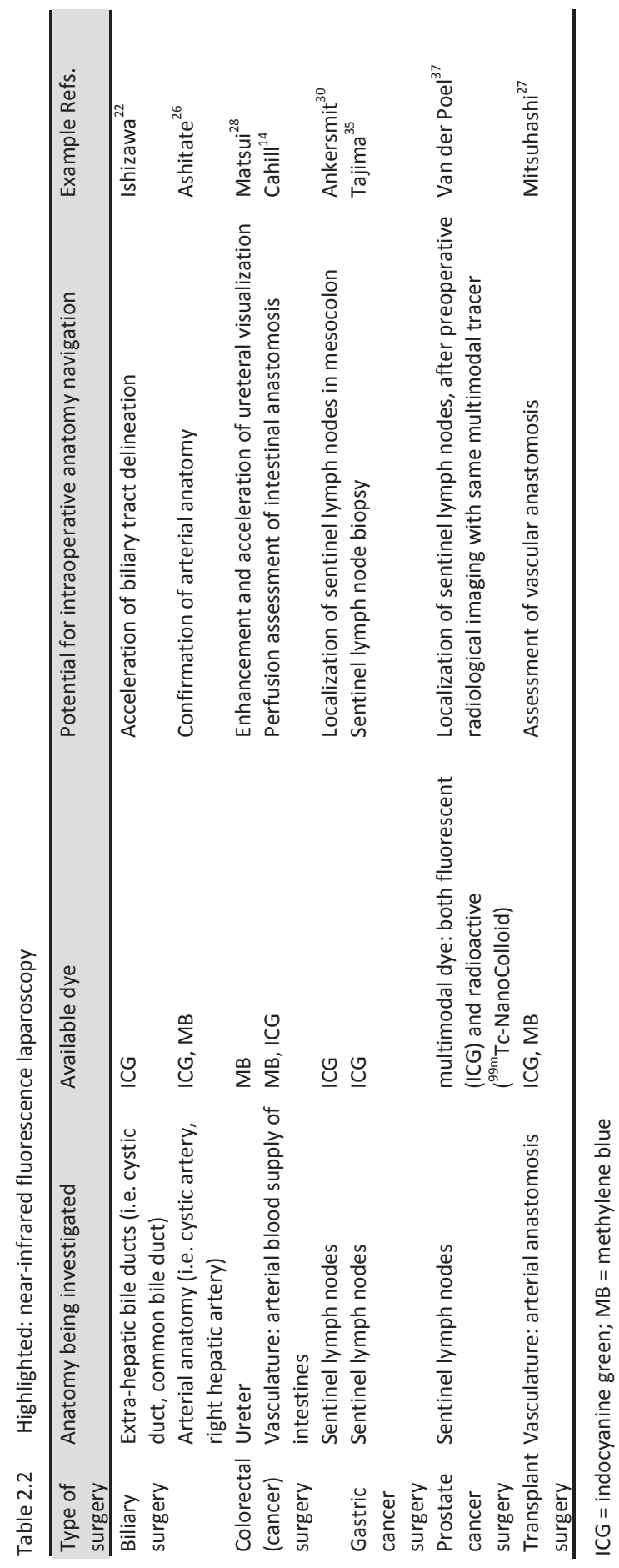


Following the fluorescent vessels, the SLNs can be identified in the mesentery as bright spots after approximately 10 minutes post-injection.

Evaluation of the detection of sentinel lymph nodes in open and laparoscopic gastric cancer surgery was conducted by Japanese researchers ${ }^{33-36}$. Their study results showed that the ICG fluorescence SLN mapping can very well facilitate dye-guided SLN biopsy in gastric cancer surgery.

The applicability of combining preoperative, intraoperative and postoperative sentinel lymph node imaging using an integrated diagnostic approach based on a multimodal (i.e. both radioactive and fluorescent) imaging agent, ICG $-{ }^{99 m}$ Tc-NanoColloid, is described $^{37}$. The fluorescent antenna ICG in combination with a laparoscopic fluorescence imaging system can facilitate the dissection of SLNs during robot-assisted laparoscopic prostatectomy.

ICG fluorescence imaging has been tested for several tissue characterization purposes: blood flow confirmation in the hepatic artery around the anastomosis in living-donor liver transplant surgery ${ }^{27}$, endoscopic visualization of the placental vascular network in the treatment of twin-twin transfusion syndrome ${ }^{38}$, and evaluation of the renal vasculature in robotic assisted laparoscopic partial nephrectomy ${ }^{39}$.

Laparoscopic fluorometry using ultraviolet light, already mentioned for delineation of the extra-hepatic biliary anatomy, was also reported as a minimally invasive tool for intraoperative evaluation of intestinal blood perfusion. In a porcine model the feasibility of this technique was evaluated for diagnosing mesenteric ischemia ${ }^{40,41}$.

\section{Optical coherence tomography}

Optical coherence tomography (OCT), using an optical fiber probe, can be applied for high-resolution, cross-sectional in vivo and in situ imaging of microstructures in biological tissues ${ }^{42}$. This technique includes a limited penetration depth $(2 \mathrm{~mm})$ that prevents deeper tissue architecture from being visualized and necessitates precise placement of the OCT probe on the tissue being examined. Therefore, in-depth imaging of smaller tissue structures is challenging ${ }^{43}$.

OCT imaging has been demonstrated to successfully differentiate the cavernous nerves from the prostate gland in a rat model ${ }^{44,45}$. Aron et al. ${ }^{43}$ described their experience with an imaging system including an OCT probe during laparoscopic and robotic radical prostatectomy to determine image characteristics of the neurovascular bundle, adipose tissue, the prostate capsule, the endopelvic fascia and lymphatics. OCT was able to correctly image the neurovascular bundle in all prostatectomy patients. Besides the prostatectomy, a potential role is conceivable in the laparoscopic low anterior resection, in order to prevent pelvic nerve injury. 
Furthermore, OCT can be used as an intraoperative optical biopsy method, for example to facilitate regional lymph node staging in the colonic mesentery ${ }^{46}$. Its feasibility of providing in situ optical tissue biopsy via a NOTES approach has been investigated with promising outcome ${ }^{47}$. A commercially available probe via the working channel of a gastroscope used as a NOTES peritoneoscope has recently been deployed. By this means, high-resolution real-time in vivo images of mesenteric sentinel nodes were obtained in a porcine model and ex vivo images were obtained from human specimen.

\section{Diffuse optical spectroscopy}

Diffuse optical spectroscopy is a non-invasive technique that can be used to measure the optical properties of physiological tissue, for example for real-time determination of blood oxygen saturation. This technique is based on a difference in light absorption between deoxyhemoglobin and oxyhemoglobin. This difference is most outspoken in the near-infrared spectral window of $600-1000 \mathrm{~nm}^{48}$. The use of spectroscopy for the identification of chemical states is common, but current available systems lack the spatial resolution necessary for video imaging.

Applying a spectrophotometric technique during elective laparoscopic and thoracoscopic surgical procedures Curran et al. ${ }^{49}$ demonstrated that this principle can be used to estimate hemoglobin concentration. The results of their preliminary report are promising, although the investigated device cannot yet be used for real-time measurements, as the data-analysis was conducted afterwards.

Automated spectral differentiation of essential tissue types encountered during the dissection phase in laparoscopic colorectal surgery (respectively blood vessel, ureter, mesenteric adipose tissue, colonic tissue), was feasible in freshly explanted human colonic specimen, using single point fiber probe measurements ${ }^{50}$. These results may be used as input for development of multi- or hyperspectrally enhanced in vivo laparoscopic surgical imaging.

\section{Hyperspectral imaging}

With hyperspectral imaging $(\mathrm{HSI})^{51}$ data are captured and analyzed from across the electromagnetic spectrum, hence allowing visualization with visible light and also within the near-infrared to infrared spectrum. Usually the difference between hyperspectral and multispectral imaging is defined by the number of spectral bands: a hyperspectral image contains hundreds to thousands of bands, a multispectral image contains tens of bands.

Zuzak et al. ${ }^{52,53}$ coupled a surgical laparoscope for conventional minimally invasive surgical procedures with a NIR hyperspectral imaging system to help guide laparoscopic 
surgeons to visualize the biliary anatomy. The spectroscopic data were collected from laparoscopic images. Data processing provided an image representative of the inherent chemical properties to the imaged tissues. Real-time imaging is not (yet) possible, because this image-processing takes about 40 seconds. The maximum light penetration depth in tissue of HSI is not reported.

HSI has proven to be a sensitive tool for real-time monitoring of renal oxygenation and blood flow ${ }^{54}$. Hence it can facilitate intraoperative decision-making to protect kidney function during partial nephrectomy.

\section{Optoacoustic imaging}

Ultrasound-modulated optical tomography and photo-acoustic tomography are modalities of optoacoustic imaging (OI). In these technologies the imaging contrast is based primarily on the optical properties of tissues, and the imaging resolution is based primarily on the ultrasonic waves that are provided externally or internally within tissues $^{55-57}$. Pure optical imaging has either a limited penetration depth (as in optical coherence tomography) or a limited resolution (as in diffuse optical spectroscopy). Pure ultrasound imaging can provide good resolution, but cannot image oxygen saturation or concentration of hemoglobin. Optoacoustic imaging can overcome these limitations, by merging the contrast advantage of pure optical imaging with the resolution advantage of pure ultrasound imaging ${ }^{57}$.

Optoacoustic imaging can be employed for real-time, high-resolution endoscopic imaging of anatomy (e.g. vascularization) and tissue physiology (e.g. hypoxia) using a single device with combined modalities, at depths larger than one centimeter ${ }^{56,58}$. For implementation of this combined technique in an endoscopic device, a small-sized probe that holds both a light source able to illuminate tissue at a wide angle and an ultrasound transducer array has yet to be designed.

\section{Discussion}

New optical imaging techniques can improve visual information beyond the capabilities of the human eye, which is interesting for the identification and characterization of critical anatomical structures encountered during laparoscopic gastrointestinal surgery. The wide number of studies, referred to in this review, augmented the relevant knowledge level for advanced laparoscopic surgical imaging. Most studies describe single-institute experiences of small animal and clinical pilot studies. These investigations mainly focus on potential applications of new imaging methods in high- 
volume laparoscopic gastrointestinal surgery, with special emphasis on biliary tract and colorectal surgery.

Deeper light penetration in tissues, by utilizing new optical imaging methods, can facilitate earlier and clearer identification of essential anatomy during surgery, for example a ureter beneath a layer of adipose or connective tissue. The assumed maximum light penetration depth in tissue varies from a few millimeters (optical coherence tomography) up to over one centimeter (NIR fluorescence imaging, optoacoustic imaging). This doubtlessly is an improvement compared to conventional laparoscopic imaging. In particular the near-infrared light spectrum is capable of penetrating relatively deeply into tissues such as the mesenteric adipose tissue. Yet, the increased penetration depth of emerging imaging technologies is limited. Anatomy navigation at depths larger than one centimeter remains challenging.

All imaging methods described in this review can be applied for the identification of anatomical structures during surgery. Infrared ray imaging and near-infrared fluorescence imaging have been tested successfully for the intraoperative localization of blood vessels, extra-hepatic bile ducts, ureter and lymph nodes or vessels. According to the literature optical coherence tomography can improve the visual contrast of blood vessels, nerves and lymphatics. Hyperspectral imaging has been investigated for blood vessel and extra-hepatic bile duct imaging. Optoacoustic imaging has not yet been tested for a wide variety of applications, but should be able to detect blood vessels at larger depths (assumed penetration depth $>1 \mathrm{~cm}$ ). Diffuse optical spectroscopy is not yet available for video imaging of anatomical structures, but there is potential for contrast enhancement of blood vessel and ureter.

Furthermore, a better real-time intraoperative understanding of physiology can be obtained by implementing novel optical imaging methods. The assessment of dynamic organ perfusion can be performed by using infrared ray imaging, NIR fluorescence imaging, hyperspectral imaging and optoacoustic imaging. For blood oxygen determination technologies like diffuse optical spectroscopy and hyperspectral imaging provide new opportunities. In gastrointestinal surgery the real-time assessment of the intestinal microcirculation might, for instance, be helpful to facilitate critical decisionmaking whether to make an intestinal anastomosis or not.

Practical advantages of the non-invasive optical imaging modalities, discussed here, are that they neither involve radiation exposure nor extra personnel in the operating theatre, together with a negligible extension of operation duration.

Only for NIR fluorescence imaging the pre- or peroperative administration of a fluorophore (optical dye) is required. The number of currently available optical dyes for fluorescence imaging is restricted. Indocyanine green and methylene blue are FDA 
approved for clinical use in humans. Other and more targeted fluorescent contrast agents are in development, but at the moment only for preclinical use.

A few advanced imaging devices for application in minimally invasive surgery are already commercially available for clinical use. These systems either possess the ability of infrared ray imaging, NIR fluorescence imaging, or optical coherence tomography (optical probe for NOTES). The other imaging modalities mentioned in this overview are still in a more basic development phase. Hyperspectral imaging has been tested in a clinical setting. Incorporation of these and the other remaining imaging modalities in commercially available imaging devices is in slow progress.

Looking at the outlined potential and remaining limitations of the advanced imaging techniques as discussed in this review, future research should mainly focus on optimization of laparoscopic systems for advanced intraoperative imaging. With respect to near-infrared fluorescence laparoscopy (highlighted in Table 2.2), a technique which is probably closest to enter the clinical practice in the near future, optimizing the current laparoscopic imaging systems is needed to make them more easily applicable in the operating room. Current systems not yet possess the ability to display the fluorescence image in anatomical context, in other words: fluorescence image overlay on white light image is not yet possible. Furthermore, imaging depth at which the imaging system can detect a fluorophore needs improvement. To overcome this obstacle, also an increase in fluorescent capabilities of contrast agents is desirable. In fact, new more powerful fluorescent dyes (e.g. CW800-CA) are expected to become available in the near future.

\section{Conclusion}

The implementation of new intraoperative imaging modalities provides the surgeon with improved real-time identification and physiological tissue characterization of essential anatomical structures encountered during laparoscopic gastrointestinal surgery. This could significantly contribute to intraoperative anatomy navigation and critical decision-making, and may eventually lead to increased patient safety and procedural efficiency. Based on the findings in literature and the increasing knowledge of the described techniques, near-infrared fluorescence imaging probably possesses the greatest potential for implementation in clinical practice in the near future. 


\section{References}

1. Schwenk W, Haase O, Neudecker J, Muller JM (2005) Short term benefits for laparoscopic colorectal resection. Cochrane Database Syst Rev:CD003145

2. Sauerland S, Walgenbach M, Habermalz B, Seiler CM, Miserez M (2011) Laparoscopic versus open surgical techniques for ventral or incisional hernia repair. Cochrane Database Syst Rev:CD007781

3. Stassen LP, Bemelman WA, Meijerink J (2010) Risks of minimally invasive surgery underestimated: a report of the Dutch Health Care Inspectorate. Surg Endosc 24:495-498

4. Cadeddu JA, Jackman SV, Schulam PG (2001) Laparoscopic infrared imaging. J Endourol 15:111-116

5. Roberts WW, Dinkel TA, Schulam PG, Bonnell L, Kavoussi LR (1997) Laparoscopic infrared imaging. Surg Endosc 11:1221-1223

6. Shussman N, Abu Gazala M, Schlager A, Elazary R, Khalaileh A, Zamir G, Kushnir D, Rivkind Al, Mintz Y (2011) Laparoscopic infrared imaging--the future vascular map. J Laparoendosc Adv Surg Tech A 21:797-801

7. Kim K, Schwaitzberg S, Onel E (2001) An infrared ureteral stent to aid in laparoscopic retroperitoneal lymph node dissection. J Urol 166:1815-1816

8. Hanna BV, Gorbach AM, Gage FA, Pinto PA, Silva JS, Gilfillan LG, Kirk AD, Elster EA (2008) Intraoperative assessment of critical biliary structures with visible range/infrared image fusion. J Am Coll Surg 206:1227-1231

9. Liu JJ, Alemozaffar M, McHone B, Dhanani N, Gage F, Pinto PA, Gorbach AM, Elster E (2008) Evaluation of real-time infrared intraoperative cholangiography in a porcine model. Surg Endosc 22:2659-2664

10. Nagata K, Endo S, Hidaka E, Tanaka J, Kudo SE, Shiokawa A (2006) Laparoscopic sentinel node mapping for colorectal cancer using infrared ray laparoscopy. Anticancer Res 26:2307-2311

11. Ishikawa K, Yasuda K, Shiromizu A, Etoh T, Shiraishi N, Kitano S (2007) Laparoscopic sentinel node navigation achieved by infrared ray electronic endoscopy system in patients with gastric cancer. Surg Endosc 21:1131-1134

12. Yano K, Nimura H, Mitsumori N, Takahashi N, Kashiwagi H, Yanaga K (2011) The efficiency of micrometastasis by sentinel node navigation surgery using indocyanine green and infrared ray laparoscopy system for gastric cancer. Gastric Cancer 15(3):287-291

13. Swijnenburg RJ, Crane LM, Buddingh KT, van de Velde CJ, Vahrmeijer AJ, van Dam GM (2012) [Intraoperative imaging using fluorescence]. Ned Tijdschr Geneeskd 156:A4316

14. Cahill RA, Ris F, Mortensen NJ (2011) Near-infrared laparoscopy for real-time intra-operative arterial and lymphatic perfusion imaging. Colorectal Dis 13 Suppl 7:12-17

15. Stiles BM, Adusumilli PS, Bhargava A, Fong Y (2006) Fluorescent cholangiography in a mouse model: an innovative method for improved laparoscopic identification of the biliary anatomy. Surg Endosc 20:1291-1295

16. Holzinger F, Krahenbuhl L, Schteingart CD, Ton-Nu HT, Hofmann AF (2001) Use of a fluorescent bile acid to enhance visualization of the biliary tract and bile leaks during laparoscopic surgery in rabbits. Surg Endosc 15:209-212

17. Mohsen AA, Elbasiouny MS, Fawzy YS (2012) Fluorescence-Guided Laparoscopic Cholecystectomy: A New Technique for Visualization of Biliary System by Using Fluorescein. Surg Innov. doi:10.1177/1553350612442794

18. Figueiredo JL, Siegel C, Nahrendorf M, Weissleder R (2010) Intraoperative near-infrared fluorescent cholangiography (NIRFC) in mouse models of bile duct injury. World J Surg 34:336-343

19. Figueiredo JL, Nahrendorf M, Vinegoni C, Weissleder R (2011) Intraoperative near-infrared fluorescent cholangiography (NIRFC) in mouse models of bile duct injury: reply. World J Surg 35:694-695

20. Tagaya N, Shimoda M, Kato M, Nakagawa A, Abe A, Iwasaki Y, Oishi H, Shirotani N, Kubota K (2010) Intraoperative exploration of biliary anatomy using fluorescence imaging of indocyanine green in experimental and clinical cholecystectomies. J Hepatobiliary Pancreat Sci 17:595-600

21. Matsui A, Tanaka E, Choi HS, Winer JH, Kianzad V, Gioux S, Laurence RG, Frangioni JV (2010) Real-time intra-operative near-infrared fluorescence identification of the extrahepatic bile ducts using clinically available contrast agents. Surgery 148:87-95 
22. Ishizawa T, Bandai Y, Ijichi M, Kaneko J, Hasegawa K, Kokudo N (2010) Fluorescent cholangiography illuminating the biliary tree during laparoscopic cholecystectomy. Br J Surg 97:1369-1377

23. Ishizawa T, Kaneko J, Inoue Y, Takemura N, Seyama Y, Aoki T, Beck Y, Sugawara Y, Hasegawa K, Harada N, Ijichi M, Kusaka K, Shibasaki M, Bandai Y, Kokudo N (2011) Application of fluorescent cholangiography to single-incision laparoscopic cholecystectomy. Surg Endosc 25:2631-2636

24. Aoki T, Murakami M, Yasuda D, Shimizu Y, Kusano T, Matsuda K, Niiya T, Kato H, Murai N, Otsuka K, Kusano M, Kato T (2010) Intraoperative fluorescent imaging using indocyanine green for liver mapping and cholangiography. J Hepatobiliary Pancreat Sci 17:590-594

25. Schols RM, Bouvy ND, van Dam RM, Stassen LP (2012) Fluorescence imaging of the extra-hepatic bile ducts during laparoscopic cholecystectomy: preliminary results of a pilot study. 20th International Congress of the EAES, 20-23 June 2012, Brussels, Belgium; http://www.eventureonline.com/eventure/publicAbstractView.do?id=185679\&congress $I d=5608$

26. Ashitate Y, Stockdale A, Choi HS, Laurence RG, Frangioni JV (2011) Real-Time Simultaneous NearInfrared Fluorescence Imaging of Bile Duct and Arterial Anatomy. J Surg Res 176(1):7-13

27. Mitsuhashi N, Kimura F, Shimizu H, Imamaki M, Yoshidome H, Ohtsuka M, Kato A, Yoshitomi H, Nozawa S, Furukawa K, Takeuchi D, Takayashiki T, Suda K, Igarashi T, Miyazaki M (2008) Usefulness of intraoperative fluorescence imaging to evaluate local anatomy in hepatobiliary surgery. J Hepatobiliary Pancreat Surg 15:508-514

28. Matsui A, Tanaka E, Choi HS, Kianzad V, Gioux S, Lomnes SJ, Frangioni JV (2010) Real-time, nearinfrared, fluorescence-guided identification of the ureters using methylene blue. Surgery 148:78-86

29. Tanaka E, Ohnishi S, Laurence RG, Choi HS, Humblet V, Frangioni JV (2007) Real-time intraoperative ureteral guidance using invisible near-infrared fluorescence. J Urol 178:2197-2202

30. Ankersmit M, van der Pas MH, van Dam DA, Meijerink WJ (2011) Near infrared fluorescence lymphatic laparoscopy of the colon and mesocolon. Colorectal Dis 13 Suppl 7:70-73

31. Cahill RA, Anderson M, Wang LM, Lindsey I, Cunningham C, Mortensen NJ (2012) Near-infrared (NIR) laparoscopy for intraoperative lymphatic road-mapping and sentinel node identification during definitive surgical resection of early-stage colorectal neoplasia. Surg Endosc 26:197-204

32. van der Pas MH, van Dongen GA, Cailler F, Pelegrin A, Meijerink WJ (2010) Sentinel node procedure of the sigmoid using indocyanine green: feasibility study in a goat model. Surg Endosc 24:2182-2187

33. Miyashiro I, Miyoshi N, Hiratsuka M, Kishi K, Yamada T, Ohue M, Ohigashi H, Yano M, Ishikawa O, Imaoka S (2008) Detection of sentinel node in gastric cancer surgery by indocyanine green fluorescence imaging: comparison with infrared imaging. Ann Surg Oncol 15:1640-1643

34. Miyashiro I, Kishi K, Yano M, Tanaka K, Motoori M, Ohue M, Ohigashi H, Takenaka A, Tomita Y, Ishikawa O (2011) Laparoscopic detection of sentinel node in gastric cancer surgery by indocyanine green fluorescence imaging. Surg Endosc 25:1672-1676

35. Tajima Y, Murakami M, Yamazaki K, Masuda Y, Kato M, Sato A, Goto S, Otsuka K, Kato T, Kusano M (2010) Sentinel node mapping guided by indocyanine green fluorescence imaging during laparoscopic surgery in gastric cancer. Ann Surg Oncol 17:1787-1793

36. Yoshida M, Kubota K, Kuroda J, Ohta K, Nakamura T, Saito J, Kobayashi M, Sato T, Beck Y, Kitagawa Y, Kitajima M (2012) Indocyanine green injection for detecting sentinel nodes using color fluorescence camera in the laparoscopy-assisted gastrectomy. J Gastroenterol Hepatol 27 Suppl 3:29-33

37. van der Poel HG, Buckle T, Brouwer OR, Valdes Olmos RA, van Leeuwen FW (2011) Intraoperative laparoscopic fluorescence guidance to the sentinel lymph node in prostate cancer patients: clinical proof of concept of an integrated functional imaging approach using a multimodal tracer. Eur Urol 60:826-833

38. Harada K, Miwa M, Fukuyo T, Watanabe S, Enosawa S, Chiba T (2009) ICG fluorescence endoscope for visualization of the placental vascular network. Minim Invasive Ther Allied Technol 18:1-5

39. Tobis S, Knopf J, Silvers C, Yao J, Rashid H, Wu G, Golijanin D (2011) Near infrared fluorescence imaging with robotic assisted laparoscopic partial nephrectomy: initial clinical experience for renal cortical tumors. J Urol 186:47-52

40. Horstmann R, Palmes D, Rupp D, Hohlbach G, Spiegel HU (2002) Laparoscopic fluorometry: a new minimally invasive tool for investigation of the intestinal microcirculation. J Invest Surg 15:343-350 
41. McGinty JJ, Jr., Hogle N, Fowler DL (2003) Laparoscopic evaluation of intestinal ischemia using fluorescein and ultraviolet light in a porcine model. Surg Endosc 17:1140-1143

42. Huang D, Swanson EA, Lin CP, Schuman JS, Stinson WG, Chang W, Hee MR, Flotte T, Gregory K, Puliafito CA, et al. (1991) Optical coherence tomography. Science 254:1178-1181

43. Aron M, Kaouk JH, Hegarty NJ, Colombo JR, Jr., Haber GP, Chung BI, Zhou M, Gill IS (2007) Second prize: preliminary experience with the Niris optical coherence tomography system during laparoscopic and robotic prostatectomy. J Endourol 21:814-818

44. Chitchian S, Weldon TP, Fried NM (2009) Segmentation of optical coherence tomography images for differentiation of the cavernous nerves from the prostate gland. J Biomed Opt 14:044033

45. Chitchian S, Weldon TP, Fiddy MA, Fried NM (2010) Combined image-processing algorithms for improved optical coherence tomography of prostate nerves. J Biomed Opt 15:046014

46. Cahill RA (2009) Regional nodal staging for early stage colon cancer in the era of endoscopic resection and N.O.T.E.S. Surg Oncol 18:169-175

47. Cahill RA, Asakuma M, Trunzo J, Schomisch S, Wiese D, Saha S, Dallemagne B, Marks J, Marescaux J (2010) Intraperitoneal virtual biopsy by fibered optical coherence tomography (OCT) at natural orifice transluminal endoscopic surgery (NOTES). J Gastrointest Surg 14:732-738

48. Durduran T, Choe R, Yu G, Zhou C, Tchou JC, Czerniecki BJ, Yodh AG (2005) Diffuse optical measurement of blood flow in breast tumors. Opt Lett 30:2915-2917

49. Curran S, McMurdy JW, Carr SR, Muratore CS, O'Brien BM, Crawford GP, Luks FI (2010) Reflectance spectrometry for real-time hemoglobin determination of placental vessels during endoscopic laser surgery for twin-to-twin transfusion syndrome. J Pediatr Surg 45:59-64

50. Schols RM, Dunias P, Wieringa FP, Stassen LP (2012) Optical characterization of fresh human colonic specimen: an initial exploration of the possibilities in laparoscopic colorectal surgery. 20th International Congress of the EAES, 20-23 June 2012, Brussels, Belgium; http://www.eventure-online.com/eventure/ publicAbstractView.do?id=185711\& congressld=5608

51. Akbari H, Kosugi Y (2009) Hyperspectral Imaging: a New Modality in Surgery. In: Naik GR (ed) Recent Advances in Biomedical Engineering, Intech, pp 223-240

52. Zuzak KJ, Naik SC, Alexandrakis G, Hawkins D, Behbehani K, Livingston EH (2007) Characterization of a near-infrared laparoscopic hyperspectral imaging system for minimally invasive surgery. Anal Chem 79:4709-4715

53. Zuzak KJ, Naik SC, Alexandrakis G, Hawkins D, Behbehani K, Livingston E (2008) Intraoperative bile duct visualization using near-infrared hyperspectral video imaging. Am J Surg 195:491-497

54. Best SL, Thapa A, Holzer MJ, Jackson N, Mir SA, Cadeddu JA, Zuzak KJ (2011) Minimal arterial in-flow protects renal oxygenation and function during porcine partial nephrectomy: confirmation by hyperspectral imaging. Urology 78:961-966

55. Tang MX, Elson DS, Li R, Dunsby C, Eckersley RJ (2010) Photoacoustics, thermoacoustics, and acoustooptics for biomedical imaging. Proc Inst Mech Eng H 224:291-306

56. Ntziachristos V, Razansky D (2010) Molecular imaging by means of multispectral optoacoustic tomography (MSOT). Chem Rev 110:2783-2794

57. Wang LV (2003) Ultrasound-mediated biophotonic imaging: a review of acousto-optical tomography and photo-acoustic tomography. Dis Markers 19:123-138

58. Beziere N, Ntziachristos V (2011) Optoacoustic imaging: an emerging modality for the gastrointestinal tract. Gastroenterology 141:1979-1985 


\section{Supplement}

\section{Search strategy for systematic electronic literature search}

PubMed search (latest search update: June $12^{\text {th }}$ 2012)

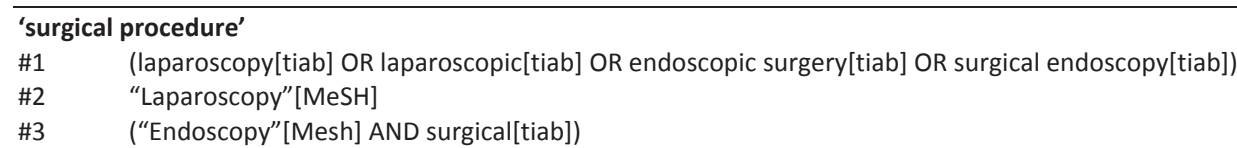

\section{'optical imaging techniques'}

\#4 (optical imaging[tiab]) OR (“Optical coherence tomography”[Mesh] OR OCT[tiab] OR optical coherence tomography[tiab]) OR (multispectral imaging[tiab] OR multispectral[tiab] OR diffuse reflectance[tiab] OR reflectance[tiab] OR absorption[tiab]) OR (hyperspectral imaging[tiab] OR hyperspectral[tiab]) OR (multispectral optoacoustic tomography[tiab] OR multispectral optoacoustic imaging[tiab] OR photoacoustic tomography[tiab]) OR (ultrasound mediated optical tomography[tiab] OR ultrasound modulated optical tomography[tiab]) OR (confocal microscopy[tiab] OR confocal laser endomicroscopy[tiab] OR confocal imaging[tiab]) OR ("Nearinfrared spectroscopy"[Mesh] OR near-infrared[tiab] OR NIR[tiab] OR spectroscopy[tiab] OR near infrared[tiab]) OR ("Fluorescence"[Mesh] OR fluorescence[tiab] OR fluorescence imaging[tiab] OR fluorescent[tiab]) OR (infrared imaging[tiab] OR infrared[tiab]) OR (high-resolution imaging[tiab] OR high-resolution[tiab] OR high resolution[tiab] OR high resolution imaging[tiab]) OR (narrowband imaging[tiab] OR narrow-band[tiab] OR narrow band imaging[tiab] OR narrow band[tiab])

\section{'anatomy identification'}

\#5 (tissue characterization[tiab] OR tissue identification[tiab] OR identification[tiab] OR characterization[tiab] OR recognition[tiab] OR distinction[tiab] OR distinguish[tiab] OR vascular[tiab] OR vessel[tiab] OR artery[tiab] OR vein[tiab] OR nerve[tiab] OR ureter[tiab] OR bile duct[tiab] OR biliary[tiab] OR common bile duct[tiab] OR gallbladder[tiab] OR anatomy[tiab] OR anatomic[tiab] OR (“Lymph Nodes”[Mesh] OR lymph[tiab] OR lymphatic[tiab] OR nodes[tiab] OR node[tiab] OR nodal[tiab]))

Final search (Limits activated: English, German and Dutch language) 


\section{PART I}

NEAR-INFRARED

\section{FLUORESCENCE-GUIDED LAPAROSCOPY}




\section{Chapter}

Fluorescence cholangiography during laparoscopic cholecystectomy: a feasibility study on

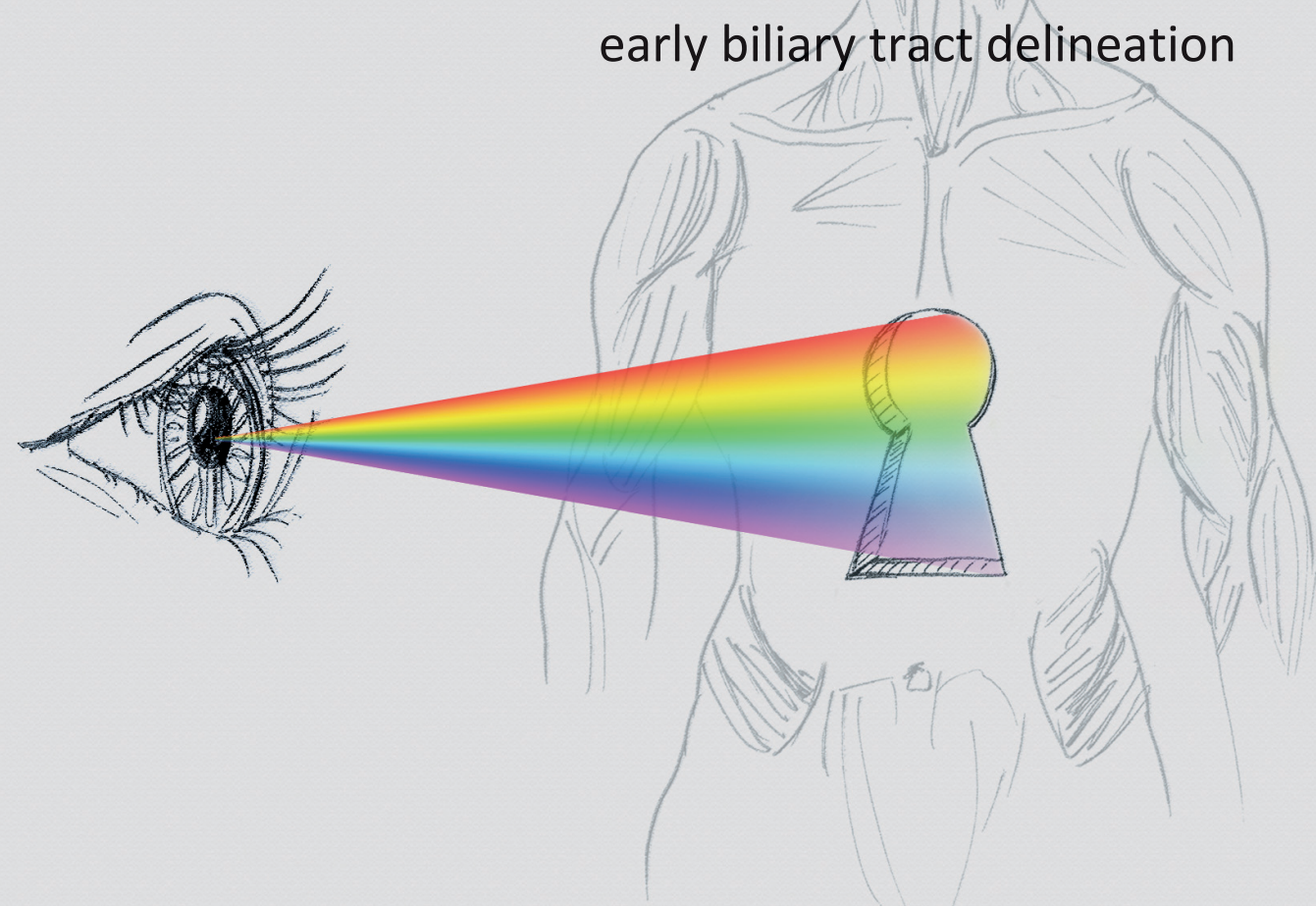

Schols RM, Bouvy ND, Masclee AA, van Dam RM, Dejong CH, Stassen LP Surgical Endoscopy 2013;27:1530-1536 


\begin{abstract}

\section{Background}

Laparoscopic cholecystectomy (LC) is one of the most commonly performed laparoscopic procedures. Bile duct injury is a rare, but serious complication during this procedure, mostly caused by misidentification of the extra-hepatic bile duct anatomy. Intraoperative cholangiography may be helpful to reduce the risk of bile duct injury; however this is not a common procedure worldwide. Near-infrared fluorescence cholangiography (NIRFC) using indocyanine green (ICG) is a promising alternative for the identification of the biliary tree. Aim of this prospective observational study was to assess the feasibility and image quality of intermittent NIRFC during LC, using a newly developed laparoscopic fluorescence system.
\end{abstract}

\title{
Methods
}

Consecutive patients undergoing elective LC were included and received a single intravenous injection of ICG directly after induction of anesthesia. During dissection of the base of the gallbladder and the cystic duct the extra-hepatic bile ducts were visualized using a dedicated laparoscope, which offers both conventional state-of-theart imaging and fluorescence imaging. Intraoperative recognition of the biliary structures was registered at set time points, as well as the establishment of the critical view of safety.

\section{Results}

Fifteen patients were included between December 2011 and May 2012. ICG was visible in the liver and bile ducts within 20 minutes after intravenous administration and remained so up to approximately 2 hours, using the fluorescence mode of the laparoscope. The common bile duct and cystic duct could be clearly identified at an early stage of the operation and more important, significantly earlier than with the conventional camera mode. No per- or postoperative complications occurred as a consequence of ICG use.

\section{Conclusions}

Intermittent fluorescence imaging using a newly developed laparoscope and preoperative administration of ICG seems a useful aid in accelerating visualization of the extra-hepatic bile ducts during laparoscopic cholecystectomy. 


\section{Introduction}

Laparoscopic cholecystectomy (LC) is one of the most commonly performed laparoscopic procedures in gastrointestinal surgery. Bile duct injury during this procedure is rare but constitutes a serious complication $(0.3-0.7 \%)^{1-4}$. Misidentification of the extra-hepatic bile duct anatomy during laparoscopic cholecystectomy is the main cause of bile duct injury ${ }^{5}$.

Intraoperative cholangiography has been advised to reduce the risk of bile duct injury ${ }^{1,6}$. However, this radiological imaging of the biliary tree is only used selectively, as the process takes time, radiation exposure is involved and additional equipment and manpower for the procedure are required. Moreover, worldwide consensus about implementation of intraoperative cholangiography is still lacking ${ }^{7}$.

Near-infrared fluorescence cholangiography (NIRFC) with preoperative intravenous injection of indocyanine green (ICG) is a promising new technique for easier intraoperative recognition of the biliary anatomy. It may help improve the outcome of laparoscopic cholecystectomy ${ }^{6,8}$. ICG is cleared quickly and exclusively by the liver after intravenous administration. Neither radiological support nor additional intervention, such as opening the biliary tree, is required.

Intraoperative fluorescence imaging using ICG is not only used during gallbladder surgery, but also in other clinical fields, including sentinel node targeting in colorectal, breast, cervical and vulvar cancer surgery ${ }^{9-12}$. Several fluorescence imaging systems for research purposes are available for both open ${ }^{10,13}$ and laparoscopic surgery ${ }^{9}$.

The primary objective of this study was to test a newly developed laparoscopic fluorescence imaging system (Karl Storz GmbH \& Co. KG, Tuttlingen, Germany) during elective laparoscopic cholecystectomy. Secondary goal was to assess whether earlier identification of the biliary anatomy could be obtained.

\section{Materials and methods}

Study procedures were conducted between December 2011 and May 2012 at the department of Surgery of Maastricht University Medical Center (MUMC, Maastricht, The Netherlands). All laparoscopic procedures were conducted by a surgical resident, assisted by a surgeon who had performed at least 150 laparoscopic cholecystectomies. The medical ethics committee of MUMC approved this study. The NIRFC-LC study was registered in the Netherlands National Trial Register: registration number NTR3211 (http://www.trialregister.nl/trialreg/admin/rctview.asp? TC=3211). 
Consecutive patients (male and female) aged 18 years and above, scheduled for elective laparoscopic cholecystectomy (i.e. for cholecystolithiasis, cholecystitis) were eligible for inclusion in this study. Patients were excluded in case of liver or renal insufficiency, known iodine or ICG hypersensitivity and pregnancy.

\section{Laparoscopic fluorescence imaging system}

A newly developed laparoscopic fluorescence imaging system by Karl Storz (including a plasma light guide and 30-degree 10-mm laparoscope applicable for white light (WL), autofluorescence and ICG-imaging) was used for intraoperative conventional imaging (WL mode) and real-time fluorescence imaging (ICG mode). The system is equipped with a foot pedal, allowing the surgeon to easily switch from WL mode to ICG mode, and back. Because of the instantaneous changing of images and the stable position of the laparoscope, anatomical orientation can be maintained. Direct overlay of the fluorescence image on the WL anatomical image is not yet possible with the current system.

\section{Indocyanine green administration}

$1 \mathrm{ml}$ of ICG $\left(2.5 \mathrm{mg} / \mathrm{ml}\right.$ Infracyanine ${ }^{\circledR}$; SERB, France) was injected intravenously directly after induction of anesthesia, in order to obtain intraoperative fluorescence illumination of the biliary tree. Infracyanine is an iodine-free preparation of ICG.

\section{Fluorescence cholangiography during laparoscopic cholecystectomy}

The surgical procedure was performed according to the Dutch Guidelines and Best Practice for laparoscopic cholecystectomy ${ }^{14}$, which is based on the so-called critical view of safety (CVS) technique - in essence the 'surgical dissection' of Calot's triangle as first described by Strasberg in $1995^{15}$ and recommended by the Society of American Gastrointestinal and Endoscopic Surgeons ${ }^{16}$. Initial NIRFC was conducted at the first view of the liver hilum. Subsequently, fluorescence imaging was obtained every 5-10 minutes until the CVS was established by the surgeon. See also Figure 3.1 for a flowchart of the study procedures.

\section{Image recording and data collection}

Intraoperatively the researcher systematically registered on a form whether the localization of specific relevant biliary structures (e.g. common bile duct, cystic duct, cystic artery) could be identified at set time points, comparing the WL camera mode to ICG mode. For agreement on the identification of the aforementioned structures the 
attending surgeon was consulted. A structure was scored as 'identified' if its localization was confirmed with great certainty by the experienced surgeon. In case of the common bile duct this does explicitly not mean that it was surgically exposed, as this is contradictory to the CVS technique.

During all laparoscopic cholecystectomies the full surgical procedure was recorded on DVD, thereby collecting both conventional and fluorescence images. After completion of surgery, length of time between the moment of ICG injection and the moment of introduction of the laparoscope until the first recognition of the following components were calculated, based on the intraoperative registration: cystic duct (CD), cystic artery (CA), common bile duct (CBD) and critical view of safety (CVS).

Using conventional imaging the CBD is often not displayed; this is partly a result of the CVS technique. The mean 'total NIRFC imaging time' during the laparoscopic procedures was calculated based on the video recordings, in order to objectify how much longer the operation lasted due to application of the NIRFC technique.

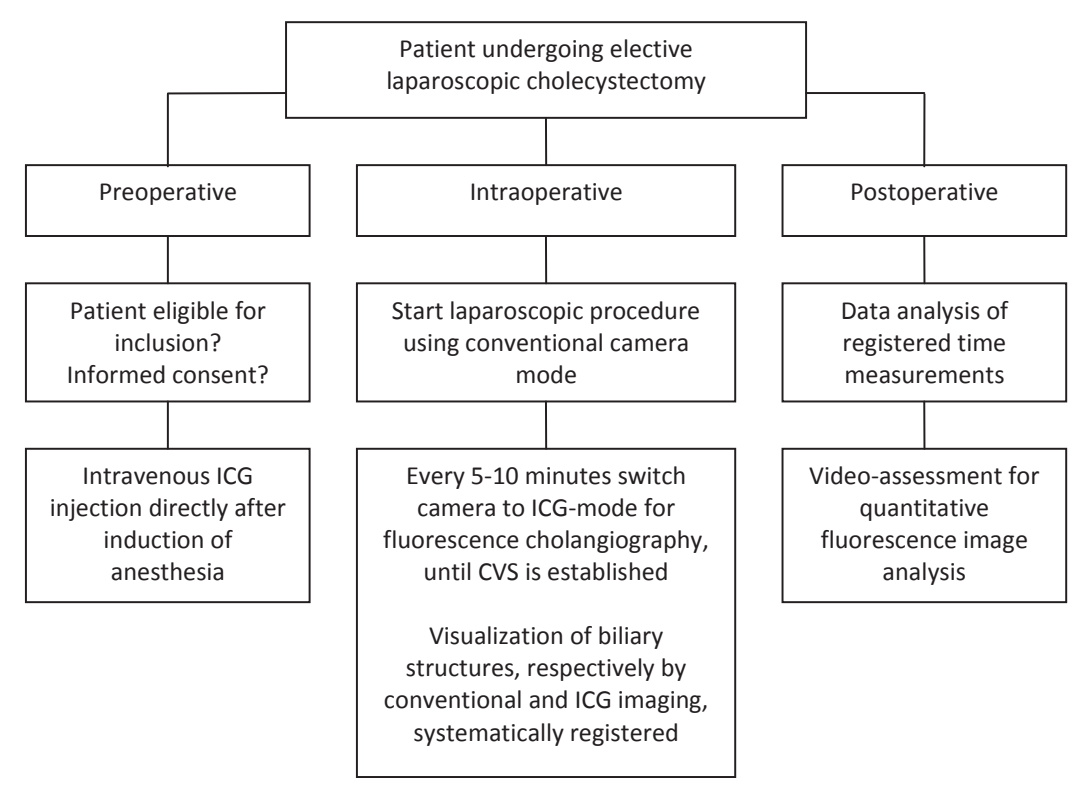

Figure 3.1 Flowchart of the NIRFC-LC study procedures

\section{Quantitative analysis of NIRFC recordings}

Osirix ${ }^{\circledR}$ software was used to objectively assess the degree of ICG illumination in the extra-hepatic bile ducts. The fluorescence images were analyzed by determining target- 
to-background ratio (TBR). TBR was defined as the mean fluorescence intensity (FI) of two point regions of interest (ROIs) in the target (being CD or CBD) minus the mean fluorescence intensity of two background (BG) ROIs in the liver hilum, divided by the mean fluorescence intensity of the two background ROIs in the liver hilum; in formula: $\mathrm{TBR}=(\mathrm{FI}$ of target $-\mathrm{FI}$ of $\mathrm{BG}) / \mathrm{FI}$ of BG.

\section{Statistical analysis of time measurements}

A paired T-test was applied for determination of possible significant differences between the time measurements from 'introduction of laparoscope' until 'identification of CD / CBD'; comparing NIRFC with conventional imaging.

\section{Results}

Fifteen consecutive patients, scheduled to undergo an elective laparoscopic cholecystectomy, were included in this study (cholecystolithiasis 11, cholecystitis 4). Preoperatively, written informed consent was obtained from all patients. Four men and eleven women had a median age of 52 (27-76) years and a median body mass index of $26.2(19.7-31.6) \mathrm{kg} / \mathrm{m}^{2}$. Preoperatively no signs of biliary tract obstruction were present. Patient characteristics are shown in Table 3.1.

Table 3.1 Patient characteristics

\begin{tabular}{ll}
\hline Number of subjects & 15 \\
Gender & 4 male \\
Age (years) & 11 female \\
Body Mass Index $\left(\mathrm{kg} / \mathrm{m}^{2}\right)$ & $52(27-76)$ \\
Indication for operation & $26.2(19.7-31.6)$ \\
& 11 cholecystolithiasis \\
ICG dose & 4 cholecystitis \\
\hline
\end{tabular}

\section{Bile duct identification using fluorescence cholangiography}

The median time interval from preoperative ICG administration until first NIRFC view with the laparoscope was 33 (19-67) minutes. The time until first NIRFC depended mainly on whether an adhesiolysis had to be conducted before initial exposure of the liver hilum could be obtained. After start of surgery the common bile duct could be identified significantly earlier using NIRFC compared with WL imaging (median 22 and 32 minutes respectively; P-value 0.001). Using NIRFC the cystic duct was delineated 
after on average of 23 minutes, whereas using WL camera mode this took on average of 31 minutes ( $P$-value 0.0004). See also Table 3.2 for intraoperative registration.

Using fluorescence cholangiography the $\mathrm{CBD}$ and $\mathrm{CD}$ could be clearly visualized and delineated before dissection of Calot's triangle in 15/15 patients. See Figure 3.2A-3.2C for an example of the peroperative WL images and corresponding NIRFC images before and during the dissection of Calot's triangle. In one patient a parallel course ${ }^{17}$ of the cystic duct and common hepatic duct was identified; see Figure 3.2B.

Critical view of safety was obtained in a median 40 minutes after incision. We observed no prolonged preparation time before start of surgery and only a negligible extension of the operation time (1-2 minutes) due to the use of the NIRFC technique.

As a preventive measure, in 3/15 patients the gall bladder was punctured and drained during surgery to facilitate manipulation; no major bile leakage occurred, and this did neither compromise fluorescence imaging of the biliary tract nor the postoperative course.

Table 3.2 Intraoperative time registration

\begin{tabular}{|c|c|c|c|c|c|c|c|c|}
\hline \multirow{3}{*}{$\begin{array}{l}\text { Number of patients } \\
(n=15)\end{array}$} & \multicolumn{2}{|c|}{ Time between ICG ${ }^{\mathrm{a}}$ injection and } & \multicolumn{6}{|c|}{ Time between introduction laparoscope and } \\
\hline & \multirow[b]{2}{*}{$\begin{array}{l}\text { Introduction } \\
\text { laparoscope }\end{array}$} & \multirow[b]{2}{*}{ First NIRFC } & First & \multicolumn{2}{|c|}{$C D^{d}$} & \multicolumn{2}{|c|}{$\mathrm{CBD}^{\mathrm{e}}$} & \multirow[t]{2}{*}{$\operatorname{CVS}^{f}$} \\
\hline & & & & NIRFC & $W L^{c}$ & NIRFC & WL & \\
\hline \multirow[t]{2}{*}{$\begin{array}{l}\text { Median time in minutes } \\
\text { [range] }\end{array}$} & $\begin{array}{c}19 \\
{[12-35]}\end{array}$ & $\begin{array}{c}33 \\
{[19-67]}\end{array}$ & $\begin{array}{c}15 \\
{[5-47]}\end{array}$ & $\begin{array}{c}23 \\
{[5-47]}\end{array}$ & $\begin{array}{c}31 \\
{[9-54]}\end{array}$ & $\begin{array}{c}22 \\
{[5-65]}\end{array}$ & $\begin{array}{c}32 \\
{[9-65]}\end{array}$ & $\begin{array}{c}40 \\
{[12-70]}\end{array}$ \\
\hline & & & & \multicolumn{2}{|c|}{$P=0.0004^{*}$} & \multicolumn{2}{|c|}{$P=0.001^{*}$} & \\
\hline
\end{tabular}

ICG=intravenous indocyanine green administration; NIRFC = near-infrared fluorescence cholangiography; WL = conventional white light imaging; $C D=$ identification of cystic duct; $C B D=$ identification of common bile duct; CVS = establishment of critical view of safety. ${ }^{*}$ Significant difference $(P<0.05)$

\section{Fluorescence data analysis}

TBR of CD was 3.6 and TBR of CBD was 3.9 (28 minutes after ICG injection), as can be seen in Figure 3.2B. Figure 3.2C shows TBR of CD of 7.9 and TBR of CBD of 6.3 (36 minutes post-ICG injection). Mean TBR at establishment of CVS (median 59 minutes after ICG administration) amounted to 5.6 for CD and 6.8 for CBD.

\section{Per- and postoperative complications}

No per- or postoperative complications (e.g. no intra-abdominal bile leakage or gallstone spill) occurred. None of the patients developed any adverse reactions to the injected ICG. 
A
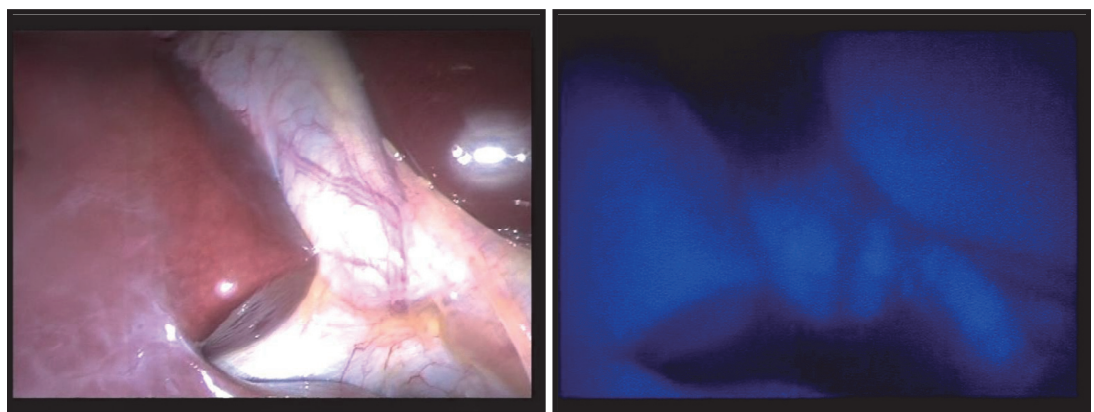

B
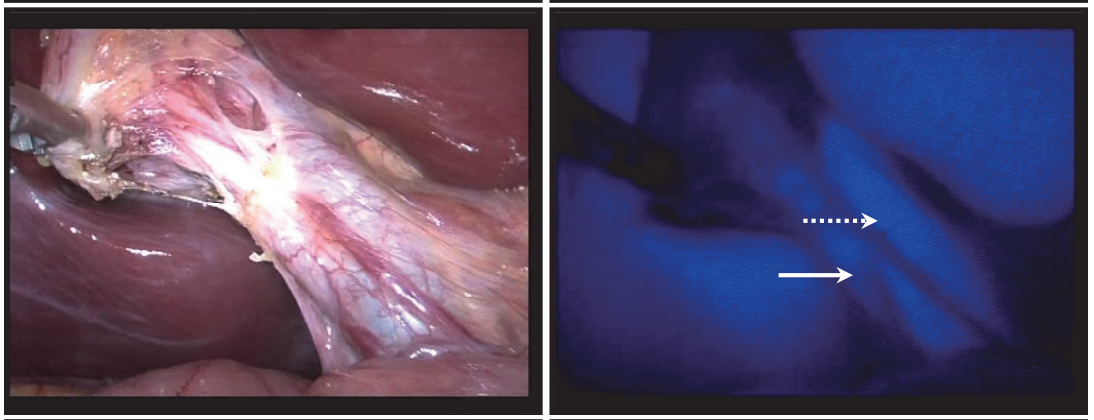

C
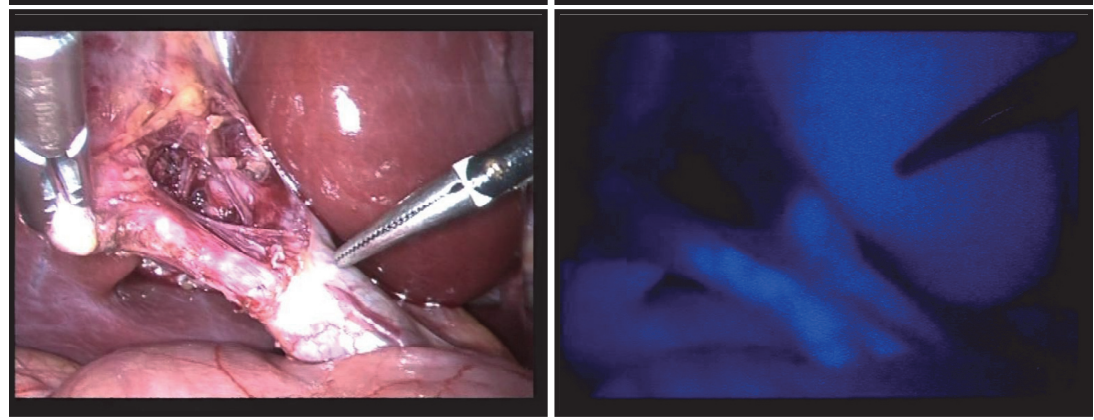

Figure 3.2 A. WL image (left) and fluorescence image (right) at first NIRFC of the liver hilum. Images recorded directly after initial exposure of the liver hilum. The liver and extra-hepatic bile ducts are illuminated bright blue; B. WL image (left) and NIRFC image (right) during dissection of Calot's triangle. Note the parallel junction between the cystic duct (continuous arrow) and the common hepatic duct (interrupted arrow) in the fluorescence image. The liver remains illuminated as well; C. WL image (left) and NIRFC image (right) in a later stage of dissection of Calot's triangle. The fluorescence image confirms the divergent course of the two separate bile ducts as already identified in an earlier stage (Figure 3.2B). The liver remains illuminated. 


\section{Discussion}

This clinical report on the application of a newly developed laparoscopic fluorescence system during laparoscopic cholecystectomy shows that conducting real-time intermittent fluorescence imaging of the extra-hepatic bile ducts during laparoscopic gallbladder surgery is feasible. It provides a significantly earlier identification and a clear delineation (high TBR) of both common bile duct and cystic duct, therewith assisting in safe and efficient dissection of the gallbladder according to the CVS technique.

Ishizawa et al. ${ }^{18}$ performed a study of fluorescent cholangiography in 52 laparoscopic cholecystectomies. By using a prototype fluorescent imaging system (Hamamatsu Photonics, Hamamatsu, Japan) coupled with a specially developed laparoscope the cystic duct could be identified intraoperatively in all subjects. In this study $1 \mathrm{ml}$ ICG $\left(2.5 \mathrm{mg} / \mathrm{ml}\right.$ Diagnogreen ${ }^{\circledR}$; Daiichi Sankyo, Tokyo, Japan) was administered 30 minutes before the patient entered the operating theatre. In our study we injected the same dose of ICG, but after induction of anesthesia, which helps overcome logistical problems (e.g. no need to monitor the patient on the ward after ICG administration).

Ishizawa et al. ${ }^{19}$ also tested their prototype system subsequently during single-incision laparoscopic cholecystectomy $(n=7)$, with promising outcomes for possible future implementation in this minimally invasive surgical technique.

Differences with other studies are that we administered iodine-free ICG (Infracyanine ${ }^{\circledR}$ ) instead of iodinated ICG (e.g. Diagnogreen ${ }^{\circledR}{ }^{18-20}$ ) and that the fluorescence signal is displayed in blue instead of green. Furthermore, in this study we conducted a 'standardized application' of NIRFC (i.e. every 5-10 minutes switching to fluorescence imaging). To our knowledge such standardized implementation of fluorescent cholangiography has not been reported before.

Compared with the other available laparoscopic fluorescence imaging system (Olympus Corp., Tokyo, Japan $)^{9}$ the newly developed Karl Storz laparoscopic fluorescence imaging system offers the advantage that it is equipped with a foot pedal to switch between conventional and fluorescence imaging using the same laparoscope.

A slight disadvantage of the current and the other available devices is that it does not yet possess the ability to real-time overlay the NIRFC images with the conventional white light images. Another improvement could be contrast enhancement of Calot's triangle during NIRFC imaging for even better delineation of the biliary tract. Quantitative fluorescence image analysis (e.g. TBR) as conducted in this study, could possibly be applied as a base for image enhancement. The present plasma light guide appeared quite rigid and in combination with the 30-degree laparoscope sometimes inconvenient to handle during surgery. With respect to the hardware this requires modification. 
In this study fluorescence imaging of the arterial anatomy was not conducted. Simultaneous NIR fluorescence imaging using ICG of bile ducts and arterial anatomy is however possible $\mathrm{e}^{20,21}$.

Our patients mostly had uncomplicated cholecystolithiasis (11/15 patients). We plan to investigate the NIRFC technique for complicated cholecystectomies as well, when better and earlier identification of Calot's triangle is even more desirable, e.g. acute cholecystitis, status after biliary pancreatitis and Mirizzi syndrome.

This study showed that faster recognition of essential biliary structures during laparoscopic cholecystectomy was obtained after a single preoperative intravenous administration of iodine-free ICG. Using a newly developed laparoscopic fluorescence device the surgeon was able to easily switch between conventional and fluorescence camera mode.

Nevertheless, a relatively small number of patients were included for this study and fluorescence imaging for confirmation of the arterial anatomy was not performed. Future research in a larger population will focus on this part.

The NIRFC technique can possibly become an excellent aid for surgical trainees in conducting safe (i.e. less adverse events) laparoscopic cholecystectomy.

\section{Conclusion}

The first application of a novel available laparoscopic fluorescence system for intermittent fluorescence cholangiography using iodine-free ICG during elective laparoscopic cholecystectomy is successful and offers clinical potential. In this study it proved to be a useful aid to obtain earlier and clearer recognition of the biliary anatomy. 


\section{References}

1. Flum DR, Dellinger EP, Cheadle A, Chan L, Koepsell T (2003) Intraoperative cholangiography and risk of common bile duct injury during cholecystectomy. JAMA 289:1639-1644

2. Fletcher DR, Hobbs MS, Tan P, Valinsky LJ, Hockey RL, Pikora TJ, Knuiman MW, Sheiner HJ, Edis A (1999) Complications of cholecystectomy: risks of the laparoscopic approach and protective effects of operative cholangiography: a population-based study. Ann Surg 229:449-457

3. Nuzzo G, Giuliante F, Giovannini I, Ardito F, D'Acapito F, Vellone M, Murazio M, Capelli G (2005) Bile duct injury during laparoscopic cholecystectomy: results of an Italian national survey on 56591 cholecystectomies. Arch Surg 140:986-992

4. Waage A, Nilsson M (2006) latrogenic bile duct injury: a population-based study of 152776 cholecystectomies in the Swedish Inpatient Registry. Arch Surg 141:1207-1213

5. Way LW, Stewart L, Gantert W, Liu K, Lee CM, Whang K, Hunter JG (2003) Causes and prevention of laparoscopic bile duct injuries: analysis of 252 cases from a human factors and cognitive psychology perspective. Ann Surg 237:460-469

6. Buddingh KT, Nieuwenhuijs VB, van Buuren L, Hulscher JB, de Jong JS, van Dam GM (2011) Intraoperative assessment of biliary anatomy for prevention of bile duct injury: a review of current and future patient safety interventions. Surg Endosc 25:2449-2461

7. Ford JA, Soop M, Du J, Loveday BP, Rodgers M (2012) Systematic review of intraoperative cholangiography in cholecystectomy. Br J Surg 99:160-167

8. Agarwal BB (2009) Patient safety in laparoscopic cholecystectomy. Arch Surg 144:979; author reply 979

9. Ankersmit M, van der Pas MH, van Dam DA, Meijerink WJ (2011) Near infrared fluorescence lymphatic laparoscopy of the colon and mesocolon. Colorectal Dis 13 Suppl 7:70-73

10. Mieog JS, Troyan SL, Hutteman M, Donohoe KJ, van der Vorst JR, Stockdale A, Liefers GJ, Choi HS, Gibbs-Strauss SL, Putter H, Gioux S, Kuppen PJ, Ashitate Y, Lowik CW, Smit VT, Oketokoun R, Ngo LH, van de Velde CJ, Frangioni JV, Vahrmeijer AL (2011) Toward optimization of imaging system and lymphatic tracer for near-infrared fluorescent sentinel lymph node mapping in breast cancer. Ann Surg Oncol 18:2483-2491

11. van der Vorst JR, Hutteman M, Gaarenstroom KN, Peters AA, Mieog JS, Schaafsma BE, Kuppen PJ, Frangioni JV, van de Velde CJ, Vahrmeijer AL (2011) Optimization of near-infrared fluorescent sentinel lymph node mapping in cervical cancer patients. Int J Gynecol Cancer 21:1472-1478

12. Hutteman M, van der Vorst JR, Gaarenstroom KN, Peters AA, Mieog JS, Schaafsma BE, Lowik CW, Frangioni JV, van de Velde CJ, Vahrmeijer AL (2012) Optimization of near-infrared fluorescent sentinel lymph node mapping for vulvar cancer. Am J Obstet Gynecol 206:89 e81-85

13. Themelis G, Yoo JS, Soh KS, Schulz R, Ntziachristos V (2009) Real-time intraoperative fluorescence imaging system using light-absorption correction. J Biomed Opt 14:064012

14. Lange JF, Stassen LPS (2006) Best practice in verband met de techniek van laparoscopische cholecystectomie (Critical View of Safety [CVS] in 7 stappen). Werkgroep Endoscopische Chirurgie van de Nederlandse vereniging voor Heelkunde, http://wwwheelkundenl/uploads/_6/re/ _6reZZkgrYUAuCG6uvcN-A/ richtlijn_galsteenpdf

15. Strasberg SM, Hertl M, Soper NJ (1995) An analysis of the problem of biliary injury during laparoscopic cholecystectomy. J Am Coll Surg 180:101-125

16. Kuwada T (2005) Highlights of the Society of American Gastrointestinal and Endoscopic Surgeons 2005, Annual Meeting april 13-16, 2005; Ft Lauderdale, Florida. Medscape General Surgery: Conference reports, http://wwwmedscapecom/viewarticle/506432

17. Johnston EV, Anson BJ (1952) Variations in the formation and vascular relationships of the bile ducts. Surg Gynecol Obstet 94:669-686

18. Ishizawa T, Bandai Y, Ijichi M, Kaneko J, Hasegawa K, Kokudo N (2010) Fluorescent cholangiography illuminating the biliary tree during laparoscopic cholecystectomy. Br J Surg 97:1369-1377

19. Ishizawa T, Kaneko J, Inoue Y, Takemura N, Seyama Y, Aoki T, Beck Y, Sugawara Y, Hasegawa K, Harada N, Ijichi M, Kusaka K, Shibasaki M, Bandai Y, Kokudo N (2011) Application of fluorescent cholangiography to single-incision laparoscopic cholecystectomy. Surg Endosc 25:2631-2636 
20. Tagaya N, Shimoda M, Kato M, Nakagawa A, Abe A, Iwasaki Y, Oishi H, Shirotani N, Kubota K (2010) Intraoperative exploration of biliary anatomy using fluorescence imaging of indocyanine green in experimental and clinical cholecystectomies. J Hepatobiliary Pancreat Sci 17:595-600

21. Ashitate Y, Stockdale A, Choi HS, Laurence RG, Frangioni JV (2011) Real-Time Simultaneous NearInfrared Fluorescence Imaging of Bile Duct and Arterial Anatomy. J Surg Res 176:7-13 
Fluorescence cholangiography during laparoscopic cholecystectomy 


\section{Chapter 4}

Combined vascular and biliary fluorescence imaging in laparoscopic cholecystectomy

Schols RM, Bouvy ND, van Dam RM, Masclee AA, Dejong CH, Stassen LP Surgical Endoscopy 2013;27:4511-4517 


\begin{abstract}

\section{Background}

Bile duct injury in patients undergoing laparoscopic cholecystectomy is a rare but serious complication. Concomitant vascular injury worsens the outcome of bile duct injury repair. Near-infrared fluorescence imaging using indocyanine green (ICG) is a promising, innovative and noninvasive method for the intraoperative identification of biliary and vascular anatomy during cholecystectomy. This study aimed to assess the practical application of combined vascular and biliary fluorescence imaging in laparoscopic gallbladder surgery for early biliary tract delineation and arterial anatomy confirmation.
\end{abstract}

\title{
Methods
}

Patients undergoing elective laparoscopic cholecystectomy were enrolled in this prospective, single-institutional study. To delineate the major bile ducts and arteries a dedicated laparoscope, offering both conventional and fluorescence imaging, was used. ICG (2.5mg) was administered intravenously immediately after induction of anesthesia and in half of the patients repeated at establishment of Critical View of Safety for concomitant arterial imaging. During dissection of the base of the gallbladder and the cystic duct the extra-hepatic bile ducts were visualized. Intraoperative recognition of the biliary structures was registered at set time points, as well as visualization of the cystic artery after repeat ICG administration.

\section{Results}

Thirty patients were included. ICG was visible in the liver and bile ducts within 20 minutes after injection and remained so up to approximately $2 \mathrm{~h}$, using the ICG-filter of the laparoscope. In most cases the common bile duct (83\%) and cystic duct (97\%) could be identified significantly earlier than with conventional camera mode. In 13 of 15 patients (87\%) confirmation of the cystic artery was successfully obtained after repeat ICG injection. No per- or postoperative complications occurred as a consequence of ICG use.

\section{Conclusion}

Biliary and vascular fluorescence imaging in laparoscopic cholecystectomy is easily applicable in clinical practice, can be helpful for earlier visualization of the biliary tree and is useful for the confirmation of the arterial anatomy. 


\section{Introduction}

Bile duct injury is a rare but severe complication in patients undergoing laparoscopic cholecystectomy $(0.3-0.7 \%)^{1-4}$. Misidentification of the extra-hepatic bile duct anatomy during this procedure is the main cause of such injury ${ }^{5}$. Concomitant vasculobiliary injury negatively affects the outcome of bile duct injury repair ${ }^{6}$.

The Critical View of Safety (CVS) technique, which was first described by Strasberg in $1995^{7}$ and recommended by the SAGES Annual Meeting of $2005^{8}$, was introduced to reduce the risk of bile duct injury. To establish CVS, two windows need to be created during dissection of Calot's triangle: one window between the cystic artery, cystic duct and gallbladder, another window between the cystic artery, gallbladder and liver. The CVS technique is especially aimed at mobilizing the gallbladder neck from the liver, in order to obtain a circumferential identification of the cystic duct.

Near-infrared fluorescence laparoscopy with preoperative intravenous injection of indocyanine green (ICG) is a promising, innovative and noninvasive imaging method for enhanced intraoperative visualization of biliary anatomy. It has the potential to improve outcome of the laparoscopic cholecystectomy procedure ${ }^{9,10}$. ICG is cleared quickly and exclusively by the liver after intravenous administration and has few, if any side effects, making it an ideal fluorophore for this application.

Previous experience with intermittent fluorescence cholangiography during elective laparoscopic cholecystectomy showed that this technique can indeed accelerate biliary tract delineation ${ }^{11}$. In the present part of a larger feasibility study project on fluorescence laparoscopy technique, simultaneous fluorescence cholangiography and angiography at the moment of establishing CVS were conducted.

The main objective of this study was to test the practical applicability of a newly developed laparoscopic fluorescence imaging system during elective laparoscopic cholecystectomy, regarding real-time intraoperative biliary and arterial imaging.

\section{Materials and methods}

This study was performed at the department of Surgery of the Maastricht University Medical Center (MUMC, Maastricht, The Netherlands) between December 2011 and October 2012. All operations were performed by a surgical resident, assisted by a surgeon with a track record of at least 150 laparoscopic cholecystectomies. The institutional review board (IRB) of the MUMC approved of this study. The study was registered in the Netherlands National Trial Register: 
http://www.trialregister.nl/trialreg/admin/rctview.asp?TC=3211, registration number NTR3211 (NIRFC-LC study).

Consecutive male and female patients, aged 18 years and above, scheduled for elective laparoscopic cholecystectomy and with written informed consent, were eligible for inclusion in this study. Indications for surgery were: cholecystolithiasis, cholecystitis, cholecystectomy after biliary pancreatitis. Patients were excluded in case of liver or renal insufficiency, known iodine or ICG hypersensitivity and pregnancy (all are contraindications for the use of intravenous ICG).

\section{Laparoscopic fluorescence imaging system}

A novel, commercially available laparoscopic fluorescence imaging system (Karl Storz $\mathrm{GmbH} \& \mathrm{CO}$. KG, Tuttlingen, Germany) -including a plasma light guide and 30-degree 10-mm laparoscope applicable for white light, autofluorescence and ICG imaging- was used for intraoperative conventional imaging (WL-mode) and near-infrared fluorescence imaging (ICG-mode). The system is equipped with a foot pedal, allowing the surgeon to easily switch from WL-mode to ICG-mode, and back. Because of the instantaneous changing of images and the stable position of the laparoscope, anatomical orientation can be maintained. However, direct fluorescence image-overlay on the conventional anatomical image is not yet possible with this system.

\section{ICG administration}

In all patients $2.5 \mathrm{mg}$ of ICG (Infracyanine ${ }^{\circledR}$; SERB, France) was injected intravenously directly after induction of anesthesia, to obtain intraoperative near-infrared fluorescence illumination of the extra-hepatic bile ducts. Half of the patients received a repeat intravenous injection of $2.5 \mathrm{mg}$ of ICG at establishment of the Critical View of Safety for concomitant arterial and biliary fluorescence delineation.

\section{Fluorescence laparoscopy}

The operation was performed according to the Dutch Guidelines and Best Practice for laparoscopic cholecystectomy ${ }^{12}$, which is based on the CVS-technique. Initial fluorescence cholangiography was conducted at the first view of the liver hilum. Subsequently, fluorescence imaging was applied every 5-10 minutes until CVS was established by the surgeon. At establishment of CVS simultaneous fluorescence angiography was obtained from 10 seconds up to approximately 1 minute after repeat intravenous ICG injection. See Figure 4.1 for a flowchart of the study procedure. 


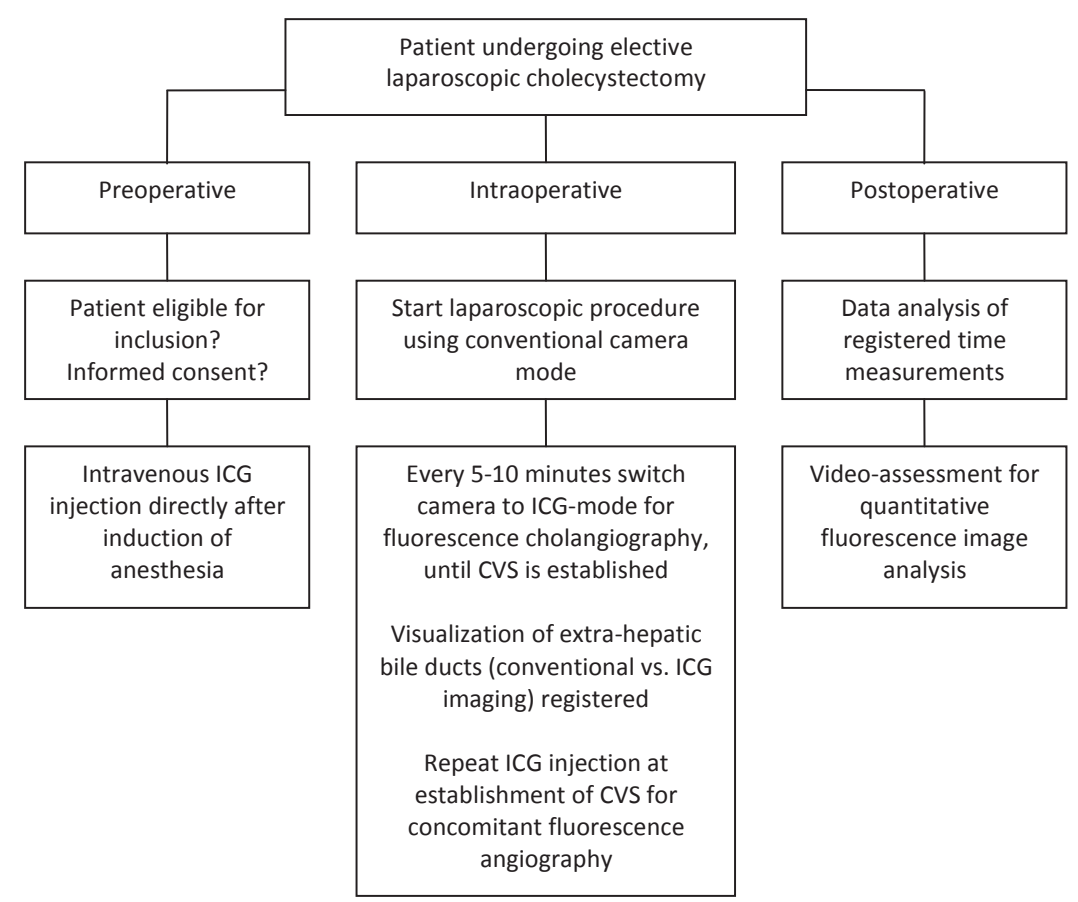

Figure 4.1 Flowchart of the NIRFC-LC study procedures

\section{Data collection}

Intraoperatively a researcher systematically registered on a paper form whether the localization of the common bile duct, cystic duct and cystic artery could be identified at set time points, comparing the WL-camera mode to ICG-mode. For agreement on the identification of the aforementioned structures the attending surgeon was consulted. $A$ structure was scored as 'identified' if its localization was confirmed with great certainty by the experienced surgeon. In case of the common bile duct this does explicitly not mean that it was surgically exposed, as this is contradictory to the CVS-technique.

During all laparoscopic cholecystectomies the full surgical procedure was recorded on DVD, thereby collecting both conventional and fluorescence images. After completion of surgery, length of time between the introduction of the laparoscope until the first recognition of the following components were calculated, based on the intraoperative registration: common bile duct (CBD), cystic duct (CD), cystic artery (CA) and Critical View of Safety (CVS).

Using conventional imaging the CBD is regularly not displayed; this is partly a result of the CVS technique. The mean 'total fluorescence imaging time' during the laparoscopic 
procedures was calculated based on the video recordings, in order to objectify how much longer the operation lasted due to application of the fluorescence technique.

\section{Quantitative fluorescence image analysis}

For objective assessment of the degree of fluorescence illumination in the extra-hepatic bile ducts and artery, Osirix 5.5.1 Imaging Software was used. The fluorescence images were analyzed by determining target-to-background ratio (TBR). TBR was defined as the mean fluorescence intensity ( $\mathrm{FI}$ ) of two point regions of interest (ROIs) in the target (i.e. $\mathrm{CBD}, \mathrm{CD}$ or $\mathrm{CA}$ ) minus the mean fluorescence intensity of two background (BG) ROIs in the liver hilum, divided by the mean fluorescence intensity of the two background ROIs in the liver hilum; in formula: $\mathrm{TBR}=$ (FI of target $-\mathrm{FI}$ of BG) / FI of BG.

\section{Statistical analysis}

Primary endpoint consisted of moment of clear visualization of the extra-hepatic bile duct anatomy. Secondary endpoint was confirmation of the course of the cystic artery at establishment of CVS. Regarding the primary endpoint, a paired T-test was applied for determination of possible significant differences between the time measurements from 'introduction of laparoscope' until 'identification of CD / CBD'; comparing fluorescence imaging with conventional imaging.

\section{Results}

Thirty patients, undergoing an elective laparoscopic cholecystectomy, were included in this study. Before start of surgery no signs of biliary tract obstruction were present. Patient characteristics are shown in Table 4.1.

Table 4.1 Patient characteristics

\begin{tabular}{ll}
\hline No. of patients & 30 \\
Gender & 11 male \\
& 19 female \\
Age $(\mathrm{y})$ & $53(26-81)$ \\
Body Mass Index $\left(\mathrm{kg} / \mathrm{m}^{2}\right)$ & $26.7(19.7-36.8)$ \\
Indication for surgery & 20 cholecystolithiasis \\
& 8 cholecystitis \\
& 2 cholecystectomy after biliary pancreatitis \\
ICG administration & 2.5 mg directly after induction of anesthesia $(n=30)$ \\
& $2.5 m g$ at establishment of CVS $(n=15)$ \\
\hline
\end{tabular}




\section{Fluorescence laparoscopy}

The median time interval from preoperative ICG administration until first fluorescence imaging with the laparoscope was 34 (19-67) minutes. The time until first fluorescence imaging depended mainly on whether an adhesiolysis had to be conducted before initial exposure of the liver hilum could be obtained. After start of surgery the common bile duct could be identified significantly earlier using fluorescence imaging compared with WL imaging (median 23 and 33 minutes respectively; $P$-value<0.001). Using fluorescence laparoscopy the cystic duct was delineated after an average of 25 minutes, whereas using WL camera mode this took on average of 36 minutes ( $P$-value<0.001). See also Table 4.2 for intraoperative registration.

Table 4.2 Intraoperative observations

\begin{tabular}{|c|c|c|c|c|c|c|}
\hline \multirow{3}{*}{ Clear identification of } & \multicolumn{4}{|c|}{$\begin{array}{l}\text { Fluorescence cholangiography } \\
\qquad(\mathrm{n}=30)\end{array}$} & \multirow{2}{*}{\multicolumn{2}{|c|}{$\begin{array}{l}\text { Fluorescence angiography } \\
\qquad \begin{array}{l}(n=15) \\
\text { Cystic Artery }\end{array}\end{array}$}} \\
\hline & \multicolumn{2}{|c|}{ Cystic Duct } & \multicolumn{2}{|c|}{ Common Bile Duct } & & \\
\hline & NIRF & WL & NIRF & $W L$ & NIRF & WL \\
\hline \multirow[t]{2}{*}{ Patients } & $29 / 30$ & $29 / 30$ & $25 / 30$ & $22 / 30$ & $13 / 15(87 \%)^{\#}$ & $13 / 15(87 \%)^{\#}$ \\
\hline & $(97 \%)$ & $(97 \%)$ & $(83 \%)$ & $(73 \%)$ & & \\
\hline \multirow{2}{*}{$\begin{array}{l}\text { Median time in minutes } \\
\text { [range] }\end{array}$} & 25 [5-49] & 36 [9-69] & $23[5-65]$ & $33[9-65]$ & & \\
\hline & \multicolumn{2}{|c|}{$P<0.001 *$} & \multicolumn{2}{|c|}{$P<0.001 *$} & & \\
\hline
\end{tabular}

" Significant difference $(P<0.05) ;{ }^{\#} \operatorname{In} 2$ cases the cystic artery was already dissected before repeat ICG injection

Using fluorescence cholangiography the $C B D$ and the $C D$ could be clearly visualized and delineated before dissection of Calot's triangle (Figure 4.2A), respectively in 25/30 patients (83\%) and $29 / 30$ patients (97\%). In four of five cases $(17 \%)$, in which the CBD could not be visualized using fluorescence imaging, a chronic inflammation of the gallbladder was present. One patient appeared to have a chronic, focally active cholecystitis. BMI of these patients ranged from 26.35 to $31.14 \mathrm{~kg} / \mathrm{m}^{2}$. However, in the 25 patients in whom the CBD could be delineated before dissection, there were also cases of chronic inflamed gallbladders and BMIs within the same range as these 5 patients.

Conventional laparoscopy provided certainty on the course of the CBD and the CD in respectively $22 / 30$ patients and $29 / 30$ patients. In one patient conversion to open cholecystectomy followed, due to insufficient sight on the liver hilum after an early perforation of a very thin-walled gallbladder, causing persistent nuisance bile leakage. Critical view of safety was obtained in a median of 45 minutes after incision. Concomitant fluorescence angiography of the cystic artery (Figure 4.2B) was successful 
in 13 of 15 patients (87\%). In two patients the cystic artery was already ligated in an earlier stage of dissection.

In the total operation time (median 90 minutes) 1 up to 2 minutes was spent for the intraoperative use of the fluorescence technique.

As a preventive measure, in 3/30 patients the gall bladder was punctured and drained during surgery to facilitate manipulation; this did neither compromise fluorescence imaging of the biliary tract nor the postoperative course.

A
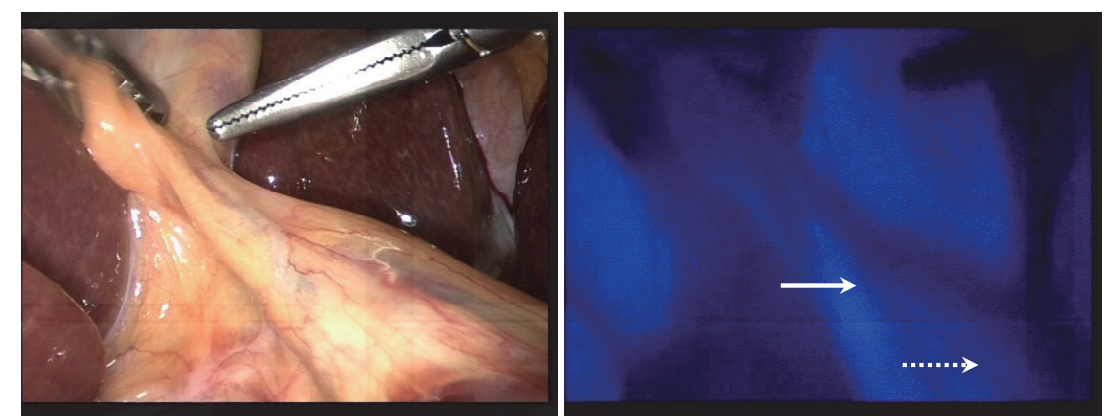

B
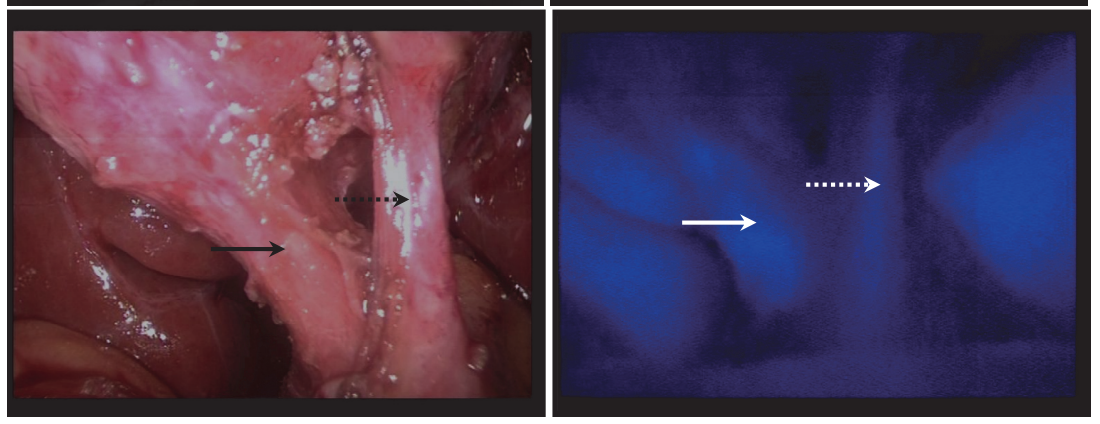

Figure 4.2 A. WL image (left) and corresponding fluorescence image (right) taken at initial exposure of the liver hilum. The liver and extra-hepatic bile ducts are illuminated bright blue: cystic duct (continuous arrow) and common bile duct (interrupted arrow) are indicated; B. WL image (left) and corresponding fluorescence image (right) at establishment of Critical View of Safety, snapshots taken 10 seconds after repeat ICG injection. The cystic duct (continuous arrow) and cystic artery (interrupted arrow) are clearly exposed.

\section{Target-to-background ratio}

Mean TBR at establishment of CVS (median 63 minutes after ICG administration) amounted to 5.6 for the $C D, 6.8$ for the $C B D$ and 4.8 for the $C A$. 


\section{Complications}

No per- or postoperative complications regarding the extra-hepatic bile ducts occurred. There was one conversion from laparoscopic to open cholecystectomy. None of the patients developed any adverse reactions to the injected ICG.

\section{Discussion}

This prospective, single-institutional, clinical study showed that the near-infrared fluorescence imaging technique was useful for earlier bile duct delineation during laparoscopic cholecystectomy. Next, it was found that repeat ICG injection at establishment of Critical View of Safety was helpful in the confirmation of arterial anatomy, in particular the course of the cystic artery. The fluorescence technique provided a significantly earlier identification and a clear delineation (high TBR) of the common bile duct, the cystic duct and the cystic artery, therewith assisting in safe and efficient dissection of the gallbladder according to the CVS technique.

The near-infrared fluorescence technique after local or intravenous administration of ICG has been evaluated in open, laparoscopic, single-incision laparoscopic and robotic single-site cholecystectomy ${ }^{13-18}$. Promising results were presented for successful intraoperative identification of the common bile duct and the cystic duct, compared to conventional laparoscopic imaging. The results of the present study showed moreover that fluorescence laparoscopy provided significantly earlier identification of the extrahepatic bile ducts during dissection.

Real-time simultaneous imaging of the bile ducts and the arterial anatomy (i.e. hepatic and cystic arteries) can also be obtained ${ }^{13,19-21}$. This study confirmed the possibility of concomitant vascular (i.e. cystic artery) and biliary (i.e. cystic duct and common bile duct) imaging at establishment of Critical View of Safety. Implementation of conducting both fluorescence cholangiography and angiography can be helpful in cases in which the establishment of CVS is challenging. Furthermore it may facilitate the intraoperative detection of bile duct and possible concomitant vasculobiliary injury (e.g. hepatic artery). The latter is an increasingly recognized complication of laparoscopic cholecystectomy ${ }^{22}$. Such combined injury negatively affects the outcome of bile duct injury repair ${ }^{6,23}$. Based on a review of vasculobiliary injury in laparoscopic and open cholecystectomy, routine arteriography in patients with biliary injury has been recommended ${ }^{24}$.

The negligible extension of operation duration in this study, related to the use of the fluorescence technique, will probably further decrease with growing experience. 
Looking at the results of the quantitative fluorescence image analysis, the moment of ICG administration (directly after induction of anesthesia) seems appropriate for the laparoscopic cholecystectomy procedure: a timely and continuous intraoperative detection of biliary structures can be obtained. Also from a practical and logistical point of view the applied timing of administration is appropriate.

In this study not only uncomplicated cholecystolithiasis patients, but also more complicated cases, such as cholecystitis or cholecystectomy after biliary pancreatitis, were included. Fluorescence cholangiography and angiography was successful in almost all cases, and no difference was found in image quality between the uncomplicated and complicated procedures. However, presence of factors as (either chronic or active) cholecystitis or obesity might compromise the efficacy of the new imaging modality. The actual impact of such conditions should be further investigated by conducting a univariate and multivariate analysis in a study population (large enough for this kind of analysis) to determine the risk factors. This was not possible in the current group of patients.

The near-infrared fluorescence laparoscopy technique possesses potential to enter the clinical practice in the near future. However, optimization of the current laparoscopic imaging systems is needed to make them more easily applicable in the operating room. Current laparoscopic systems do not yet possess the ability to display the fluorescence image in anatomical context. Furthermore, penetration depth at which the imaging system can detect a fluorophore in tissues needs improvement (currently up to maximum of 1 centimeter). An increase in fluorescence capabilities of contrast agents is also desirable ${ }^{25}$.

A comparison with conventional intraoperative cholangiography would be desirable. However, intraoperative cholangiography is only rarely applied in the Netherlands and many parts of the world. Intraoperative cholangiography has been suggested to reduce the risk of bile duct injury ${ }^{1,10}$. However, this radiological imaging of the biliary tree is only used selectively, as the process takes time, radiation exposure is involved and additional equipment and manpower for the procedure are required. Moreover, worldwide consensus about implementation of intraoperative cholangiography is still lacking ${ }^{26}$.

It could be argued that the fluorescence laparoscopy technique is especially useful for the less experienced surgeon to perform safe laparoscopic gallbladder removal, or in more complicated cholecystectomies. However, it may be most effective when performed routinely in all cases. Increased costs are involved in terms of the light source, camera and fluorescent dye. However, it is anticipated that worldwide, standard application of this technique will be accompanied by cheaper devices and 
shorter operation duration, when proven that CVS can actually be obtained significantly earlier compared to conventional laparoscopic imaging.

Fluorescence laparoscopy could also be implemented as a final check of the liver hilum before closing the pneumoperitoneum, in order to rule out or detect bile duct or vasculobiliary injury. This could be checked through the presence or absence of fluorescence contrast leakage into the abdomen.

\section{Conclusion}

Both biliary and vascular fluorescence imaging in laparoscopic cholecystectomy are easily applicable, can be helpful for earlier identification of the extra-hepatic bile ducts, and are useful for the confirmation of the arterial anatomy. 


\section{References}

1. Flum DR, Dellinger EP, Cheadle A, Chan L, Koepsell T (2003) Intraoperative cholangiography and risk of common bile duct injury during cholecystectomy. JAMA 289:1639-1644

2. Fletcher DR, Hobbs MS, Tan P, Valinsky LJ, Hockey RL, Pikora TJ, Knuiman MW, Sheiner HJ, Edis A (1999) Complications of cholecystectomy: risks of the laparoscopic approach and protective effects of operative cholangiography: a population-based study. Ann Surg 229:449-457

3. Nuzzo G, Giuliante F, Giovannini I, Ardito F, D'Acapito F, Vellone M, Murazio M, Capelli G (2005) Bile duct injury during laparoscopic cholecystectomy: results of an Italian national survey on 56591 cholecystectomies. Arch Surg 140:986-992

4. Waage A, Nilsson M (2006) latrogenic bile duct injury: a population-based study of 152776 cholecystectomies in the Swedish Inpatient Registry. Arch Surg 141:1207-1213

5. Way LW, Stewart L, Gantert W, Liu K, Lee CM, Whang K, Hunter JG (2003) Causes and prevention of laparoscopic bile duct injuries: analysis of 252 cases from a human factors and cognitive psychology perspective. Ann Surg 237:460-469

6. Sarno G, Al-Sarira AA, Ghaneh P, Fenwick SW, Malik HZ, Poston GJ (2012) Cholecystectomy-related bile duct and vasculobiliary injuries. Br J Surg 99:1129-1136

7. Strasberg SM, Hertl M, Soper NJ (1995) An analysis of the problem of biliary injury during laparoscopic cholecystectomy. J Am Coll Surg 180:101-125

8. Kuwada T (2005) Highlights of the Society of American Gastrointestinal and Endoscopic Surgeons 2005, Annual Meeting april 13-16, 2005; Ft Lauderdale, Florida. Medscape General Surgery: Conference reports, http://wwwmedscapecom/viewarticle/506432

9. Agarwal BB (2009) Patient safety in laparoscopic cholecystectomy. Arch Surg 144:979; author reply 979

10. Buddingh KT, Nieuwenhuijs VB, van Buuren L, Hulscher JB, de Jong JS, van Dam GM (2011) Intraoperative assessment of biliary anatomy for prevention of bile duct injury: a review of current and future patient safety interventions. Surg Endosc 25:2449-2461

11. Schols RM, Bouvy ND, Masclee AA, van Dam RM, Dejong CH, Stassen LP (2012) Fluorescence cholangiography during laparoscopic cholecystectomy: a feasibility study on early biliary tract delineation. Surg Endosc 27(5):1530-1536

12. Lange JF, Stassen LPS (2006) Best practice in verband met de techniek van laparoscopische cholecystectomie (Critical View of Safety [CVS] in 7 stappen). Werkgroep Endoscopische Chirurgie van de Nederlandse vereniging voor Heelkunde, http://wwwheelkundenl/uploads/_6/re/ _6reZZkgrYUAuCG6uvcN-A/richtlijn_galsteenpdf

13. Tagaya N, Shimoda M, Kato M, Nakagawa A, Abe A, Iwasaki Y, Oishi H, Shirotani N, Kubota K (2010) Intraoperative exploration of biliary anatomy using fluorescence imaging of indocyanine green in experimental and clinical cholecystectomies. J Hepatobiliary Pancreat Sci 17:595-600

14. Ishizawa T, Bandai Y, Ijichi M, Kaneko J, Hasegawa K, Kokudo N (2010) Fluorescent cholangiography illuminating the biliary tree during laparoscopic cholecystectomy. Br J Surg 97:1369-1377

15. Ishizawa T, Kaneko J, Inoue Y, Takemura N, Seyama Y, Aoki T, Beck Y, Sugawara Y, Hasegawa K, Harada N, Ijichi M, Kusaka K, Shibasaki M, Bandai Y, Kokudo N (2011) Application of fluorescent cholangiography to single-incision laparoscopic cholecystectomy. Surg Endosc 25:2631-2636

16. Aoki T, Murakami M, Yasuda D, Shimizu Y, Kusano T, Matsuda K, Niiya T, Kato H, Murai N, Otsuka K, Kusano M, Kato T (2010) Intraoperative fluorescent imaging using indocyanine green for liver mapping and cholangiography. J Hepatobiliary Pancreat Sci 17:590-594

17. Spinoglio G, Priora F, Bianchi PP, Lucido FS, Licciardello A, Maglione V, Grosso F, Quarati R, Ravazzoni F, Lenti LM (2012) Real-time near-infrared (NIR) fluorescent cholangiography in single-site robotic cholecystectomy (SSRC): a single-institutional prospective study. Surg Endosc 27:2156-2162

18. Buchs NC, Hagen ME, Pugin F, Volonte F, Bucher P, Schiffer E, Morel P (2012) Intra-operative fluorescent cholangiography using indocyanin green during robotic single site cholecystectomy. Int J Med Robot 8:436-440

19. Ashitate Y, Stockdale A, Choi HS, Laurence RG, Frangioni JV (2011) Real-Time Simultaneous NearInfrared Fluorescence Imaging of Bile Duct and Arterial Anatomy. J Surg Res 176:7-13 
20. Mitsuhashi N, Kimura F, Shimizu H, Imamaki M, Yoshidome H, Ohtsuka M, Kato A, Yoshitomi H, Nozawa S, Furukawa K, Takeuchi D, Takayashiki T, Suda K, Igarashi T, Miyazaki M (2008) Usefulness of intraoperative fluorescence imaging to evaluate local anatomy in hepatobiliary surgery. J Hepatobiliary Pancreat Surg 15:508-514

21. Kaneko J, Ishizawa T, Masuda K, Kawaguchi Y, Aoki T, Sakamoto Y, Hasegawa K, Sugawara Y, Kokudo N (2012) Indocyanine green reinjection technique for use in fluorescent angiography concomitant with cholangiography during laparoscopic cholecystectomy. Surg Laparosc Endosc Percutan Tech 22:341-344

22. Pulitano C, Parks RW, Ireland H, Wigmore SJ, Garden OJ (2011) Impact of concomitant arterial injury on the outcome of laparoscopic bile duct injury. Am J Surg 201:238-244

23. Schmidt SC, Langrehr JM, Raakow R, Klupp J, Steinmuller T, Neuhaus P (2002) Right hepatic lobectomy for recurrent cholangitis after combined bile duct and right hepatic artery injury during laparoscopic cholecystectomy: a report of two cases. Langenbecks Arch Surg 387:183-187

24. Strasberg SM, Helton WS (2011) An analytical review of vasculobiliary injury in laparoscopic and open cholecystectomy. HPB (Oxford) 13:1-14

25. Schols RM, Bouvy ND, van Dam RM, Stassen LP (2012) Advanced intraoperative imaging methods for laparoscopic anatomy navigation: an overview. Surg Endosc

26. Ford JA, Soop M, Du J, Loveday BP, Rodgers M (2012) Systematic review of intraoperative cholangiography in cholecystectomy. Br J Surg 99:160-167 


\section{Chapter}

Near-infrared fluorescence laparoscopy of the cystic duct and artery in pigs: performance of a preclinical dye

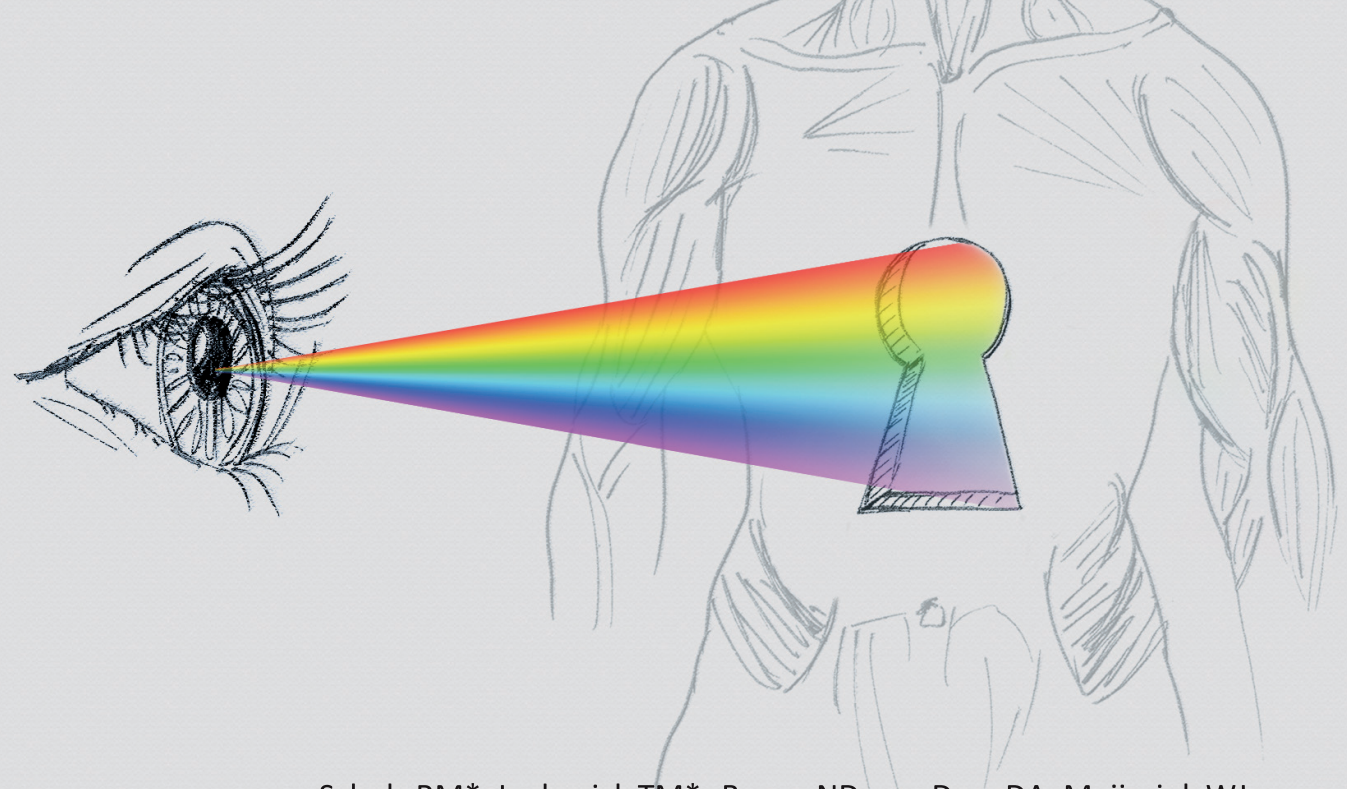

Schols RM*, Lodewick TM*, Bouvy ND, van Dam DA, Meijerink WJ, van dam $\mathrm{GM}$, Dejong $\mathrm{CH}$, Stassen $\mathrm{LP}$

* Both authors contributed equally to the manuscript and share first authorship Journal of Laparoendoscopic \& Advanced Surgical Techniques. Part A. 2014;24:318-322 


\begin{abstract}

\section{Background}

Near-infrared fluorescence laparoscopy after intravenous indocyanine green (ICG) administration has been proposed as a promising surgical imaging technique for realtime visualization of the extra-hepatic bile ducts and arteries in clinical laparoscopic cholecystectomies. However, optimization of this new technique with respect to the imaging system combined with the fluorophore is desirable. The performance of a preclinical near-infrared dye CW800-CA was compared with ICG for near-infrared fluorescence laparoscopy of the cystic duct and artery in pigs.
\end{abstract}

\title{
Methods
}

Laparoscopic cholecystectomy was performed in six pigs (35 kg) using a commercially available laparoscopic fluorescence imaging system. The fluorophores CW800-CA and ICG (both $800 \mathrm{~nm}$ fluorescent dyes) were administered by intravenous injection in four and two pigs respectively. CW800-CA was administered in three different doses (consecutively $0.25,1$ and $3 \mathrm{mg}$ ), ICG was intravenously injected (2.5 mg) for comparison. Intraoperative recognition of the biliary structures was registered at set time points. Target-to-background-ratio was determined to quantify the fluorescence signal of the designated tissues.

\section{Results}

A clinically proven dose of $2.5 \mathrm{mg}$ ICG resulted in a successful fluorescence delineation of both the cystic duct and artery. In the CW800-CA injected pigs a clear visualization of the cystic duct and artery was obtained after administration of $3 \mathrm{mg}$ CW800-CA. Time from injection until fluorescence identification of the cystic duct was reduced when CW800-CA was used compared with ICG (respectively 11.5 versus 21.5 minutes). CW800-CA provided clearer illumination of the cystic artery, in terms of target-tobackground-ratio.

\section{Conclusion}

Next to ICG, CW800-CA can be applied for fluorescence identification of the cystic artery and duct using a commercially available laparoscopic fluorescence imaging system. Fluorescence cholangiography of the cystic duct can be obtained earlier after intravenous injection of CW800-CA, compared to ICG. These findings increase the possibilities of use and of optimization of this imaging technique. 


\section{Introduction}

In patients with symptomatic cholecystolithiasis and/or cholecystitis, laparoscopic cholecystectomy is currently the standard of care in most Western countries. Although an incidence of only 0.7 percent is reported for bile duct injury during laparoscopic cholecystectomy, it constitutes a severe complication which may result in increased long-term morbidity and as a consequence, increased costs. Furthermore it may negatively affect the quality of life of patients ${ }^{1-3}$.

Near-infrared fluorescence imaging after intravenous indocyanine green (ICG) administration is an innovative and promising laparoscopic imaging method for intraoperative visualization of crucial anatomical structures ${ }^{4}$. Several clinical pilot studies have demonstrated its usefulness and feasibility for real-time intraoperative identification of extra-hepatic bile ducts and arteries to assist in safe and time-efficient gallbladder removal. However, this new technique needs optimization with respect to imaging systems and injected fluorophores.

CW800-CA is a relatively new fluorophore, which like ICG also has $800 \mathrm{~nm}$ fluorescent capabilities. It has not yet been FDA cleared for clinical use, but has equal low risk of toxicity as ICG and incorporates favourable characteristics for fluorescence imaging of vital anatomy ${ }^{5,6}$. The most advantageous characteristic of CW800-CA is its increased hydrophilicity, resulting in improved secretion into bile and earlier fluorescence illumination of the bile ducts ${ }^{5,6}$. This study was conducted to assess the performance of CW800-CA versus the clinically already available ICG for near-infrared fluorescence laparoscopy of the cystic duct and cystic artery in pigs using a commercially available laparoscopic fluorescence imaging system.

\section{Materials and methods}

This study was conducted at the central animal facilities of Maastricht University (Maastricht, The Netherlands). Animals were used in compliance with the regulations of the Dutch legislation for animal research, and the study protocol was approved by the Animal Ethics Committee of Maastricht University (DEC-UM, project number 2012-098). A pig model was chosen because of its similarity with human anatomy. Six female Dutch landrace pigs, weighing $35 \mathrm{~kg}$, were used for the current study.

\section{Laparoscopic fluorescence imaging system}

A commercially available, laparoscopic fluorescence imaging system (Karl Storz GmbH \& CO. KG, Tuttlingen, Germany) was used. The system includes a plasma light guide and 
30-degree 10-mm laparoscope applicable for both white light and near-infrared fluorescence imaging. A foot pedal allows the surgeon to easily switch from conventional imaging to fluorescence imaging, and back. Procedures were digitally recorded.

\section{Preparation of near-infrared fluorophore}

In these animal experiments, the system, which is primarily developed for indocyanine green (ICG) imaging, was now also tested for its feasibility for real-time intraoperative fluorescence visualization of biliary anatomy (cystic duct and cystic artery) after intravenous administration of the pre-clinical fluorescent dye CW800-CA (a carboxylate of near-infrared fluorophore IRDye ${ }^{\circledR} 800$ CW, LI-COR, Lincoln, Nebraska). CW800-CA was diluted in a sterile PBS solution.

\section{Surgical technique}

Premedication comprised of intramuscular injection of azaperone $3 \mathrm{mg} / \mathrm{kg}$, ketamine $10 \mathrm{mg} / \mathrm{kg}$ and atropine $0.05 \mathrm{mg} / \mathrm{kg}$. Anesthesia was induced with intravenous administration of thiopental $10-15 \mathrm{mg} / \mathrm{kg}$, intubated and maintained under anesthesia with isoflurane (depending on effect) and oxygen $(20-40 \mathrm{ml} / \mathrm{kg} / \mathrm{min})$. Thereafter a laparoscopy was performed.

In each pig a laparoscopic cholecystectomy was performed, according to the Dutch Guidelines and best practice for laparoscopic cholecystectomy ${ }^{7}$, which is based on the Critical View of Safety technique.

One experiment per animal was conducted. In the first two pigs $1 \mathrm{ml}$ ICG $(2.5 \mathrm{mg} / \mathrm{ml}$ Infracyanine ${ }^{\circledR}$; SERB, France) was injected intravenously. This dose has proven sufficient for clinical use ${ }^{8}$. For the third experiment (pig no. 3) $5 \mathrm{mg}$ of CW800-CA was diluted in $20 \mathrm{ml}$ of PBS solution $(0.25 \mathrm{mg} / \mathrm{ml})$. One $\mathrm{ml}$ of this solution $(0.25 \mathrm{mg})$ was intravenously administered. For the subsequent three experiments, $5 \mathrm{mg}$ of CW800-CA was diluted in $5 \mathrm{ml}$ of PBS solution $(1 \mathrm{mg} / \mathrm{ml})$. Next, $1 \mathrm{ml}(1.0 \mathrm{mg})$ of the solution was injected in pig no. 4. Three $\mathrm{ml}(3.0 \mathrm{mg})$ of the solution was administered in pig no. 5 and 6 .

Fluorescence imaging was obtained directly after dye injection and subsequently every 5-10 minutes. Intraoperatively the researcher systematically registered on a form whether the localization of cystic duct or cystic artery could be identified at set time points, comparing the WL camera mode to ICG mode. For agreement on the identification of the aforementioned structures the attending surgeon was consulted. A structure was scored as 'identified' if its localization was confirmed with great certainty by the experienced surgeon. An overview of the six experiments is presented in Table 5.1 . 
Table 5.1 Overview of experimental results

\begin{tabular}{ccccccc}
\hline Experiment & $\begin{array}{c}\text { Injected } \\
\text { dye }\end{array}$ & $\begin{array}{c}\text { Concentration of } \\
\text { administered dye } \\
(\mathrm{mg} / \mathrm{ml})\end{array}$ & $\begin{array}{c}\text { Amount of } \\
\text { dye injected } \\
(\mathrm{ml})\end{array}$ & $\begin{array}{c}\text { Visualization Visualization } \\
\text { of cystic } \\
\text { artery? }\end{array}$ & $\begin{array}{c}\text { Time to } \\
\text { of cystic } \\
\text { duct? }\end{array}$ & $\begin{array}{c}\text { identification of } \\
\text { cystic duct (min) }\end{array}$ \\
\hline 1 & ICG & 2.5 & 1.0 & $\mathrm{Y}$ & $\mathrm{Y}$ & 20 \\
2 & ICG & 2.5 & 1.0 & $\mathrm{Y}$ & $\mathrm{Y}$ & 22 \\
3 & CW800-CA & 0.25 & 1.0 & $\mathrm{~N}$ & $\mathrm{~N}$ & $/$ \\
4 & CW800-CA & 1.0 & 1.0 & $\mathrm{~N}$ & $\mathrm{~N}$ & $/$ \\
5 & CW800-CA & 1.0 & 3.0 & $\mathrm{Y}$ & $\mathrm{Y}$ & 11 \\
6 & CW800-CA & 1.0 & 3.0 & $\mathrm{Y}$ & $\mathrm{Y}$ & 12 \\
\hline
\end{tabular}

ICG = indocyanine green

\section{Quantitative fluorescence image analysis}

For objective assessment of the degree of fluorescence illumination in the extra-hepatic bile ducts and artery, OsiriX 5.5.1 Imaging Software was used. The fluorescence images were analyzed by determining target-to-background ratio (TBR). TBR was defined as the mean fluorescence intensity (FI; in arbitrary units, A.U.) of three point regions of interest (ROIs) in the target (i.e., cystic duct, or cystic artery) minus the mean FI of three background (BG) ROIs in the liver hilum, divided by the mean FI of the three BG ROIs in the liver hilum; in formula: $\mathrm{TBR}=(\mathrm{FI}$ of target $-\mathrm{FI}$ of BG)/FI of BG.

\section{Results}

In the first two experiments ICG fluorescence laparoscopy for identification of the cystic artery (Figure 5.1B) and cystic duct (Figure 5.2B) was successfully conducted. CW800CA dosage in experiments $3(0.25 \mathrm{mg})$ and $4(1.0 \mathrm{mg})$ was insufficient to obtain fluorescence delineation of these structures. Using a dose of $3 \mathrm{mg} \mathrm{CW800-CA}$ in the last two experiments led to clear visualization of the cystic artery (Figure 5.1D) and cystic duct (Figure 5.2D) in both pigs. Observations of the six experiments are summarized in Table 5.1.

\section{Target-to-background ratio}

The target-to-background-ratios (TBR) of the cystic artery versus gallbladder and cystic artery versus liver parenchyma in the arterial phase after ICG injection were -0.6 and 0.5 respectively (pig 2 , Figure $5.1 \mathrm{~B}, \pm 30$ seconds after dye administration). These data confirm the inability of ICG based imaging to identify the cystic artery when positioned directly on the liver parenchyma. After injection of CW800-CA, the TBRs of the cystic artery versus gallbladder and cystic artery versus liver parenchyma were 1.1 and 1.7 
(Figure 5.1D, \pm 30 seconds after dye administration). This indicates a clear recognition of the cystic artery when positioned above liver parenchyma and the gallbladder if CW800-CA is used. The TBR of the cystic duct versus liver parenchyma was respectively 3.2 for ICG (Figure 5.2B) and 2.3 for CW800-CA (Figure 5.2D).

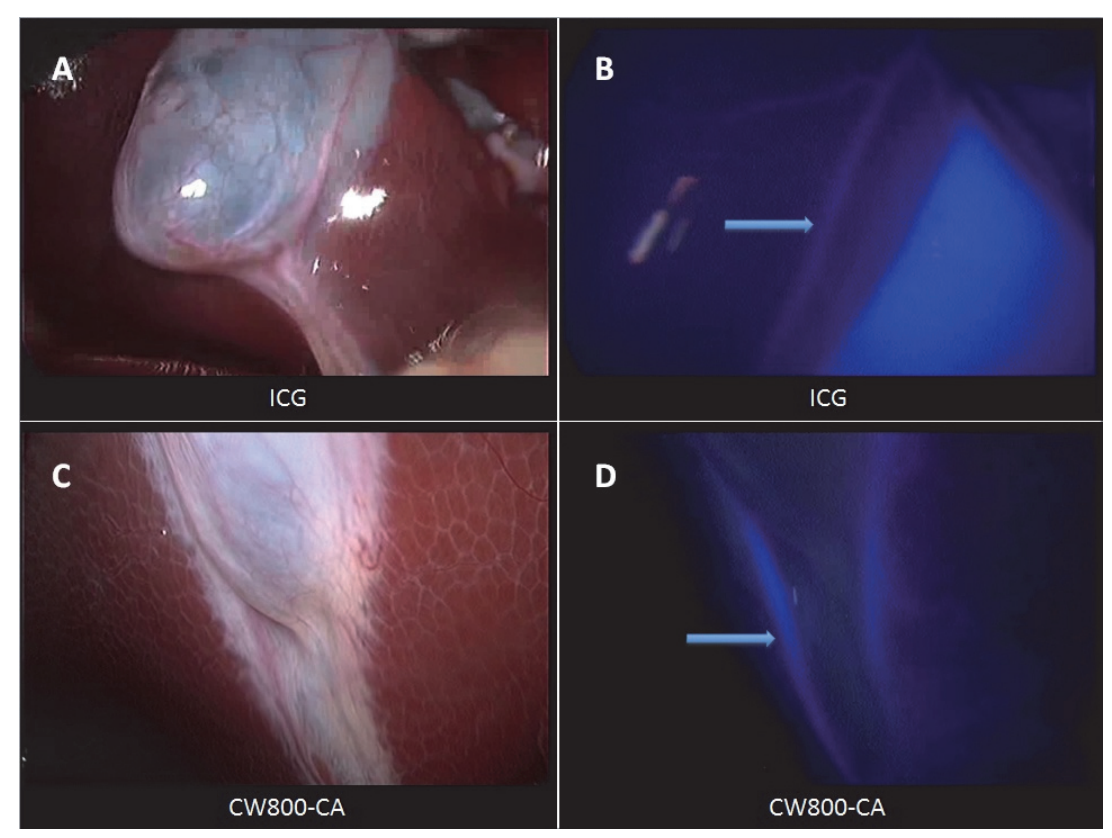

Figure 5.1 Cystic artery imaging.

Figures $\mathbf{A}$ and $\mathbf{B}$ are snap-shots taken during ICG fluorescence laparoscopy experiments in pig 1: A shows the anatomical view of the gallbladder and liver hilum. The associated ICG fluorescence image of the cystic artery is shown in B (cystic artery is indicated by the arrow, TBR $=0.5$ ). Fluorescence angiography using CW800-CA in pig 5 is presented in figures C and D: respectively the anatomical view and the associated fluorescence delineation of the cystic artery are presented (cystic artery is indicated by the arrow, TBR $=1.7$ ).

\section{Complications}

No per- or postoperative complications regarding the extra-hepatic bile ducts occurred. None of the pigs developed any adverse reactions to the injected ICG or CW800-CA. No interference with intraoperative monitoring of Saturation of peripheral Oxygen $\left(\mathrm{SpO}_{2}\right)$ was observed. 

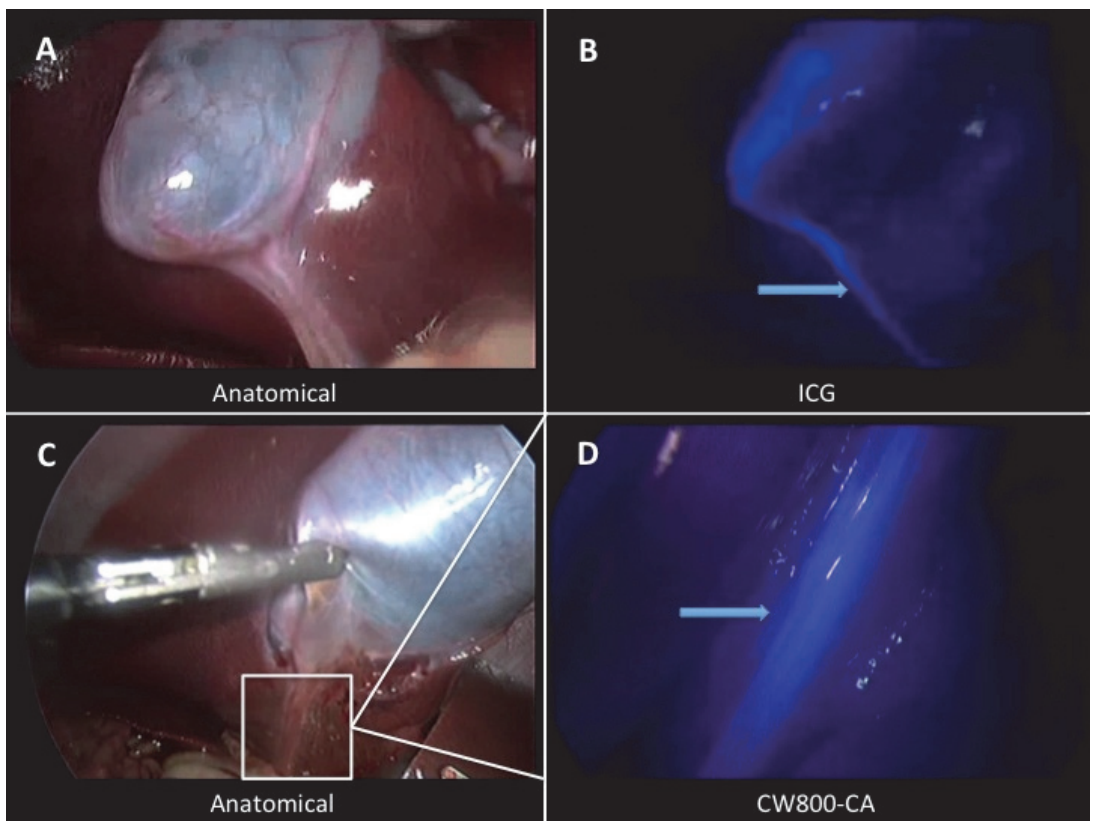

Figure 5.2 Cystic duct delineation.

Figures $\mathbf{A}$ and $\mathbf{B}$ are snap-shots taken during ICG fluorescence laparoscopy experiments in pig 1: A shows the anatomical view of the gallbladder and liver hilum; the associated fluorescence cholangiogram of the gallbladder and cystic duct is shown in B (cystic duct is indicated by the arrow, TBR = 3.2). Result of CW800-CA fluorescence laparoscopy in pig 5 is displayed in figures $\mathbf{C}$ and $\mathbf{D}$ : respectively the anatomical view and the associated fluorescence delineation of the cystic duct are presented (cystic duct is indicated by the arrow, TBR $=2.3$ ).

\section{Discussion}

In the present study the feasibility of fluorescence imaging of the cystic duct and artery using CW800-CA and a commercially available laparoscopic fluorescence imaging system was investigated. To assess the performance of this preclinical contrast agent, ICG was used for comparison. CW800-CA provided comparable visualization of the course of the cystic duct and better identification of the cystic artery.

With respect to the investigated fluorophores in this study it is important to address the following characteristics. ICG is a di-sulphonated heptamethine indocyanine that is FDA-approved for clinical use. After intravenous injection, it is rapidly cleared from the blood by the liver and transported into the bile. Consequently intravenously injected ICG is applicable for cholangiography. CW800-CA is a carboxylate of IRDye ${ }^{\circledR} 800 \mathrm{CW}$, a tetra-sulphonated heptamethine indocyanine. Emission of this dye is quite similar to 
ICG (also at $800 \mathrm{~nm}$ ). However, after intravenous injection it is not only rapidly cleared by the liver and excreted into bile, but also by the kidneys and excreted into the urine. As a result this dye is eligible for imaging of the biliary anatomy and of the ureters ${ }^{9}$.

Previously Tanaka et al. tested ICG and CW800-CA for bile duct imaging in rats and pigs ${ }^{5}$ during open surgery. CW800-CA proved to be more selective, as ICG suffered from lack of efficient secretion into bile from the liver. In addition, CW800-CA was excreted into bile in a predominantly unmetabolized form, which increases the rapidity and signal intensity by which images can be obtained after administration.

In the present study, CW800-CA dosage in the first experiment was based on the report by Tanaka et al. ${ }^{5}$. A dose of $7.5 \mu \mathrm{g} / \mathrm{kg}$ bodyweight appeared not sufficient for laparoscopic fluorescence detection of the cystic duct and artery. With a significantly higher dose $(85 \mu \mathrm{g} / \mathrm{kg})$ of the injected dye, clear visualization of the course of the cystic duct and artery was obtained in this study.

Furthermore, from this study it was noticed that time from injection until fluorescence identification of the cystic duct was reduced when CW800-CA was used compared to ICG (respectively 11.5 versus 21.5 minutes). Based on target-to-back-ground-ratios this study demonstrates the ability of identifying the cystic duct after injection of both fluorophores. Regarding arterial fluorescence imaging, background signal (i.e. dye uptake by the liver parenchyma) was more profound when ICG was used, compared to CW800-CA. Therefore recognition of the cystic artery might be easier with CW800-CA. Besides laparoscopic cholecystectomy, fluorescence imaging of crucial biliary structures might be beneficial in other (laparoscopic) hepato-pancreato-biliary (HPB) surgical procedures as well. Possible applications of this technique during HPB surgery include tumor detection in liver and pancreas resections, and real-time imaging of intra- and extra-hepatic bile ducts and (branches of) hepatic, cystic, pancreatic, gastroduodenal and pancreatoduodenal arteries ${ }^{10-12}$.

Moreover, fluorescence imaging could be performed to detect bile leakage during open and laparoscopic partial liver resections. This complication after hepatectomy occurs in approximately $8 \%$ of all patients undergoing partial liver resection and is associated with greater postoperative mortality and health care costs ${ }^{13}$. Prevention of bile leakage after hepatectomy therefore deserves attention. A randomized clinical trial evaluated the use of ICG fluorescence cholangiography to prevent postoperative bile leakage after hepatic resections. The ability to detect leaking bile duct stumps at the cut surface of the remnant liver, which were missed by conventional bile leak tests, was demonstrated $^{14}$. Given its pharmacokinetics, CW800-CA might prove to be even more suitable for the detection of bile leakage.

Although this report only describes a small experimental animal study and a large difference in dosage of CW800-CA, the concept of fluorescence visualization of the 
cystic duct and artery using CW800-CA has successfully been demonstrated using a commercially available laparoscopic fluorescence imaging system. A clinical pilot study investigating the feasibility of near-infrared fluorescence imaging using CW800-CA in laparoscopic cholecystectomy is the next step. Such a pilot study should focus on dosefinding of the administered dye, as even a lower dose than $3 \mathrm{mg} / \mathrm{ml}$ (used in experiments 5 and 6 ) might be sufficient.

\section{Conclusion}

Next to ICG, CW800-CA can be applied for laparoscopic fluorescence identification of the cystic artery and duct using a commercially available imaging system. Laparoscopic fluorescence cholangiography of the cystic duct can be obtained earlier after intravenous injection of CW800-CA, compared to ICG. With the availability of two instead of one fluorophore, the possibilities increase to further optimize the imaging capabilities of the presently available fluorescence systems. A dose-finding and clinical feasibility study for CW800-CA is the next step. 


\section{References}

1. Landman MP, Feurer ID, Moore DE, Zaydfudim V, Pinson CW (2013) The long-term effect of bile duct injuries on health-related quality of life: a meta-analysis. HPB (Oxford) 15:252-259

2. Roy PG, Soonawalla ZF, Grant HW (2009) Medicolegal costs of bile duct injuries incurred during laparoscopic cholecystectomy. HPB (Oxford) 11:130-134

3. Walsh RM, Henderson JM, Vogt DP, Brown N (2007) Long-term outcome of biliary reconstruction for bile duct injuries from laparoscopic cholecystectomies. Surgery 142:450-456; discussion 456-457

4. Schols RM, Bouvy ND, van Dam RM, Stassen LP (2013) Advanced intraoperative imaging methods for laparoscopic anatomy navigation: an overview. Surg Endosc 27:1851-1859

5. Tanaka E, Choi HS, Humblet V, Ohnishi S, Laurence RG, Frangioni JV (2008) Real-time intraoperative assessment of the extrahepatic bile ducts in rats and pigs using invisible near-infrared fluorescent light. Surgery 144:39-48

6. Tanaka E, Ohnishi S, Laurence RG, Choi HS, Humblet V, Frangioni JV (2007) Real-time intraoperative ureteral guidance using invisible near-infrared fluorescence. J Urol 178:2197-2202

7. Lange JF, Stassen LPS (2006) Best practice in verband met de techniek van laparoscopische cholecystectomie (Critical View of Safety [CVS] in 7 stappen). Werkgroep Endoscopische Chirurgie van de Nederlandse vereniging voor Heelkunde, http://wwwheelkundenl/uploads/_6/re/ _6reZZkgrYUAuCG6uvcN-A/richtlijn_galsteenpdf

8. Schols RM, Bouvy ND, van Dam RM, Masclee AA, Dejong CH, Stassen LP (2013) Combined vascular and biliary fluorescence imaging in laparoscopic cholecystectomy. Surg Endosc 27:4511-7

9. Frangioni JV, Tanaka E, Borud L Intraoperative imaging methods. Patent Cooperation Treaty WO / 2008 / 076467, http://patentscopewipoint/search/en/WO2008076467

10. Verbeek FP, van der Vorst JR, Schaafsma BE, Hutteman M, Bonsing BA, van Leeuwen FW, Frangioni JV, van de Velde CJ, Swijnenburg RJ, Vahrmeijer AL (2012) Image-guided hepatopancreatobiliary surgery using near-infrared fluorescent light. J Hepatobiliary Pancreat Sci 19:626-637

11. Aoki T, Murakami M, Yasuda D, Shimizu Y, Kusano T, Matsuda K, Niiya T, Kato H, Murai N, Otsuka K, Kusano M, Kato T (2010) Intraoperative fluorescent imaging using indocyanine green for liver mapping and cholangiography. J Hepatobiliary Pancreat Sci 17:590-594

12. Mitsuhashi N, Kimura F, Shimizu H, Imamaki M, Yoshidome H, Ohtsuka M, Kato A, Yoshitomi H, Nozawa S, Furukawa K, Takeuchi D, Takayashiki T, Suda K, Igarashi T, Miyazaki M (2008) Usefulness of intraoperative fluorescence imaging to evaluate local anatomy in hepatobiliary surgery. J Hepatobiliary Pancreat Surg 15:508-514

13. Guillaud A, Pery C, Campillo B, Lourdais A, Sulpice L, Boudjema K (2013) Incidence and predictive factors of clinically relevant bile leakage in the modern era of liver resections. HPB (Oxford) 15:224-229

14. Kaibori M, Ishizaki M, Matsui K, Kwon AH (2011) Intraoperative indocyanine green fluorescent imaging for prevention of bile leakage after hepatic resection. Surgery 150:91-98 
Near-infrared fluorescence laparoscopy of the cystic duct and artery in pigs 


\section{Chapter}

Application of a new dye for near-infrared

fluorescence laparoscopy of the ureters:

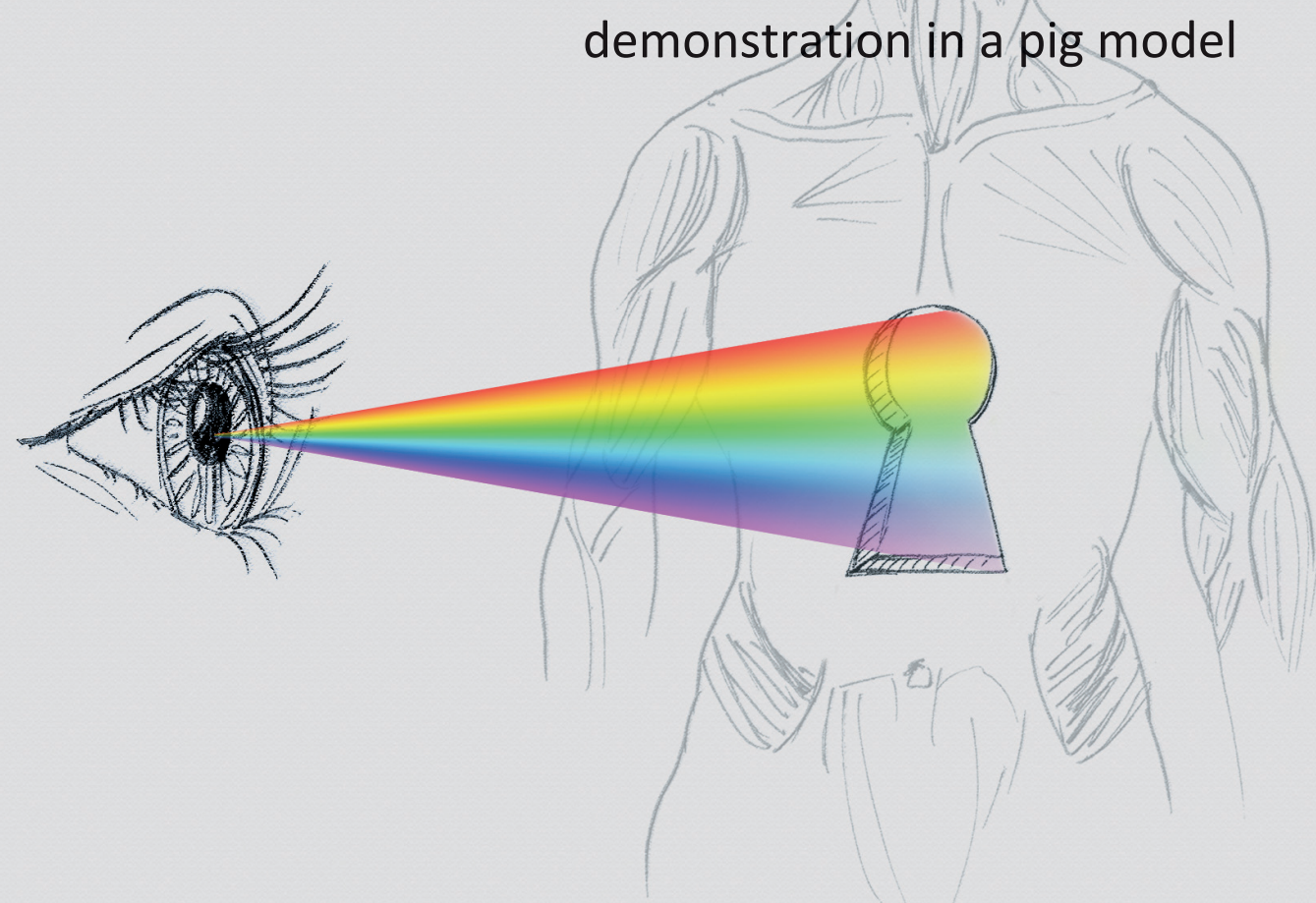

Schols RM, Lodewick TM, Bouvy ND, van Dam GM, Dejong CH, Stassen LP Diseases of the Colon \& Rectum 2014;57:407-411 


\begin{abstract}

\section{Background}

Ureteral injury during laparoscopic colorectal surgery is a rare but serious complication with reported incidence rates of $0.66 \%$. The early detection and prevention of ureteral injury is clinically relevant and important. The successful use of pre-clinical nearinfrared (NIR) fluorophore CW800-CA for real-time intraoperative identification of the anatomical course of the ureters using a laparoscopic fluorescence imaging system is reported.
\end{abstract}

\title{
Methods
}

The usefulness of this new imaging technique was explored in two $35 \mathrm{~kg}$ pigs. Intravenous CW800-CA was administered 10 minutes before conducting fluorescence imaging, using a commercially available laparoscopic fluorescence imaging system.

\section{Results}

A dose of $1 \mathrm{mg} / \mathrm{ml} \mathrm{CW800-CA} \mathrm{(bolus} \mathrm{injection} \mathrm{of} 3 \mathrm{ml}$ ) provided clear delineation of the course of both ureters by using fluorescence mode of the laparoscope. There were no adverse reactions to the injected dye.

\section{Conclusion}

Near-infrared fluorescence laparoscopy of the ureters, following intravenous CW800CA administration, is easily applicable and provides real-time identification of the course of the ureters. 


\section{Introduction}

Great public attention is present for the safety of surgery, especially in laparoscopic surgery. The Dutch Health Care Inspectorate has drawn attention to this in its report of November 2007, "Risks of minimally invasive surgery underestimated" ${ }^{1}$. Colorectal surgery is the latest form of high-volume-surgery for which laparoscopic techniques have now widely been introduced and is considered a technically advanced procedure requiring a high level of endoscopic skills and anatomical orientation in a twodimensional plane.

Ureteral injury during this type of surgery is rare with a reported incidence of $0.66 \%^{2}$, however, when it occurs, it can be a serious clinical problem possibly resulting in intraabdominal sepsis, renal failure and loss of renal function ${ }^{3}$. Early recognition of such injuries can be challenging because they are detected only after other, more serious injuries are addressed, which may lead to a worse outcome. Furthermore, the incidence of iatrogenic ureteral injuries was found to be significantly greater in patients undergoing laparoscopic surgery compared to open abdominal operations ${ }^{2,4}$. Hence, the prevention and early detection of ureteral injury during laparoscopic colorectal surgery is desirable.

An advanced intraoperative imaging method, called near-infrared (NIR) fluorescence imaging, can be applied for real-time fluorescence ureteral guidance after intravenous administration of a fluorophore ${ }^{5}$. At this moment the only clinically available dye for this purpose is methylene blue. A more recently described NIR fluorophore, CW800-CA, is another fluorophore that is excreted in urine. It has fluorescent characteristics at similar wavelengths as the clinical fluorophore indocyanine green (ICG) and this can be detected by commercially available fluorescence imaging apparatus. Therefore, this new dye may have great potential for fluorescence imaging of crucial anatomical structures. CW800-CA is not yet FDA cleared for clinical use, but like ICG it belongs to a class of heptamethine indocyanines with low inherent toxicity ${ }^{6}$.

This technical report demonstrates the concept of near-infrared fluorescence identification of the ureters using a commercially available laparoscopic fluorescence imaging system after intravenous injection of CW800-CA.

\section{Methods}

This study was conducted at the central animal facilities of Maastricht University (Maastricht, The Netherlands). Animals were used in compliance with the regulations of the Dutch legislation for animal research, and a study protocol was approved by the 
Animal Ethics Committee of Maastricht University (DEC-UM, project number 2012-098). A pig model was chosen because of its similarity with human anatomy. Two female Dutch landrace pigs, weighing $35 \mathrm{~kg}$, were used for the current study.

\section{Laparoscopic fluorescence imaging system}

A commercially available, laparoscopic fluorescence imaging system (Karl Storz GmbH \& CO. KG, Tuttlingen, Germany) was used. The system included a plasma light guide and 30-degree 10-mm laparoscope applicable for both white light and near-infrared fluorescence imaging. A foot pedal allows the surgeon to easily switch from conventional imaging to fluorescence imaging, and back. Procedures were digitally recorded.

\section{Preparation of near-infrared fluorophore}

In these animal experiments, the system, which is primarily developed for indocyanine green (ICG) imaging, was tested for its feasibility for real-time intraoperative fluorescence delineation of the course of the ureters after intravenous administration of pre-clinical fluorescent dye CW800-CA (the carboxylic acid form of the near-infrared fluorophore IRDye ${ }^{\mathrm{TM}} 800 \mathrm{CW}$, LI-COR, Lincoln, Nebraska). CW800-CA was diluted in a sterile PBS solution.

\section{Surgical technique}

Premedication comprised of intramuscular injection of azaperone $3 \mathrm{mg} / \mathrm{kg}$, ketamine $10 \mathrm{mg} / \mathrm{kg}$ and atropine $0.05 \mathrm{mg} / \mathrm{kg}$. Anesthesia was induced with intravenous administration of thiopental $10-15 \mathrm{mg} / \mathrm{kg}$, intubated and maintained under anesthesia with isoflurane (depending on effect) and oxygen $(20-40 \mathrm{ml} / \mathrm{kg} / \mathrm{min})$. Thereafter laparoscopy was performed. For the first experiment, $5 \mathrm{mg}$ of CW800-CA was diluted in $20 \mathrm{ml}$ of PBS solution $(0.25 \mathrm{mg} / \mathrm{ml})$. Next, $1 \mathrm{ml}$ of solution was injected intravenously ${ }^{7}$. During the second experiment $5 \mathrm{mg}$ of CW800-CA was diluted in $5 \mathrm{ml}$ of PBS solution $(1 \mathrm{mg} / \mathrm{ml})$. Three $\mathrm{ml}$ of solution ( $3 \mathrm{mg}$ ) was then administered intravenously. Summary of experiments is shown in Table 6.1.

In both experiments, visualization of the course of the ureters was assessed by conventional laparoscopy and fluorescence laparoscopy. Fluorescence imaging was performed initially ten minutes after dye injection and repeated every 15 minutes. Time until clear visualization of the ureters was observed, up to 120 minutes after administration. 
Table 6.1 Intraoperative observations

\begin{tabular}{lcccc}
\hline Experiment & $\begin{array}{c}\text { Concentration of administered } \\
\text { CW800-CA }(\mathrm{mg} / \mathrm{ml})\end{array}$ & $\begin{array}{c}\text { Amount of dye } \\
\text { injected }(\mathrm{ml})\end{array}$ & $\begin{array}{c}\text { No. of ureters } \\
\text { found }\end{array}$ & $\begin{array}{c}\text { Time to ureter } \\
\text { visualization }(\mathrm{min})\end{array}$ \\
\hline 1 & 0.25 & 1 & 0 & - \\
2 & 1.0 & 3 & 2 & 10 \\
\hline
\end{tabular}

\section{Quantitative fluorescence image analysis}

For objective assessment of the degree of fluorescence illumination in the ureters, OsiriX 5.5.1 Imaging Software was used. The fluorescence images were analyzed by determining target-to-background ratio (TBR), as previously described ${ }^{8}$. TBR was defined as the mean fluorescence intensity (FI; in arbitrary units, A.U.) of three point regions of interest (ROIs) in the target (i.e., ureter) minus the mean $\mathrm{FI}$ of three background (BG) ROIs, divided by the mean FI of the three BG ROIs; in formula: TBR = (FI of target - FI of BG)/FI of BG.

\section{Results}

In the first experiment no fluorescence identification of the ureters could be obtained. Up to 120 minutes after administration visualization remained unsuccessful.

During the second experiment (dose of $3.0 \mathrm{mg}$ CW800-CA) a clear delineation of the course of both ureters was visualized with the fluorescence mode of the laparoscope, even in those areas where conventional imaging did not reveal the ureters yet. The snap-shots in Figure 6.1 were obtained ten minutes after dye administration and show the fluorescence images of the left and right ureter, with corresponding conventional images. A short narrated video demonstrating the procedure is included as a supplement with the online version of this technical note.

\section{Target-to-background-ratio}

The target-to-background-ratio (TBR) of the left and right ureter amounted respectively 1.6 and 3.5 , ten minutes after dye injection.

\section{Complications}

No intra- or postoperative complications regarding the ureters occurred. None of the pigs developed any adverse reactions to the injected CW800-CA. No interference with intraoperative monitoring of Saturation of peripheral Oxygen $\left(\mathrm{SpO}_{2}\right)$ was observed. 


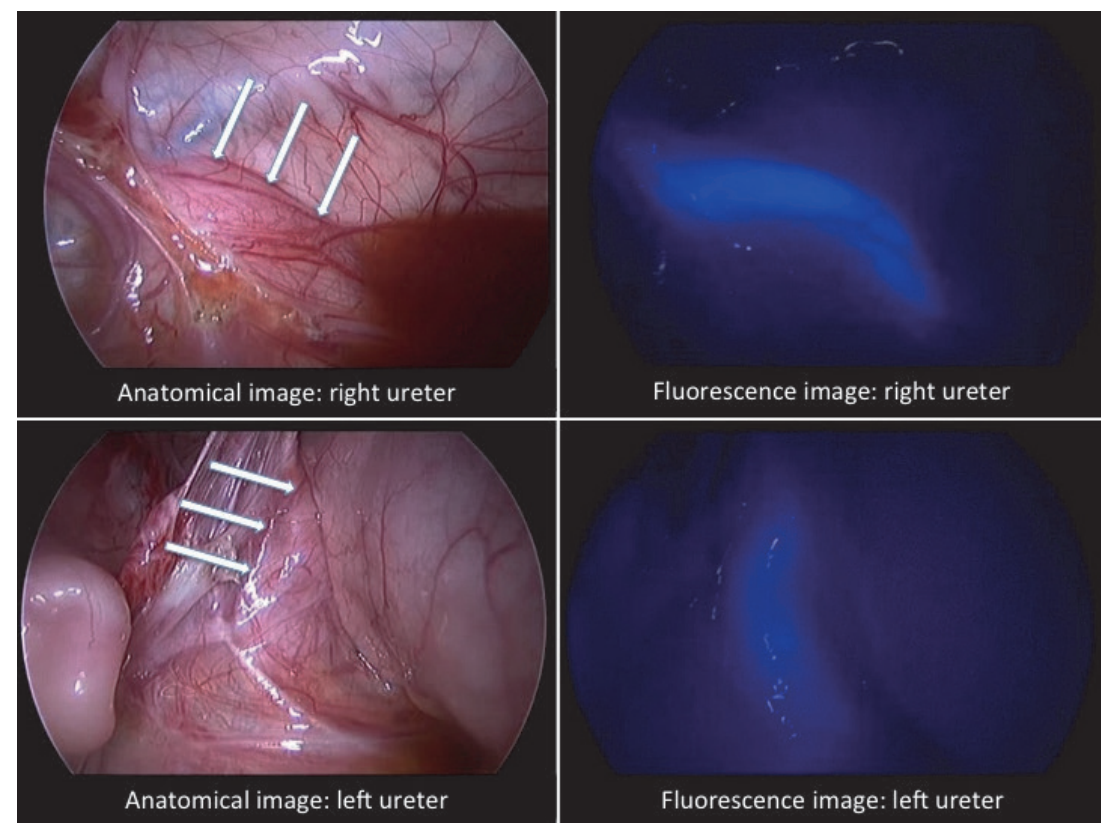

Figure 6.1 Snap-shots obtained ten minutes after intravenous CW800-CA administration: presentation of the conventional anatomical images (ureters indicated by arrows) and associated fluorescence laparoscopy images of the left $(T B R=1.6)$ and right ureter $(T B R=3.5)$.

\section{Discussion}

This technical report describes the possibility of obtaining real-time intraoperative identification of the ureters using a novel technique called near-infrared fluorescence laparoscopy using CW800-CA.

Prophylactic use of ureteral stents has been proposed for intraoperative visualization of the ureters ${ }^{9}$. A drawback is that insertion of the stents itself may cause damage to the ureters. Moreover, ureteral stenting is especially useful in open surgery because it leads to identification by palpation. This feature is almost absent in laparoscopy, except for hand-assisted laparoscopy techniques, where palpation would be possible.

As stated, non-invasive advanced laparoscopic imaging methods, such as near-infrared fluorescence laparoscopy after intravenous dye administration ${ }^{5}$ are being developed for the purpose of enhanced anatomical imaging. Low-dose methylene blue, injected intravenously, was successfully used for ureteral identification in laparoscopic pig experiments $^{10}$ and in open human abdominal surgery ${ }^{11}$. The currently available CE- 
marked laparoscopic fluorescence imaging systems cannot yet visualize methylene blue though. Furthermore, methylene blue sometimes causes severe adverse reactions, such as methemoglobinaemia or anaphylaxis. Intravenous methylene blue interferes with the ability of the oximeter to measure the saturation of peripheral oxygen $\left(\mathrm{SpO}_{2}\right)$, resulting in a transient, marked decrease in $\mathrm{SpO}_{2}$, potentially lasting up to several minutes $^{12}$.

The pre-clinical near-infrared dye CW800-CA has fluorescent characteristics at similar wavelengths as indocyanine green (ICG), for which laparoscopic imaging systems are already available ${ }^{8,13}$. Intravenously administered ICG is not useful for ureteral fluorescence imaging, because it is rapidly cleared by the liver and has no detectable urinary excretion $^{12}$.

In contrast, CW800-CA can provide bright visualization of ureters by renal clearance ${ }^{7,12}$. Visualization of the ureters can be rapidly obtained following intravenous injection as shown in this small feasibility study in pigs. In these experiments no influence of the intravenously injected $\mathrm{CW} 800-\mathrm{CA}$ on $\mathrm{SpO}_{2}$ monitoring was observed.

No adverse effects to the administered dye were observed in the present study. Moreover, a single-dose intravenous toxicity study of CW800-CA in rats, concluded that a dose of up to $20 \mathrm{mg} / \mathrm{kg}$ did not result in adverse reactions following intravenous administration of the dye ${ }^{14}$. This constitutes a much higher dose than was used in the present study. In the same toxicity study, clearance half-life of CW800-CA following intravenous injection was determined to be 35.7 minutes ${ }^{14}$. This seems sufficient for the described application, as the ureters are normally identified early during the surgical procedure.

CW800-CA dosage in the first experiment of this study was based on the report by Tanaka et al. ${ }^{7}$. A dose of $7.5 \mu \mathrm{g} / \mathrm{kg}$ bodyweight appeared not to be sufficient for laparoscopic fluorescence detection of the ureters in pigs. With a significantly higher dose $(85 \mu \mathrm{g} / \mathrm{kg}$ ) of injected dye, clear visualization of the course of both ureters was obtained. Preinjection of a diuretic (furosemide) has been investigated for its potential to increase near-infrared fluorescence signal of the intravenously administered dye (in this case methylene blue). However, neither a qualitative nor quantitative improvement was found ${ }^{10}$. Therefore no furosemide was given before CW800-CA injection in the present study.

With the present commercially available system, the surgeon is able to switch in a split second from the conventional to the fluorescence camera mode and back, using a foot pedal. Unfortunately, direct fluorescence image-overlay on the conventional anatomical image is not yet possible with the current imaging systems.

Although this study only reports on a small sample size and a large difference in dosage of CW800-CA, the concept of fluorescence visualization of the ureters using CW800-CA 
has successfully been demonstrated using a commercially available laparoscopic fluorescence imaging system.

This technique may be most effective when performed routinely during all laparoscopic colectomies. Increased costs are involved in terms of the light source, camera and fluorescent dye. It is, however, anticipated that this technique can be helpful to improve the outcome of laparoscopic colorectal surgery through early recognition of ureters, lowering risk of ureteral injury and reducing time of surgical dissection.

As the pigs used in this study were rather thin, human studies will need to determine if the dye will be visible in obese patients and if CW800-CA dose adjustment is needed to accomplish clear detection of the ureters. A clinical pilot study investigating the feasibility of near-infrared fluorescence imaging using CW800-CA for intraoperative delineation of the course of the ureters is the next step. Such a pilot study should focus on a more targeted dose-finding of the administered dye, as even a lower dose than $3 \mathrm{mg} / \mathrm{ml}$ (used in experiment 2) might be sufficient.

\section{Conclusion}

This technical report describes the possibility of near-infrared fluorescence delineation of the ureters using a commercially available laparoscopic fluorescence imaging system and CW800-CA in a pig model. 


\section{References}

1. Stassen LP, Bemelman WA, Meijerink J (2010) Risks of minimally invasive surgery underestimated: a report of the Dutch Health Care Inspectorate. Surg Endosc 24:495-498

2. Palaniappa NC, Telem DA, Ranasinghe NE, Divino CM (2012) Incidence of iatrogenic ureteral injury after laparoscopic colectomy. Arch Surg 147:267-271

3. Abboudi H, Ahmed K, Royle J, Khan MS, Dasgupta P, N'Dow J (2013) Ureteric injury: a challenging condition to diagnose and manage. Nat Rev Urol 10:108-115

4. Assimos DG, Patterson LC, Taylor CL (1994) Changing incidence and etiology of iatrogenic ureteral injuries. J Urol 152:2240-2246

5. Schols RM, Bouvy ND, van Dam RM, Stassen LP (2013) Advanced intraoperative imaging methods for laparoscopic anatomy navigation: an overview. Surg Endosc 27:1851-1859

6. Tanaka E, Choi HS, Humblet V, Ohnishi S, Laurence RG, Frangioni JV (2008) Real-time intraoperative assessment of the extrahepatic bile ducts in rats and pigs using invisible near-infrared fluorescent light. Surgery 144:39-48

7. Tanaka E, Ohnishi S, Laurence RG, Choi HS, Humblet V, Frangioni JV (2007) Real-time intraoperative ureteral guidance using invisible near-infrared fluorescence. J Urol 178:2197-2202

8. Schols RM, Bouvy ND, Masclee AA, van Dam RM, Dejong CH, Stassen LP (2013) Fluorescence cholangiography during laparoscopic cholecystectomy: a feasibility study on early biliary tract delineation. Surg Endosc 27:1530-1536

9. Beraldo S, Neubeck K, Von Friderici E, Steinmuller L (2013) The prophylactic use of a ureteral stent in laparoscopic colorectal surgery. Scand J Surg 102:87-89

10. Matsui A, Tanaka E, Choi HS, Kianzad V, Gioux S, Lomnes SJ, Frangioni JV (2010) Real-time, nearinfrared, fluorescence-guided identification of the ureters using methylene blue. Surgery 148:78-86

11. Verbeek FP, van der Vorst JR, Schaafsma BE, Swijnenburg RJ, Gaarenstroom KN, Elzevier HW, van de Velde CJ, Frangioni JV, Vahrmeijer AL (2013) Intraoperative near infrared fluorescence guided identification of the ureters using low dose methylene blue: a first in human experience. J Urol 190:574-579

12. Frangioni JV, Tanaka E, Borud L Intraoperative imaging methods. Patent Cooperation Treaty WO / 2008 / 076467, http://patentscopewipoint/search/en/WO2008076467

13. van der Pas MH, Ankersmit M, Stockmann HB, Silvis R, van Grieken NC, Bril H, Meijerink WJ (2013) Laparoscopic sentinel lymph node identification in patients with colon carcinoma using a near-infrared dye: description of a new technique and feasibility study. Journal of laparoendoscopic \& advanced surgical techniques Part A 23:367-371

14. Marshall MV, Draney D, Sevick-Muraca EM, Olive DM (2010) Single-dose intravenous toxicity study of IRDye 800CW in Sprague-Dawley rats. Mol Imaging Biol 12:583-594 
PART II

\section{DIFFUSE REFLECTANCE SPECTROSCOPY \\ DURING SURGERY}




\section{Chapter 7}

Multispectral characterization of tissues encountered during laparoscopic colorectal surgery

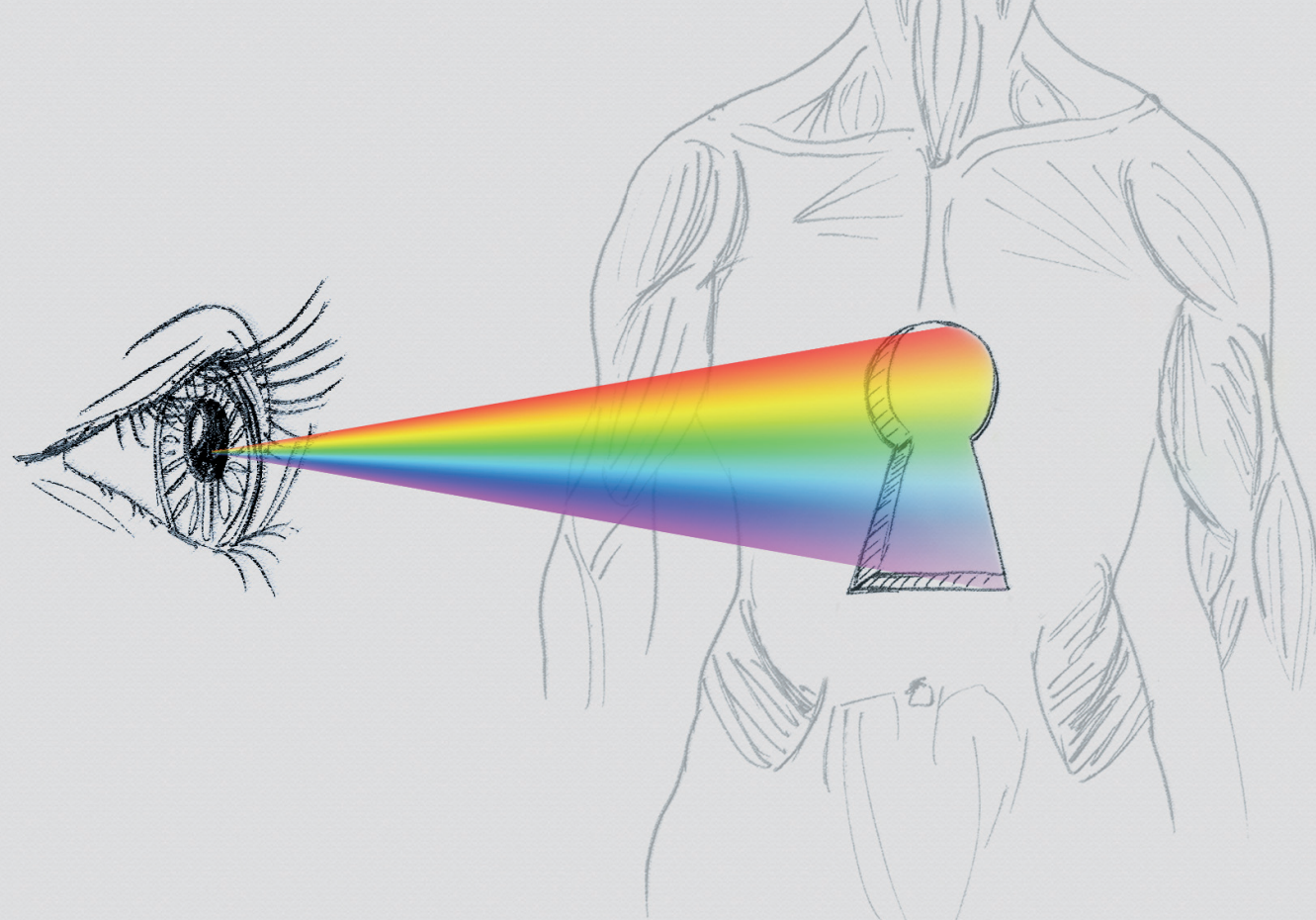

Schols RM, Dunias P, Wieringa FP, Stassen LP Medical Engineering \& Physics 2013;35:1044-1050 


\section{Abstract}

\section{Aim}

This study investigated the feasibility of automated differentiation between essential tissue types encountered during laparoscopic colorectal surgery using spectral analysis.

\section{Methods}

Wide band (440 - $1830 \mathrm{~nm}$ ) spectra were collected using an optical fiber probe and spectrometer from freshly explanted, ex vivo, human colonic specimens. The data was normalized at $810 \mathrm{~nm}$ (an isobestic wavelength for hemoglobin and oxy-hemoglobin) and mathematically analyzed using Total Principal Component Regression (TPCR).

\section{Results}

929 spectra were collected from specimens of 19 patients, distinguishing 5 tissue types: mesenteric fat (MF, $n=269)$, blood vessels ( $B V, n=377)$, colonic tissue $(C T, n=213$ ), ureter $(U R, n=10)$ and tumorous tissue in colon $(T T, n=60)$. For each individual tissue type the distinctive ability was determined against all other tissue types pooled as a group. Paired probability density function (PDF) of "tissue" (centered around label 1) versus "all other pooled tissues" (centered around label 0 ) and the cumulative distribution function (CDF) at label cross-over value 0.5 were determined for each tissue type (MF: CDF=0.99 [SD=0.19]; BV: $C D F=0.95$ [SD=0.29]; CT: $C D F=0.98$ [SD=0.22]; UR: $C D F=0.99$ [SD=0.09]; TT: $C D F=0.99$ [SD=0.18]).

\section{Conclusion}

Automated spectral differentiation of blood vessel, ureter, mesenteric adipose tissue, colonic tissue and tumorous tissue in colon, is feasible in freshly explanted human colonic specimens. These results may be exploited for further steps towards multi- or hyperspectrally enhanced in vivo (laparoscopic) surgical imaging. 


\section{Introduction}

Great public attention is paid to surgical safety, in particular the safety of endoscopic surgery ${ }^{1}$. In addition, efficiency is of constant concern in modern healthcare. Hence, dedicated clinical programs have been designed for inguinal hernia and gallbladder surgery to increase patient volume, improve safety and efficiency and thus save money. Colorectal surgery is the latest form of high-volume-surgery for which laparoscopic techniques have now widely been introduced. This is an advanced procedure requiring a high level of endoscopic skills. As an example, Kim (2009) gives a detailed description of the laparoscopic low anterior resection (or rectum resection) in an electronic reference ${ }^{2}$. Finding and identifying the right tissue structures and anatomical planes takes time and has its risks. latrogenic vascular injury, ureter lesion and nerve damage are some examples of complications that may occur.

To identify the correct anatomical planes, different types of fatty tissue and blood vessels are used for orientation. If in addition to normal vision and common anatomical knowledge, essential anatomical planes and structures could be additionally enhanced or even specifically identified, this would beneficially influence the safety and efficiency of laparoscopic colorectal surgery.

Multispectral imaging uses light at wavelengths beyond the visible range to enhance tissue structures. Tissue contrasts and light penetration depth vary with wavelength. Using these phenomena, hidden structures under a layer of fatty or connective tissue can, for instance, be visualized by utilizing spectral differences of the reflected light. For example, it is well known that vasculature perfused with highly oxygenated blood reflects near-infrared light in a different way than vasculature perfused with deoxygenated blood ${ }^{3,4}$. With electronic processing, the difference can be visually enhanced. In cardiac surgery, these two characteristics have led to a clearer, in-depth visualization of the coronary arteries, and clearer differentiation from adjacent veins $s^{5-7}$.

The goal is to help develop an endoscopic imaging device enabling laparoscopic surgeons to more clearly distinguish critical anatomical structures (e.g. ureter, arteries, veins, nerves) by selective contrast enhancement and in-depth visualization of these structures (without administration of a chromophore or fluorophore or other contrast agent).

As a first step to achieve this, diffusely reflected wide band light spectra were measured from different tissue types in freshly resected colonic specimens: healthy colonic tissue, arteries, veins, ureter, and mesenteric fat. A mathematical method was then applied to distinguish between these tissue types based upon analysis of the observed spectra. 


\section{Methods}

Ex vivo measurements on freshly resected human colonic specimens were performed in the operating theatres of Maastricht University Medical Center (MUMC, Maastricht, The Netherlands).

\section{Material}

The equipment used for these ex vivo measurements was installed on a modified 'goLab Mobile Work Station' (see schematic set-up in Figure 7.1), which consisted of: a notebook, a transformer, a spectrometer, a light source and a non-sterile fiber probe. The 'Medical Technology Service Department' tested and approved the equipment according to the essential requirements of IEC 60601-1 to assure the patient's safety.

The equipment was centrally driven by a computer. To facilitate the mobility of the equipment, a notebook (HP Pavilion dv6, installed with Windows ${ }^{\circledR} 7$ Home Premium) was chosen instead of a desktop. The spectra recorded were directly saved on the notebook hard disk for further analysis.

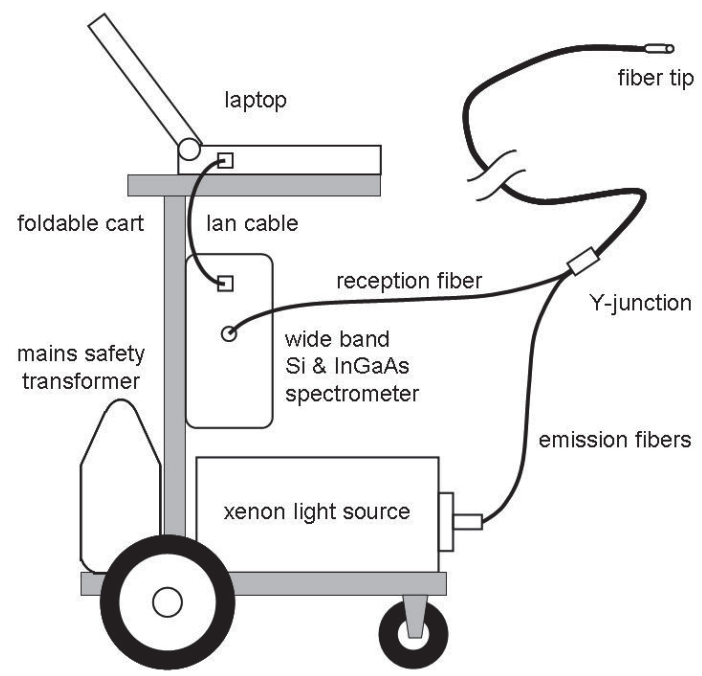

Figure 7.1 Schematic set-up equipment

A medical isolating transformer (KLMX/S-1200-230/230, Muuntosähkö Oy/Trafox, Helsinki Finland) was used to connect the different electrical components to mains power thereby ensuring that leakage currents were limited to values permitted for medical equipment ${ }^{8}$. 
A QualitySpec ${ }^{\circledR}$ Pro (Analytical Spectral Devices, Inc., Colorado USA) spectrometer was used. This is a transportable VIS/NIR spectrometer covering a wavelength range between 350 and $1830 \mathrm{~nm}$, equipped with two detector technologies: Silicon from 350-1100 $\mathrm{nm}$ and InGaAs from 900-1830 $\mathrm{nm}$ and controlled by a spectral acquisition package called Indico ${ }^{\mathrm{TM}}$ Pro (Version 5.6, Analytical Spectral Devices, Inc., Colorado USA). The spectrometer software facilitated optimized choice of cross-over wavelength between the "silicon" and "beyond silicon" range.

The applied light source was a modified xenon lamp (D-light C, Karl Storz, Tuttlingen Germany). The IR-filter was removed in order to produce wavelengths in both the visible (VIS) and near-infrared (NIR) as well as part of the short wave infrared (SWIR) ranges of the electromagnetic spectrum. A custom fiber coupler was applied to prevent burn-in of the light guide fibers. In addition to some narrow NIR peaks, this lamp also emits a continuum within the deeper infrared (IR) region, but with a lower intensity than the continuum in the VIS-region.

The fiber probe was designed by TNO and custom built. The fiber probe is the medium through which light is transported from light source towards tissue, and back from the tissue to the spectrometer. Scatter diffused reflection and absorption within the tissue form the tissue interactions.

In Figure 7.2 the fiber probe tip is shown in detail. The fiber probe (bandwidth $350 \mathrm{~nm}-$ $2400 \mathrm{~nm}$ ) is composed of eight small optical fibers: one central receiving fiber tip (illuminated yellow) which has a core diameter of $0.44 \mathrm{~mm}$ and seven illuminating fibers (illuminated white) which have core diameters of $0.33 \mathrm{~mm}$. The total external tip measures $2 \mathrm{~mm}$ in diameter. Numerical aperture of both fiber types is 0.22 . The stainless steel tip has a length of $10 \mathrm{~mm}$. The rest of the sterile fiber is highly flexible.

A custom built SMA-adapter was used to connect the fiber probe to the cold light guide connector of the medical light source. For ex vivo tissue measurements a non-sterile fiber probe was used on the specimens immediately after surgical extirpation.

\section{Human colonic specimen}

Approval from the local medical ethical review board was granted before ex vivo human tissue measurements were performed. These measurements were intended to collect the spectra of different tissue types in freshly extirpated human colon tissue. Colonic, sigmoid and rectum specimens of patients who underwent open or laparoscopic colorectal surgery during the time of this study were included. 


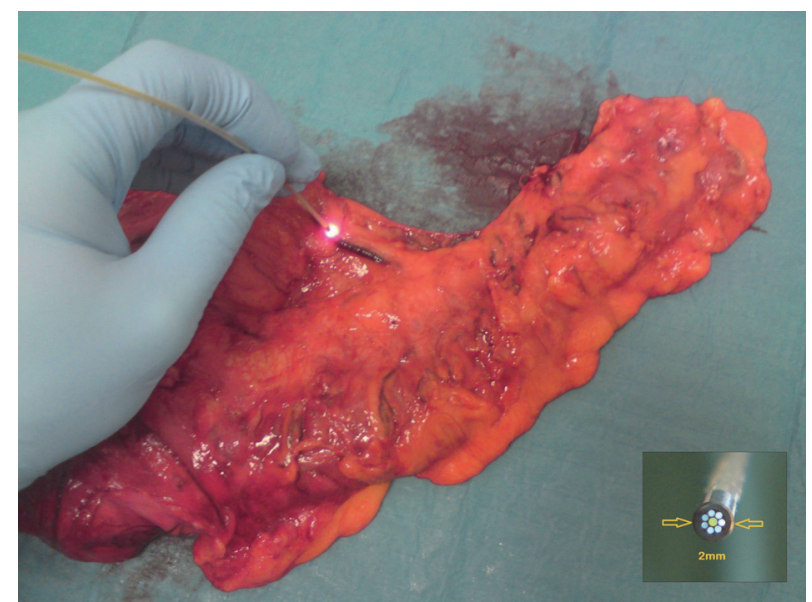

Figure 7.2 Optical fiber probe measurement + detail of fiber probe tip

\section{Data collection}

Before specimen measurements, a reflectance baseline was recorded with spectralon (Optical-grade spectralon reference material; Labsphere, Inc., North Sutton, New Hampshire USA). Spectralon is used very commonly as reference spectrum for baseline correction as it behaves as a nearly perfect cosine-diffused reflector from 250-2500 nm. Baseline values were measured with the fiber probe in direct contact with the spectralon surface. During the baseline recordings the light source was set at $50 \%$ power capacity. The same fiber probe that was used for the baseline recordings was also used for the ex vivo tissue measurements. Overall tissue reflection was much lower than spectralon reflectance. Hence, the light source was turned up to $100 \%$ during spectroscopic measurements on tissue, thus achieving a better dynamic range during tissue measurements (light source linearity was verified separately). The fiber probe was gently brought into direct contact with the tissue surface by hand as demonstrated in Figure 7.2. Between measurements of different tissue types the fiber probe was cleaned with saline.

Spectra of all tissue types were acquired from fresh human tissue, immediately after surgical removal while the specimen was still within the operating theatre. Several spectra were recorded for each tissue type: healthy colonic tissue, mesenteric fat, arteries, and veins; if present in the specimen, also: ureter, palpable tumor in lumen of intestine. At least two different locations were measured per tissue type and each location was measured five times. This provided a total of at least ten spectra per tissue 
type per subject. Directly after completion of the measurements (average 10-15 minutes) the specimen was sent, undamaged, to the pathology department.

\section{Data processing of spectral measurements}

Data were processed using MATLAB (Version 7.7.0, MathWorks Inc., Natick, Massachussetts, USA). All spectra were normalized at a wavelength of $810 \mathrm{~nm}$, which was chosen since, at this isobestic wavelength, the absorption of oxygenized and deoxygenized blood are equal; water absorption is also low ${ }^{3}$. This choice of normalization wavelength minimized the influence of blood smears on the fiber probe top. The acquired spectra were divided by the baseline reference spectrum acquired on spectralon. This resulted in optical reflectance spectra which are largely independent of the optical characteristics of the applied illumination source.

\section{Determination of an appropriate classification method}

The classification methods applied for this study consisted of two parts - training and validation - like many classification methods generally do. During the training part a set of representative measurements and the corresponding outcome were used to learn how to classify the measurements under consideration. In this case the measurements were reflectance spectra $(X)$ of different types of tissue; the classification was the tissue type $(Y)$ itself.

We applied a Total Principal Component Regression (TPCR), a method that is well described in literature ${ }^{9,10}$. Within the Supplementary section our application of TPCR is discussed in more detail.

\section{Results}

A total of 929 spectral measurements were performed on fresh colonic specimens of 19 patients who underwent open or laparoscopic colorectal surgery. The following tissue types were distinguished: mesenteric fat $(n=269)$, blood vessels $(n=377)$, colonic tissue $(n=213)$, ureter $(n=10)$ and tumorous tissue in colon $(n=60)$. See Table 7.1 for study subject characteristics and the number of collected spectra per tissue type. The spectral profile of each tissue type is plotted combined in Figure 7.3A and separately in Figure $7.3 \mathrm{~B}-7.3 \mathrm{~F}$. 


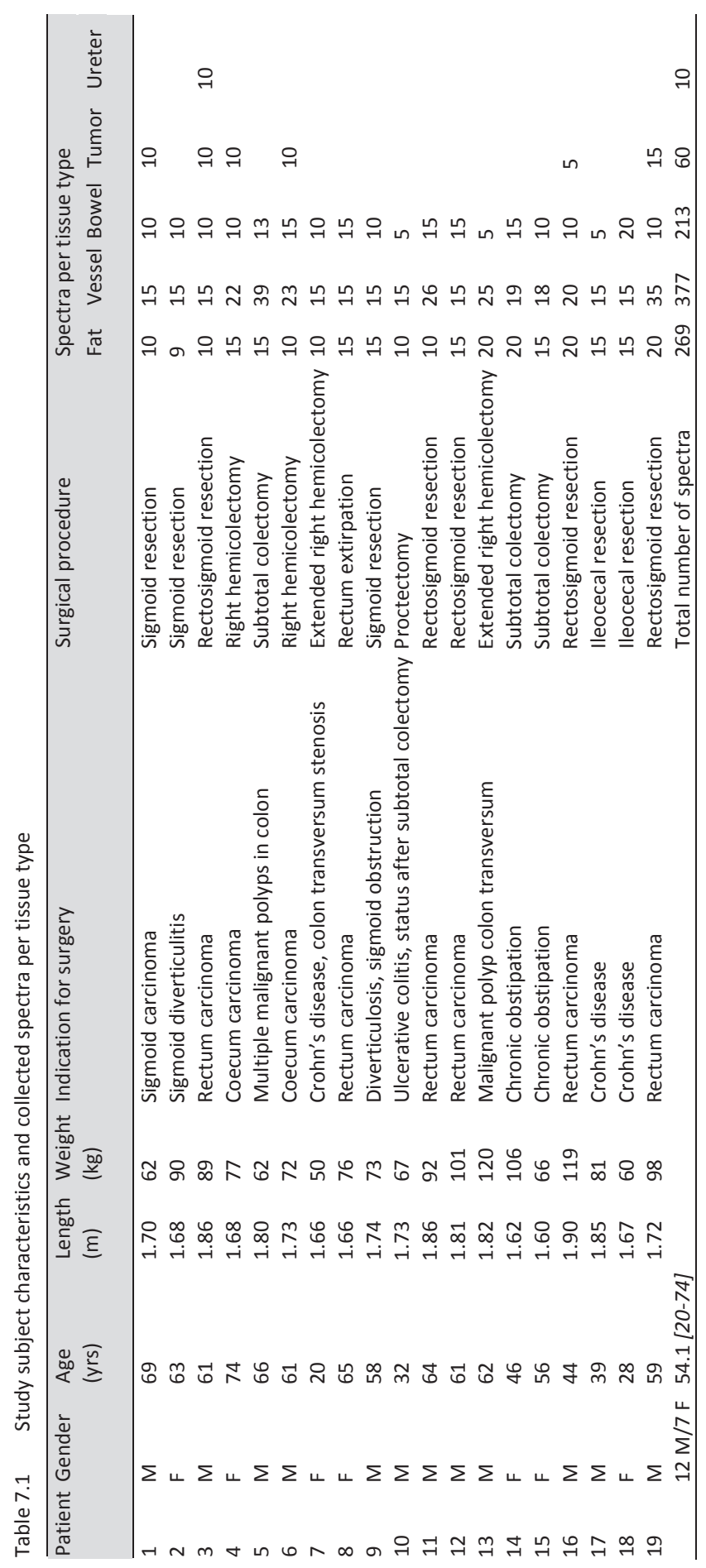


A

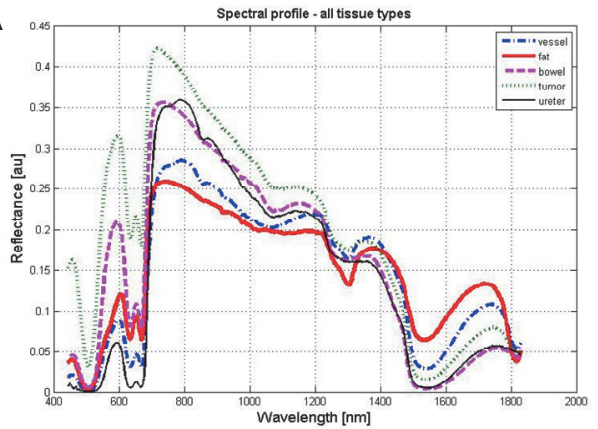

C

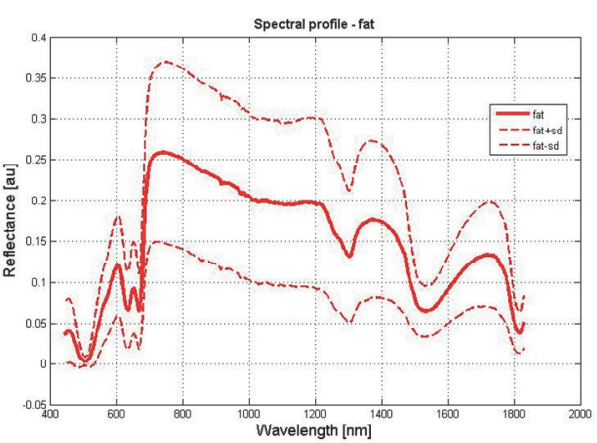

$\mathrm{E}$

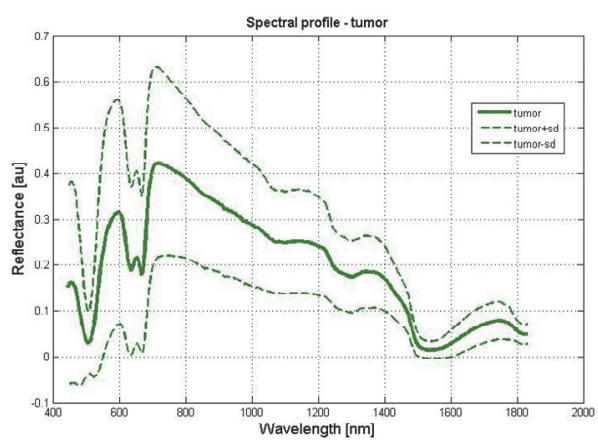

B

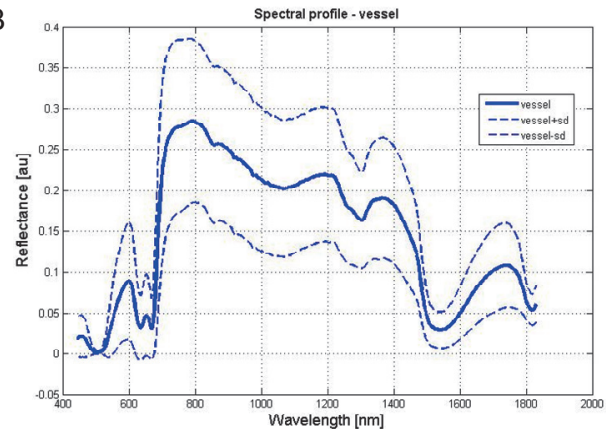

D

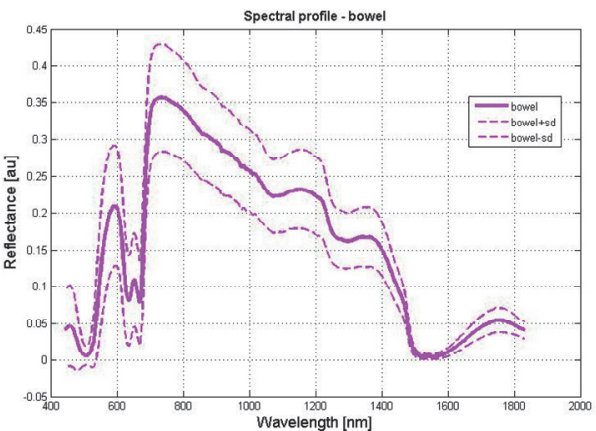

$\mathrm{F}$

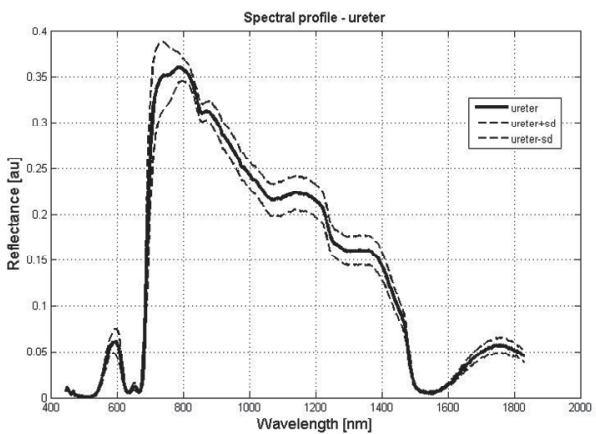

Figure 7.3 Spectral profile of tissue types

Results of the TPCR method for spectral measurement classification are presented combined in Figure 7.4A (see explanation in Supplementary section) and plotted for each individual tissue type versus the four others in Figure 7.4B - 7.4F. Note that Figure 7.4A merely serves as a summary for comparison, the order of tissue types along the $x$-axis is arbitrary. The primary aim was selective image enhancement for specific tissue, 
because in surgery it can be highly relevant to be able to selectively enhance the contrast of one specific tissue type against all other tissues grouped together. For example, in laparoscopic colorectal surgery it can be very useful to enhance ureteral visualization to prevent iatrogenic injury ${ }^{11}$.

In general the comparison has been made between one type of tissue, say 'vessel', and 'all other tissue types' aggregated in a pool. The corresponding labeling ( $Y$ vector, explained in the Supplementary section) is set to a "digital" one or zero meaning presence of the tissue or not. In Figure 7.4B the result of the above described method on two different tissue sets is depicted for tissue type "vessel" versus "all other tissue types".

A normal distribution is assumed as described in the following equation:

$$
f(x)=\frac{1}{\sqrt{2 \pi \sigma^{2}}} e^{-\frac{(x-\mu)^{2}}{2 \sigma^{2}}}
$$

Where:

$f(x)=$ Probability Density Function (PDF, see Supplementary section)

$\sigma \quad=$ Standard Deviation (SD)

$\mu=$ Label value on the $x$-axis around which the PDF envelope curve is centered

Two envelope curves, according to the assumed normal distribution, are plotted in the figure. They represent the assumed probability distribution of the algorithm results regarding the labeling of two groups of measurements. Figure 7.4B plots the individual results for 'vessel' centered around $\mu_{\text {vessel }}=1$, whereas 'all other tissue types' are centered around $\mu_{\text {other }}=0$ (colored asterixes indicate both groups). Figure 7.4C $-7.4 \mathrm{~F}$ are likewise but for fat, bowel, tumor and ureter.

Both envelope curves intersect at the crossover value of 0.5 on the X-axis, which represents the decision border between both groups. The cumulative distribution function result ${ }^{12}$ (CDF, see Supplementary section) obtained at this cross-over point of 0.5 now indicates the chance that the algorithm indeed correctly classified the tissue type under consideration. The CDF (0.5) thus can serve as a confidence indicating factor for tissue type recognition (i.e. the closer to 1 , the better). For all considered tissue types the corresponding CDF (0.5) results and the associated standard deviation are listed in Table 7.2. The Supplementary section contains some more details on our data analysis. 

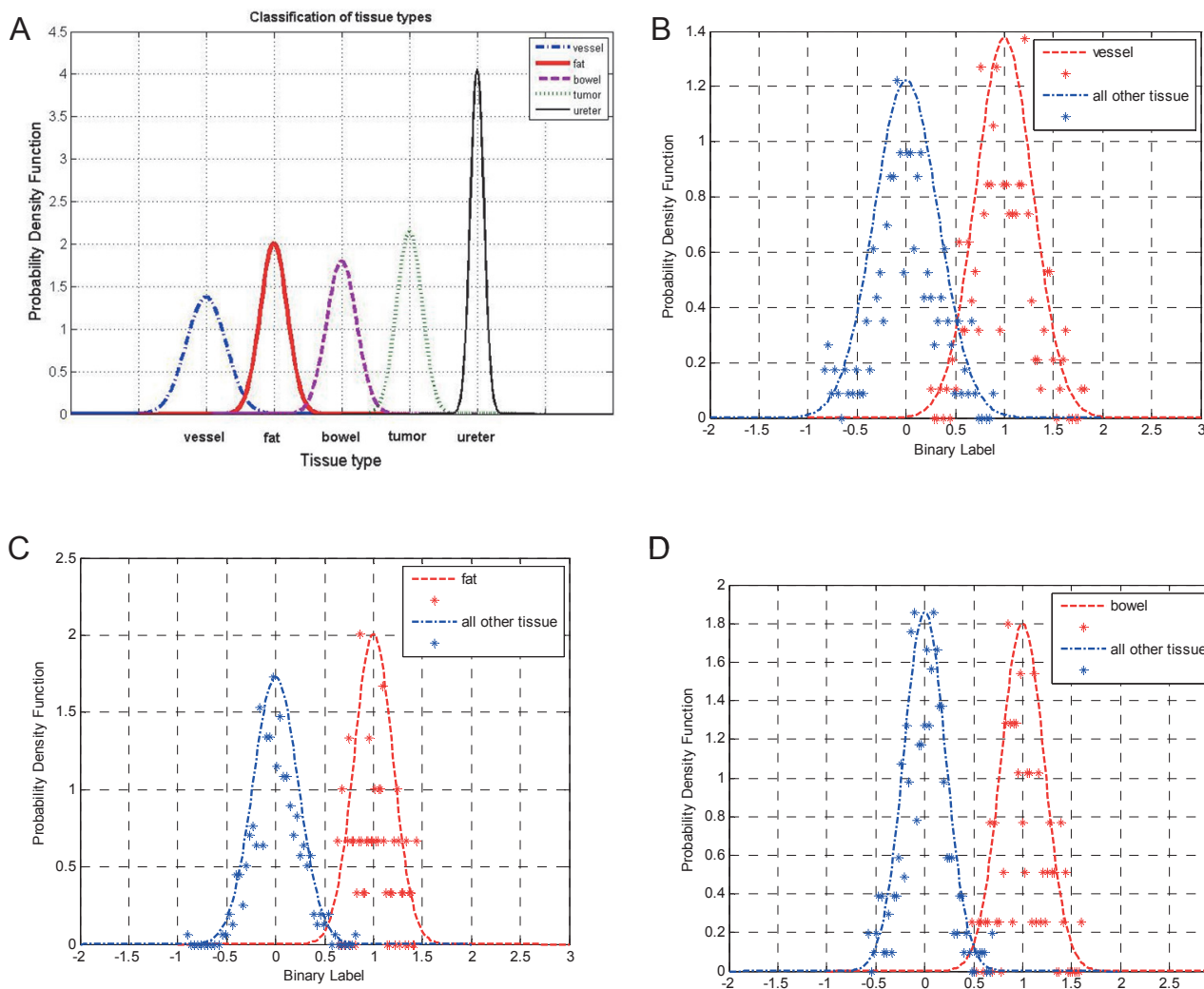

$\mathrm{D}$

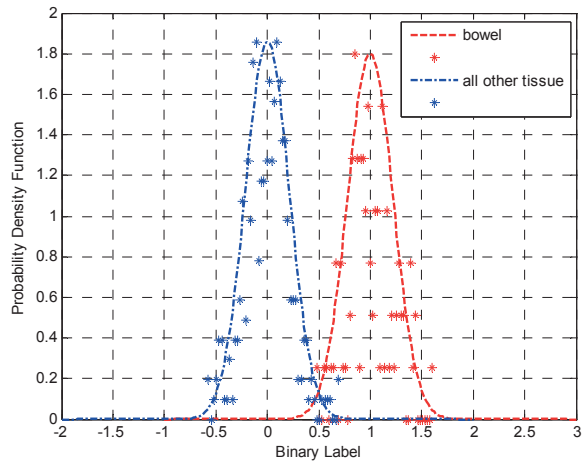

E

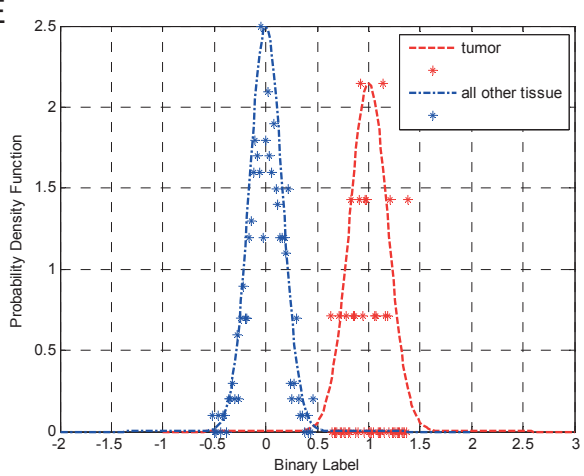

F

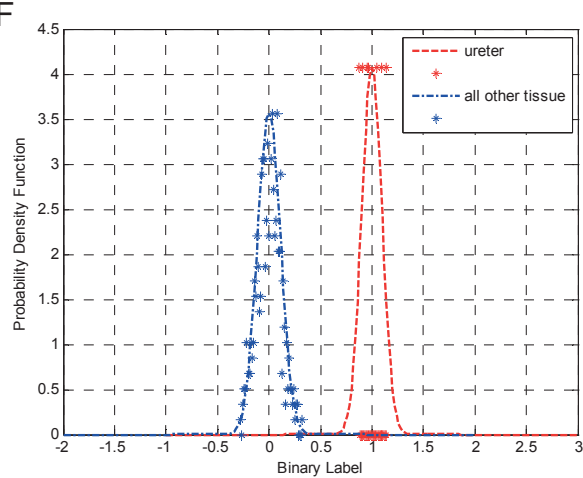

Figure 7.4 Classification of tissue types 
Table 7.2 Cumulative distribution function per tissue type

\begin{tabular}{llc}
\hline Tissue type & CDF & SD \\
\hline Vessel & 0.95 & 0.29 \\
Mesenteric fat & 0.99 & 0.20 \\
Colonic tissue & 0.98 & 0.22 \\
Tumor in colonic tissue & 0.99 & 0.19 \\
Ureter & 0.99 & 0.10 \\
\hline
\end{tabular}

$\mathrm{CDF}=$ cumulative distribution function, calculated on $0.5 ; \mathrm{SD}=$ standard deviation

\section{Discussion}

Wideband (440 - $1830 \mathrm{~nm}$ ) spectral properties of various tissue types have been investigated in freshly explanted human colonic specimens: normal human colonic tissue, tumorous tissue in the colon, mesenteric fat, arteries, veins and ureter. Translating the acquired spectra into clinically useful information by automated diagnostic algorithms was demonstrated for single spot data.

Differentiation of tissue structures, which is essential during orientation and dissection in laparoscopic colorectal surgery, seems indeed possible based on the performed spectral measurements. The results for CDF (0.5) listed in Table 7.2, which represent the fraction of correctly classified measurements, vary between 0.95 and 0.99 when distinguishing one type of tissue from surrounding other tissue types. This tissue recognition method opens new possibilities within the rapidly expanding field of spectroscopic analysis of data from multi- or hyperspectral cameras ${ }^{13-15}$ to produce real-time in vivo endoscopic identification and selective image contrast enhancement of essential anatomical structures.

In the present study an important potential of spectral analysis has been shown, i.e. characterization of different essential tissue types. Although measurements were performed immediately after specimen resection, perfusion was already disrupted. Thus, vascular filling and oxygenation were different from the in vivo situation, which most likely influences the measurements.

Furthermore, spectral measurements were assumed to be performed superficially whereas the wavelength dependency of optical tissue penetration depth has not specifically been modeled in this study.

Future research will thus need to focus on several aspects in order to increase the clinical relevance of this technique: 
- The depth penetration at different wavelengths and the in-depth tissue characterization, e.g. beneath a layer of fatty tissue. This is highly relevant as many tissue structures in patients are (partly) covered by others.

- Influence of perfusion and oxygenation. These aspects vary between the in vivo and ex vivo situation ${ }^{16,17}$ and need to be identified with respect to spectral analysis.

Modeling the influence of these parameters will raise insights above the empirical, 'black box' level. Hence, future research should repeat these measurements in vivo. The presented results offer motivation for such future research.

\section{Conclusion}

Spectral differentiation of blood vessels, mesenteric adipose tissue, colonic tissue, tumorous tissue inside the colon, and ureter is feasible in freshly explanted human colonic specimen using ex vivo spectral analysis without the addition of a contrast agent. In future research the results and insights from this study may be applied for the design of dedicated spectral imaging instruments to enhance in vivo visual contrasts of the investigated essential structures with respect to surrounding tissues and ultimately help prevent intraoperative iatrogenic injury. 


\section{References}

1. Stassen LP, Bemelman WA, Meijerink J (2010) Risks of minimally invasive surgery underestimated: a report of the Dutch Health Care Inspectorate. Surg Endosc 24:495-498

2. Kim SH (2009;01: http://www.websurg.com/doi-lt03enkim001.htm) Laparoscopic low anterior resection (LAR): step by step technique on standardization.

3. Roggan A, Friebel M, Doerschel K, Hahn A, Mueller GJ (1999) Optical properties of circulating human blood in the wavelength range 400-2500 $\mathrm{nm}$. J Biomedical Optics 4:36-46

4. Zijlstra WG, Buursma A, Meeuwsen-van der Roest WP (1991) Absorption spectra of human fetal and adult oxyhemoglobin, de-oxyhemoglobin, carboxyhemoglobin, and methemoglobin. Clin Chem 37:1633-1638

5. Wieringa FP, Mastik F, Cate FJ, Neumann HA, van der Steen AF (2006) Remote non-invasive stereoscopic imaging of blood vessels: first in-vivo results of a new multispectral contrast enhancement technology. Ann Biomed Eng 34:1870-1878

6. Wieringa FP, Mastik F, Duncker DJ, Bogers AJ (2006) Contrast enhancement of coronary arteries in cardiac surgery: a new multispectral stereoscopic camera technique. Eurolntervention 2:389-394

7. Wieringa FP, Mastik F, Duncker DJ, Bogers AJ, Zeelenberg C, van der Steen AFW (2006) Remote optical stereoscopic multispectral imaging during cardiac surgery. Computers in Cardiology 33:693-696

8. Wieringa FP, Leefmans A, Dias LJ, Abkoude CMA (2004) Praktijkgids: Elektrische veiligheid in medisch gebruikte ruimten. NEN-Uitgeverij, Delft, The Netherlands

9. Tan Y, Shi L, Tong W, Wang C (2005) Multi-class cancer classification by total principal component regression (TPCR) using microarray gene expression data. . Nucleic Acids Research 33:56-65

10. Majumder SK, Gupta A, Gupta S, Ghosh N, Gupta PK (2006) Multi-class classification algorithm for optical diagnosis of oral cancer. J Photochem Photobiol B 85:109-117

11. Cahill RA, Ris F, Mortensen NJ (2011) Near-infrared laparoscopy for real-time intra-operative arterial and lymphatic perfusion imaging. Colorectal Dis 13 Suppl 7:12-17

12. Gentle JE (2010) Computational Statistics. Springer, pp 348

13. Keereweer S, Kerrebijn JD, van Driel PB, Xie B, Kaijzel EL, Snoeks TJ, Que I, Hutteman M, van der Vorst JR, Mieog JS, Vahrmeijer AL, van de Velde CJ, Baatenburg de Jong RJ, Löwik CW (2011) Optical imageguided surgery--where do we stand? Mol Imaging Biol 13:199-207

14. Akbari H, Kosugi Y (2009) Hyperspectral Imaging: a New Modality in Surgery. In: Naik GR (ed) Recent Advances in Biomedical Engineering, Intech, pp 223-240

15. Best SL (2012) Hyperspectral imaging in the operating room: what a surgeon wants. Proc SPIE 8254, 825403

16. Wilson BC, Jeeves WP, Lowe DM (1985) In vivo and post mortem measurements of the attenuation spectra of light in mammalian tissues. Photochem Photobiol 42:153-162

17. Best SL, Thapa A, Holzer MJ, Jackson N, Mir SA, Cadeddu JA, Zuzak KJ (2011) Minimal arterial in-flow protects renal oxygenation and function during porcine partial nephrectomy: confirmation by hyperspectral imaging. Urology 78:961-966 


\section{Supplementary section}

\section{$T P C R^{9}$}

Total Principal Component Regression (TPCR) is a mathematical method that can be applied to automatically learn specific features in measured patterns (sometimes referred to as 'fingerprints'). These features correspond to particular types of objects. In the reported investigation the object types are different tissues and the measured patterns are the respective optical reflectance spectra. TPCR can essentially be seen as a classification method. The TPCR method consists of two phases, the training phase and the classification phase. During the training phase the method is used to calculate a classifier that can be used during the subsequent classification phase on a measured spectrum to determine the sample tissue type. In the following paragraph, the training phase is explained in more detail.

Consider a number of measured tissue samples of different types. A matrix $X$ can be formed where each column contains the optical spectrum values at different selected wavelengths. In addition a matrix $Y$ is formed where each row represents a different tissue type and each column contains the corresponding tissue type indication, 1 for positive and 0 for negative. For illustration purposes consider the following example. Suppose 5 samples are measured ( 5 columns of $X$ ) and each at 8 different light wavelengths ( 8 rows of $X$ ):

$$
\begin{aligned}
X & =\left[\begin{array}{lllll}
0.10 & 0.12 & 3.00 & 3.23 & 2.99 \\
0.40 & 0.43 & 3.56 & 3.50 & 3.20 \\
0.70 & 0.77 & 2.21 & 2.34 & 3.01 \\
0.83 & 0.80 & 1.80 & 1.79 & 1.87 \\
0.91 & 0.92 & 1.01 & 1.00 & 0.99 \\
0.88 & 0.80 & 0.98 & 1.00 & 0.97 \\
0.30 & 0.22 & 0.10 & 0.20 & 0.19 \\
0.01 & 0.00 & 0.21 & 0.33 & 0.20
\end{array}\right] \\
Y & =\left[\begin{array}{ccccl}
1 & 1 & 0 & 0 & 0 \\
0 & 0 & 1 & 1 & 1
\end{array}\right]
\end{aligned}
$$

The label matrix $Y$ contains the tissue types. Each type is assigned an input label based on the visual judgment of the surgeon who indicates the tissue type for each measurement; this is sometimes referred to as the "ground truth". In this example there are 2 tissue types ( 2 rows of $Y$ ) and 5 measurements, of which some will be type 1 and some will be type 2 . In this instance the first 2 measurements represent the first 
tissue type (hence the input label is set at 1 in the top row) and the next three measurements represent a second tissue type (input label value of 1 in the bottom row). Using these matrices an aggregated matrix $A$ is formed, containing the observations $X$ and the corresponding input labels $Y$.

$$
A=\left\lfloor\begin{array}{ll}
X^{T} & \lambda \cdot Y^{T}
\end{array}\right]
$$

There is also a weighting factor $\lambda$ between $X$ and $Y$ which indicates the measure of confidence in the observations $X$ versus the labels.

The combination matrix $A$ is now used in an algorithm to determine the most interesting features to be used. In this case, however, the labeling information is additionally taken into account by using the labeling $Y$ ensuring a more useful output for characterization.

The identified features can be used to construct a transformation $B$ which transforms the observations $X$ into an estimation of the labeling $\hat{Y}$.

Actually, what is achieved is a learning matrix $B$ based on the observations and the input labeling which estimates as well as possible the labels through the observations, hence:

$$
\hat{Y}=X \cdot B
$$

That means that when a new (unlabeled) measurement is acquired, it has to be multiplied by the matrix $B$ to obtain the label of the measurement (in this particular case the most likely tissue type).

In the example the learning matrix could now be applied to observations to evaluate how well the system is trained. The result is:

$$
\hat{Y}=\left[\begin{array}{ccccc}
1.0231 & 0.9726 & -0.0550 & -0.0925 & 0.1472 \\
-0.0080 & 0.0087 & 0.9938 & 1.0281 & 0.9797
\end{array}\right]
$$

For instance the first column of the result matrix indicates that the observation was of the first type because the result value of 1.023 is closer to 1 than to 0 . And the observation was not likely to be of the second type because the result value of -0.0080 is closer to 0 than to 1 . It is clear that the result has to approach the real label matrix $Y$. In case a new unlabeled measurement $x$ is acquired, for example:

$$
x=\left[\begin{array}{llllllll}
0.89 & 0.42 & 0.74 & 0.81 & 0.87 & 0.883 & 0.334 & 0.098
\end{array}\right]
$$


The result then is:

$$
\hat{Y}=X \cdot B=\left[\begin{array}{ll}
0.7348 & 0.13
\end{array}\right]
$$

Meaning that the new measured tissue most likely is of the first type, because the result value of 0.7348 is closer to 1 than to 0 . And the observation was not likely to be of the second type because the result value of 0.13 is closer to 0 than to 1 .

However, it is clear there is an overlapping area between the label 0 and label 1 , where it becomes difficult to decide which tissue type label is closest to the measured label. Therefore the statistical distribution of the trained labels is used to determine the threshold between 0 and 1 which separates one tissue type label from another. In the next paragraph the way this threshold is determined will be addressed.

Important to mention is the case of more than two tissue types. More input labels may be defined in the label matrix $Y$. To calculate Figure 7.4A a larger matrix $\hat{Y}$ with 5 rows is defined (plotted around numerical x-values 0, 1, 2, 3, 4 for every tissue under consideration).

\section{$P D F$ and $C D F^{12}$}

The cumulative distribution function (CDF) represents the 'accumulated' probability 'up to $x^{\prime}$ for a given Probability Density Function (PDF). $C D F(x)$ is an anti-derivative of $\operatorname{PDF}(x)$. In this study CDF has been used to determine the threshold values between the tissue type labels $(0,1,2 \ldots)$ which can be used to classify the calculated label of a new measured tissue type. Based on the calculated labels $\hat{Y}$ on the training data $X$ we can calculate the CDF of every tissue type's calculated label. This actually is an indicator for the variation of the labels calculated by the TPCR method. 


\section{Chapter}

Automated spectroscopic tissue classification

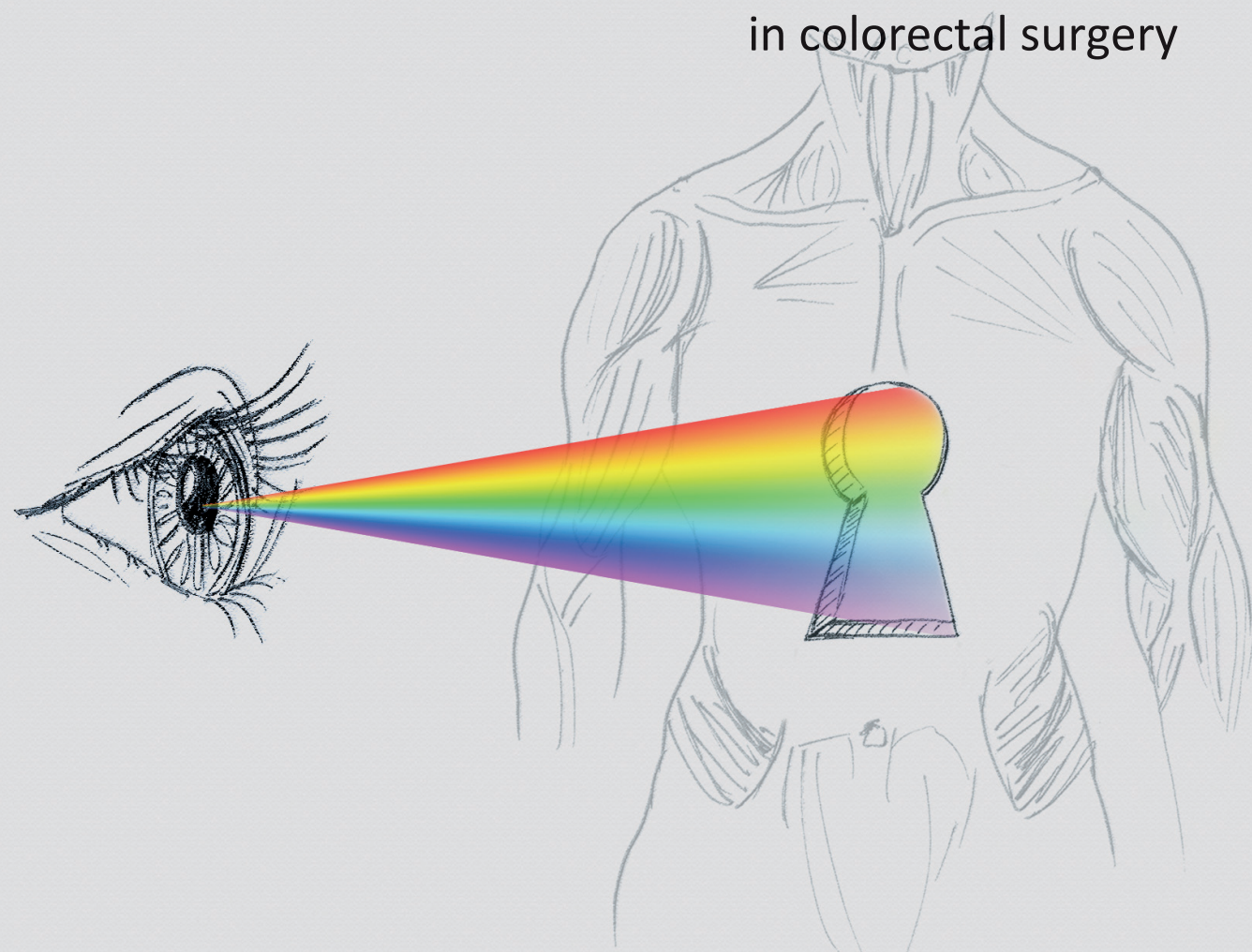

Schols RM, Alic L, Beets GL, Breukink SO, Wieringa FP, Stassen LP Accepted for publication in Surgical Innovation 


\begin{abstract}

\section{Background}

In colorectal surgery detecting ureters and mesenteric arteries is of utmost importance to prevent iatrogenic injury and to facilitate intraoperative decision making. A tool enabling ureter- and artery-specific image enhancement within (and possibly through) surrounding adipose tissue would facilitate this need, especially during laparoscopy. To evaluate the potential of hyperspectral imaging in colorectal surgery, we explored spectral tissue signatures using single-spot diffuse reflectance spectroscopy (DRS). As hyperspectral cameras with silicon ( $\mathrm{Si}$ ) and indium gallium arsenide (InGaAs) sensor chips are becoming available, we investigated spectral distinctive features for both sensor ranges.
\end{abstract}

\title{
Methods
}

In vivo wide-band (wavelength range 350-1830 nm) DRS was performed during open colorectal surgery. From the recorded spectra 36 features were extracted at predefined wavelengths: 18 gradients and 18 amplitude differences. For classification of respectively ureter and artery in relation to surrounding adipose tissue, the best distinctive feature was selected using binary logistic regression for Si- and InGaAssensor spectral ranges separately. Classification performance was evaluated by leaveone-out cross-validation.

\section{Results}

In 10 consecutive patients 253 spectra were recorded on 53 tissue sites (including colon, adipose tissue, muscle, artery, vein, ureter). Classification of ureter versus adipose tissue revealed accuracy of $100 \%$ for both Si-range and InGaAs-range. Classification of artery versus surrounding adipose tissue revealed accuracies of $95 \%$ (Si) and $89 \%$ (InGaAs).

\section{Conclusion}

Intraoperative DRS showed that Si- and InGaAs-sensors are equally suited for automated classification of ureter versus surrounding adipose tissue. Si-sensors seem better suited for classifying artery versus mesenteric adipose tissue. Progress towards hyperspectral imaging within this field is promising. 


\section{Introduction}

In colorectal resection, surgical dissection and intraoperative decision-making involves visual distinction of critical anatomy, such as ureters and arteries. Especially during laparoscopy, when spatial perception from direct sight and haptic feedback from palpation are absent, identifying these tissues can be even more challenging than during open surgery. Reported incidence of ureteral injury during this type of surgery is $0.66 \%{ }^{1}$, which may cause serious clinical problems like intra-abdominal sepsis, renal failure and loss of renal function ${ }^{2}$. Additionally, incidence of iatrogenic ureteral injuries in patients undergoing laparoscopy was found to be significantly higher compared to open procedures $(0.15 \% \text { in open surgery and } 0.66 \% \text { in laparoscopic surgery })^{1,3}$. In obese patients, ureter identification can be especially challenging and time-consuming. While the ureter is a unique structure, there are several arteries in the mesentery of the colon. Detecting the course of these arteries is e.g. crucial in deciding how to maintain proper arterial blood supply of the colorectal anastomosis after colorectal resection. Proper arterial blood supply is an important factor of anastomotic viability ${ }^{4}$ and, if disrupted, a risk factor for anastomotic leakage. Anastomotic leakage occurs in 6.4-7.5\% of patients undergoing colonic cancer surgery ${ }^{5,6}$.

A non-invasive tool enhancing the visual contrast of ureters and arteries within adipose surroundings is desirable for improved intraoperative recognition of these structures. Near-infrared fluorescence imaging has been demonstrated for real-time, intraoperative visualization of ureters $^{7-9}$ and arteries ${ }^{10-12}$. However, this technique requires administration of a contrast agent. Exploration of optical spectroscopic techniques based on endogenous contrasts might offer an alternative.

Hyperspectral camera technology, with pre-acquired library-spectra recorded on the earth surface are used to generate satellite images for discovering places of interest for e.g. agricultural purposes ${ }^{13,14}$ or military and homeland security applications ${ }^{15}$. This technology incorporates potential to facilitate image-guided surgery as well ${ }^{16}$. It has, for example, been investigated for contrast enhancement of coronary arteries during open heart surgery ${ }^{17}$, for intraoperative assessment of tissue oxygen saturation ${ }^{18,19}$, for intraoperative enhancement of bile ducts ${ }^{20}$ and for intraoperative tumor detection ${ }^{21}$. Medical hyperspectral imaging systems usually are based on silicon ( $\mathrm{Si}$ ) or indium gallium arsenide (InGaAs) camera chips. Si roughly covers the wavelength range of $400-1000 \mathrm{~nm}$, whereas InGaAs is typically sensitive in the $900-1700 \mathrm{~nm}$ wavelength region with the possibility to push its boundary up to $2500 \mathrm{~nm}^{16}$.

In an abdominal surgery pig model, Akbari et al. $^{22}$, demonstrated the potential of hyperspectral imaging (wavelength range $400-1700 \mathrm{~nm}$ ) for detection and differentiation of arteries and veins. Furthermore, the potential of in vivo multispectral 
imaging in the so-called extended near-infrared window (i.e. beyond the silicon detection range) based upon endogenous chromophores (e.g. water and lipid) has recently been described by Cao et al. ${ }^{23}$. Using a mouse model spectral characterization of various tissues (skeletal muscle, liver, kidney, cardiac tissue, cerebrum, cerebellum and adipose tissue) was obtained.

Diffuse reflectance spectroscopy (DRS) has been used previously to acquire spectral characteristics of different tissue types in order to discriminate between e.g. normal, premalignant and malignant colonic tissue ${ }^{24,25}$. The present in vivo human study follows-up on our previously reported study on freshly extirpated samples of colon, ureter and mesenteric adipose tissue by using wide-band $\left(350-1830 \mathrm{~nm}\right.$ ) DRS ${ }^{26}$.

To evaluate the potential of hyperspectral imaging in colorectal surgery, we collected in vivo wide-band (350 - $1830 \mathrm{~nm}$ ) spectral reflectance-signatures during colon surgery, i.e. of colon, mesenteric adipose tissue, muscle, artery, vein and ureter. The main focus of tissue spectral analysis was identifying endogenous contrasts of respectively ureter and artery versus surrounding adipose tissue. In contrast to earlier studies, which rely upon signal intensity to classify tissues using a support vector machine (SVM) ${ }^{22}$, we propose the exploration of spectral tissue signatures by extraction of relative spectral features from DRS signal which are quite robust with regard to variations in signal intensity ${ }^{27}$.

\section{Methods}

In vivo human tissue measurements were performed at the Surgery Department of Maastricht University Medical Center (MUMC, Maastricht, The Netherlands) during open colorectal surgery. Prior to measurements, the local institutional review board of Maastricht University Medical Center (registration number METC 10-4-035) granted approval and preoperative written informed consent was obtained from all patients.

\section{Material}

Diffuse reflectance spectra were acquired using custom developed sterile disposable optical fibre probes (TNO, Eindhoven the Netherlands \& Light Guide Optics, Rheinbach Germany), a modified Xenon light source (D-light C, Karl Storz, Tuttlingen Germany), and a spectrometer (Analytical Spectral Devices, Inc., Colorado USA) covering the range of $350-1830 \mathrm{~nm}$. The spectrometer is equipped with two sensor technologies: a silicon (Si) based sensor and an indium gallium arsenide (InGaAs) based sensor with a crossover point at $1000 \mathrm{~nm}$. The fibre probe is the medium through which light is 
transported from light source to tissue, and back again from tissue to spectrometer. The system was installed on a compact trolley to facilitate in vivo tissue measurements during routine surgery. The setup was tested and approved according to the essential requirements of IEC 60601-1 to assure patient safety. The equipment has previously been described in more detail ${ }^{26}$.

Figure 8.1 shows the fibre probe tip composed of eight optical fibres: One central receiving fibre (400 um diameter, NA $0.22 \pm 0.02$ ) and seven illuminating fibres (300 um diameter, NA $0.22 \pm 0.02$ ). The rigid stainless steel probe tip has a $2 \mathrm{~mm}$ diameter and a length of $10 \mathrm{~mm}$. The remaining length of the sterile fibre probe is highly flexible.

\section{In vivo data acquisition}

During open colorectal surgery, in vivo wide-band diffuse reflectance spectra (350-1830 nm, $1 \mathrm{~nm}$ spectral resolution) were collected. For each tissue type, five spectra per site (taking 30 seconds per site) were recorded, covering at least one site per tissue type (see also Table 8.1). The sterile fibre probe was handled by the surgeon and gently brought into direct contact with one of the designated tissues (see Figure 8.1). When blood was visibly present on the tissue surface, it was dapped away using sterile gauze. Between spectral measurements on different sites, the fibre probe tip was swiped with clean sterile gauze (wetted in saline). Acquired data was labeled according to the tissue type description of the attending surgeon.

To correct for dark current ${ }^{16}$, the spectrometer was calibrated prior to in vivo data acquisition. After the completion of in vivo spectroscopy, a reference spectrum was acquired, for calibration purposes, by direct contact measurement on a white reference phantom (Optical-grade spectralon reference; Labsphere, Inc., North Sutton, New Hampshire USA). The integration times of the Silicon and InGaAs sensor were individually optimized during the Spectralon calibration. No correction for ambient light was performed. 


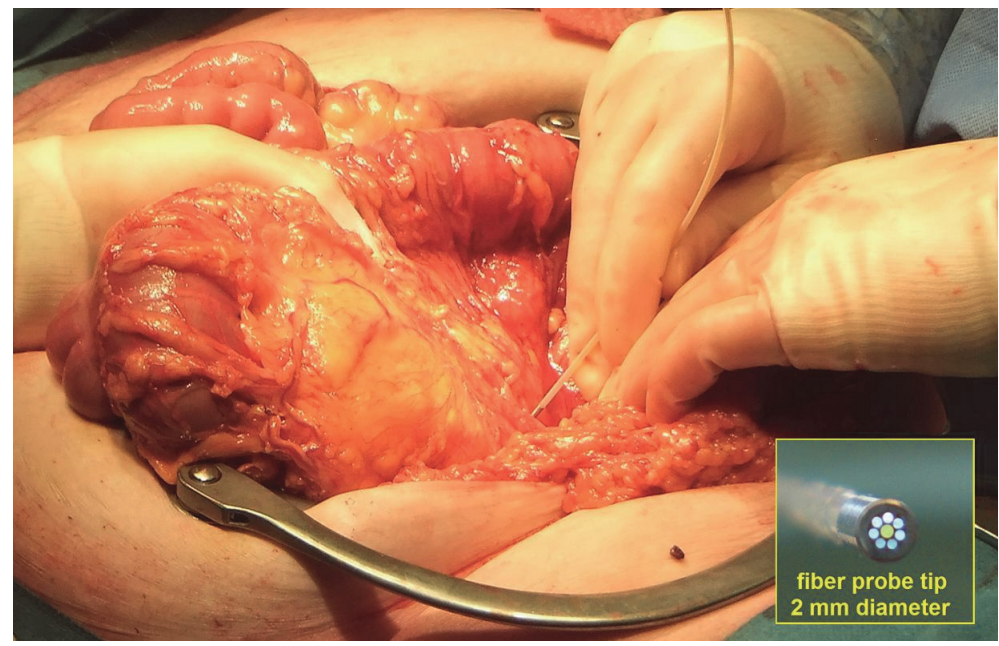

Figure 8.1 Intraoperative fiber probe measurement

Intraoperative spectral fibre probe measurement performed during a transverse colon resection (resection of a tumor in the transverse colon). The sterile optical fibre probe is gently brought into contact with one of the designated tissues. Right lower corner: close-up of the fiber probe tip. A ring light of seven fibers (illuminated white) injects light into the tissue, one central fiber (here for illustration purposes illuminated yellow) collects the diffusely reflected light and transports it towards the spectrometer.

\section{Data processing}

For inter-patient comparability, all raw in vivo spectra were corrected using the dark current and reference reflectance spectrum. Since both reflectance intensity and spectral shape are related to the composition of the tissue, no further normalization steps were performed. To identify possible distinctive features for tissue-specific enhancement, 36 features (i.e. 18 gradients and 18 amplitude differences at predefined points in the tissue spectra) were extracted based on known wavelengths related to characteristic absorption features for blood, water and fat ${ }^{28-30}$. We described these features in more detail in a previous publication ${ }^{27}$. Figure 8.2 illustrates the characteristic wavelengths and features in a mean spectrum for human mesenteric adipose tissue. All data processing was performed by in-house developed software (using MATLAB environment Version 7.7.0, MathWorks Inc., Natick, Massachussetts, USA).

Further analysis of the in vivo spectra was divided into two detector ranges: Si-detector $(\leq 1000 \mathrm{~nm})$ and InGaAs-detector ( $\geq 900 \mathrm{~nm})$. 
The number of extracted features $(n=36)$ is too large to perform a statistically meaningful classification, as the extracted features could be redundant in the information they retain. Therefore, using combinations of all 36 features to build a classifier would result in a dimensionality problem and over-fitting ${ }^{31}$. We identified the best distinctive features for classification of ureter/artery in an adipose surrounding by using binary logistic regression (SPSS Inc., Chicago, IL, USA) for both wavelength regions separately. This concerns a statistical technique that allows prediction of categorical dependent variables (i.e. the tissue type: ureter/artery versus adipose tissue) using a set of independent variables (i.e., the spectral features) ${ }^{32}$.

Using the approach for tissue classification based on hyperspectral data reported earlier by Akbari et al. $^{22}$, we used support vector machine (SVM) to classify ureter/artery within adipose surrounding. The SVM classifier was trained with a polynomial kernel function ${ }^{33}$. This classifier attempts to find an optimum line to separate the training data groups with a minimum risk ${ }^{31}$.

To estimate classification performance and to prevent overly optimistic results ${ }^{34-36}$, we implemented a cross-validation (CV) approach. With a goal to obtain the classification accuracy as a performance measure, the data set is divided into a training set (to train the classifier) and a test set (to validate the classifier). The CV approach uses leave-oneout (LOO) validation of the acquired ureter/artery and adipose hyperspectral data. This approach utilizes the same data set for both training and testing purposes and is very useful in cases of a relatively small data sample.

In-house developed classifiers (using MATLAB environment Version 7.7.0, MathWorks Inc., Natick, Massachussetts, USA) were used to estimate the classification performance by calculating sensitivity, specificity, positive predictive value, negative predictive value and accuracy for both wavelength regions (i.e. Si-sensor and InGaAs-sensor detection range). The methods used for data-processing of the in vivo hyperspectral data in this study, have previously been applied for constructing a classification system for automated nerve differentiation within adipose surrounding in another in vivo study ${ }^{27}$. 


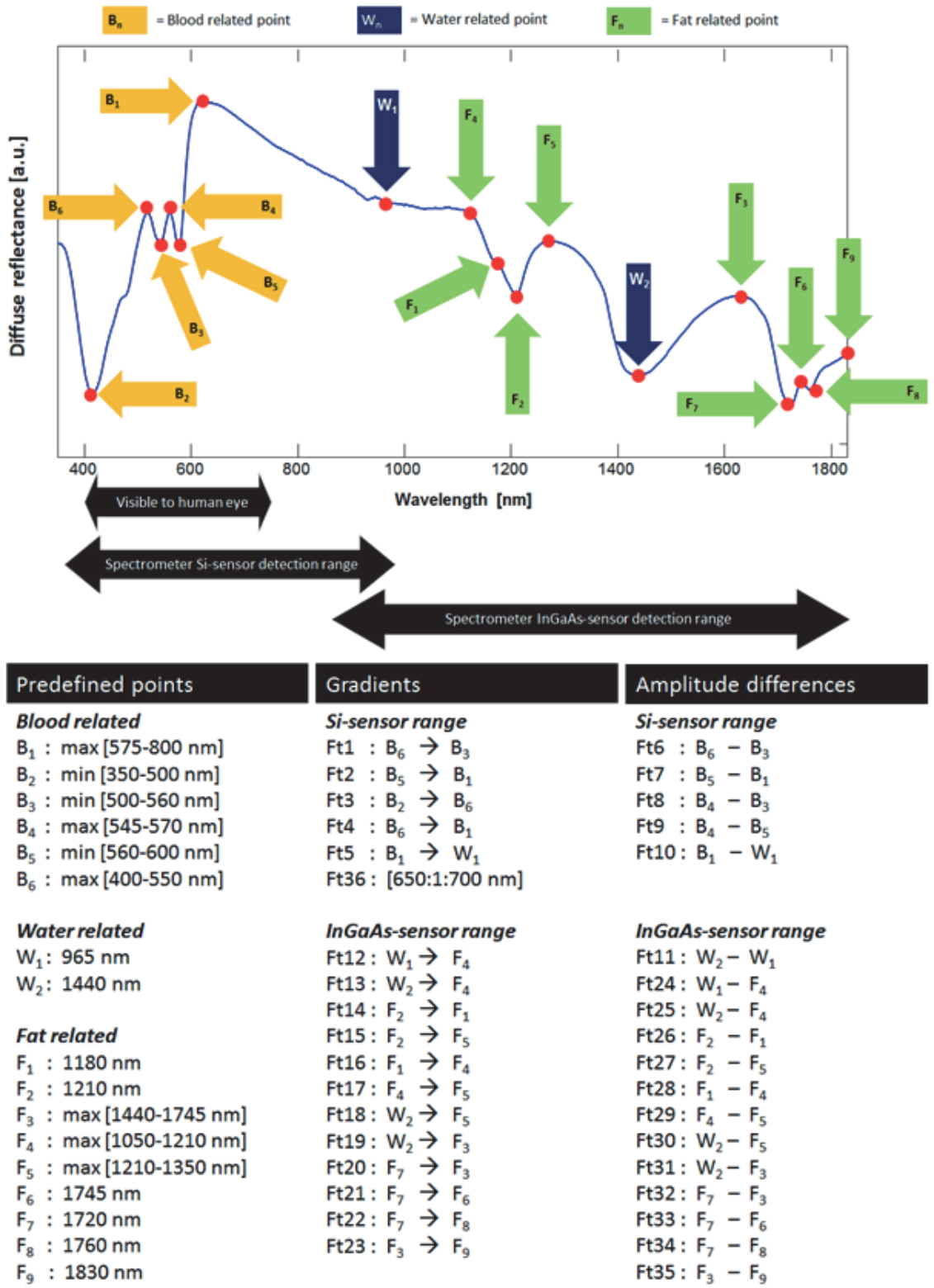

Figure 8.2 Example of spectrum (mesenteric adipose tissue) with characteristic wavelengths and investigated features

The arrows indicate qualitative landmarks for: oxygenated/reduced hemoglobin (characteristic "W-shape" between 500 and $600 \mathrm{~nm}$ ), water (absorption peaks at 965 and $1440 \mathrm{~nm}$ ) and human fat (absorption peaks at 1210 and $1720 \mathrm{~nm})^{28-30}$. The spectral detection ranges of respectively the human eye as well of Si-sensor and InGaAs-sensor based camera chips are indicated. 


\section{Results}

In 10 consecutive patients ( 5 male, 5 female) undergoing open colorectal surgery 253 in vivo tissue spectra were recorded on 53 tissue sites (colon $n=12$, adipose $n=9$, muscle $n=7$, artery $n=10$, vein $n=8$, ureter $n=7$ ). Table 8.1 summarizes patient characteristics and the number of measured sites and spectra per tissue type. Figure 8.3 shows mean diffuse reflectance spectra for colon, adipose, muscle, artery, vein and ureter. In respectively Figure $8.4 \mathrm{~A}$ and $8.4 \mathrm{~B}$ mean spectra, with corresponding standard deviations, for ureter and artery are plotted paired with adipose tissue.

\section{Classification of spectral data in Si-detector response range}

From the 36 extracted features (see Figure 8.2) 11 were located within the silicon detection range. Given the study sample of an average of 10 spots per tissue type, inclusion of maximum 1 feature is allowed. Binary logistic regression identified amplitude difference Ft6 $\left(B_{6}-B_{3}\right)$ as best distinctive feature for differentiation of ureter from adipose tissue. Gradient Ft4 $\left(B_{6}-B_{1}\right)$ was found to be best distinctive for differentiation of artery within mesenteric adipose tissue. Figure 8.5A and 8.5B show box plots for these Si-detector based features, extracted for respectively ureter versus adipose tissue and artery versus adipose tissue.

The quantitative results of classification performance are listed in Table 8.2. LOO crossvalidation is based on Si-detector range data acquired during colorectal surgery for train and test purposes.

\section{Classification of spectral data in InGaAs-detector response range}

From the 36 extracted features 25 were located within the spectral detection range of InGaAs (see Figure 8.2). After binary logistic regression, amplitude difference Ft35 $\left(F_{3}-F_{9}\right)$ was selected as the most promising feature for differentiation of ureter from adipose tissue. For differentiation of artery from adipose tissue, gradient Ft13 $\left(\mathrm{W}_{2}-\mathrm{F}_{4}\right)$ was identified as best distinctive feature. Figure 8.6A and 8.6B show box plots for these InGaAs-detector based features, extracted for respectively ureter versus adipose tissue and artery versus adipose tissue.

The quantitative results of LOO cross-validation classification performance are listed in Table 8.3. LOO cross-validation is solely based on InGaAs-detector range data acquired during colorectal surgery for train and test purposes. 


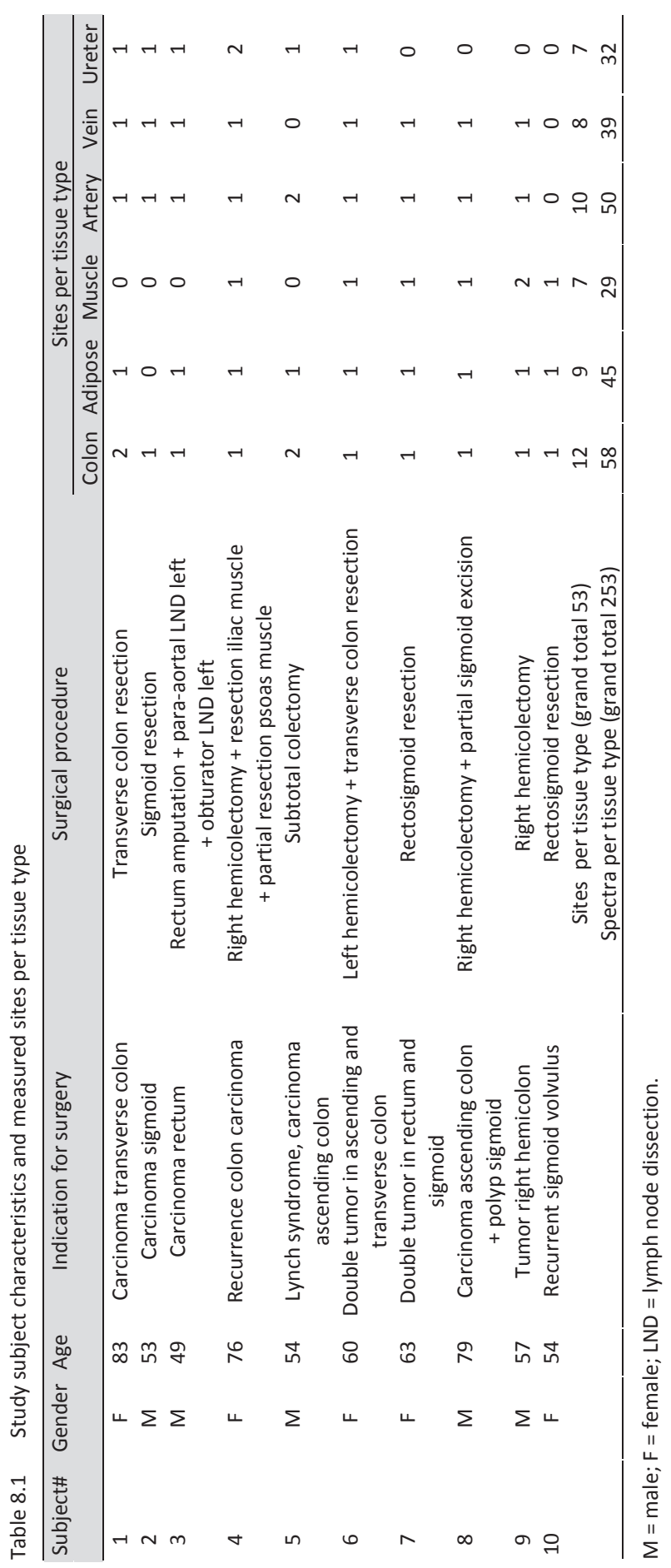




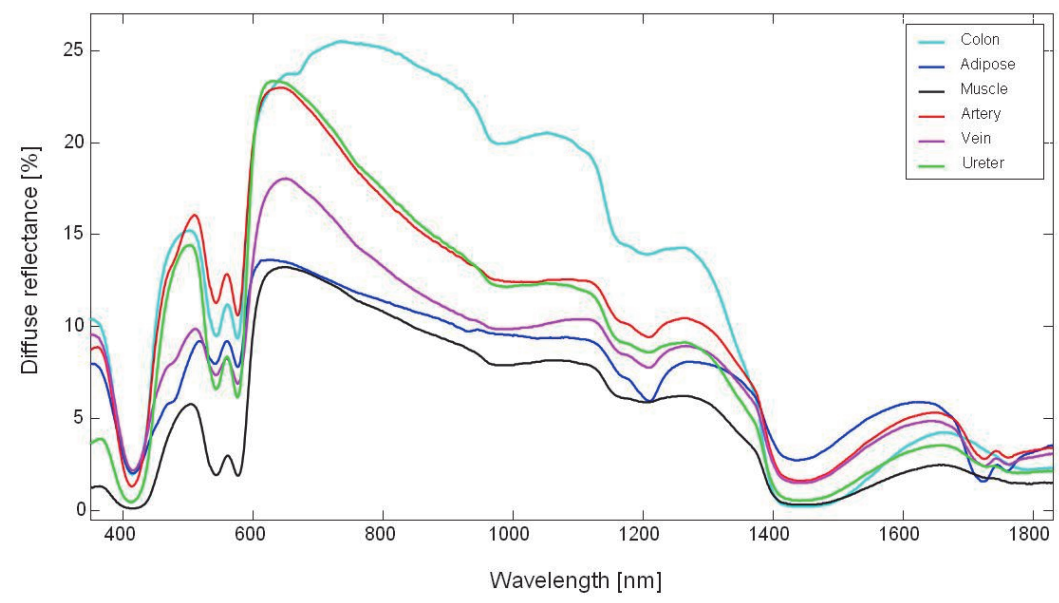

Figure 8.3 Mean spectra per tissue type acquired during colorectal surgery

Average tissue spectra for ureter (green), mesenteric adipose tissue (dark blue), artery (red), colon (light blue), muscle (black) and vein (purple).

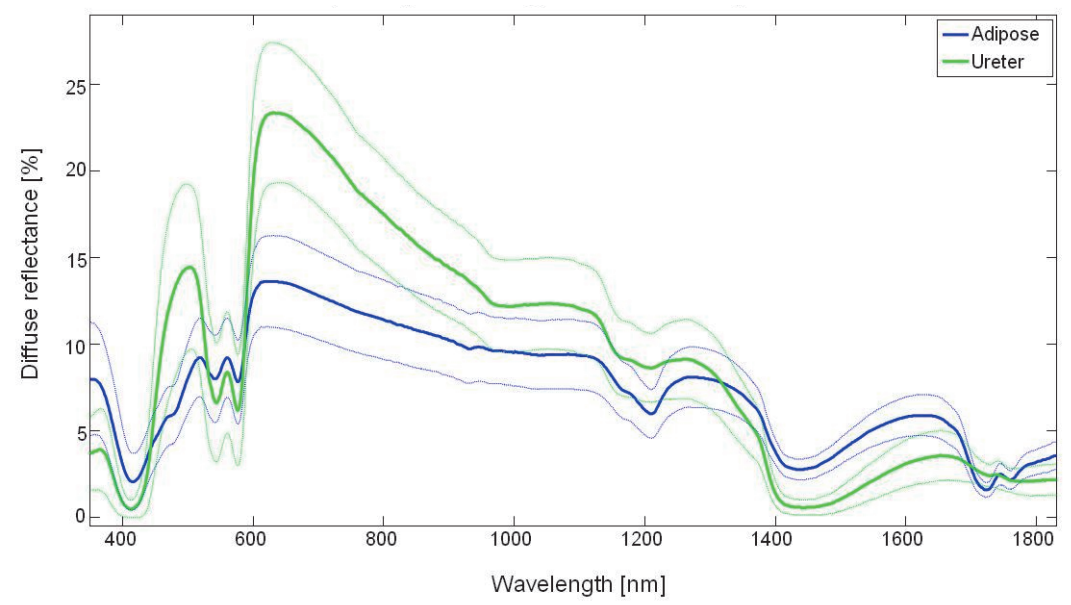

Figure 8.4A Mean spectra of ureter and adipose tissue

Average tissue spectra for ureter (green) and mesenteric adipose tissue (dark blue). Dashed lines in the corresponding colors indicate the respective standard deviations. 


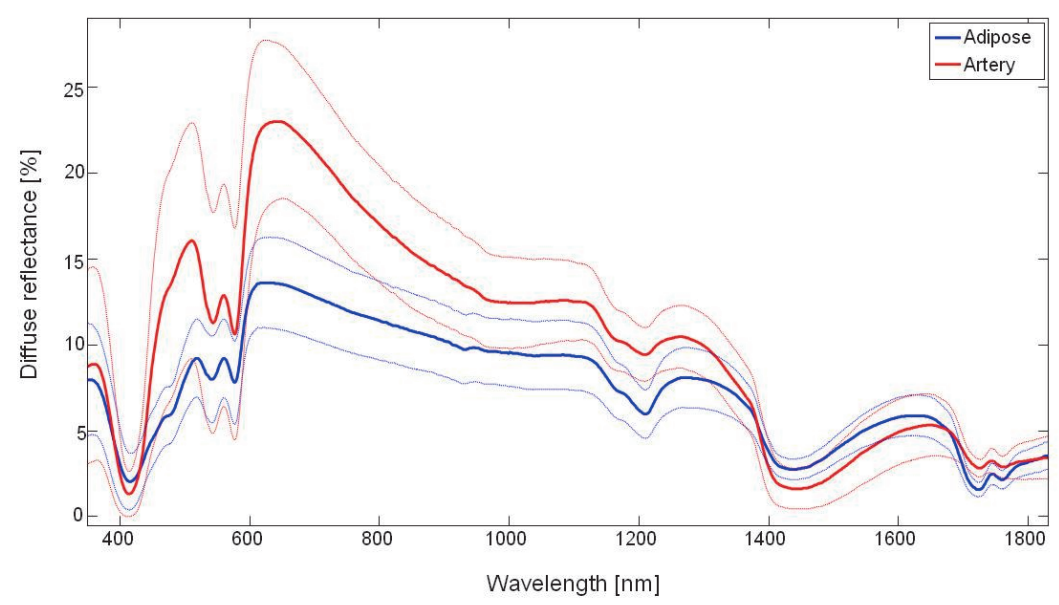

Figure 8.4B Mean spectra of artery and adipose tissue

Average tissue spectra for artery (red) and mesenteric adipose tissue (dark blue). Dashed lines in the corresponding colors indicate the respective standard deviations.
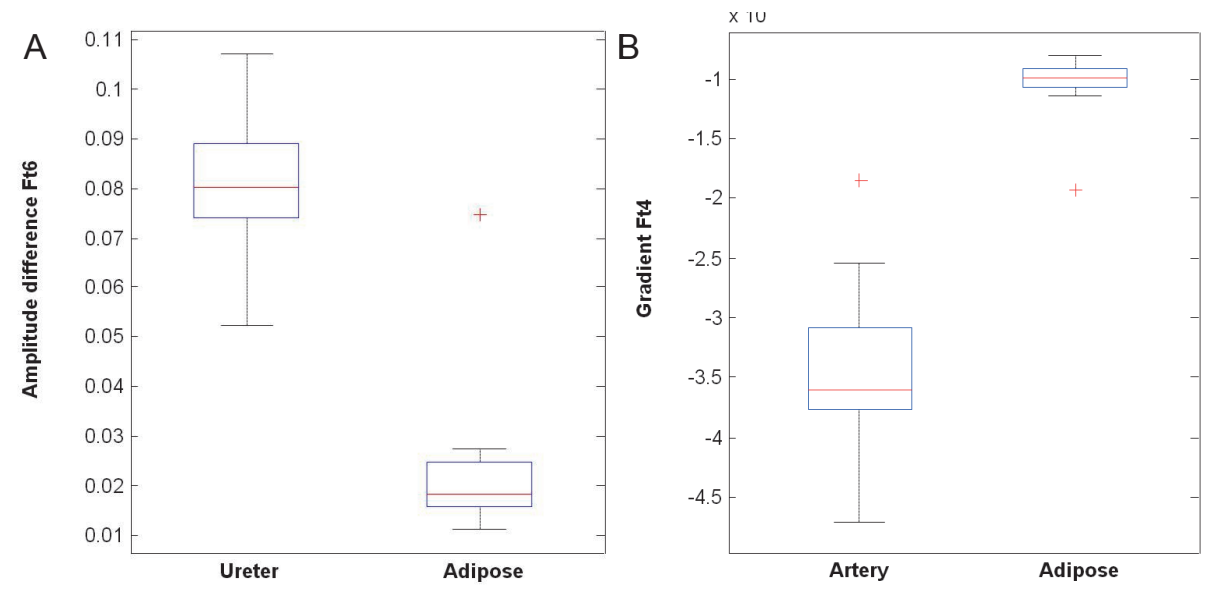

$\begin{array}{lll}\text { Figure } 8.5 & \text { A) Box plots of selected features within Si-range }\end{array}$ Ureter versus adipose tissue: box plot showing selected feature, amplitude difference Ft6 B) Box plots of selected features within Si-range Artery versus adipose tissue: box plot showing selected feature, gradient Ft4. 
Table 8.2 Classification performance of selected Si-detector features

\begin{tabular}{lccccccc}
\hline LOO CV & TP & TN & Sensitivity & Specificity & PPV & NPV & Accuracy \\
\hline Ureter - Adipose tissue & $7 / 7$ & $9 / 9$ & $100(56-100)$ & $100(63-100)$ & $100(56-100)$ & $100(63-100)$ & 100 \\
Artery - Adipose tissue & $9 / 10$ & $9 / 9$ & $90(54-99)$ & $100(63-100)$ & $100(63-100)$ & $90(54-99)$ & 95 \\
\hline
\end{tabular}

$\mathrm{TP}=$ true positive; $\mathrm{TN}=$ true negative $\rightarrow$ numbers indicate identified tissue spots. A positive test is defined as the tissue observed being either ureter or artery; a negative test is defined as the tissue observed being adipose tissue. Sensitivity; specificity; PPV = positive predictive value; NPV = negative predictive value; accuracy $\rightarrow$ numbers are percentages; numbers in parentheses indicate $95 \%$ confidence interval. LOO CV = leave-one-out cross-validation.
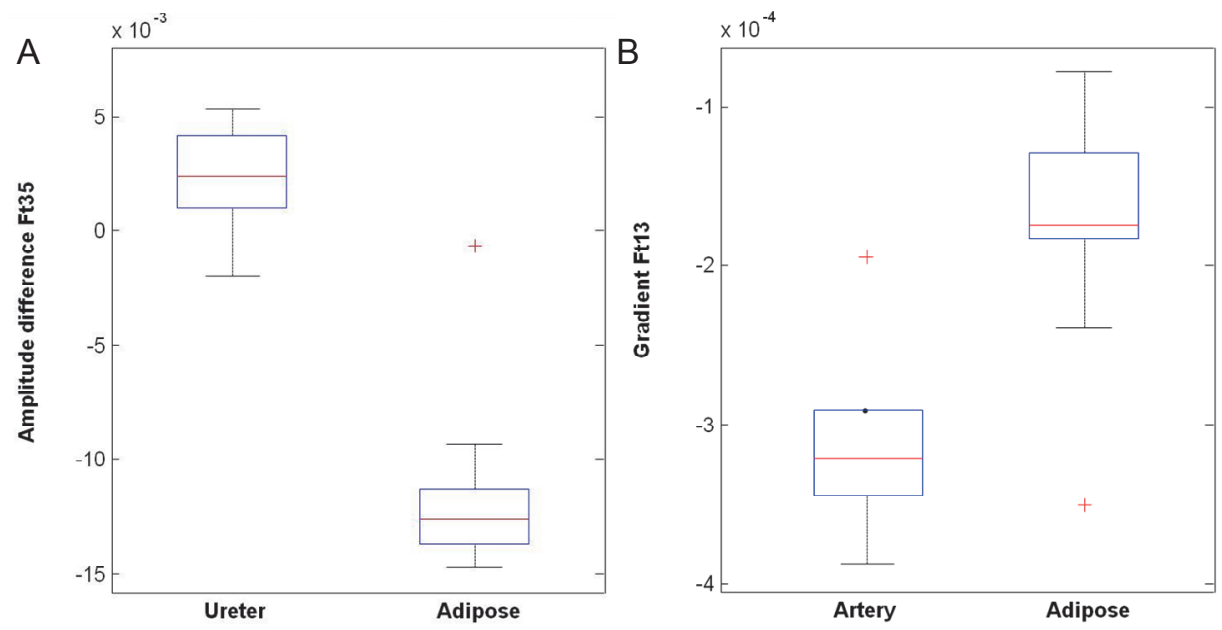

Figure $8.6 \quad$ A) Box plots of selected features within InGaAs-range.

Ureter versus adipose tissue: box plot showing selected feature, amplitude difference Ft35.

B) Box plots of selected features within InGaAs-range.

Artery versus adipose tissue: box plot showing selected feature, gradients Ft13.

Table 8.3 Classification performance of selected InGaAs-detector features

\begin{tabular}{lccccccc}
\hline LOO CV & TP & TN & Sensitivity & Specificity & PPV & NPV & Accuracy \\
\hline Ureter - Adipose tissue & $7 / 7$ & $9 / 9$ & $100(56-100)$ & $100(63-100)$ & $100(56-100)$ & $100(63-100)$ & 100 \\
Artery - Adipose tissue & $9 / 10$ & $8 / 9$ & $90(54-99)$ & $89(51-99)$ & $90(54-99)$ & $89(51-99)$ & 89 \\
\hline
\end{tabular}

$\mathrm{TP}=$ true positive; $\mathrm{TN}=$ true negative $\rightarrow$ numbers indicate identified tissue spots. A positive test is defined as the tissue observed being either ureter or artery; a negative test is defined as the tissue observed being adipose tissue. Sensitivity; specificity; PPV = positive predictive value; NPV = negative predictive value; accuracy $\rightarrow$ numbers are percentages; numbers in parentheses indicate $95 \%$ confidence interval.

LOO CV = leave-one-out cross-validation. 


\section{Discussion}

With this explorative study we revealed in vivo wide-band diffuse reflectance spectra (350 - $1830 \mathrm{~nm}$, with $1 \mathrm{~nm}$ spectral resolution) of six tissue types within the human abdomen: colon, muscle, artery, vein, ureter and mesenteric adipose tissue. These spectra covered silicon (Si) and indium gallium arsenide (InGaAs) detector ranges, thereby exceeding wavelength boundaries (1600 $\mathrm{nm}$ respectively $1700 \mathrm{~nm}$ ) reported by preceding work ${ }^{22,23,37,38}$. Spectroscopic measurements on human skin samples in the wavelength range of $1000-2200 \mathrm{~nm}$ have been reported previously ${ }^{39}$, but not regarding any of the tissues included by our study. Previously we reported DRS on freshly extirpated human colonic specimens, where vascular filling and oxygenation were disrupted $^{26}$. The present in vivo study eliminates this shortcoming.

Although the acquired reflectance spectra (Figure 8.3) show some similarities between the different tissue types, we reached promising results for automated tissue-specific classification (ureter and artery from surrounding adipose tissue) in both sensor ranges (i.e., Si and InGaAs). Based on the classification accuracies (Tables 8.2 and Table 8.3) we can conclude that $\mathrm{Si}$ and InGaAs sensors are equally suited for automated discrimination between ureters and surrounding adipose tissue. Si sensors seem better suited for differentiation of arteries from mesenteric adipose tissue than InGaAs sensors.

For both classifications (i.e. ureter-adipose and artery-adipose) in the Si sensor range, the blood-related features (Figure 8.5, respectively Ft6 and Ft4) demonstrate the best results. Within the InGaAs sensor range, water-related and fat-related features (Figure 8.6, respectively $\mathrm{Ft} 35$ and Ft13) classified ureter and artery most accurately. The features used for classification are potentially significant due to differences in chemical composition (e.g., water/lipid content) of the investigated tissues and structures.

Near-infrared fluorescence imaging using exogenous contrast agents has been demonstrated as useful for real-time, intraoperative visualization of ureters $^{7-9}$ and arteries $^{10-12}$. In our study the diffuse reflectance spectra were the basis to extract gradient and amplitude difference features. These spectra originate from intrinsic tissue properties (i.e., endogenous chromophores) that do not require contrast administration. Consequently, there are no problems with potential toxicity or allergy to a contrast agent.

Future studies, comparing optical techniques based on either exogenous contrasts (e.g. near-infrared fluorescence imaging) or endogenous contrasts (e.g. diffuse reflectance spectroscopy) contrasts, are necessary to disclose the clinical applications for these techniques. 
As this study describes an initial exploration towards future spectral imaging guided surgery, providing an indication of the procedural costs of optical guidance during surgery, based on diffuse reflectance spectroscopy or hyperspectral imaging technique, is rather difficult at this moment. However, it is reasonably to expect that costs will be in the same range as already commercially available imaging systems for image-guided surgery, such as near-infrared fluorescence imaging. An advantage of endogenous contrast based imaging is that there is no need for administration of a contrast agent, which already results in a cost-reduction compared to e.g. near-infrared fluorescence imaging technique.

Spectral imaging using absolute signal intensity to classify tissues ${ }^{22}$ might experience problems with robustness regarding variations in conditions in the operation room (e.g. operating theatre light intensity). We explored the spectral tissue signatures by extraction of relative spectral features from DRS signal which are quite robust with regard to variations in signal intensity ${ }^{27}$.

Although the study sample was reasonable and justifiable in research setting (from a statistical point of view), we only describe experience in ten study subjects. From a practical perspective a more extensive study is needed to judge the full clinical relevance in daily practice.

As the LOO cross-validation method inherently produces relatively optimistic classification results, external validation remains essential before classification models can be implemented in clinical practice ${ }^{40}$. Such validation would need to be performed on newly acquired data in a multi-center study.

In this study, we use physiological knowledge on composition of different tissue types, and thereby use the pre-defined spectral regions of interest covering water, fat and hemoglobin. Tissue differentiation on the basis of completely automatically extracted features from a larger data set might achieve better results, and should be explored in future work. Additionally, as the acquired reflectance spectra are specific to the probe geometry, more research is needed on the relation between these reflectance spectra and in vivo intrinsic tissue biological properties which potentially could be captured by optical tissue properties. This is needed to obtain a better understanding of the nature of discrimination performance: i.e. whether ureters and arteries can be optically distinguished from surrounding adipose tissues based on differences in light scattering behaviour (related to structural differences) or due to differences in absorption behaviour (related to chromophore concentrations such as blood, water and fat). Such an approach would also be tissue-specific and robust to inter-patient and multi-center variability.

The gold standard used in this study was the surgeon's visual judgment. This judgment is based on color (spectral) information, on the recognition of anatomical position and 
on spatial structure of a specific tissue, and palpation. For our technique to add most to this judgment, it should be extended from spot-wise probe-measurements to full field imaging of the whole surgical field. Furthermore, additional value is gained when tissue classification is enhanced even in cases where a ureter or artery is covered under a layer of fatty or connective tissue. This also needs further investigation.

\section{Conclusions}

In this study we have identified that Si and InGaAs sensors are equally suited for automated discrimination between ureters and surrounding adipose tissue. Furthermore, Si sensors are slightly better for artery versus mesenteric adipose tissue differentiation. Our results underline the potential for automated (hyper-)spectral classification of ureter and artery in adipose surroundings using relative spectral features in the DRS signal. 


\section{References}

1. Palaniappa NC, Telem DA, Ranasinghe NE, Divino CM (2012) Incidence of iatrogenic ureteral injury after laparoscopic colectomy. Arch Surg 147:267-271

2. Abboudi H, Ahmed K, Royle J, Khan MS, Dasgupta P, N'Dow J (2013) Ureteric injury: a challenging condition to diagnose and manage. Nat Rev Urol 10:108-115

3. Assimos DG, Patterson LC, Taylor CL (1994) Changing incidence and etiology of iatrogenic ureteral injuries. J Urol 152:2240-2246

4. Allison AS, Bloor C, Faux W, Arumugam P, Widdison A, Lloyd-Davies E, Maskell G (2010) The angiographic anatomy of the small arteries and their collaterals in colorectal resections: some insights into anastomotic perfusion. Ann Surg 251:1092-1097

5. Krarup PM, Jorgensen LN, Harling H, Danish Colorectal Cancer G (2014) Management of anastomotic leakage in a nationwide cohort of colonic cancer patients. Journal of the American College of Surgeons 218:940-949

6. Bakker IS, Grossmann I, Henneman D, Havenga K, Wiggers T (2014) Risk factors for anastomotic leakage and leak-related mortality after colonic cancer surgery in a nationwide audit. Br J Surg 101:424-432

7. Schols RM, Lodewick TM, Bouvy ND, van Dam GM, Dejong CH, Stassen LP (2014) Application of a new dye for near-infrared fluorescence laparoscopy of the ureters: demonstration in a pig model. Dis Colon Rectum 57:407-411

8. Matsui A, Tanaka E, Choi HS, Kianzad V, Gioux S, Lomnes SJ, Frangioni JV (2010) Real-time, nearinfrared, fluorescence-guided identification of the ureters using methylene blue. Surgery 148:78-86

9. Verbeek FP, van der Vorst JR, Schaafsma BE, Swijnenburg RJ, Gaarenstroom KN, Elzevier HW, van de Velde CJ, Frangioni JV, Vahrmeijer AL (2013) Intraoperative near infrared fluorescence guided identification of the ureters using low dose methylene blue: a first in human experience. J Urol 190:574-579

10. Cahill RA, Ris F, Mortensen NJ (2011) Near-infrared laparoscopy for real-time intra-operative arterial and lymphatic perfusion imaging. Colorectal Dis 13 Suppl 7:12-17

11. Schols RM, Bouvy ND, van Dam RM, Masclee AA, Dejong CH, Stassen LP (2013) Combined vascular and biliary fluorescence imaging in laparoscopic cholecystectomy. Surg Endosc 27:4511-7

12. Ashitate Y, Stockdale A, Choi HS, Laurence RG, Frangioni JV (2012) Real-time simultaneous nearinfrared fluorescence imaging of bile duct and arterial anatomy. J Surg Res 176:7-13

13. Huang W, Lamb DW, Niu Z, Zhang Y, Liu L, Wang L (2007) Identification of yellow rust in wheat using insitu spectral reflectance measurements and airborne hyperspectral imaging. Precision Agriculture 8:187-197

14. Hively WD, McCarty GW, Reeves JB, Lang MW, Oesterling RA, Delwiche SR (2011) Use of Airborne Hyperspectral Imagery toMap Soil Properties in Tilled Agricultural Fields. Applied and Environmental Soil Science 2011:Article ID 358193

15. Yuen PWT, Richardson M (2010) An introduction to hyperspectral imaging and its application for security, surveillance and target acquisition. The Imaging Science Journal 58:241-253

16. Lu G, Fei B (2014) Medical hyperspectral imaging: a review. J Biomed Opt 19:10901

17. Wieringa FP, Mastik F, Duncker DJ, Bogers AJ (2006) Contrast enhancement of coronary arteries in cardiac surgery: a new multispectral stereoscopic camera technique. Eurolntervention : journal of EuroPCR in collaboration with the Working Group on Interventional Cardiology of the European Society of Cardiology 2:389-394

18. Holzer MS, Best SL, Jackson N, Thapa A, Raj GV, Cadeddu JA, Zuzak KJ (2011) Assessment of renal oxygenation during partial nephrectomy using hyperspectral imaging. J Urol 186:400-404

19. Olweny EO, Faddegon S, Best SL, Jackson N, Wehner EF, Tan YK, Zuzak KJ, Cadeddu JA (2013) Renal oxygenation during robot-assisted laparoscopic partial nephrectomy: characterization using laparoscopic digital light processing hyperspectral imaging. J Endourol 27:265-269

20. Zuzak KJ, Naik SC, Alexandrakis G, Hawkins D, Behbehani K, Livingston E (2008) Intraoperative bile duct visualization using near-infrared hyperspectral video imaging. Am J Surg 195:491-497 
21. Panasyuk SV, Yang S, Faller DV, Ngo D, Lew RA, Freeman JE, Rogers AE (2007) Medical hyperspectral imaging to facilitate residual tumor identification during surgery. Cancer Biol Ther 6:439-446

22. Akbari H, Kosugi Y, Kojima K, Tanaka N (2009) Blood vessel detection and artery-vein differentiation using hyperspectral imaging. Conf Proc IEEE Eng Med Biol Soc 2009:1461-1464

23. Cao Q, Zhegalova NG, Wang ST, Akers WJ, Berezin MY (2013) Multispectral imaging in the extended near-infrared window based on endogenous chromophores. J Biomed Opt 18:101318

24. Zonios G, Perelman LT, Backman V, Manoharan R, Fitzmaurice M, Van Dam J, Feld MS (1999) Diffuse reflectance spectroscopy of human adenomatous colon polyps in vivo. Applied optics 38:6628-6637

25. Wang HW, Jiang JK, Lin CH, Lin JK, Huang GJ, Yu JS (2009) Diffuse reflectance spectroscopy detects increased hemoglobin concentration and decreased oxygenation during colon carcinogenesis from normal to malignant tumors. Optics express 17:2805-2817

26. Schols RM, Dunias P, Wieringa FP, Stassen LP (2013) Multispectral characterization of tissues encountered during laparoscopic colorectal surgery. Med Eng Phys 35:1044-1050

27. Schols RM, ter Laan M, Stassen LP, Bouvy ND, Amelink A, Wieringa FP, Alic L (2014) Differentiation between nerve and adipose tissue using wide-band $(350-1830 \mathrm{~nm})$ in vivo diffuse reflectance spectroscopy. Lasers in Surgery and Medicine 46:538-545

28. Zijlstra WG, Buursma A, Meeuwsen-van der Roest WP (1991) Absorption spectra of human fetal and adult oxyhemoglobin, de-oxyhemoglobin, carboxyhemoglobin, and methemoglobin. Clin Chem 37:1633-1638

29. Anderson RR, Farinelli W, Laubach H, Manstein D, Yaroslavsky AN, Gubeli J, 3rd, Jordan K, Neil GR, Shinn M, Chandler W, Williams GP, Benson SV, Douglas DR, Dylla HF (2006) Selective photothermolysis of lipid-rich tissues: a free electron laser study. Lasers Surg Med 38:913-919

30. Roggan A, Friebel M, Do Rschel K, Hahn A, Mu Ller G (1999) Optical Properties of Circulating Human Blood in the Wavelength Range 400-2500 nm. J Biomed Opt 4:36-46

31. Boser BE, Guyon IM, Vapnik VN (1992) A Training Algorithm for Optimal Margin Classifiers. Proceedings of the 5th Annual ACM Workshop on Computational Learning Theory:144-152

32. Tabachnick BG, Fidell LS (2007) Using multivariate statistics, 5th edn, Allyn-Bacon, Boston, MA

33. Mercier G, Lennon M (2003) Support vector machines for hyperspectral image classification with spectral-based kernels. Geoscience and Remote Sensing Symposium, 2003 IGARSS '03 Proceedings 2003 IEEE International 1:288-290

34. Stelzle F, Zam A, Adler W, Tangermann-Gerk K, Douplik A, Nkenke E, Schmidt M (2011) Optical nerve detection by diffuse reflectance spectroscopy for feedback controlled oral and maxillofacial laser surgery. J Transl Med 9:20

35. Stelzle F, Tangermann-Gerk K, Adler W, Zam A, Schmidt M, Douplik A, Nkenke E (2010) Diffuse reflectance spectroscopy for optical soft tissue differentiation as remote feedback control for tissuespecific laser surgery. Lasers Surg Med 42:319-325

36. Stelzle F, Adler W, Zam A, Tangermann-Gerk K, Knipfer C, Douplik A, Schmidt M, Nkenke E (2012) In vivo optical tissue differentiation by diffuse reflectance spectroscopy: preliminary results for tissue-specific laser surgery. Surg Innov 19:385-393

37. Nachabe R, Hendriks BH, van der Voort M, Desjardins AE, Sterenborg HJ (2010) Estimation of biological chromophores using diffuse optical spectroscopy: benefit of extending the UV-VIS wavelength range to include 1000 to $1600 \mathrm{~nm}$. Biomed Opt Express 1:1432-1442

38. Nachabe R, Hendriks BH, Desjardins AE, van der Voort M, van der Mark MB, Sterenborg HJ (2010) Estimation of lipid and water concentrations in scattering media with diffuse optical spectroscopy from 900 to 1,600 nm. J Biomed Opt 15:037015

39. Troy TL, Thennadil SN (2001) Optical properties of human skin in the near infrared wavelength range of 1000 to $2200 \mathrm{~nm}$. J Biomed Opt 6:167-176

40. Bleeker SE, Moll HA, Steyerberg EW, Donders AR, Derksen-Lubsen G, Grobbee DE, Moons KG (2003) External validation is necessary in prediction research: a clinical example. J Clin Epidemiol 56:826-832 
Automated spectroscopic tissue classification in colorectal surgery 


\section{Chapter}

Differentiation between nerve and adipose tissue using wide-band $(350-1830 \mathrm{~nm})$ in vivo diffuse reflectance spectroscopy

Schols RM, ter Laan M, Stassen LP, Bouvy ND, Amelink A, Wieringa FP, Alic L Lasers in Surgery and Medicine 2014;46:538-545 


\begin{abstract}
Background

Intraoperative nerve localization is of great importance in surgery. In certain procedures, where nerves show visual resemblance to surrounding adipose tissue, this can be particularly challenging for the human eye. An example of such a delicate procedure is thyroid and parathyroid surgery, where iatrogenic injury of the recurrent laryngeal nerve can result in transient or permanent vocal problems $(0.5-2.0 \%$ reported incidence). A camera system, enabling nerve-specific image enhancement, would be useful in preventing such complications. This might be realized with hyperspectral camera technology using silicon (Si) or indium gallium arsenide (InGaAs) sensor chips.
\end{abstract}

\title{
Methods
}

As a first step towards such a camera, we evaluated the performance of diffuse reflectance spectroscopy by analysing spectra collected during 18 thyroid and parathyroid resections. We assessed the contrast information present in two different spectral ranges, for respectively $\mathrm{Si}$ and InGaAs sensors. 253 in vivo, wide-band diffuse reflectance spectra ( $350-1830 \mathrm{~nm}$ range, $1 \mathrm{~nm}$ resolution) were acquired on 52 tissue spots, including nerve $(n=22)$, muscle $(n=12)$ and adipose tissue $(n=18)$. We extracted 36 features from these spectroscopic data: 18 gradients and 18 amplitude differences at predefined points in the tissue spectra. Best distinctive feature combinations were established using binary logistic regression. Classification performance was evaluated in a cross-validation (CV) approach by leave-one-out (LOO). To generalize nerve recognition applicability, we performed a train-test (TT) validation using the thyroid and parathyroid surgery data for training purposes and carpal tunnel release surgery data (10 nerve spots and 5 adipose spots) for classification purposes.

\section{Results}

For combinations of two distinctive spectral features, LOO revealed an accuracy of respectively $78 \%$ for Si-sensors and $95 \%$ for InGaAs-sensors. TT revealed accuracies of respectively $67 \%$ and $100 \%$.

\section{Conclusion}

Using diffuse reflectance spectroscopy we have identified that InGaAs sensors are better suited for automated discrimination between nerves and surrounding adipose tissue than Si sensors. 


\section{Introduction}

The ability to visually distinguish vital anatomy, such as nerve tissue, is of great importance during all surgical procedures. There is a wide variety of procedures with a realistic chance of peroperative nerve injury that may result in temporary or permanent dysfunction of motor or sensory nerves. Extra caution is, for example, required during complicated surgical procedures like thyroidectomy ${ }^{1}$ and total mesorectal excision ${ }^{2,3}$, but also during less difficult procedures such as inguinal hernia repair ${ }^{4}$. When spatial perception from direct sight and haptic feedback from direct touch are lacking (e.g. during minimally invasive surgery) nerve identification can be even more challenging than during delicate open surgery. Therefore, a reliable tool to enhance the contrast of nerve tissue from its surroundings is desirable for improved intraoperative nerve detection and preservation. Exploring optical spectroscopy techniques might offer a roadmap towards such a tool.

Aerospace science combines hyperspectral camera technology, with pre-acquired library spectra recorded on the earth surface, to generate satellite images for discovering places of interest for e.g. agricultural purposes ${ }^{5,6}$ and military and homeland security applications ${ }^{7}$. Furthermore, hyperspectral imaging incorporates potential to facilitate image-guided surgery $^{8}$. It has, for example, been investigated for noninvasive intraoperative assessment of renal oxygenation (i.e., tissue oxygen saturation) during partial nephrectomy ${ }^{9,10}$, for intraoperative enhancement of biliary imaging (i.e., anatomical imaging) during laparoscopic cholecystectomy ${ }^{11}$ and for intraoperative assessment of resection margins for residual tumor tissue (i.e., tumor detection) in breast cancer surgery ${ }^{12}$.

Arrays of Charge-Coupled Devices (CCD) and Complementary Metal Oxide Semiconductors (CMOS) are the most commonly used detectors (camera chips) in medical hyperspectral imaging systems, which can be composed of silicon (Si) and indium gallium arsenide (InGaAs) sensors. Si sensors cover the wavelength range of $400-1000 \mathrm{~nm}$, whereas InGaAs sensors are typically sensitive in the $900-1700 \mathrm{~nm}$ wavelength region and depending on the amount of Indium-doping the longer wavelength boundary can shift up to $2500 \mathrm{~nm}^{8}$.

Intraoperative recurrent laryngeal nerve (RLN) identification before removal of the thyroid gland is of great importance. The RLN diameter is on average $2 \mathrm{~mm}^{13}$. In a retrospective analysis of 5104 primary and 685 secondary thyroidectomies, transient vocal problems as a consequence of RLN palsy occurred in respectively $2 \%$ and $1 \%$ of cases (permanent in $0.5 \%$ and $1.5 \%$ ). Furthermore the rate of permanent complications was found to be significantly higher in reoperative surgery ${ }^{14}$. Routine visual RLN identification currently remains the gold standard for preventing iatrogenic nerve injury 
during thyroid surgery ${ }^{15}$. Intraoperative EMG-based nerve monitoring $\left(\right.$ IONM) ${ }^{16}$, has been introduced to improve the incidence of RLN palsy. However, so far no significant benefit of IONM above visual inspection alone has been found ${ }^{17}$.

Optical spectroscopy techniques have shown potential for differentiation of biological tissues as a basis for a feedback system to enhance nerve preservation in oral and maxillofacial surgery ${ }^{18}$. Ex vivo ${ }^{18,19}$ and in vivo ${ }^{20}$ spectroscopic measurements $(350-650$ $\mathrm{nm}$ ) have been performed on skin, fat, muscle and nerve tissues during animal experiments. ROC analysis (after leave-one-out cross-validation) showed that almost all tissue types could be differentiated very well (accuracies of up to $100 \%$ ) by diffuse reflectance spectroscopy, followed by principal component analysis and linear discriminant analysis. However this study was performed on a limited number of animals. From ex vivo and in vivo experiments in a swine model, Nachabé et al. ${ }^{21,22}$ showed the benefit of extending the ultraviolet and visible wavelength range into the infrared, up to $1600 \mathrm{~nm}$, providing additional information regarding tissue concentrations of the biological chromophores water and lipid. Cao et al. underlined the potential of multispectral imaging in the so-called extended near-infrared window based upon these endogenous chromophores ${ }^{23}$.

The present study is a first fibre-optic wide band $(350-1830 \mathrm{~nm})$ in vivo human spectrometric exploration, with the ultimate long term goal of obtaining nerve-specific image enhancement during surgery. We use signal-intensity independent features derived from spectroscopic data acquired during thyroid and parathyroid surgery. To explore the robustness of the classification, we tested the performance using the spectral data from nerve tissue in a different anatomical region, acquired during carpal tunnel release surgery.

\section{Methods}

In vivo human tissue measurements were performed at the Department of Surgery of Maastricht University Medical Center (MUMC, Maastricht, The Netherlands) during thyroid and parathyroid surgery (surgeon N.D.B.) and at the Department of Neurosurgery of Canisius Wilhelmina Hospital (CWZ, Nijmegen, The Netherlands) during carpal tunnel release procedures (surgeon M.t.L.). Prior to measurements, approvals were granted by the local institutional review boards of Maastricht University Medical Center (registration number METC 10-4-035) and Radboud University Nijmegen Medical Center (registration number 2012/446), and preoperative written informed consent was obtained from all patients. 


\section{Material}

Diffuse reflectance spectra were acquired using custom developed sterile disposable optical fibre probes (TNO, Eindhoven the Netherlands \& Light Guide Optics, Rheinbach Germany), a modified Xenon light source (D-light C, Karl Storz, Tuttlingen Germany), and a spectrometer (Analytical Spectral Devices, Inc., Colorado USA) equipped with two sensor technologies: a silicon ( $\mathrm{Si}$ ) based sensor and an indium gallium arsenide (InGaAs) based sensor (cross-over point at $1000 \mathrm{~nm}$ ). The fibre probe transports the light from the light source to the tissue and from the tissue to the spectrometer. The spectrometer acquires the spectral data in the range of $350-1830 \mathrm{~nm}$ with $1 \mathrm{~nm}$ spectral resolution. The system was installed on a compact trolley to facilitate in vivo tissue measurements during routine surgery. The setup was tested and approved according to the essential requirements of IEC 60601-1 to assure patient safety. The equipment previously has been described in more detail ${ }^{24}$.

Figure 9.1 shows the fibre probe tip composed of eight small optical fibres: One central receiving fibre (400 um diameter, NA $0.22 \pm 0.02$ ) and seven illuminating fibres (300 um diameter, NA $0.22 \pm 0.02$ ). The rigid stainless steel probe tip has a $2 \mathrm{~mm}$ diameter and a length of $10 \mathrm{~mm}$. The remaining length of the sterile fibre probe is flexible.

\section{In vivo data acquisition}

During respectively thyroid and parathyroid surgery and carpal tunnel release surgery, in vivo wide-band diffuse reflectance spectra were collected. For each tissue type, we recorded five spectra per site (taking 30 seconds per site) covering at least one site per tissue type (see also Table 9.1). The sterile fibre probe was handled by the surgeon and gently brought into direct contact with one of the designated tissues (see Figure 9.1). If blood was visibly present on the tissue surface, it was dapped away using a sterile gauze. Between the measurements on different locations, the probe tip was swiped with a clean sterile gauze wetted with saline. Acquired data was labeled according to the tissue type description of the attending surgeon. To correct for dark current ${ }^{8}$, the spectrometer was calibrated prior to in vivo data acquisition. After the completion of in vivo spectroscopy, a reference spectrum was acquired, for calibration purposes, by direct contact measurement on a white reference phantom (Optical-grade spectralon reference; Labsphere, Inc., North Sutton, New Hampshire USA). The integration times of the Silicon and InGaAs sensor were individually optimized during the Spectralon calibration. No correction for ambient light was performed. 


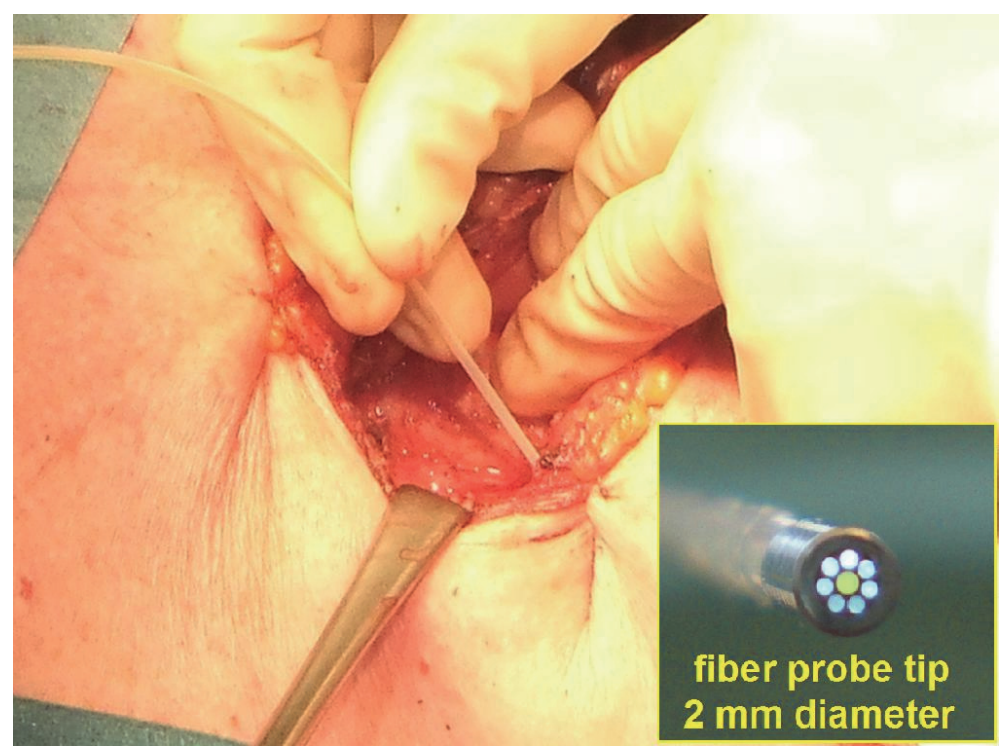

Figure 9.1 Fibre probe data acquisition during thyroid surgery

Intraoperative spectral fibre probe measurement performed during a left hemithyroidectomy procedure. The sterile optical fibre probe is gently brought into contact with the recurrent laryngeal nerve (average diameter $2 \mathrm{~mm}^{13}$ ). Right lower corner: close-up of the fibre probe tip. A ring light of seven fibres (illuminated white) injects light into the tissue, one central fibre (here for illustration purposes illuminated yellow) collects the diffusely reflected light.

\section{Data processing}

For inter-patient comparability, all raw in vivo spectra were corrected using the dark current and reference reflectance spectrum. Since both reflectance intensity and spectral shape are related to the composition of the tissue, no further normalization steps were performed. To identify possible distinctive features for tissue-specific enhancement, 36 features (i.e. 18 gradients and 18 amplitude differences at predefined points in the tissue spectra) were extracted based on known wavelengths related to characteristic absorption features for blood, water and fat ${ }^{25-27}$. Gradients are "slopes" between two predefined points in the tissue spectra, i.e.: $\left(D R_{2}-D R_{1}\right) /\left(\lambda_{2}-\lambda_{1}\right)$. Amplitude differences are "intensity differences" between two predefined spectral points, i.e. $\left(D R_{2}-D R_{1}\right) . D R=$ diffuse reflectance; $\lambda=$ wavelength. Figure 9.2 illustrates the characteristic wavelengths and features in a mean spectrum for adipose tissue data. All data processing was performed by in-house developed software (using MATLAB environment Version 7.7.0, MathWorks Inc., Natick, Massachussetts, USA). 


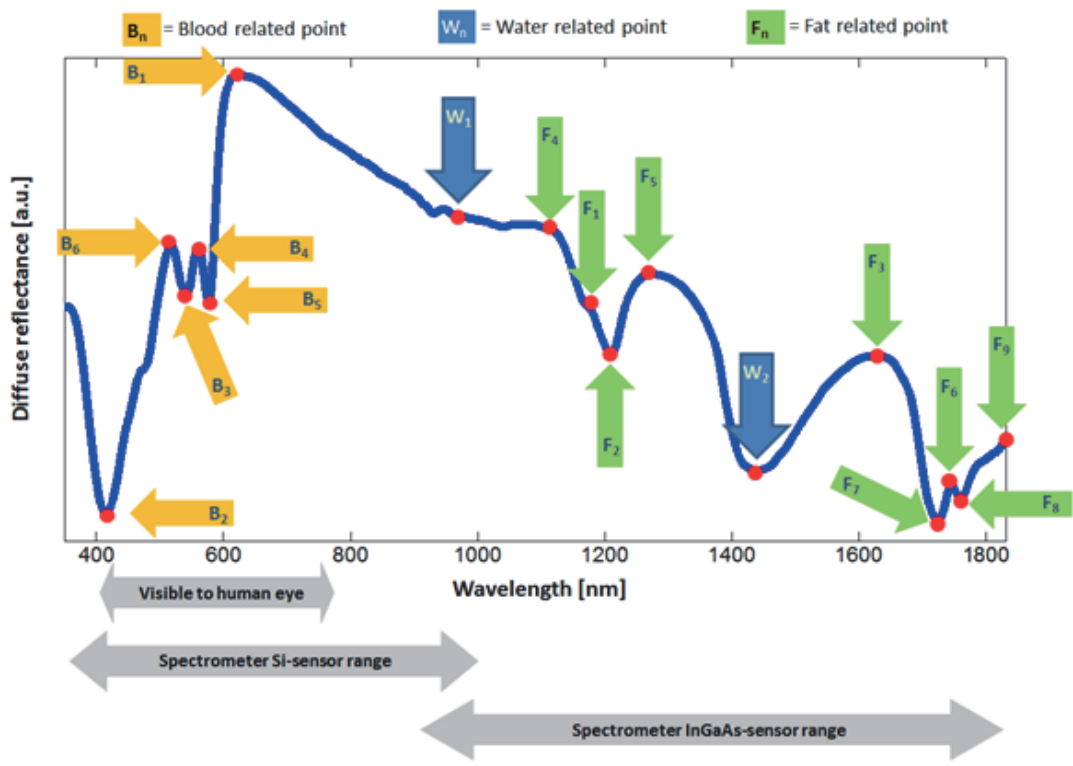

\section{Predefined points \\ Blood related \\ $B_{1}: \max [575-800 \mathrm{~nm}]$ \\ $B_{2}: \min [350-500 \mathrm{~nm}]$ \\ $B_{3}: \min [500-560 \mathrm{~nm}]$ \\ $B_{4}: \max [545-570 \mathrm{~nm}]$ \\ $B_{5}: \min [560-600 \mathrm{~nm}]$ \\ $\mathrm{B}_{6}: \max [400-550 \mathrm{~nm}]$}

\section{Water related}

$W_{1}: 965 \mathrm{~nm}$

$\mathrm{W}_{2}: 1440 \mathrm{~nm}$

\section{Fat related}

$F_{1}: 1180 \mathrm{~nm}$

$F_{2}: 1210 \mathrm{~nm}$

$F_{3}: \max [1440-1745 \mathrm{~nm}]$

$F_{4}: \max [1050-1210 \mathrm{~nm}]$

$F_{5}: \max [1210-1350 \mathrm{~nm}]$

$F_{6}: 1745 \mathrm{~nm}$

$F_{7}: 1720 \mathrm{~nm}$

$F_{8}: 1760 \mathrm{~nm}$

$F_{9}: 1830 \mathrm{~nm}$

Gradients
Si-sensor range
Ft1 : $\mathrm{B}_{6} \rightarrow \mathrm{B}_{3}$
$\mathrm{Ft} 2: \mathrm{B}_{5} \rightarrow \mathrm{B}_{1}$
$\mathrm{Ft} 3: \mathrm{B}_{2} \rightarrow \mathrm{B}_{6}$
$\mathrm{Ft} 4: \mathrm{B}_{6} \rightarrow \mathrm{B}_{1}$
$\mathrm{Ft5}: \mathrm{B}_{1} \rightarrow \mathrm{W}_{1}$
$\mathrm{Ft} 36:[650: 1: 700 \mathrm{~nm}]$

\section{Amplitude differences}

\section{Si-sensor range}

Ft6 : $\mathrm{B}_{6}-\mathrm{B}_{3}$

Ft7 : $\mathrm{B}_{5}-\mathrm{B}_{1}$

Ft8 : $\mathrm{B}_{4}-\mathrm{B}_{3}$

Ft9 : $B_{4}-B_{5}$

Ft10: $B_{1}-W_{1}$

InGaAs-sensorrang
Ft12: $W_{1} \rightarrow F_{4}$
Ft13: $W_{2} \rightarrow F_{4}$
Ft14: $F_{2} \rightarrow F_{1}$
Ft15: $F_{2} \rightarrow F_{5}$
Ft16: $F_{1} \rightarrow F_{4}$
Ft17: $F_{4} \rightarrow F_{5}$
Ft18: $W_{2} \rightarrow F_{5}$
Ft19: $W_{2} \rightarrow F_{3}$
Ft20: $F_{7} \rightarrow F_{3}$
Ft21: $F_{7} \rightarrow F_{6}$
Ft22: $F_{7} \rightarrow F_{8}$
Ft23: $F_{3} \rightarrow F_{9}$

\section{InGaAs-sensor range}

$\mathrm{Ft} 14: \mathrm{F}_{2} \rightarrow \mathrm{F}_{1}$

Ft15: $F_{2} \rightarrow F_{5}$

Ft16: $F_{1} \rightarrow F_{4}$

Ft17: $F_{4} \rightarrow F_{S}$

Ft18: $W_{2} \rightarrow F_{5}$

Ft19: $W_{2} \rightarrow F_{3}$

Ft23: $F_{3} \rightarrow F_{9}$
InGaAs-sensor rang
Ft11: $\mathrm{W}_{2}-\mathrm{W}_{1}$
Ft24: $W_{1}-F_{4}$
Ft25: $W_{2}-F_{4}$
Ft26: $F_{2}-F_{1}$
Ft27: $F_{2}-F_{5}$
Ft28: $F_{1}-F_{4}$
Ft29: $F_{4}-F_{5}$
Ft30: $W_{2}-F_{5}$
Ft31: $\mathrm{W}_{2}-\mathrm{F}_{3}$
Ft32: $F_{7}-F_{3}$
Ft33: $F_{7}-F_{6}$
Ft34: $F_{7}-F_{8}$
Ft35: $F_{3}-F_{9}$

Figure 9.2 Example of spectrum (adipose tissue neck) with characteristic wavelengths and investigated features

The arrows indicate qualitative landmarks for: oxygenated/reduced hemoglobin (characteristic "W-shape" between 500 and $600 \mathrm{~nm}$ ), water (absorption peaks at 965 and $1440 \mathrm{~nm}$ ) and human fat (absorption peaks at 1210 and $1720 \mathrm{~nm})^{25-27}$. The spectral detection ranges of the human eye, as well as for the Si-sensor and InGaAs-sensor from the applied spectrometer are also indicated. $B_{n}=$ Blood related; $W_{n}=$ Water related; $F_{n}=$ Fat related; Ft $=$ Feature 
Further analysis of the in vivo spectra was divided into two wavelength response ranges: Si-sensor ( $\leq 1000 \mathrm{~nm}$ ) and InGaAs-sensor ( $\geq 900 \mathrm{~nm})$.

The number of extracted features $(n=36)$ is too large to perform a statistically meaningful classification, as the extracted features could be redundant in the information they retain. Therefore, using combinations of all 36 features to build a classifier would result in a dimensionality problem and over-fitting. We identified the most distinctive features, for classification of nerve in an adipose surrounding, by using binary logistic regression (SPSS Inc., Chicago, IL, USA) for both wavelength regions separately. This is a statistical technique that allows the prediction of categorical dependent variables (here the tissue type: nerve or adipose tissue) using a set of independent variables (here the spectral features) ${ }^{28}$.

Using the approach for tissue classification based on hyperspectral data reported earlier by Akbari et al. ${ }^{29}$, we used support vector machine (SVM) to classify nerve within adipose surrounding. We used a polynomial kernel function ${ }^{30}$ for both wavelength regions. The SVM classifier attempts to find an optimum line in the two-dimensional feature space, consisting of support vectors, to separate the training data with a minimum risk ${ }^{31}$. To estimate classification performance and to prevent overly optimistic results $^{18-20}$, we implemented a cross-validation (CV) approach. With a goal to obtain the classification accuracy as a performance measure, the data set is divided into a training set (to train the classifier) and a test set (to validate the classifier). First the CV approach uses leave-one-out (LOO) validation of nerve and adipose hyperspectral data acquired during thyroid and parathyroid surgery. This approach utilizes the same data set for both training and testing purposes and is very useful in cases of a relatively small data sample. Additionally the CV approach uses train-test (TT) validation. In this approach we divided the data into a train set (consisting of nerve and adipose hyperspectral data acquired during thyroid and parathyroid surgery) and a test set (consisting of nerve and adipose hyperspectral data acquired during carpal tunnel release surgery). TT validation provides additional information as it estimates the performance of this system in the clinical setting by expanding the validation to other anatomical sites.

Sensitivity, specificity, positive predictive value, negative predictive value and accuracy were calculated to quantify the classification performance for both wavelength regions (i.e. Si-sensor and InGaAs-sensor detection range), and for both cross-validation methods (LOO and TT). In-house developed classifiers (using MATLAB environment Version 7.7.0, MathWorks Inc., Natick, Massachussetts, USA) were used to estimate the classification performance. 


\section{Results}

In 18 patients (4 male, 14 female) undergoing parathyroid or thyroid surgery, 253 spectra from 52 in vivo tissue sites were recorded (nerve $=22$, muscle $=12$ and adipose tissue $=18$ ). Table 9.1 summarizes patient characteristics and the number of measured sites per tissue type. Mean diffuse reflectance spectra and corresponding standard deviations for RLN, surrounding adipose tissue and sternocleidomastoid muscle are shown in Figure 9.3A. Figure 9.3B shows mean spectra of tissue measurements performed during five carpal tunnel release procedures. During these measurements 20 in vivo tissue sites were studied (nerve $=10$, muscle $=5$, adipose tissue $=5$ ).

Table 9.1 Spectroscopy in thyroid and parathyroid surgery: study subject characteristics

\begin{tabular}{|c|c|c|c|c|c|c|c|}
\hline \multirow[t]{2}{*}{ Subject\# } & \multirow[t]{2}{*}{ Gender } & \multirow[t]{2}{*}{ Age } & \multirow[t]{2}{*}{ Indication for surgery } & \multirow[t]{2}{*}{ Surgical procedure } & \multicolumn{3}{|c|}{ Sites per tissue type } \\
\hline & & & & & Nerve & dipos & Muscle \\
\hline 1 & M & 67 & Bethesda $3 *$ node left thyroid & Left HT & 2 & 0 & 0 \\
\hline 2 & $\mathrm{~F}$ & 55 & $\mathrm{PH}$ & Right PAR & 0 & 2 & 0 \\
\hline 3 & M & 54 & $\begin{array}{l}\text { MEN-2a syndrome, left medullar } \\
\text { thyroid carcinoma }\end{array}$ & $\begin{array}{l}\mathrm{TT}+\text { radical LND neck, } \\
\text { right axillary LND }\end{array}$ & 2 & 1 & 0 \\
\hline 4 & $\mathrm{~F}$ & 14 & $\mathrm{PH}$ & Left PAR & 0 & 2 & 0 \\
\hline 5 & $\mathrm{~F}$ & 67 & $\begin{array}{c}\text { Status after right hemithyroidectomy, } \\
\text { in which a follicular carcinoma was } \\
\text { found }\end{array}$ & $\begin{array}{l}\text { Resection of } \\
\text { remainingthyroid } \\
\text { (left HT) }\end{array}$ & 2 & 1 & 0 \\
\hline 6 & $\mathrm{~F}$ & 53 & Multinodular goiter & TT & 2 & 1 & 0 \\
\hline 7 & $\mathrm{~F}$ & 56 & Bethesda $2 *$ node right thyroid & Right HT & 2 & 1 & 0 \\
\hline 8 & $\mathrm{~F}$ & 67 & Multinodular goiter & Left HT & 1 & 0 & 0 \\
\hline 9 & $\mathrm{~F}$ & 55 & Multinodular goiter & $\begin{array}{l}\text { Left } \mathrm{HT}+\text { subtotal right } \\
\text { thyroidectomy }\end{array}$ & 1 & 0 & 0 \\
\hline 10 & $\mathrm{~F}$ & 50 & Multinodular goiter & Left HT & 1 & 1 & 1 \\
\hline 11 & M & 80 & $\mathrm{PH}$ & Left PAR & 0 & 1 & 1 \\
\hline 12 & $\mathrm{~F}$ & 54 & $\mathrm{PH}$ & Right PAR & 1 & 1 & 1 \\
\hline 13 & M & 74 & $\mathrm{PH}$ & Right PAR & 0 & 1 & 1 \\
\hline 14 & $\mathrm{~F}$ & 60 & Multinodular goiter & Left HT & 1 & 1 & 1 \\
\hline 15 & $\mathrm{~F}$ & 46 & Substernal multinodular goiter & Sternotomy + left HT & 2 & 1 & 3 \\
\hline 16 & $\mathrm{~F}$ & 53 & Bethesda $3 *$ node right thyroid & Right HT & 2 & 2 & 2 \\
\hline 17 & $\mathrm{~F}$ & 23 & Graves' disease & TT & 2 & 1 & 1 \\
\hline \multirow[t]{3}{*}{18} & $\mathrm{~F}$ & 49 & Multinodular goiter & Left HT & 1 & 1 & 1 \\
\hline & & & & $\begin{array}{l}\text { Sites per tissue type } \\
\quad \text { (total } n=52)\end{array}$ & 22 & 18 & 12 \\
\hline & & & & $\begin{array}{l}\text { Spectra per tissue type } \\
\text { (total } n=253 \text { ) }\end{array}$ & 108 & 90 & 55 \\
\hline
\end{tabular}

\footnotetext{
${ }^{*}$ The Bethesda system was used for reporting thyroid cytopathology ${ }^{29} . \mathrm{M}=$ male; $\mathrm{F}=$ female; $\mathrm{PH}=$ primary hyperparathyroidism; $\mathrm{PAR}=$ parathyroid adenoma resection; $\mathrm{HT}=$ hemithyroidectomy; $\mathrm{TT}=$ total thyroidectomy; LND = lymph node dissection.
} 


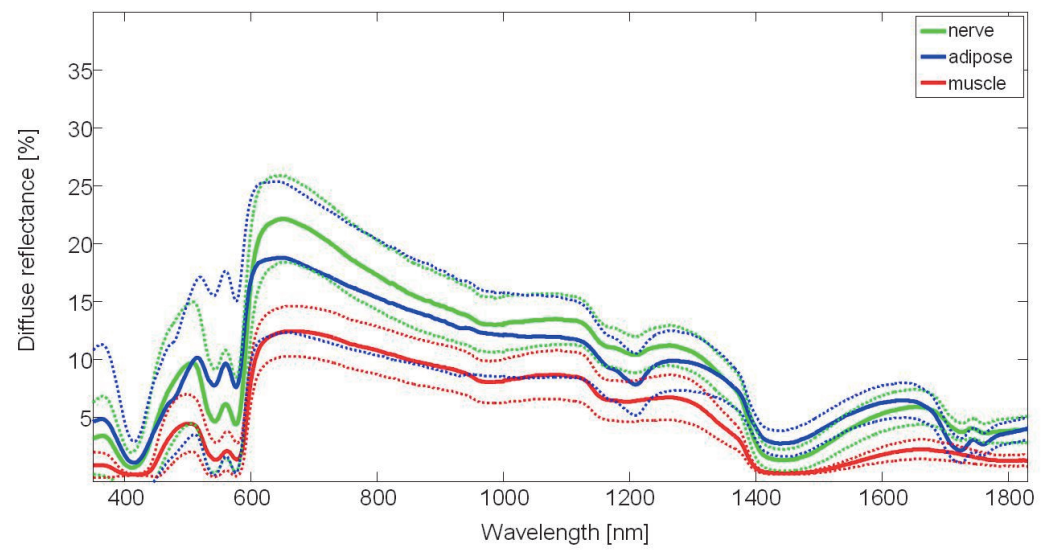

Figure 9.3A Mean spectra per tissue type acquired during thyroid and parathyroid surgery Average tissue spectra for recurrent laryngeal nerve (green), adipose tissue (blue) and sternocleidomastoid muscle (red). Dashed lines in the corresponding colors indicate the respective standard deviations. RLN diameter is on average $2 \mathrm{~mm}^{13}$ at the measurement site.

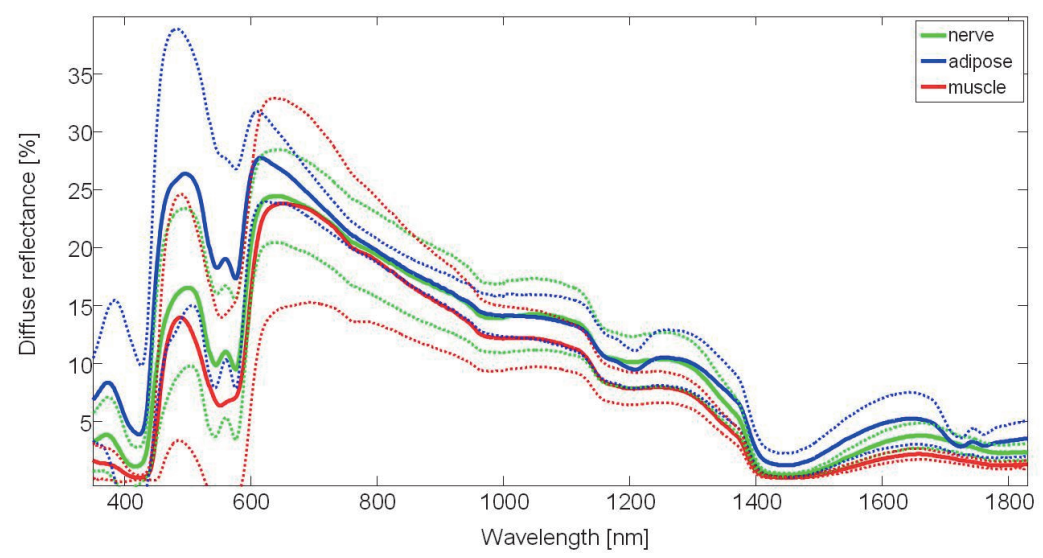

Figure 9.3B Mean spectra per tissue type acquired during carpal tunnel release surgery

Average tissue spectra for median nerve (green), subcutaneous adipose tissue (blue) and transverse thenar/hypothenar muscle fibres overlying the transverse carpal ligament (red). Dashed lines in the corresponding colors indicate the respective standard deviations. Median nerve diameter is on average $6 \mathrm{~mm}$ at the measurement site (i.e., at distal fore-arm ${ }^{40}$ ).

\section{Classification of spectral data in Si-sensor range}

From the 36 extracted features, defined in Figure 9.2, 11 were located within the silicon detection range. Given the study sample of 22 RLN spots, inclusion of maximum 
2 features is allowed. Binary logistic regression identified gradient Ft5 $\left(B_{1}-W_{1}\right)$ and amplitude difference $\mathrm{Ft} 7\left(\mathrm{~B}_{5}-\mathrm{B}_{1}\right)$ as most promising combination for differentiation of RLN from surrounding adipose tissue. Figure 9.4 shows a scatter plot for these Si-sensor based features, extracted for nerve and adipose tissue. Data for both thyroid and parathyroid surgery, and carpal tunnel release surgery are included.

The quantitative results of classification performance are listed in Table 9.2 for both cross-validation approaches. LOO cross-validation is solely based on Si-sensor range data from thyroid and parathyroid surgery for train and test purposes. TT crossvalidation is based on data from thyroid and parathyroid surgery for train purposes and on additional carpal tunnel release surgery data for test purposes.

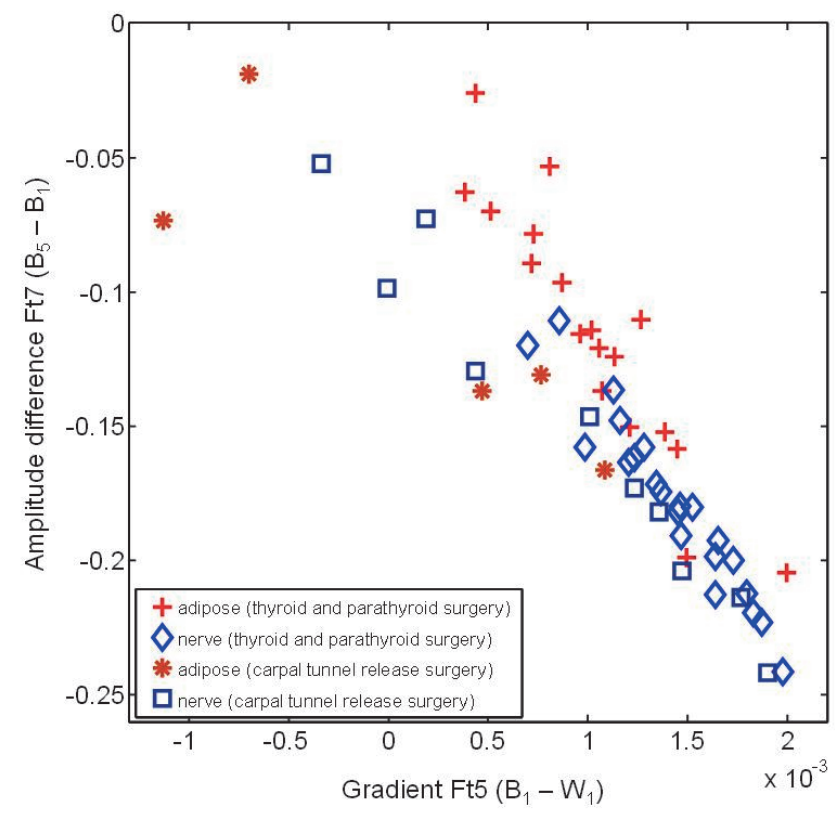

Figure 9.4 Scatter plot of two selected features within Si-range

Scatter plot showing two computer-selected features (gradient Ft5 and amplitude difference Ft7). Data measured during thyroid and parathyroid surgery and carpal tunnel release surgery are included. 
Table 9.2 Classification performance of selected Si-sensor features

\begin{tabular}{lccccccc}
\hline & TP & TN & Sensitivity & Specificity & PPV & NPV & Accuracy \\
\hline LOO CV & $20 / 22$ & $11 / 18$ & $91(69-98)$ & $61(36-82)$ & $74(53-88)$ & $85(54-97)$ & 78 \\
TT CV & $10 / 10$ & $0 / 5$ & $100(66-100)$ & $0(0-54)$ & $67(39-87)$ & - & 67 \\
\hline
\end{tabular}

$\mathrm{TP}=$ true positive; $\mathrm{TN}=$ true negative $\rightarrow$ numbers indicate identified tissue spots. A positive test is defined as the tissue observed being RLN; a negative test is defined as the tissue observed being adipose tissue. Sensitivity; specificity; PPV = positive predictive value; NPV = negative predictive value; accuracy $\rightarrow$ numbers are percentages; numbers in parentheses indicate 95\% confidence interval. LOO CV = leave-one-out crossvalidation; TT CV = train-test cross-validation.

\section{Classification of spectral data in InGaAs-sensor range}

From the 36 extracted features, defined in Figure 9.2, 25 were located within the spectral detection range of InGaAs. After binary logistic regression, gradient Ft12 $\left(W_{1}-F_{4}\right)$ and amplitude difference $F t 26\left(F_{2}-F_{1}\right)$ were selected as the most promising combination for differentiation of RLN from surrounding adipose tissue. Figure 9.5 shows a scatter plot for these InGaAs-sensor based features extracted for nerve and adipose tissue. Data for thyroid and parathyroid surgery and carpal tunnel release surgery data are included.

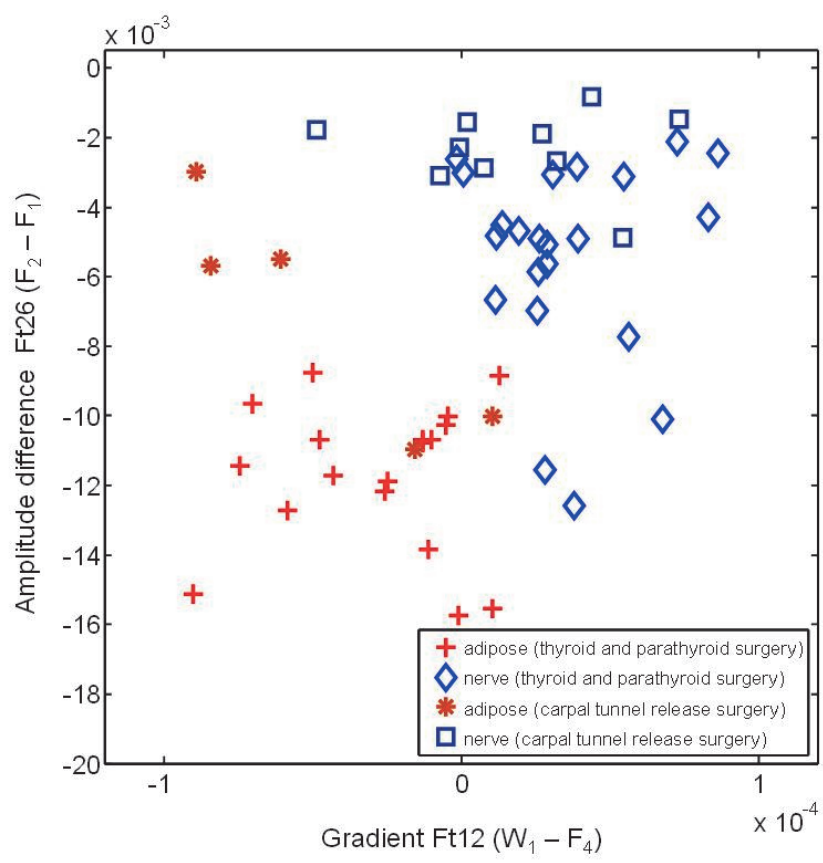

Figure 9.5 Scatter plot of two selected features within InGaAs-range

Scatter plot showing two computer-selected features (gradient Ft12 and amplitude difference Ft26). Data measured during thyroid and parathyroid surgery and carpal tunnel release surgery are included. 
The classification performance for respectively LOO cross-validation and TT crossvalidation are listed in Table 9.3. LOO cross-validation is solely based on InGaAs-sensor range data from thyroid and parathyroid surgery for train and test purposes. TT crossvalidation is based on data from thyroid and parathyroid surgery for train purposes and on additional carpal tunnel release surgery data for test purposes.

Table 9.3 Classification performance of selected InGaAs-sensor features

\begin{tabular}{lccccccr}
\hline & TP & TN & Sensitivity & Specificity & PPV & NPV & Accuracy \\
\hline LOO CV & $22 / 22$ & $16 / 18$ & $100(82-100)$ & $89(64-98)$ & $92(72-99)$ & $100(76-100)$ & 95 \\
TT CV & $10 / 10$ & $5 / 5$ & $100(66-100)$ & $100(46-100)$ & $100(66-100)$ & $100(46-100)$ & 100 \\
\hline
\end{tabular}

$\mathrm{TP}=$ true positive; TN = true negative $\rightarrow$ numbers indicate identified tissue spots. A positive test is defined as the tissue observed being nerve; a negative test is defined as the tissue observed being adipose tissue. Sensitivity; specificity; PPV = positive predictive value; NPV = negative predictive value; accuracy $\rightarrow$ numbers are percentages; numbers in parentheses indicate 95\% confidence interval. LOO CV = leave-one-out crossvalidation; TT CV = train-test cross-validation.

\section{Discussion and conclusion}

This explorative study reveals the in vivo wide-band $(350-1830 \mathrm{~nm})$ diffuse reflectance spectra of human recurrent laryngeal nerve, surrounding adipose tissue and sternocleidomastoid muscle (anatomical region: neck). Also in vivo spectra are presented for human median nerve, subcutaneous adipose tissue and transverse thenar/hypothenar muscle fibres overlying the transverse carpal ligament (anatomical region: wrist). The presented spectra covered both silicon (Si) and indium gallium arsenide (InGaAs) sensor ranges (350 - $1830 \mathrm{~nm}$ with $1 \mathrm{~nm}$ resolution), thereby exceeding beyond the $1600 \mathrm{~nm}$ boundary reported by preceding work $^{21-23,32}$. Spectroscopy on human skin samples in the wavelength range of $1000-2200 \mathrm{~nm}$ has been reported ${ }^{33}$. However, this report did not include any of the tissues covered by our study.

Even though the measured reflectance spectra, shown in Figure 9.3, illustrate a great similarity between different tissue types, the nerve classification within an adipose surrounding was fairly accurate within the detection ranges of both Si and InGaAs. Based on the classification accuracies for these detection ranges (Tables 9.2 and 9.3) we can conclude that InGaAs sensors are better suited for automated discrimination between nerves and surrounding adipose tissue than Si sensors.

With respect to the statistically different spectral features of nerve versus adipose tissue in the InGaAs range, our results indicate that especially water and lipid absorption differences around $1210 \mathrm{~nm}$ play an important role. This is also strongly 
supported by previously reported data on composition of nerve and adipose tissue $^{23,34,35}$. In essence, nerve tissue contains $20 \%$ lipid and $80 \%$ protein $^{34}$, while adipose tissue contains $61-87 \%$ lipid, $8 \%$ protein and $11-31 \%$ water $^{35}$.

The reflectance spectra, which were the basis to extract gradient and amplitude difference features, originate from intrinsic tissue properties (endogenous contrasts) that do not require preoperative contrast administration. Consequently there are no problems with potential toxicity or allergy to a contrast agent.

Regarding exogenous contrast-based optical techniques, in vivo optical imaging of peripheral nerves using systemically administered myelin-selective fluorescent dyes ${ }^{36}$ or nerve-highlighting fluorescent peptides ${ }^{37}$ has been reported. Development of a new NIR fluorescent dye for use in the design of nerve-targeted optical imaging probes has also been described ${ }^{38}$.

The LOO cross-validation method inherently produces relatively optimistic classification results (therefore we additionally applied the TT cross-validation method). External validation remains essential before classification models can be implemented in clinical practice $^{39}$. Such validation would need to be performed on newly acquired data. Additional data acquired in a multi-center study would also be needed.

The choice to use a limited set of pre-known spectral regions of interest for water, fat and hemoglobin was made based upon the limited number of spectra included in our data set. Differentiation based on completely automatically extracted features from a larger data set might achieve better results, and could be explored in future work.

The identified reflectance spectra are specific to the probe geometry used in this study. To extend this study even further, translation of these reflectance spectra to in vivo biological parameters is needed. Such an approach would yield information about the optical tissue properties, and provide a better understanding of the nature of discrimination performance, i.e. whether nerves can be optically distinguished from surrounding (adipose) tissues based on differences in light scattering behaviour (related to structural differences) or due to differences in absorption behaviour (related to chromophore concentrations such as blood, water and fat). Such an approach would also be tissue-specific and robust to inter-patient and multi-center variability.

The "gold standard" used in this study was the surgeons' visual judgment. This judgment is not solely based on color (spectral) information, but also relies on the recognition of spatial anatomical position of a specific tissue. Therefore, this study needs extension from spot-wise probe-measurements to imaging of the whole surgical field.

In contrast to our previous ex vivo experiments using wide band diffuse reflectance spectroscopy $^{24}$, the current measurements were performed during surgery. In vivo circumstances as vascular filling and oxygenation were not disrupted. Using diffuse 
reflectance spectroscopy we have identified that InGaAs sensors are better suited for automated discrimination between nerves and surrounding adipose tissue than $\mathrm{Si}$ sensors. This underlines the importance of extending the wavelength region beyond the detection boundary of silicon cameras for automated classification of nerve tissue in adipose surroundings. Hyperspectral camera technology covering both Si and InGaAs sensor response ranges could offer even greater possibilities for automated tissue differentiation. 


\section{References}

1. Christou N, Mathonnet M (2013) Complications after total thyroidectomy. J Visc Surg 150:249-256

2. Lange MM, Maas CP, Marijnen CA, Wiggers T, Rutten HJ, Kranenbarg EK, van de Velde CJ (2008) Urinary dysfunction after rectal cancer treatment is mainly caused by surgery. Br J Surg 95:1020-1028

3. Lange MM, van de Velde CJ (2011) Urinary and sexual dysfunction after rectal cancer treatment. Nat Rev Urol 8:51-57

4. Lange JF, Wijsmuller AR, van Geldere D, Simons MP, Swart R, Oomen J, Kleinrensink GJ, Jeekel J (2009) Feasibility study of three-nerve-recognizing Lichtenstein procedure for inguinal hernia. Br J Surg 96: 1210-1214

5. Huang W, Lamb DW, Niu Z, Zhang Y, Liu L, Wang L (2007) Identification of yellow rust in wheat using insitu spectral reflectance measurements and airborne hyperspectral imaging. Precision Agriculture 8: 187-197

6. Hively WD, McCarty GW, Reeves JB, Lang MW, Oesterling RA, Delwiche SR (2011) Use of Airborne Hyperspectral Imagery toMap Soil Properties in Tilled Agricultural Fields. Applied and Environmental Soil Science 2011:Article ID 358193

7. Yuen PWT, Richardson M (2010) An introduction to hyperspectral imaging and its application for security, surveillance and target acquisition. The Imaging Science Journal 58:241-253

8. Lu G, Fei B (2014) Medical hyperspectral imaging: a review. J Biomed Opt 19:10901

9. Holzer MS, Best SL, Jackson N, Thapa A, Raj GV, Cadeddu JA, Zuzak KJ (2011) Assessment of renal oxygenation during partial nephrectomy using hyperspectral imaging. J Urol 186:400-404

10. Olweny EO, Faddegon S, Best SL, Jackson N, Wehner EF, Tan YK, Zuzak KJ, Cadeddu JA (2013) Renal oxygenation during robot-assisted laparoscopic partial nephrectomy: characterization using laparoscopic digital light processing hyperspectral imaging. J Endourol 27:265-269

11. Zuzak KJ, Naik SC, Alexandrakis G, Hawkins D, Behbehani K, Livingston E (2008) Intraoperative bile duct visualization using near-infrared hyperspectral video imaging. Am J Surg 195:491-497

12. Panasyuk SV, Yang S, Faller DV, Ngo D, Lew RA, Freeman JE, Rogers AE (2007) Medical hyperspectral imaging to facilitate residual tumor identification during surgery. Cancer Biol Ther 6:439-446

13. Serpell JW, Woodruff S, Bailey M, Grodski S, Yeung M (2011) Recurrent laryngeal nerve diameter increases during thyroidectomy. Ann Surg Oncol 18:1742-1747

14. Lefevre JH, Tresallet C, Leenhardt L, Jublanc C, Chigot JP, Menegaux F (2007) Reoperative surgery for thyroid disease. Langenbecks Arch Surg 392:685-691

15. Chiang FY, Wang LF, Huang YF, Lee KW, Kuo WR (2005) Recurrent laryngeal nerve palsy after thyroidectomy with routine identification of the recurrent laryngeal nerve. Surgery 137:342-347

16. Dralle H, Sekulla C, Lorenz K, Brauckhoff M, Machens A (2008) Intraoperative monitoring of the recurrent laryngeal nerve in thyroid surgery. World J Surg 32:1358-1366

17. Pisanu A, Porceddu G, Podda M, Cois A, Uccheddu A (2014) Systematic review with meta-analysis of studies comparing intraoperative neuromonitoring of recurrent laryngeal nerves versus visualization alone during thyroidectomy. J Surg Res 188:152-161

18. Stelzle F, Zam A, Adler W, Tangermann-Gerk K, Douplik A, Nkenke E, Schmidt M (2011) Optical nerve detection by diffuse reflectance spectroscopy for feedback controlled oral and maxillofacial laser surgery. J Transl Med 9:20

19. Stelzle F, Tangermann-Gerk K, Adler W, Zam A, Schmidt M, Douplik A, Nkenke E (2010) Diffuse reflectance spectroscopy for optical soft tissue differentiation as remote feedback control for tissuespecific laser surgery. Lasers Surg Med 42:319-325

20. Stelzle F, Adler W, Zam A, Tangermann-Gerk K, Knipfer C, Douplik A, Schmidt M, Nkenke E (2012) In vivo optical tissue differentiation by diffuse reflectance spectroscopy: preliminary results for tissue-specific laser surgery. Surg Innov 19:385-393

21. Nachabe R, Hendriks BH, Desjardins AE, van der Voort M, van der Mark MB, Sterenborg HJ (2010) Estimation of lipid and water concentrations in scattering media with diffuse optical spectroscopy from 900 to 1,600 nm. J Biomed Opt 15:037015 
22. Nachabe R, Hendriks BH, van der Voort M, Desjardins AE, Sterenborg HJ (2010) Estimation of biological chromophores using diffuse optical spectroscopy: benefit of extending the UV-VIS wavelength range to include 1000 to $1600 \mathrm{~nm}$. Biomed Opt Express 1:1432-1442

23. Cao Q, Zhegalova NG, Wang ST, Akers WJ, Berezin MY (2013) Multispectral imaging in the extended near-infrared window based on endogenous chromophores. J Biomed Opt 18:101318

24. Schols RM, Dunias P, Wieringa FP, Stassen LP (2013) Multispectral characterization of tissues encountered during laparoscopic colorectal surgery. Med Eng Phys 35:1044-1050

25. Zijlstra WG, Buursma A, Meeuwsen-van der Roest WP (1991) Absorption spectra of human fetal and adult oxyhemoglobin, de-oxyhemoglobin, carboxyhemoglobin, and methemoglobin. Clin Chem 37: 1633-1638

26. Anderson RR, Farinelli W, Laubach H, Manstein D, Yaroslavsky AN, Gubeli J, 3rd, Jordan K, Neil GR, Shinn M, Chandler W, Williams GP, Benson SV, Douglas DR, Dylla HF (2006) Selective photothermolysis of lipidrich tissues: a free electron laser study. Lasers Surg Med 38:913-919

27. Roggan A, Friebel M, Do Rschel K, Hahn A, Mu Ller G (1999) Optical Properties of Circulating Human Blood in the Wavelength Range 400-2500 nm. J Biomed Opt 4:36-46

28. Tabachnick BG, Fidell LS (2007) Using multivariate statistics, 5th edn, Allyn-Bacon, Boston, MA

29. Akbari H, Kosugi Y, Kojima K, Tanaka N (2009) Blood vessel detection and artery-vein differentiation using hyperspectral imaging. Conf Proc IEEE Eng Med Biol Soc 2009:1461-1464

30. Mercier G, Lennon M (2003) Support vector machines for hyperspectral image classification with spectral-based kernels. Geoscience and Remote Sensing Symposium, 2003 IGARSS '03 Proceedings 2003 IEEE International 1:288-290

31. Boser BE, Guyon IM, Vapnik VN (1992) A Training Algorithm for Optimal Margin Classifiers. Proceedings of the 5th Annual ACM Workshop on Computational Learning Theory:144-152

32. Desjardins $A E$, van der Voort $M$, Roggeveen $S$, Lucassen $G$, Bierhoff $W$, Hendriks $B H$, Brynolf $M$, Holmstrom B (2011) Needle stylet with integrated optical fibers for spectroscopic contrast during peripheral nerve blocks. J Biomed Opt 16:077004

33. Troy TL, Thennadil SN (2001) Optical properties of human skin in the near infrared wavelength range of 1000 to $2200 \mathrm{~nm}$. J Biomed Opt 6:167-176

34. Malmivuo J, Plonsey R (1995) Bioelectromagnetism: Principles and Applications of Bioelectric and Biomagnetic Fields, 1st edn, Oxford University Press, Oxford

35. Woodard HQ, White DR (1986) The composition of body tissues. The British journal of radiology 59: 1209-1218

36. Gibbs-Strauss SL, Nasr KA, Fish KM, Khullar O, Ashitate Y, Siclovan TM, Johnson BF, Barnhardt NE, Tan Hehir CA, Frangioni JV (2011) Nerve-highlighting fluorescent contrast agents for image-guided surgery. Molecular imaging 10:91-101

37. Whitney MA, Crisp JL, Nguyen LT, Friedman B, Gross LA, Steinbach P, Tsien RY, Nguyen QT (2011) Fluorescent peptides highlight peripheral nerves during surgery in mice. Nature biotechnology 29: 352-356

38. Gustafson TP, Yan Y, Newton P, Hunter DA, Achilefu S, Akers WJ, Mackinnon SE, Johnson PJ, Berezin MY (2012) A NIR Dye for Development of Peripheral Nerve Targeted Probes. MedChemComm 3:685-690

39. Bleeker SE, Moll HA, Steyerberg EW, Donders AR, Derksen-Lubsen G, Grobbee DE, Moons KG (2003) External validation is necessary in prediction research: a clinical example. J Clin Epidemiol 56:826-832

40. Mani B, Sarawagi R, Cherian RA (2011) Review of the dimensions of the median nerve and carpal tunnel using sonography in asymptomatic adults. J Med Imaging Radiat Oncol 55:126-131 


\section{Chapter 10}

Parathyroid differentiation during thyroid and parathyroid surgery by spectroscopy $(350-1830 \mathrm{~nm})$

Schols RM, Alic L, Wieringa FP, Bouvy ND, Stassen LP Submitted for publication 


\section{Abstract}

\section{Background}

In thyroid and parathyroid surgery iatrogenic parathyroid injury should be prevented. Parathyroid-specific image enhancement might be realized with hyperspectral cameras using silicon ( $\mathrm{Si}$ ) or indium-gallium-arsenide (InGaAs) sensors. Feasibility of this technology for automated parathyroid detection was examined by analyzing performance of single-spot diffuse reflectance spectroscopy (DRS).

\section{Methods}

DRS (350 - $1830 \mathrm{~nm}$ ) was performed during thyroid and parathyroid resections. From the acquired spectra 36 features at predefined wavelengths were extracted. Best features for parathyroid classification versus adipose tissue or thyroid were assessed by binary logistic regression for $\mathrm{Si}$ - and InGaAs-sensor ranges. Classification performance was evaluated by leave-one-out cross-validation.

\section{Results}

In 19 patients 299 spectra were recorded (62 tissue sites: thyroid $n=23$, parathyroid $\mathrm{n}=21$, adipose $\mathrm{n}=18$ ). Classification accuracy of parathyroid-adipose was respectively 79\% (Si), 82\% (InGaAs) and $97 \% \quad$ (Si/InGaAs combined). Parathyroid-thyroid classification accuracies: $80 \%, 75 \%, 82 \%$.

\section{Conclusion}

Si and InGaAs sensors are fairly accurate for automated parathyroid discrimination from adipose or thyroid tissue. Combination of both sensor technologies improves accuracy. 


\section{Introduction}

To perform safe and efficient thyroid and parathyroid surgery, a high level of surgical skills is required together with understanding of natural variations in head and neck anatomy (e.g. thyroid, parathyroid, lymph nodes, and recurrent laryngeal nerves). Especially detecting the small sized parathyroid glands and performing re-operative thyroid surgery can be challenging and time consuming. This visual task can be even more challenging due to anatomical variations in location, especially for the lower parathyroid glands ${ }^{1}$. During these complicated surgical procedures iatrogenic injury to the parathyroid glands may occur ${ }^{2}$. In a retrospective analysis of 5104 primary and 685 secondary thyroidectomies, temporary hypocalcaemia associated with hypoparathyroidism occurred in respectively $7.1 \%$ and $5 \%$ of cases (permanent in $1.8 \%$ and $2.5 \%)$. The rate of permanent complications was found to be significantly higher in reoperative surgery ${ }^{3}$. Intraoperative identification of parathyroid glands before removal of the thyroid gland is of great importance to prevent these complications. Therefore, a tool for improved intraoperative parathyroid gland detection is desirable. Exploring the capabilities of spectroscopy beyond the limitations of the human eye offers a possible roadmap towards such a tool.

Several innovative optical techniques have been under investigation for their potential in differentiating benign from malignant cells in thyroid and parathyroid specimens: multispectral image analysis ${ }^{4,5}$, Raman spectroscopy ${ }^{6}$ and elastic scattering spectroscopy ${ }^{7}$. Fluorescence imaging after peripheral infusion of aminolevulinic acid ${ }^{8,9}$ or methylene blue ${ }^{10}$ can be used for intraoperative detection of parathyroid adenomas. Near-infrared auto-fluorescence incorporates potential for real-time parathyroid tissue localization as well ${ }^{11}$. Furthermore, optical coherence tomography is reported as a tool for parathyroid gland identification ${ }^{12,13}$.

For color vision, the human eye contains only blue, green and red cones, which also partly overlap in sensitivity (poor channel separation). Yet, the trained human eye can discern quite subtle color differences within the visible range $(400-780 \mathrm{~nm})$. Hyperspectral cameras discern a multitude of well-separated bands for each pixel, including the near-infrared which is (by definition) invisible to the human eye, incorporating potential to facilitate image-guided surgery ${ }^{14}$. It has, for example, been investigated for noninvasive intraoperative assessment of tissue oxygen saturation ${ }^{15,16}$, for intraoperative enhancement of anatomical structures ${ }^{17,18}$ and for intraoperative tumor detection $^{19}$. Medical hyperspectral imaging-systems typically use silicon (Si) or indium gallium arsenide (InGaAs) camera chips. The wavelength range of $400-1000 \mathrm{~nm}$ is covered by $\mathrm{Si}$, whereas InGaAs is typically sensitive in the $900-1700 \mathrm{~nm}$ wavelength region (and depending on chip composition even up to $2500 \mathrm{~nm})^{14}$. 
Diffuse reflectance spectroscopy was studied for tissue differentiation as basis for a feedback system to enhance nerve preservation in oral and maxillofacial surgery ${ }^{20}$, but not yet for other anatomical structures such as parathyroid or thyroid tissue. Nachabé et al. ${ }^{21,22}$ showed the benefit of extending visualization up to a wavelength of $1600 \mathrm{~nm}$, providing additional information regarding tissue concentrations of the biological chromophores water and lipid. The present translational study is a first fiber-optic spectrometric exploration with the ultimate long-term goal of obtaining parathyroid gland-specific image enhancement. In vivo, wide band (350 - $1830 \mathrm{~nm})$ diffuse reflectance spectra of human thyroid, parathyroid and surrounding adipose tissue were collected and assessed for the presence of endogenous contrasts that might enable future tissue-specific contrast enhancement. Therefore we applied tissue classification using spectral features that are largely independent to signal intensity using a previously reported approach ${ }^{23}$.

\section{Methods}

All in vivo data acquisition was performed at the Surgery Department of Maastricht University Medical Center (MUMC, Maastricht, The Netherlands) during thyroid and parathyroid surgery (surgeon N.D.B.). Prior to measurements, the local institutional review board of Maastricht University Medical Center (registration number METC 10-4-035) granted approval and preoperative written informed consent was obtained from all patients.

\section{Material}

Diffuse reflectance spectra were acquired using custom developed sterile disposable optical fibre probes (TNO, Eindhoven the Netherlands \& Light Guide Optics, Rheinbach Germany), a modified Xenon light source (D-light C, Karl Storz, Tuttlingen Germany), and a spectrometer (Analytical Spectral Devices, Inc., Colorado USA) covering the range of $350-1830 \mathrm{~nm}$. The spectrometer is equipped with two sensor technologies: a silicon (Si) based sensor and an indium gallium arsenide (InGaAs) based sensor. The cross-over point between these sensors is at $1000 \mathrm{~nm}$. The fibre probe is the medium to transport light from source to tissue, and to transport reflected light from tissue to spectrometer. The system was installed on a compact trolley to facilitate in vivo tissue data acquisition during routine surgery. The setup was tested and approved according to the essential requirements of IEC 60601-1 to assure patient safety. The equipment has previously been described in more detail ${ }^{24}$. 
Figure 10.1 shows the fibre probe tip composed of eight optical fibres: One central receiving fibre (400 um diameter, NA $0.22 \pm 0.02$ ) and seven illuminating fibres (300 um diameter, NA $0.22 \pm 0.02$ ). The rigid stainless steel probe tip has a $2 \mathrm{~mm}$ diameter and a length of $10 \mathrm{~mm}$. The remaining length of the sterile fibre probe is highly flexible.

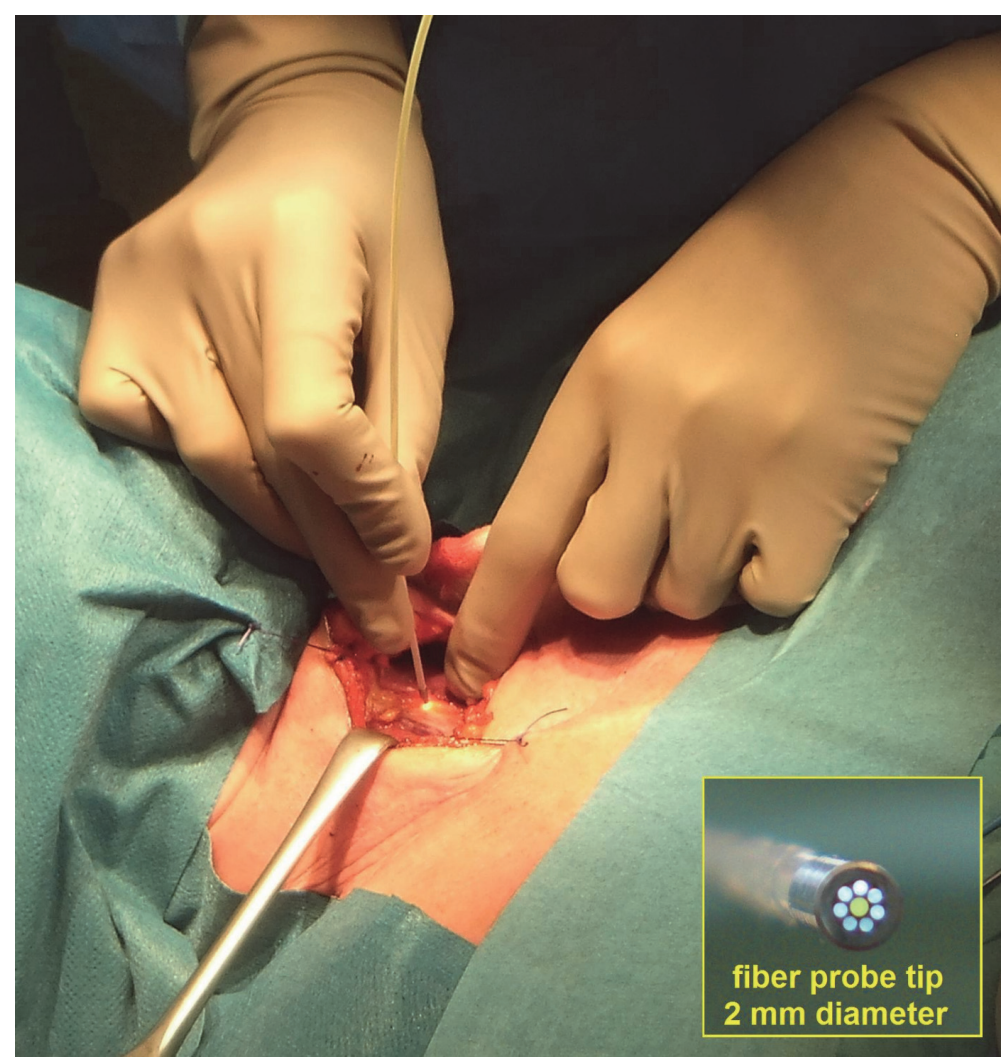

Figure 10.1 Intraoperative fibre probe tissue measurement Intraoperative spectral fibre probe measurement performed during a left hemithyroidectomy procedure. The sterile optical fibre probe is gently brought into contact with one of the parathyroid glands. Right lower corner: close-up of the fiber probe tip. A ring light of seven fibers (illuminated white) injects light into the tissue, one central fiber (here for illustration purposes illuminated yellow) transports the diffusely reflected light to the spectrometer.

\section{In vivo data acquisition}

During parathyroid and thyroid resections, in vivo wide-band diffuse reflectance spectra (350-1830 nm, $1 \mathrm{~nm}$ spectral resolution) were collected. For each tissue type, five spectra per site (taking 30 seconds per site) were acquired, covering at least one site 
per tissue type (see also Table 10.1). The sterile fibre probe was handled by the surgeon and gently brought into direct contact with one of the designated tissues (see Figure 10.1). If blood was visibly present on the tissue surface, it was dapped away using a sterile gauze. Between the measurements on different locations, the probe tip was swiped with a clean sterile gauze wetted with saline. Acquired data was labeled according to the tissue type description of the attending surgeon.

To correct for dark current ${ }^{14}$, the spectrometer was calibrated prior to in vivo data acquisition. After the completion of in vivo spectroscopy, a reference spectrum was acquired, for calibration purposes, by direct contact measurement on a white reference phantom (Optical-grade spectralon reference; Labsphere, Inc., North Sutton, New Hampshire USA). The integration times of the Silicon and InGaAs sensor were individually optimized during the Spectralon calibration. No correction for ambient light was performed.

\section{Data processing}

For inter-patient comparability, all raw in vivo spectra were calibrated using the dark current and reference reflectance spectrum. This normalizes the radiance spectrum to yield the reflectance, which manages the problem of spectral non-uniformity of the illumination device and influence of the dark current ${ }^{25}$. Since both reflectance intensity and spectral shape are related to the composition of the tissue, no further normalization steps were performed. To identify possible distinctive features for tissuespecific enhancement, 36 features (i.e. 18 gradients and 18 amplitude differences at predefined points in the tissue spectra) were extracted based on known wavelengths related to characteristic absorption features for blood, water and $\mathrm{fat}^{26-28}$. These features are described in more detail in our previous publication ${ }^{23}$. Figure 10.2 illustrates the characteristic wavelengths and features in a mean spectrum for human adipose tissue (anatomical region: neck). All data processing was performed by inhouse developed software (using MATLAB environment Version 7.7.0, MathWorks Inc., Natick, Massachussetts, USA).

To evaluate the results for application in imaging technology for identification of parathyroid within its natural surroundings, we performed three separate classification steps: i.e. Si-sensor ( $\leq 1000 \mathrm{~nm}$ ) features, InGaAs-sensor ( $\geq 900 \mathrm{~nm}$ ) features, and features covering the whole range $(350-1830 \mathrm{~nm})$. Considering the number of subjects, the number of extracted features $(n=36)$ is too large to perform a statistically meaningful classification, as the extracted features could be redundant in the information they retain. Therefore, using combinations of all 36 features to build a classifier would result in a dimensionality problem and over-fitting ${ }^{29}$. To omit this 
problem, we identified the most distinctive features, for classification of parathyroid in relation to surrounding adipose tissue or adjacent thyroid tissue, by using binary logistic regression (SPSS Inc., Chicago, IL, USA) for both wavelength regions separately. This is a statistical technique that allows the prediction of categorical dependent variables (here the tissue type: parathyroid or adipose/thyroid) using a set of independent variables (here the 36 spectral features) ${ }^{30}$.

In accordance with our previous report on classifying nerve tissue within adipose surroundings $^{23}$, we trained a support vector machine (SVM) classifier ${ }^{31}$ which attempts to find an optimum line to separate the training data groups with a minimum risk ${ }^{29}$. To estimate classification performance and to prevent overly optimistic results ${ }^{20,32,33}$, we implemented a cross-validation (CV) approach. With a goal to obtain the classification accuracy as a performance measure, the data set is divided into a training set (to train the classifier) and a test set (to validate the classifier). The CV approach uses leave-oneout (LOO) validation of the collected parathyroid and adipose/thyroid hyperspectral data. This approach utilizes the same data set for both training and testing purposes and is very useful in cases of a relatively small data sample.

In-house developed classifiers (using MATLAB environment Version 7.7.0, MathWorks Inc., Natick, Massachussetts, USA) were used to estimate the classification performance by calculating sensitivity, specificity, positive predictive value, negative predictive value and accuracy for both wavelength regions (i.e., Si-sensor and InGaAs-sensor detection range). 


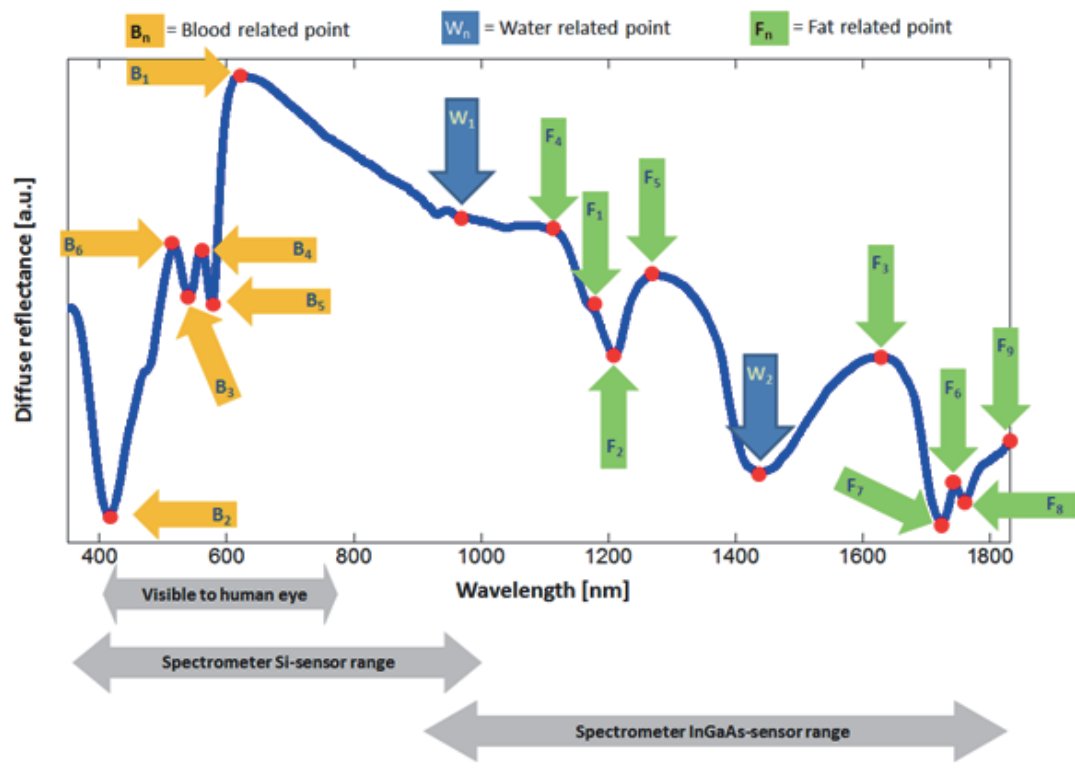

Predefined points
Blood related
$B_{1}: \max [575-800 \mathrm{~nm}]$
$B_{2}: \min [350-500 \mathrm{~nm}]$
$B_{3}: \min [500-560 \mathrm{~nm}]$
$B_{4}: \max [545-570 \mathrm{~nm}]$
$B_{5}: \min [560-600 \mathrm{~nm}]$
$B_{6}: \max [400-550 \mathrm{~nm}]$

\section{Water related}

$\mathrm{W}_{1}: 965 \mathrm{~nm}$

$\mathrm{W}_{2}: 1440 \mathrm{~nm}$

\section{Fat related}

$F_{1}: 1180 \mathrm{~nm}$

$F_{2}: 1210 \mathrm{~nm}$

$F_{3}: \max [1440-1745 \mathrm{~nm}]$

$\mathrm{F}_{4}: \max [1050-1210 \mathrm{~nm}]$

$F_{5}: \max [1210-1350 \mathrm{~nm}]$

$F_{6}: 1745 \mathrm{~nm}$

$F_{7}: 1720 \mathrm{~nm}$

$F_{8}: 1760 \mathrm{~nm}$

$F_{9}: 1830 \mathrm{~nm}$

Gradients
Si-sensor range
$\mathrm{Ft1}: \mathrm{B}_{6} \rightarrow \mathrm{B}_{3}$
$\mathrm{Ft} 2: \mathrm{B}_{5} \rightarrow \mathrm{B}_{1}$
$\mathrm{Ft3}: \mathrm{B}_{2} \rightarrow \mathrm{B}_{6}$
$\mathrm{Ft} 4: \mathrm{B}_{6} \rightarrow \mathrm{B}_{1}$
$\mathrm{Ft5}: \mathrm{B}_{1} \rightarrow \mathrm{W}_{1}$
$\mathrm{Ft} 36:[650: 1: 700 \mathrm{~nm}]$

InGaAs-sensor range

Ft12: $\mathrm{W}_{1} \rightarrow \mathrm{F}_{4}$

Ft13: $W_{2} \rightarrow F_{4}$

Ft14: $F_{2} \rightarrow F_{1}$

Ft15: $F_{2} \rightarrow F_{5}$

Ft16: $F_{1} \rightarrow F_{4}$

Ft17: $F_{4} \rightarrow F_{5}$

Ft18: $W_{2} \rightarrow F_{5}$

Ft19: $W_{2} \rightarrow F_{3}$

Ft20: $F_{7} \rightarrow F_{3}$

Ft21: $F_{7} \rightarrow F_{6}$

Ft22: $F_{7} \rightarrow F_{8}$

Ft23: $F_{3} \rightarrow F_{9}$

\section{Amplitude differences}

$$
\begin{aligned}
& \text { Si-sensor range } \\
& \text { Ft6 : } \mathrm{B}_{6}-\mathrm{B}_{3} \\
& \text { Ft7 : } \mathrm{B}_{5}-\mathrm{B}_{1} \\
& \text { Ft8 }: \mathrm{B}_{4}-\mathrm{B}_{3} \\
& \text { Ft9 }: \mathrm{B}_{4}-\mathrm{B}_{5} \\
& \text { Ft10: } \mathrm{B}_{1}-\mathrm{W}_{1}
\end{aligned}
$$
InGaAs-sensor range
Ft11: $\mathrm{W}_{2}-\mathrm{W}_{1}$
Ft24: $W_{1}-F_{4}$
Ft25: $W_{2}-F_{4}$
Ft26: $F_{2}-F_{1}$
Ft27: $F_{2}-F_{5}$
Ft28: $F_{1}-F_{4}$
Ft29: $F_{4}-F_{5}$
Ft30: $W_{2}-F_{5}$
Ft31: $W_{2}-F_{3}$
Ft32: $F_{7}-F_{3}$
Ft33: $F_{7}-F_{6}$
Ft34: $F_{7}-F_{8}$
Ft35: $F_{3}-F_{9}$

Figure 10.2 Example of spectrum (adipose tissue) with characteristic wavelengths and investigated features Qualitative landmarks for oxygenated/reduced hemoglobin (characteristic "W-shape" between 500 and $600 \mathrm{~nm}$ ), water (absorption peaks at 965 and $1440 \mathrm{~nm}$ ) and human fat (absorption peaks at 1210 and $1720 \mathrm{~nm})^{26-28}$ are indicated by the arrows. The spectral detection ranges of respectively the human eye and of Si-sensor and InGaAs-sensor based camera chips are indicated. This Figure was previously published as Figure 2 in: "Differentiation between nerve and adipose tissue using wide-band (350-1,830 nm) in vivo diffuse reflectance spectroscopy", by Schols RM, ter Laan M, Stassen LP, Bouvy ND, Amelink A, Wieringa FP, Alic L; Lasers in Surgery and Medicine, 2014;46:538-845, (C) 2014 Wiley Periodicals, Inc. Wiley-Blackwell. Used with permission. 


\section{Results}

In 19 patients (4 male, 15 female) undergoing parathyroid or thyroid surgery, 299 in vivo tissue spectra were recorded on 62 tissue sites (thyroid $n=23$, parathyroid gland $n=21$, adipose tissue $n=18$ ). Table 10.1 summarizes patient characteristics and the number of measured sites per tissue type. Figure 10.3 shows mean diffuse reflectance spectra and corresponding standard deviations for thyroid, parathyroid and surrounding adipose tissue.

Table 10.1 Study subject characteristics and measured sites per tissue type

\begin{tabular}{|c|c|c|c|c|c|c|c|c|}
\hline \multirow[t]{2}{*}{ Subject } & \multirow[t]{2}{*}{ Gender } & \multirow{2}{*}{\multicolumn{2}{|c|}{ Age BMI }} & \multirow[t]{2}{*}{ Indication for surgery } & \multirow[t]{2}{*}{ Surgical procedure } & \multicolumn{3}{|c|}{ Sites per tissue type } \\
\hline & & & & & & Thyroid & Parathyroid & Adipose \\
\hline 1 & $M$ & 67 & 24 & $\begin{array}{c}\text { Bethesda } 3^{*} \text { node thyroid } \\
\text { left }\end{array}$ & Left HT & 2 & 2 & 0 \\
\hline 2 & $\mathrm{~F}$ & 55 & 32 & $\mathrm{PH}$ & Right PAR & 2 & 1 & 2 \\
\hline 3 & M & 54 & 31 & $\begin{array}{c}\text { MEN-2a syndrome, } \\
\text { medullar thyroid carcinoma } \\
\text { left }\end{array}$ & $\begin{array}{l}\mathrm{TT}+\text { radical LND neck, } \\
\text { right axillary LND }\end{array}$ & 0 & 0 & 1 \\
\hline 4 & $\mathrm{~F}$ & 14 & 21 & $\mathrm{PH}$ & Left PAR & 2 & 2 & 2 \\
\hline 5 & $\mathrm{~F}$ & 67 & 37 & $\begin{array}{c}\text { Status after } \\
\text { hemithyroidectomy right, in } \\
\text { which a follicular carcinoma } \\
\text { was found }\end{array}$ & $\begin{array}{l}\text { Resection of } \\
\text { remaining thyroid } \\
\text { (left HT) }\end{array}$ & 0 & 2 & 1 \\
\hline 6 & $\mathrm{~F}$ & 53 & 34 & Multinodular goiter & $\mathrm{TT}$ & 2 & 2 & 1 \\
\hline 7 & $\mathrm{~F}$ & 56 & 44 & $\begin{array}{c}\text { Bethesda } 2 * \text { node thyroid } \\
\text { right }\end{array}$ & Right HT & 0 & 0 & 1 \\
\hline 8 & $\mathrm{~F}$ & 67 & 30 & Multinodular goiter & Left HT & 1 & 0 & 0 \\
\hline 9 & $\mathrm{~F}$ & 60 & 43 & $\begin{array}{c}\text { Tertiary } \\
\text { hyperparathyroidism after } \\
\text { kidney transplantation }\end{array}$ & $\begin{array}{l}\text { Subtotal parathyroid } \\
\text { resection }\end{array}$ & 1 & 1 & 0 \\
\hline 10 & $\mathrm{~F}$ & 55 & - & Multinodular goiter & $\begin{array}{l}\text { Left } \mathrm{HT}+\text { subtotal } \\
\text { right thyroidectomy }\end{array}$ & 1 & 0 & 0 \\
\hline 11 & $\mathrm{~F}$ & 50 & 18 & Multinodular goiter & Left HT & 1 & 1 & 1 \\
\hline 12 & M & 80 & 26 & $\mathrm{PH}$ & Left PAR & 1 & 0 & 1 \\
\hline 13 & $\mathrm{~F}$ & 54 & 35 & $\mathrm{PH}$ & Right PAR & 1 & 1 & 1 \\
\hline 14 & M & 74 & 29 & $\mathrm{PH}$ & Right PAR & 1 & 0 & 1 \\
\hline 15 & $\mathrm{~F}$ & 60 & 31 & Multinodular goiter & Left HT & 1 & 1 & 1 \\
\hline 16 & $\mathrm{~F}$ & 46 & 30 & Multinodular goiter & Left HT & 1 & 2 & 1 \\
\hline 17 & $\mathrm{~F}$ & 53 & 34 & $\begin{array}{c}\text { Bethesda } 3 * \text { node thyroid } \\
\text { right }\end{array}$ & Right HT & 2 & 2 & 2 \\
\hline 18 & $\mathrm{~F}$ & 23 & 23 & Graves' disease & $\mathrm{TT}$ & 2 & 2 & 1 \\
\hline \multirow[t]{3}{*}{19} & $\mathrm{~F}$ & 49 & 19 & Multinodular goiter & Left HT & 2 & 2 & 1 \\
\hline & & & & & $\begin{array}{l}\text { Sites per tissue type } \\
\text { (grand total 62) }\end{array}$ & 23 & 21 & 18 \\
\hline & & & & & $\begin{array}{c}\text { Spectra per tissue } \\
\text { type (grand total 299) }\end{array}$ & 112 & 97 & 90 \\
\hline
\end{tabular}

* The Bethesda system was used for reporting thyroid cytopathology ${ }^{34} . \mathrm{M}=$ male; $\mathrm{F}=$ female; $\mathrm{BMI}=$ body mass index; $\mathrm{PH}=$ primary hyperparathyroidism; $\mathrm{PAR}=$ parathyroid adenoma resection; $\mathrm{HT}=$ hemithyroidectomy; TT = total thyroidectomy; LND = lymph node dissection. 


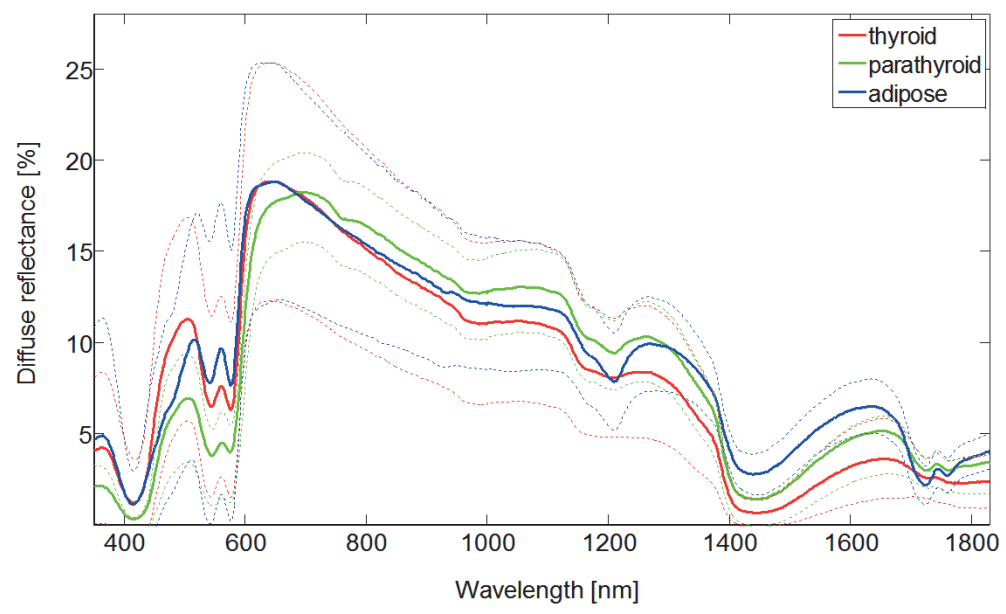

Figure 10.3 Mean spectra per tissue type

Average tissue spectra for thyroid (red), parathyroid (green) and adipose tissue (blue). Dashed lines in the corresponding colors indicate the respective standard deviations.

\section{Classification of spectral data in Si-sensor range}

From the 36 extracted features (see Figure 10.2) 11 were located within the silicon detection range. Given the study sample of an average of 20 spots per tissue type, inclusion of maximum 2 features is allowed. Binary logistic regression identified gradients Ft3 $\left(B_{2}-B_{6}\right)$ and Ft36 $(650-700 \mathrm{~nm})$ as most promising combination for differentiation of parathyroid from surrounding adipose tissue. Gradient Ft36 (650-700 nm) solely, also appeared to be the best distinctive feature for differentiation of parathyroid from thyroid tissue. Figure 10.4A shows a scatter plot (Ft36 and Ft3) for classification of parathyroid in adipose surrounding. Figure 10.4B shows a boxplot (Ft 36) for classification of parathyroid in thyroid surrounding.

The quantitative results of classification performance are listed in Table 10.2. Leaveone-out cross-validation (LOO CV) is based on Si-sensor range data from thyroid and parathyroid surgery for train and test purposes. 


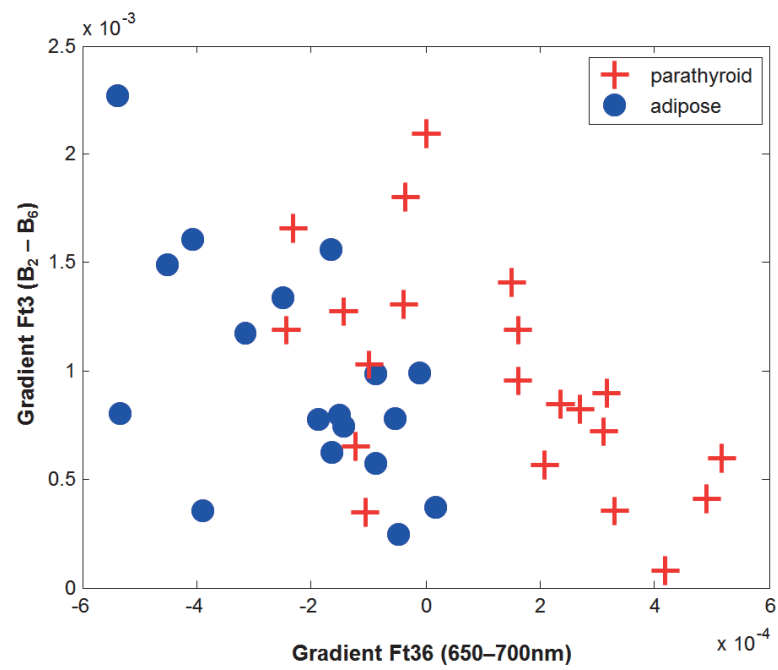

Figure 10.4A Parathyroid versus adipose tissue: Scatter plot of two selected features within Si-range Scatter plot showing two selected features: gradients Ft3 and Ft36.

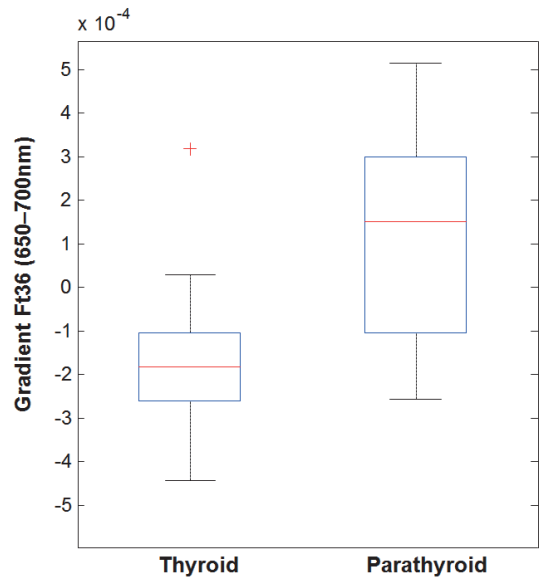

Figure 10.4B Parathyroid versus thyroid: Scatter plot of selected feature within Si-range Scatter plot showing selected feature: gradient Ft36 
Table 10.2 Classification performance of selected Si-sensor features

\begin{tabular}{lccccccc}
\hline LOO CV & TP & TN & Sensitivity & Specificity & PPV & NPV & Accuracy \\
\hline Parathyroid - Adipose & $15 / 21$ & $16 / 18$ & $71(48-88)$ & $89(64-98)$ & $88(62-98)$ & $73(50-88)$ & 79 \\
Parathyroid - Thyroid & $15 / 21$ & $20 / 23$ & $71(48-88)$ & $87(65-97)$ & $83(58-96)$ & $77(56-90)$ & 80 \\
\hline
\end{tabular}

$\mathrm{TP}=$ true positive; $\mathrm{TN}=$ true negative $\rightarrow$ numbers indicate identified tissue spots. A positive test is defined as the tissue observed being parathyroid gland; a negative test is defined as the tissue observed being adipose tissue / thyroid. Sensitivity; specificity; PPV = positive predictive value; NPV = negative predictive value; accuracy $\rightarrow$ numbers are percentages; numbers in parentheses indicate $95 \%$ confidence interval. LOO CV $=$ leave-one-out cross-validation.

\section{Classification of spectral data in InGaAs-sensor range}

From the 36 extracted features 25 were located within the spectral detection range of InGaAs (see Figure 10.2). After binary logistic regression, gradients Ft12 $\left(W_{1}-F_{4}\right)$ and Ft17 $\left(F_{4}-F_{5}\right)$ were selected as the most promising combination for differentiation of parathyroid from surrounding adipose tissue. Gradients Ft12 $\left(W_{1}-F_{4}\right)$ and Ft14 $\left(F_{2}-F_{1}\right)$ were identified as most best distinctive feature combination for differentiation of parathyroid from thyroid tissue. Figure 10.5A and 10.5B show scatter plots for these InGaAs-sensor based features, extracted for respectively parathyroid versus adipose tissue and parathyroid versus thyroid tissue.

The quantitative results of LOO CV classification performance are listed in Table 10.3. LOO CV is solely based on InGaAs-sensor range data from thyroid and parathyroid surgery for train and test purposes.

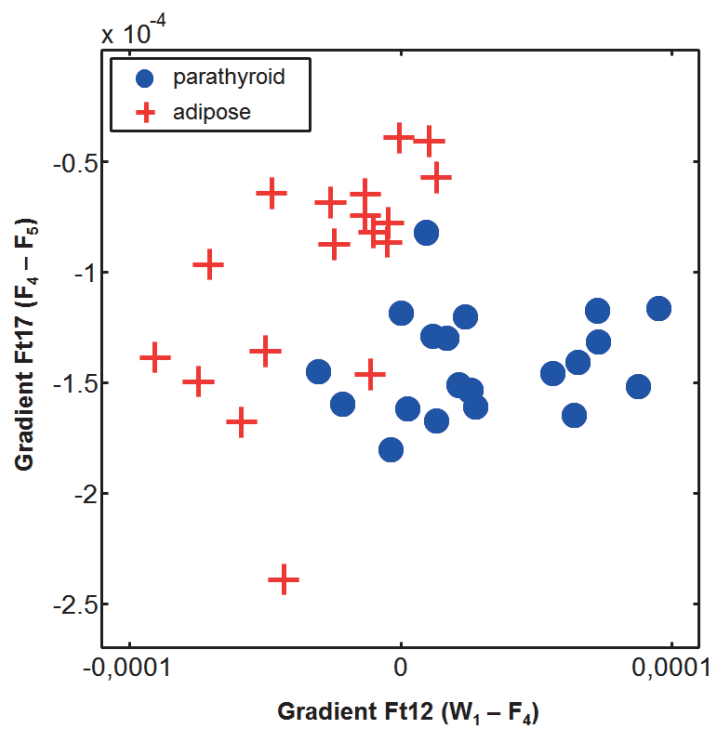

Figure 10.5A Parathyroid versus adipose tissue: Scatter plot of two selected features within InGaAs-range Scatter plot showing two selected features (gradients Ft12 and Ft17) 


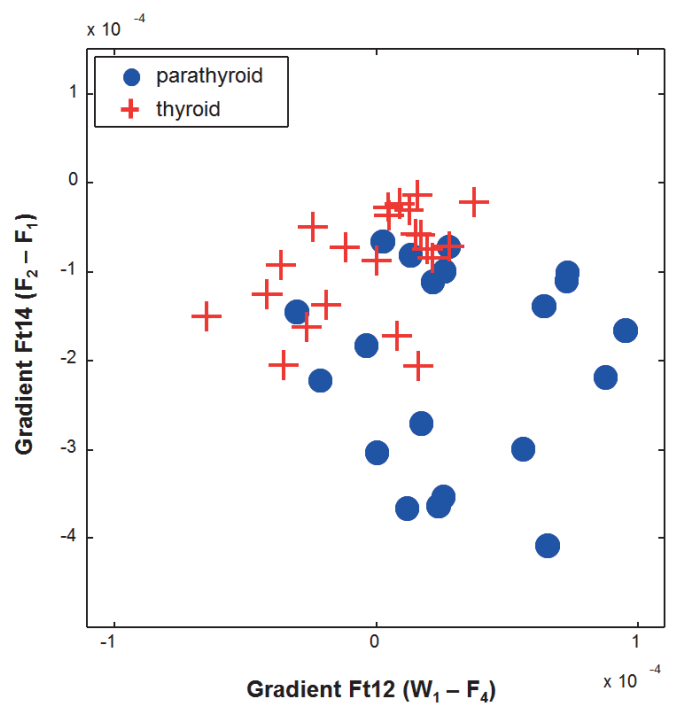

Figure 10.5B Parathyroid versus thyroid tissue: Scatter plot of two selected features within InGaAs-range Scatter plot showing selected features (gradients Ft12 and Ft14)

Table 10.3 Classification performance of selected InGaAs-sensor features

\begin{tabular}{lccccccc}
\hline LOO CV & TP & TN & Sensitivity & Specificity & PPV & NPV & Accuracy \\
\hline Parathyroid - Adipose & $19 / 21$ & $13 / 18$ & $90(68-98)$ & $72(46-89)$ & $79(57-92)$ & $87(58-98)$ & 82 \\
Parathyroid - Thyroid & $16 / 21$ & $17 / 23$ & $76(52-91)$ & $74(51-89)$ & $73(50-88)$ & $77(54-91)$ & 75 \\
\hline
\end{tabular}

$\mathrm{TP}=$ true positive; TN $=$ true negative $\rightarrow$ numbers indicate identified tissue spots. A positive test is defined as the tissue observed being parathyroid gland; a negative test is defined as the tissue observed being adipose tissue / thyroid. Sensitivity; specificity; PPV = positive predictive value; NPV = negative predictive value; accuracy $\rightarrow$ numbers are percentages; numbers in parentheses indicate $95 \%$ confidence interval. LOO CV $=$ leave-one-out cross-validation.

\section{Combining Si-sensor and InGaAs-sensor ranges for spectral data classification}

Classification performance was also evaluated when combining the Si-sensor and InGaAs-sensor detector ranges, including up to 3 spectral features. After binary logistic regression, gradients Ft12 $\left(\mathrm{W}_{1}-\mathrm{F}_{4}\right)$, Ft17 $\left(\mathrm{F}_{4}-\mathrm{F}_{5}\right)$ and Ft36 $(650-700 \mathrm{~nm})$ were selected as the most promising combination for differentiation of parathyroid from surrounding adipose tissue.

Gradients Ft27 $\left(\mathrm{W}_{1}-\mathrm{F}_{4}\right)$ and Ft32 $\left(\mathrm{F}_{2}-\mathrm{F}_{1}\right)$ and Ft36 $(650-700 \mathrm{~nm})$ were identified as best distinctive feature combination for differentiation of parathyroid from thyroid tissue. 
Figure $10.6 \mathrm{~A}$ and $10.6 \mathrm{~B}$ show scatter plots for these combined Si-sensor and InGaAssensor based features, extracted for respectively parathyroid versus adipose tissue and parathyroid versus thyroid tissue.

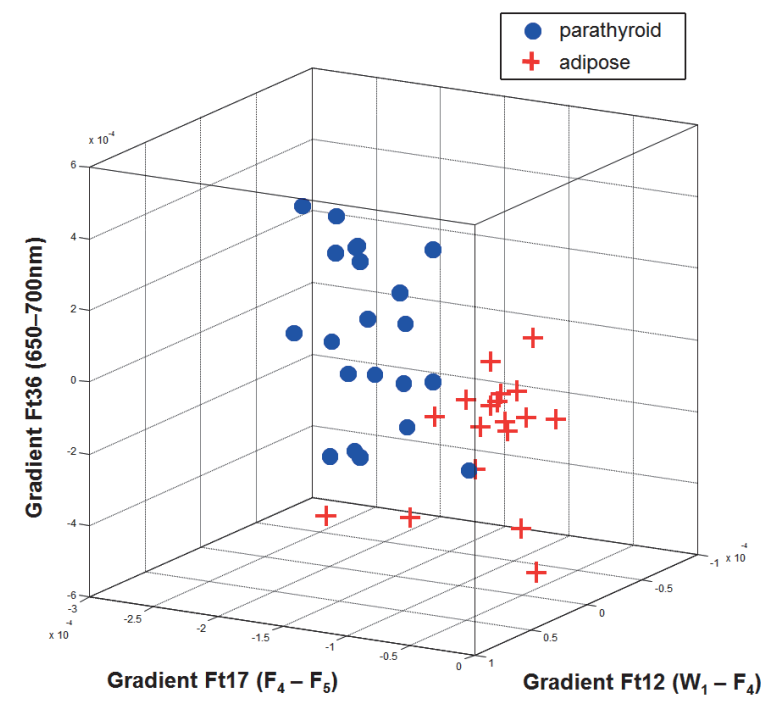

Figure 10.6A Parathyroid versus adipose tissue: Scatter plot of three selected features Three-dimensional scatter plot showing selected features (gradients Ft12, Ft17 and Ft36)

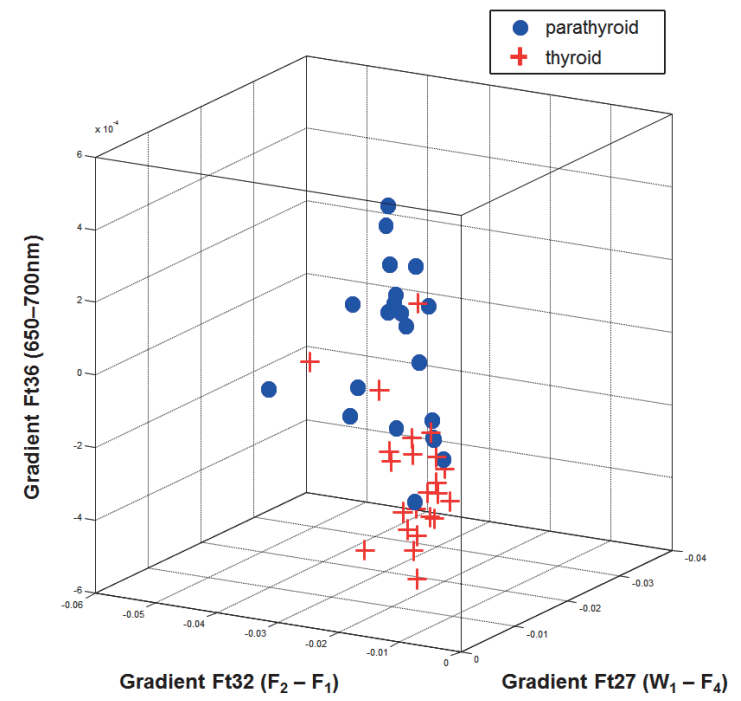

Figure 10.6B Parathyroid versus thyroid tissue: Scatter plot of three selected features Three-dimensional scatter plot showing selected features (gradients Ft27, Ft32 and Ft36). 
The quantitative results of LOO CV classification performance are listed in Table 10.4. LOO CV is based on the whole wide-band spectral range covering both Si-sensor and InGaAs-sensor range data from thyroid and parathyroid surgery for train and test purposes.

Table 10.4 Classification performance of combined Si-sensor and InGaAs-sensor features

\begin{tabular}{llllllll}
\hline LOO CV & TP & TN & Sensitivity & Specificity & PPV & NPV & Accuracy \\
\hline Parathyroid - Adipose & $21 / 21$ & $17 / 18$ & $100(81-100)$ & $94(71-100)$ & $95(75-100)$ & $100(77-100)$ & 97 \\
Parathyroid-Thyroid & $18 / 21$ & $18 / 23$ & $86(63-96)$ & $78(56-92)$ & $78(56-92)$ & $86(63-96)$ & 82 \\
\hline
\end{tabular}

$\mathrm{TP}=$ true positive; TN $=$ true negative $\rightarrow$ numbers indicate identified tissue spots. A positive test is defined as the tissue observed being parathyroid gland; a negative test is defined as the tissue observed being adipose tissue / thyroid. Sensitivity; specificity; PPV = positive predictive value; NPV = negative predictive value; accuracy $\rightarrow$ numbers are percentages; numbers in parentheses indicate $95 \%$ confidence interval. LOO CV $=$ leave-one-out cross-validation.

\section{Discussion}

The wide band (350 - $1830 \mathrm{~nm}$ ) diffuse optical reflectance fingerprints of human thyroid, parathyroid and surrounding adipose tissue were identified in this explorative study. These spectra covered silicon ( $\mathrm{Si}$ ) and indium gallium arsenide (InGaAs) detector ranges, thereby exceeding wavelength boundaries (1600 $\mathrm{nm}$ or $1700 \mathrm{~nm}$ ) reported by preceding work $^{21,22,25,35}$. Spectroscopic measurements on human skin samples in the wavelength range of $1000-2200 \mathrm{~nm}$ have been reported previously ${ }^{36}$, but not regarding any of the tissues included by our study.

Although the presented reflectance spectra (Figure 10.3) show great similarity between the three different tissue types, performance of automated tissue-specific classification was fairly accurate in both sensor detection ranges (i.e. Si and InGaAs) to discriminate parathyroid tissue from either surrounding adipose tissue or adjacent thyroid tissue. Based on the classification accuracies (Table 10.2 and Table 10.3) we can conclude that Si and InGaAs sensors are equally suited for automated discrimination between parathyroid glands and surrounding adipose tissue or adjacent thyroid tissue. As tissueclassification accuracies of around $80 \%$ are far from clinically relevant, we also investigated combining the two spectral sensor ranges, which resulted in improved classification performance regarding differentiation of parathyroid tissue from surrounding adipose tissue (Table 10.4).

Regarding the spectral signatures of the three tissue types (Figure 10.3) we observed a clear opposite course (i.e., ascending slope between 650 - $700 \mathrm{~nm}$ ) for parathyroid compared to the spectra of adipose tissue and thyroid (i.e., descending slope). From 
this, feature Ft36 was established. Another blood-related feature (Ft3) in the Si sensor range was complementary for distinguishing parathyroid from surrounding adipose tissue (Figure 10.4). Within the InGaAs sensor range fat-related features (Figure 10.5, respectively Ft12 and Ft14, and Ft12 and Ft17) performed best for enabling automated tissue classification. Combining $\mathrm{Si}$ and InGaAs sensor features resulted in improved tissue classification, this was especially profound when discriminating parathyroid from adipose tissue. The statistically different spectral features used for classification of parathyroid versus adipose tissue or thyroid are probably due to differences in chemical composition (e.g., water/lipid content) of the investigated tissues and structures.

Experimental methods such as near-infrared fluorescence imaging after peripheral infusion of aminolevulinic acid ${ }^{8,9}$ or methylene blue ${ }^{10}$ (i.e. exogenous contrast agents) can be used for parathyroid gland or parathyroid adenoma localization. The reflectance spectra in our study, which were the basis to extract spectral features, originate from intrinsic tissue properties (i.e. endogenous chromophores) that do not require dye administration. Consequently there is no risk of potential toxicity or allergy to a contrast agent.

As the LOO cross-validation method inherently produces relatively optimistic classification results, external validation remains essential before classification models can be implemented in clinical practice ${ }^{37}$. Such validation would need to be performed on newly acquired data in a multi-center study.

In this study, we use physiological knowledge on composition of different tissue types, and thereby use the pre-defined spectral regions of interest covering hemoglobin, water and fat. Tissue differentiation on the basis of completely automatically extracted features from a larger data set might achieve better results, and should be explored in future work. Additionally, as the acquired reflectance spectra are specific to the probe geometry, more research is needed on the relation between these reflectance spectra and in vivo intrinsic tissue biological properties which potentially could be captured by optical tissue properties. This is needed to obtain a better understanding of the nature of discrimination performance: i.e. whether parathyroid glands can be optically distinguished from surrounding adipose tissues or adjacent thyroid tissue based on differences in light scattering behaviour (related to structural differences) or due to differences in absorption behaviour (related to chromophore concentrations such as blood, water and fat). Such an approach would also be tissue-specific and robust to inter-patient and multi-center variability.

The gold standard used in this study was the surgeon's visual judgment (one surgeon who has performed $>1000$ thyroid surgeries; histo-pathological confirmation of the in vivo measured tissues was not possible). This judgment is based on color (spectral) information, on the recognition of anatomical position as well as on spatial structure of 
a specific tissue, and on palpation. For our technique to add most to this judgment, it should be extended from spot-wise probe-measurements to imaging of the complete surgical field of view.

In contrast to previous ex vivo experiments using wide-band diffuse reflectance spectroscopy $^{24}$, these measurements were performed during surgery. In vivo circumstances as vascular filling and oxygenation were thus not disrupted.

In conclusion, in this study we have identified that Si and InGaAs sensors are fairly accurate for automated discrimination between parathyroid glands and surrounding adipose tissue or adjacent thyroid tissue (but not yet with clinically relevant levels of accuracy). Combination of these two sensor technologies improves accuracy especially regarding parathyroid-adipose tissue classification. The potential for automated parathyroid gland detection based on endogenous contrasts is underlined by our results. 


\section{References}

1. Mohebati A, Shaha AR (2012) Anatomy of thyroid and parathyroid glands and neurovascular relations. Clin Anat 25:19-31

2. Christou N, Mathonnet M (2013) Complications after total thyroidectomy. J Visc Surg 150:249-256

3. Lefevre JH, Tresallet C, Leenhardt L, Jublanc C, Chigot JP, Menegaux F (2007) Reoperative surgery for thyroid disease. Langenbecks Arch Surg 392:685-691

4. Hahn LD, Hoyt C, Rimm DL, Theoharis C (2013) Spatial spectral imaging as an adjunct to the Bethesda classification of thyroid fine-needle aspiration specimens. Cancer Cytopathol 121:162-167

5. Mansoor I, Zalles C, Zahid F, Gossage K, Levenson RM, Rimm DL (2008) Fine-needle aspiration of follicular adenoma versus parathyroid adenoma: the utility of multispectral imaging in differentiating lesions with subtle cytomorphologic differences. Cancer 114:22-26

6. Das K, Stone N, Kendall C, Fowler C, Christie-Brown J (2006) Raman spectroscopy of parathyroid tissue pathology. Lasers Med Sci 21:192-197

7. Suh H, A'Amar O, Rodriguez-Diaz E, Lee S, Bigio I, Rosen JE (2011) Elastic light-scattering spectroscopy for discrimination of benign from malignant disease in thyroid nodules. Ann Surg Oncol 18:1300-1305

8. Prosst RL, Willeke F, Schroeter L, Post S, Gahlen J (2006) Fluorescence-guided minimally invasive parathyroidectomy: a novel detection technique for parathyroid glands. Surg Endosc 20:1488-1492

9. Prosst RL, Weiss J, Hupp L, Willeke F, Post S (2010) Fluorescence-guided minimally invasive parathyroidectomy: clinical experience with a novel intraoperative detection technique for parathyroid glands. World J Surg 34:2217-2222

10. van der Vorst JR, Schaafsma BE, Verbeek FP, Swijnenburg RJ, Tummers Q, Hutteman M, Hamming JF, Kievit J, Frangioni JV, van de Velde CJ, Vahrmeijer AL (2014) Intraoperative Near-Infrared Fluorescence Imaging of Parathyroid Adenomas using Low-Dose Methylene Blue. Head Neck 36:853-858.

11. Paras C, Keller M, White L, Phay J, Mahadevan-Jansen A (2011) Near-infrared autofluorescence for the detection of parathyroid glands. J Biomed Opt 16:067012

12. Ladurner R, Hallfeldt KK, Al Arabi N, Stepp H, Mueller S, Gallwas JK (2013) Optical coherence tomography as a method to identify parathyroid glands. Lasers Surg Med 45:654-659

13. Conti de Freitas LC, Phelan E, Liu L, Gardecki J, Namati E, Warger WC, Tearney GJ, Randolph GW (2014) Optical coherence tomography imaging during thyroid and parathyroid surgery: A novel system of tissue identification and differentiation to obviate tissue resection and frozen section. Head Neck 36:1329-1334

14. Lu G, Fei B (2014) Medical hyperspectral imaging: a review. J Biomed Opt 19:10901

15. Holzer MS, Best SL, Jackson N, Thapa A, Raj GV, Cadeddu JA, Zuzak KJ (2011) Assessment of renal oxygenation during partial nephrectomy using hyperspectral imaging. J Urol 186:400-404

16. Olweny EO, Faddegon S, Best SL, Jackson N, Wehner EF, Tan YK, Zuzak KJ, Cadeddu JA (2013) Renal oxygenation during robot-assisted laparoscopic partial nephrectomy: characterization using laparoscopic digital light processing hyperspectral imaging. J Endourol 27:265-269

17. Zuzak KJ, Naik SC, Alexandrakis G, Hawkins D, Behbehani K, Livingston E (2008) Intraoperative bile duct visualization using near-infrared hyperspectral video imaging. Am J Surg 195:491-497

18. Wieringa FP, Mastik F, Duncker DJ, Bogers AJ (2006) Contrast enhancement of coronary arteries in cardiac surgery: a new multispectral stereoscopic camera technique. Eurolntervention : journal of EuroPCR in collaboration with the Working Group on Interventional Cardiology of the European Society of Cardiology 2:389-394

19. Panasyuk SV, Yang S, Faller DV, Ngo D, Lew RA, Freeman JE, Rogers AE (2007) Medical hyperspectral imaging to facilitate residual tumor identification during surgery. Cancer Biol Ther 6:439-446

20. Stelzle F, Zam A, Adler W, Tangermann-Gerk K, Douplik A, Nkenke E, Schmidt M (2011) Optical nerve detection by diffuse reflectance spectroscopy for feedback controlled oral and maxillofacial laser surgery. J Transl Med 9:20

21. Nachabe R, Hendriks BH, Desjardins AE, van der Voort M, van der Mark MB, Sterenborg HJ (2010) Estimation of lipid and water concentrations in scattering media with diffuse optical spectroscopy from 900 to $1,600 \mathrm{~nm}$. J Biomed Opt 15:037015 
22. Nachabe R, Hendriks BH, van der Voort M, Desjardins AE, Sterenborg HJ (2010) Estimation of biological chromophores using diffuse optical spectroscopy: benefit of extending the UV-VIS wavelength range to include 1000 to $1600 \mathrm{~nm}$. Biomed Opt Express 1:1432-1442

23. Schols RM, ter Laan M, Stassen LP, Bouvy ND, Amelink A, Wieringa FP, Alic L (2014) Differentiation between nerve and adipose tissue using wide-band $(350-1830 \mathrm{~nm})$ in vivo diffuse reflectance spectroscopy. Lasers in Surgery and Medicine. 46:538-545

24. Schols RM, Dunias P, Wieringa FP, Stassen LP (2013) Multispectral characterization of tissues encountered during laparoscopic colorectal surgery. Med Eng Phys 35:1044-1050

25. Akbari H, Kosugi Y, Kojima K, Tanaka N (2009) Blood vessel detection and artery-vein differentiation using hyperspectral imaging. Conf Proc IEEE Eng Med Biol Soc 2009:1461-1464

26. Zijlstra WG, Buursma A, Meeuwsen-van der Roest WP (1991) Absorption spectra of human fetal and adult oxyhemoglobin, de-oxyhemoglobin, carboxyhemoglobin, and methemoglobin. Clin Chem 37:1633-1638

27. Anderson RR, Farinelli W, Laubach H, Manstein D, Yaroslavsky AN, Gubeli J, 3rd, Jordan K, Neil GR, Shinn M, Chandler W, Williams GP, Benson SV, Douglas DR, Dylla HF (2006) Selective photothermolysis of lipid-rich tissues: a free electron laser study. Lasers Surg Med 38:913-919

28. Roggan A, Friebel M, Do Rschel K, Hahn A, Mu Ller G (1999) Optical Properties of Circulating Human Blood in the Wavelength Range 400-2500 nm. J Biomed Opt 4:36-46

29. Boser BE, Guyon IM, Vapnik VN (1992) A Training Algorithm for Optimal Margin Classifiers. Proceedings of the 5th Annual ACM Workshop on Computational Learning Theory:144-152

30. Tabachnick BG, Fidell LS (2007) Using multivariate statistics, 5th edn, Allyn-Bacon, Boston, MA

31. Mercier G, Lennon M (2003) Support vector machines for hyperspectral image classification with spectral-based kernels. Geoscience and Remote Sensing Symposium, 2003 IGARSS '03 Proceedings 2003 IEEE International 1:288-290

32. Stelzle F, Tangermann-Gerk K, Adler W, Zam A, Schmidt M, Douplik A, Nkenke E (2010) Diffuse reflectance spectroscopy for optical soft tissue differentiation as remote feedback control for tissuespecific laser surgery. Lasers Surg Med 42:319-325

33. Stelzle F, Adler W, Zam A, Tangermann-Gerk K, Knipfer C, Douplik A, Schmidt M, Nkenke E (2012) In vivo optical tissue differentiation by diffuse reflectance spectroscopy: preliminary results for tissue-specific laser surgery. Surg Innov 19:385-393

34. Cibas ES, Ali SZ (2009) The Bethesda System For Reporting Thyroid Cytopathology. Am J Clin Pathol 132:658-665

35. Cao Q, Zhegalova NG, Wang ST, Akers WJ, Berezin MY (2013) Multispectral imaging in the extended near-infrared window based on endogenous chromophores. J Biomed Opt 18:101318

36. Troy TL, Thennadil SN (2001) Optical properties of human skin in the near infrared wavelength range of 1000 to $2200 \mathrm{~nm}$. J Biomed Opt 6:167-176

37. Bleeker SE, Moll HA, Steyerberg EW, Donders AR, Derksen-Lubsen G, Grobbee DE, Moons KG (2003) External validation is necessary in prediction research: a clinical example. J Clin Epidemiol 56:826-832 


\section{Chapter 11}

Summary, discussion and future perspectives 
Chapter 11 


\section{Summary}

Numerous technological innovations have entered the operating room in the past decades. Especially minimally invasive surgery is associated with a continuous stream of new technological developments. Image-guided surgery is one of the latest innovations knocking at the door of the operating room of the future ${ }^{1,2}$.

Detection of vital anatomical structures (e.g. nerves, ureters, arteries, bile ducts) is of utmost importance during all kinds of surgical procedures, as anatomical misidentification of these structures may lead to iatrogenic injury. The exploration of innovative optical techniques offers a roadmap to improve intraoperative identification and characterization of these tissues.

Following a systematic literature search, Chapter $\mathbf{2}$ describes six optical techniques as potential intraoperative tools for real-time anatomical guidance in surgery: infrared-ray imaging, fluorescence imaging, optical coherence tomography, diffuse reflectance spectroscopy, hyperspectral imaging and optoacoustic imaging. An overview is given of the most recent developments regarding these optical techniques for enhanced anatomical identification and physiological characterization. To evaluate optical techniques based on exogenous or endogenous contrasts this thesis focuses on two techniques: near-infrared fluorescence imaging using exogenous contrasts (Part I) and diffuse reflectance spectroscopy using endogenous contrasts (Part II).

\section{Near-infrared fluorescence-guided laparoscopy (Part I)}

Laparoscopic cholecystectomy is one of the most commonly performed laparoscopic procedures. Bile duct injury is a rare but serious complication during this procedure, mostly caused by misidentification of the extra-hepatic bile duct anatomy. Conventional intraoperative cholangiography may be helpful to reduce the risk of bile duct injury; however this is not a common procedure worldwide. Chapter $\mathbf{3}$ describes the first application of a laparoscopic fluorescence imaging system for intermittent near-infrared fluorescence cholangiography (NIRFC) using iodine-free indocyanine green (ICG) during elective laparoscopic cholecystectomy. This pilot study demonstrates the merit of NIRFC as an aid to obtain earlier and clearer recognition of the extra-hepatic bile duct anatomy, compared to conventional laparoscopic imaging alone.

Chapter 4 reports the possibility of concomitant vascular (i.e. cystic artery) and biliary (i.e. cystic duct and common bile duct) imaging at establishment of Critical View of Safety (CVS). Repeated ICG injection at establishment of CVS provides confirmation of arterial anatomy, in particular the course of the cystic artery. Implementation of 
conducting both fluorescence cholangiography and angiography can be helpful in cases in which the establishment of CVS is challenging. Furthermore it may facilitate the intraoperative detection of bile duct and possible concomitant vasculobiliary injury (e.g. hepatic artery). The observations in Chapters $\mathbf{3}$ and $\mathbf{4}$ show that both biliary and vascular fluorescence imaging are easily applicable in laparoscopic cholecystectomy.

Despite these promising findings, optimization of this new technique is desirable with respect to the imaging system combined with the fluorophore. For example, increased penetration depth at which the imaging system can detect a fluorophore in tissues would enhance its applicability (current maximum of 1 centimeter). This also is the case for an increase in fluorescence capabilities (e.g. increased uptake by target tissue, better contrast-to-background signal) of contrast agents. Chapter 5 compares the performance of the pre-clinical near-infrared dye CW800-CA with ICG for near-infrared fluorescence laparoscopy of the cystic duct and artery in pigs. We demonstrated that, next to ICG, CW800-CA can be applied for laparoscopic fluorescence identification of the cystic artery and duct using the same commercially available imaging system. Laparoscopic fluorescent identification of the cystic duct can be obtained earlier after injection of CW800-CA than after injection of ICG. With the availability of another fluorophore (with more powerful fluorescent characteristics), the possibilities increase to further optimize the imaging capabilities of the presently available fluorescence systems. A dose-finding and clinical feasibility study for CW800-CA is the next step.

Ureteral injury seldom occurs during laparoscopic colorectal surgery, but can cause serious problems. Therefore, the early and easy detection of the ureters and prevention of ureteral injury is clinically relevant and important. Chapter 6 describes near-infrared fluorescence delineation of the ureters in a pig model by using a commercially available laparoscopic fluorescence imaging system and CW800-CA. A single dose of CW800-CA ( $85 \mu \mathrm{g}$ per kg bodyweight) provides clear delineation of the course of both ureters approximately ten minutes after intravenous injection. As a possible next step, we envision a clinical pilot study investigating the feasibility of nearinfrared fluorescence imaging (using CW800-CA) for intraoperative delineation of the course of the ureters. Such a future study should focus on a more targeted dose finding of the administered dye.

\section{Diffuse reflectance spectroscopy during surgery (Part II)}

Diffuse reflectance spectroscopy (DRS) is a non-invasive technique measuring the characteristic reflectance spectrum produced by different tissues. The primary mechanism is absorption and scattering of the light, both varying with the wavelength 
of the incident light and the optical properties of the tissue. The reflectance spectrum is used to characterize the nature or type of the tissue being studied.

Human color vision is trichromatic: the eye has three cone types for blue, green and red light. Hyperspectral imaging technology provides an abundance of spectral bands and a wider spectral bandwidth. This technique incorporates the potential to facilitate imageguided surgery. It has, for example, been investigated for noninvasive intraoperative assessment of tissue oxygen saturation, intraoperative enhanced anatomical imaging and intraoperative assessment of resection margins for residual tumor tissue.

Arrays of Charge-Coupled Devices (CCD) and Complementary Metal Oxide Semiconductors (CMOS) are the most commonly used detectors (camera chips) in medical hyperspectral imaging systems, which can be composed of silicon (Si) and indium gallium arsenide (InGaAs) sensors. Si sensors cover the wavelength range of $400-1000 \mathrm{~nm}$, whereas InGaAs sensors are typically sensitive in the $900-1700 \mathrm{~nm}$ wavelength region.

As a first step to evaluate the potential of hyperspectral imaging in surgery, the spectral signatures of a variety of tissue types were explored for distinctive endogenous contrasts using DRS. Presently hyperspectral cameras with Si (covering the visible and near-infrared wavelengths) and InGaAs (covering the extended near-infrared and infrared range) sensor chips are becoming available. Therefore, we report investigations on including spectral distinctive features for these two sensor ranges.

A first ex vivo exploration of DRS was described in Chapter 7. The wide-band spectral properties of various tissue types were investigated in freshly explanted human colonic specimens: normal colonic tissue, tumorous tissue in the colon, mesenteric adipose tissue, arteries, veins and ureter. Translating the acquired spectra into clinically useful information by automated diagnostic algorithms is demonstrated for single spot data. The potential of such first (non-imaging) DRS is the possibility to incorporate the technique in a hyperspectral imaging modality.

In colorectal surgery detecting ureters and mesenteric arteries is of utmost importance to prevent iatrogenic injury and to facilitate intraoperative decision-making. A tool enabling ureter- and artery-specific image enhancement within surrounding adipose tissue would facilitate this need, especially during laparoscopy. Chapter $\mathbf{8}$ describes the use of DRS in open colorectal surgery for classification of ureter and artery in surrounding adipose tissue. To identify possible distinctive features for tissue classification, 36 features (i.e., 18 gradients and 18 amplitude differences at predefined points in the tissue spectra) were extracted based on known wavelengths related to characteristic absorption features for blood, water and fat. Gradients are "slopes" between two predefined points in the tissue spectra, i.e.: $\left(D R_{2}-D R_{1}\right) /\left(\lambda_{2}-\lambda_{1}\right)$. Amplitude differences are "intensity differences" between two predefined spectral 
points, i.e. $\left(D R_{2}-D R_{1}\right)$. $D R=$ diffuse reflectance; $\lambda=$ wavelength. The features used for classification are potentially significant due to differences in chemical composition (e.g. haemoglobin, water and lipid content) of the investigated tissues and structures. This study shows that $\mathrm{Si}$ - and InGaAs-sensors (i.e. the spectral detection ranges which were used in the spectral data analysis, as outlined above) are equally suited for automated classification of ureter versus surrounding adipose tissue. Si-sensors seem better suited for classifying artery versus mesenteric adipose tissue.

Also, intraoperative nerve localization is of great importance in surgery. In certain procedures, where nerves show visual resemblance to surrounding adipose tissue, this can be particularly challenging for the human eye. A camera system, enabling nervespecific image enhancement, would be useful. Chapter 9 identifies InGaAs-sensors as better suited for automated discrimination between nerves and surrounding adipose tissue than Si-sensors. This is probably based on the different ratio in which the endogenous chromophores water and lipid are present in respectively nerve and adipose tissue. Selective enhancement of nerves versus surrounding adipose tissue can be expected to be beneficial within all surgical disciplines.

In thyroid and parathyroid surgery iatrogenic parathyroid injury should be prevented. Detecting the small sized parathyroid glands can be challenging and time consuming. In Chapter 10, automated parathyroid differentiation is investigated. Si- and InGaAssensors seem fairly accurate for automated tissue classification of parathyroid versus adipose tissue or adjacent thyroid tissue. However, clinically relevant accuracy levels were not established for the single sensor types. The combination of the two sensor technologies significantly improves accuracy, especially regarding parathyroid-adipose tissue classification.

Given the results obtained by the several explorative studies using fibre-optic DRS in this thesis, the potential for automated tissue classification is underlined. Therefore, further investigation of hyperspectral enhanced surgical imaging certainly looks worthwhile.

The intraoperative visual judgment of a surgeon is not solely based on color (spectral) information, but also relies on the recognition of spatial anatomical position of a specific tissue. Therefore, the spot-wise probe measurements (i.e. the "ground-truth" reference spectra of specific tissue types) performed in the explorative studies reported in this thesis, should be considered just a first step towards the clinically more relevant technique of hyperspectral imaging of the whole surgical field (i.e. offering tissuespecific contrast-enhancement). 


\section{Discussion and future perspectives}

The research performed in this thesis underlines the potential of real-time, intraoperative optical tools facilitating improved anatomical navigation. Innovative optical techniques might ultimately be implemented during routine surgery as an adjunct to current imaging modalities or even (partly) replace conventional imaging methods, such as conventional intraoperative cholangiography in laparoscopic cholecystectomy.

\section{Tissue differentiation beyond the limits of the human eye}

As already highlighted in the Introduction of this thesis (Chapter 1), in vivo optical techniques can be based on exogenous or endogenous contrasts. The research described in this thesis studied both types of optical techniques. Current state-of-theart fluorescence imaging of tissues is based on exogenous contrast agents active in the near-infrared (NIR) spectral range (wavelength range: $700-900 \mathrm{~nm}$ ). Tissue autofluorescence, absorbance and scattering are minimized in this wavelength range, making NIR fluorophores advantageous over optical dyes which are fluorescent in the

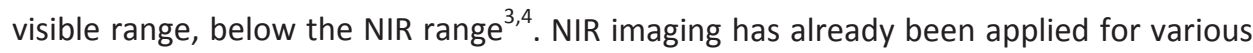
clinical applications in surgery, for both anatomical guidance (Chapter 2) and intraoperative cancer detection ${ }^{5-8}$.

Wide-band (wavelength range: $350-1830 \mathrm{~nm}$ ) diffuse reflectance spectroscopy is based on endogenous tissue contrasts. In the so-called extended NIR spectral range (wavelength range: $1100-1400 \mathrm{~nm}$ ) particularly the endogenous tissue chromophores water and lipid generate different spectra. The different spectra are due to the fact that the chemical tissue composition differs per tissue type. For example, adipose tissue contains 11.4 to $30.5 \%$ water and 61.4 to $87.3 \%$ lipid; blood constitutes for $79.0 \%$ of water and only for $0.6 \%$ of lipid $^{9}$.

This "second near-infrared window" 10 is a relatively undiscovered field in biomedical imaging. This is mainly due to the spectral response limit of silicon (Si) cameras that are blind beyond $1100 \mathrm{~nm}$. With the availability of indium gallium arsenide (InGaAs: $\geq 900 \mathrm{~nm}$ ) sensor camera chips next to standard silicon (Si: $\leq 1000 \mathrm{~nm}$ ) sensors ${ }^{11}$, this extended spectral window now becomes applicable for affordable optical imaging.

In the extended NIR spectral range, deep tissue imaging is very well possible, given an even further minimized auto-fluorescence and scattering compared to the "first NIR window". Cao et al have demonstrated that multispectral imaging in the extended NIR range provides new opportunities for label-free imaging, i.e. without administration of exogenous contrast agents ${ }^{9}$. 


\section{Near-infrared fluorescence imaging: limitations and future perspectives}

As underlined by this thesis, near-infrared fluorescence imaging enables identification of several vital anatomical structures (e.g. bile ducts, arteries, ureters), even when covered under a layer of fatty tissue. These are all hollow structures that can be delineated using endoluminal transported dyes. For nerve imaging, indirect nerve detection by illumination of a neurovascular bundle has been reported ${ }^{12}$. Nerve-specific agents are not yet available for clinical testing. In vivo optical imaging of peripheral nerves using systemically administered myelin-selective fluorescent dyes in a rat and pig model ${ }^{13}$ or nerve-highlighting fluorescent peptides in mice ${ }^{14}$, have been described though. A new NIR fluorescent dye for use in the design of nerve-targeted optical imaging probes is also being developed using a rat model ${ }^{15}$.

Besides anatomical imaging, NIRF imaging is extensively explored for image-guided cancer surgery (e.g. for sentinel lymph node detection in breast cancer, gastric cancer, melanoma and colorectal cancer surgery) ${ }^{16}$.

Compared to conventional radiological imaging techniques, NIRF imaging has already been deemed cost-effective ${ }^{19}$. Also, this new optical imaging technique is regarded as a safe, simple method with the great advantage of enabling real-time imaging of tissues $^{17,18,20-22}$. The safety of the clinically approved fluorescent dyes ICG and methylene blue (MB) is supported by the absence of reported adverse reactions in the literature ${ }^{6,17,18,20-34}$. To further minimize the risk of a possible adverse reaction to the iodine in $\mathrm{ICG}^{8}$, an iodine-free preparation of $I C G^{31}$ can be used for NIRF imaging.

NIRF imaging has the potential and promise to become standard clinical practice during minimally invasive surgery when identification of a critical anatomical structure is required. However, this technique still has limitations that require optimization.

The first of these limitations is the current state of the NIRF imaging systems. It is obvious that the presently available imaging systems will be subjected to further development to improve performance and user-friendliness. Presently, the surgeon is merely "left in the dark" when viewing in fluorescence mode, so one of the improvements that can greatly influence the performance of NIRF imaging during surgery would be the ability to merge white light and fluorescence images in real-time, thereby showing fluorescent structures in their anatomical context.

Another limitation of NIRF imaging is the limited penetration depth at which structures can be visualized using the currently available dyes and imaging systems. Various values have been reported in the literature ${ }^{5,35}$, with a maximum penetration depth found of 10 $\mathrm{mm}$ in fatty tissue. Novel fluorescent dyes and dedicated NIRF imaging systems are needed to improve penetration depth, as in surgery essential structures are not seldom covered by a layer of $\geq 10 \mathrm{~mm}$ fatty tissue. 
The combination of these two factors will allow for an expansion of potential applications for NIRF imaging, by improving the maximum penetration depth of fluorophores and the contrast-to-background-ratio (CBR) through better optics ${ }^{6}$.

Regarding sentinel lymph node detection in cancer surgery, the use of combined radioactive and fluorescent imaging agents has the potential to improve both preoperative (i.e. by planning of the surgical procedure) and intraoperative (i.e., by real-time fluorescence detection) image-guidance ${ }^{36}$.

Next, extending the range of available clinically approved fluorescent dyes is another point that needs attention. To date, only ICG and MB are FDA approved for clinical use. The preclinical fluorescent dyes CW800-CA (investigated in Chapter $\mathbf{5}$ and Chapter $\mathbf{6}$ of this thesis), CW800-NHS and ZW800-1 have been reported as promising new fluorophores due to their excretion through bile (CW800) and/or urine (both CW800 and ZW800-1), high extinction coefficient, high quantum yield, rapid onset of NIR fluorescent signal and the ability for prolonged imaging when compared to ICG and $\mathrm{MB}^{23,30}$. Furthermore, ICG only has a poor binding capacity, whereas this is an area in which fluorophores such as CW800-NHS and ZW800-1 perform very well ${ }^{37,38}$. Unfortunately, it will take some time before these dyes can be included in human trials in order to prove their true potential ${ }^{30}$.

The timing of dye administration is another point of attention. Various strategies have been reported with as many outcomes in terms of performance. For example, in laparoscopic fluorescence cholangiography, twenty-four hours preoperative administration has shown to provide a better CBR compared to two hours preoperative administration $^{39}$. However, logistically this strategy might prove difficult to incorporate for procedures performed in day-care. Future studies are necessary to determine a standard protocol for fluorophore administration in combination with NIRF imaging. This should be performed per type of application.

The implementation of NIRF imaging in standard clinical practice will take time and randomized clinical trials are needed to prove its true benefit compared to current intraoperative imaging techniques ${ }^{6}$. Optimization of both imaging systems and dyes for NIRF imaging (e.g., improving the quality of fluorescence images in terms of higher CBR) can help to reach this goal.

For intraoperative bile duct imaging during laparoscopic cholecystectomy, a multicenter randomized controlled trial is currently being prepared. This study aims to evaluate whether earlier establishment as well as improved visualization of Critical View of Safety can be obtained during laparoscopic cholecystectomy, by applying NIRF laparoscopic imaging as an adjunct to conventional laparoscopic imaging versus conventional laparoscopic imaging alone. 
Ultimately, it is expected that the risk of intraoperative iatrogenic injury, especially during minimally invasive surgical procedures, will decrease as the surgeon can be provided with a clearer and increased in-depth understanding of the whereabouts of vital anatomical structures during surgical dissection ${ }^{25}$.

\section{Spectroscopy and Hyperspectral imaging: limitations and future perspectives}

With the explorative studies on ex vivo and in vivo spectroscopy in this thesis, wideband $(350-1830 \mathrm{~nm}$ ) spectral signatures of several human tissue types were revealed. Regarding the spectral analysis of these data, predefined spectral wavelengths related to three predominant tissue parameters (oxygenated/deoxygenated hemoglobin, water and fat) were applied to extract distinctive spectral features. The relevance of these three parameters with respect to spectroscopic data processing is underlined by a recent review article by Bydlon et al. ${ }^{40}$. These are the three most common endogenous chromophores in the human body and also the most utilized parameters in all of the clinical studies using DRS.

The spectroscopic measurements in this thesis were confined to single-spot data acquisition. A surgeon's judgment regarding anatomical navigation is not solely based on color spectral information, but also relies on the recognition of the spatial anatomical position of a specific tissue. Therefore, future work needs extension from spot-wise data acquisition to spectral image acquisition of the full surgical field. In other words, translation of the DRS findings to multispectral or hyperspectral imaging is needed before surgical image-enhancement can be achieved. For this ultimate goal the first steps have been taken by the studies described in this thesis. Based on the results of the in vivo spectral analyses we now have clues to what sensor detector ranges (i.e., Si- and/or InGaAs-sensors), tissue-specific (e.g. nerve, ureter, artery, parathyroid) contrast-enhancement is feasible to investigate.

When considering probe-based spectroscopy for clinical implementation, a DRS system and the associated optical probes will have to be manufactured on a large scale. Safety regulations have to be met before a probe is suitable for commercial use. The custom developed optical probe as used in the studies described in this thesis, was already CE marked and available for sterile applications during surgery. To facilitate large scale manufacturing of optical systems, a reduction in costs and complexity is needed.

Furthermore, calibration of a DRS system, which is currently necessary each time prior to use, is time-consuming and not desirable as an additive optical tool should decrease the procedural time. This problem could be solved by an automatic internal calibration. 
Not unimportantly, is the role of the end-user of the optical system. In terms of intraoperative anatomical guidance, the surgeon will most likely handle the new optical tool. Depending on the way spectroscopic data will be presented (preferably imagewise, so that the surgeon can relate real-time optical feedback to the conventional surgical view) it has to be determined if and how training of the end-user is required.

It is likely that DRS and/or hyperspectral imaging will eventually serve as an additional intraoperative tool for the surgeon to facilitate automated tissue differentiation (e.g. arterial, ureteral, biliary, nerve) in challenging types of surgery. Applicability is possible in a wide variety of surgical specialties, e.g. general surgery, head and neck surgery, urology, plastic surgery, gynecology and neurosurgery.

As with NIRF imaging, the spectroscopic technique will most likely also be incorporated in e.g. robotic systems, enabling real-time image-guidance during for example robotic microsurgery ${ }^{41}$. Ultimately, surgical navigation will move forward to three-dimensional spectroscopically enhanced endoscopy; not only in telemanipulated (robotic) endoscopic surgery, but also in handheld endoscopy.

In conclusion, future implementation of new intraoperative optical methods, such as NIRF or DRS, can provide the surgeon with improved real-time identification and physiological tissue characterization of essential anatomical structures encountered during a wide variety of surgical procedures. This could significantly contribute to intraoperative anatomy navigation and facilitate critical decision-making. The NIRF technique is closest to clinical implementation. Endogenous contrast-based techniques such as DRS can be a strong surgical tool when further development has been completed. Both NIRF and DRS still have their limitations but certainly also have potential to improve surgical care as additive intraoperative tools. This can ultimately result in higher procedural safety and efficiency. Health-care costs could be reduced by avoiding costly re-operations (and thereby re-admission to or longer stay in the hospital) for e.g. repair of a ureteral injury or a common bile duct injury. When certain routine surgical procedures can be performed faster, as a consequence of earlier identification of vital anatomical structures, this can also lead to a cost reduction. 


\section{References}

1. Koninckx PR, Stepanian A, Adamyan L, Ussia A, Donnez J, Wattiez A (2013) The digital operating room and the surgeon. Gynecological Surgery 10:57-62

2. Broeders IA, Niessen W, van der Werken C, van Vroonhoven TJ (2000) [The operating room of the future]. Nederlands tijdschrift voor geneeskunde 144:204-210

3. Frangioni JV (2003) In vivo near-infrared fluorescence imaging. Current opinion in chemical biology 7:626-634

4. Klohs J, Wunder A, Licha K (2008) Near-infrared fluorescent probes for imaging vascular pathophysiology. Basic research in cardiology 103:144-151

5. Schols RM, Bouvy ND, van Dam RM, Stassen LP (2013) Advanced intraoperative imaging methods for laparoscopic anatomy navigation: an overview. Surg Endosc 27:1851-1859

6. Verbeek FP, van der Vorst JR, Schaafsma BE, Hutteman M, Bonsing BA, van Leeuwen FW, Frangioni JV, van de Velde CJ, Swijnenburg RJ, Vahrmeijer AL (2012) Image-guided hepatopancreatobiliary surgery using near-infrared fluorescent light. J Hepatobiliary Pancreat Sci 19:626-637

7. Marano A, Priora F, Lenti LM, Ravazzoni F, Quarati R, Spinoglio G (2013) Application of fluorescence in robotic general surgery: review of the literature and state of the art. World J Surg 37:2800-2811

8. Cahill RA, Ris F, Mortensen NJ (2011) Near-infrared laparoscopy for real-time intra-operative arterial and lymphatic perfusion imaging. Colorectal Dis 13 Suppl 7:12-17

9. Cao Q, Zhegalova NG, Wang ST, Akers WJ, Berezin MY (2013) Multispectral imaging in the extended near-infrared window based on endogenous chromophores. J Biomed Opt 18:101318

10. Smith AM, Mancini MC, Nie S (2009) Bioimaging: second window for in vivo imaging. Nature nanotechnology 4:710-711

11. Lu G, Fei B (2014) Medical hyperspectral imaging: a review. J Biomed Opt 19:10901

12. Wagner OJ, Louie BE, Vallieres E, Aye RW, Farivar AS (2012) Near-infrared fluorescence imaging can help identify the contralateral phrenic nerve during robotic thymectomy. Ann Thorac Surg 94:622-625

13. Gibbs-Strauss SL, Nasr KA, Fish KM, Khullar O, Ashitate Y, Siclovan TM, Johnson BF, Barnhardt NE, Tan Hehir CA, Frangioni JV (2011) Nerve-highlighting fluorescent contrast agents for image-guided surgery. Molecular imaging 10:91-101

14. Whitney MA, Crisp JL, Nguyen LT, Friedman B, Gross LA, Steinbach P, Tsien RY, Nguyen QT (2011) Fluorescent peptides highlight peripheral nerves during surgery in mice. Nature biotechnology 29: 352-356

15. Gustafson TP, Yan Y, Newton P, Hunter DA, Achilefu S, Akers WJ, Mackinnon SE, Johnson PJ, Berezin MY (2012) A NIR Dye for Development of Peripheral Nerve Targeted Probes. MedChemComm 3:685-690

16. Vahrmeijer AL, Hutteman M, van der Vorst JR, van de Velde CJ, Frangioni JV (2013) Image-guided cancer surgery using near-infrared fluorescence. Nature reviews Clinical oncology 10:507-518

17. Miyashiro I, Kishi K, Yano M, Tanaka K, Motoori M, Ohue M, Ohigashi H, Takenaka A, Tomita Y, Ishikawa O (2011) Laparoscopic detection of sentinel node in gastric cancer surgery by indocyanine green fluorescence imaging. Surg Endosc 25:1672-1676

18. Tobis S, Knopf J, Silvers C, Yao J, Rashid H, Wu G, Golijanin D (2011) Near infrared fluorescence imaging with robotic assisted laparoscopic partial nephrectomy: initial clinical experience for renal cortical tumors. J Urol 186:47-52

19. Dip FD, Asbun D, Rosales-Velderrain A, Menzo EL, Simpfendorfer CH, Szomstein S, Rosenthal RJ (2014) Cost analysis and effectiveness comparing the routine use of intraoperative fluorescent cholangiography with fluoroscopic cholangiogram in patients undergoing laparoscopic cholecystectomy. Surg Endosc 28:1838-43

20. Ankersmit M, van der Pas MH, van Dam DA, Meijerink WJ (2011) Near infrared fluorescence lymphatic laparoscopy of the colon and mesocolon. Colorectal Dis 13 Suppl 7:70-73

21. Aoki T, Murakami M, Yasuda D, Shimizu Y, Kusano T, Matsuda K, Niiya T, Kato H, Murai N, Otsuka K, Kusano M, Kato T (2010) Intraoperative fluorescent imaging using indocyanine green for liver mapping and cholangiography. J Hepatobiliary Pancreat Sci 17:590-594 
22. van der Pas MH, van Dongen GA, Cailler F, Pelegrin A, Meijerink WJ (2010) Sentinel node procedure of the sigmoid using indocyanine green: feasibility study in a goat model. Surg Endosc 24:2182-2187

23. Ashitate Y, Stockdale A, Choi HS, Laurence RG, Frangioni JV (2012) Real-time simultaneous nearinfrared fluorescence imaging of bile duct and arterial anatomy. J Surg Res 176:7-13

24. Buchs NC, Hagen ME, Pugin F, Volonte F, Bucher P, Schiffer E, Morel P (2012) Intra-operative fluorescent cholangiography using indocyanin green during robotic single site cholecystectomy. Int J Med Robot 8:436-440

25. Cahill RA, Anderson M, Wang LM, Lindsey I, Cunningham C, Mortensen NJ (2012) Near-infrared (NIR) laparoscopy for intraoperative lymphatic road-mapping and sentinel node identification during definitive surgical resection of early-stage colorectal neoplasia. Surg Endosc 26:197-204

26. Ishizawa T, Bandai Y, Ijichi M, Kaneko J, Hasegawa K, Kokudo N (2010) Fluorescent cholangiography illuminating the biliary tree during laparoscopic cholecystectomy. Br J Surg 97:1369-1377

27. Ishizawa T, Kaneko J, Inoue Y, Takemura N, Seyama Y, Aoki T, Beck Y, Sugawara Y, Hasegawa K, Harada N, Ijichi M, Kusaka K, Shibasaki M, Bandai Y, Kokudo N (2011) Application of fluorescent cholangiography to single-incision laparoscopic cholecystectomy. Surg Endosc 25:2631-2636

28. Jeschke S, Lusuardi L, Myatt A, Hruby S, Pirich C, Janetschek G (2012) Visualisation of the lymph node pathway in real time by laparoscopic radioisotope- and fluorescence-guided sentinel lymph node dissection in prostate cancer staging. Urology 80:1080-1086

29. Matsui A, Tanaka E, Choi HS, Kianzad V, Gioux S, Lomnes SJ, Frangioni JV (2010) Real-time, nearinfrared, fluorescence-guided identification of the ureters using methylene blue. Surgery 148:78-86

30. Matsui A, Tanaka E, Choi HS, Winer JH, Kianzad V, Gioux S, Laurence RG, Frangioni JV (2010) Real-time intra-operative near-infrared fluorescence identification of the extrahepatic bile ducts using clinically available contrast agents. Surgery 148:87-95

31. Schols RM, Bouvy ND, Masclee AA, van Dam RM, Dejong CH, Stassen LP (2013) Fluorescence cholangiography during laparoscopic cholecystectomy: a feasibility study on early biliary tract delineation. Surg Endosc 27:1530-1536

32. Tagaya N, Shimoda M, Kato M, Nakagawa A, Abe A, Iwasaki Y, Oishi H, Shirotani N, Kubota K (2010) Intraoperative exploration of biliary anatomy using fluorescence imaging of indocyanine green in experimental and clinical cholecystectomies. J Hepatobiliary Pancreat Sci 17:595-600

33. Tajima Y, Murakami M, Yamazaki K, Masuda Y, Kato M, Sato A, Goto S, Otsuka K, Kato T, Kusano M (2010) Sentinel node mapping guided by indocyanine green fluorescence imaging during laparoscopic surgery in gastric cancer. Ann Surg Oncol 17:1787-1793

34. Yoshida M, Kubota K, Kuroda J, Ohta K, Nakamura T, Saito J, Kobayashi M, Sato T, Beck Y, Kitagawa Y, Kitajima M (2012) Indocyanine green injection for detecting sentinel nodes using color fluorescence camera in the laparoscopy-assisted gastrectomy. J Gastroenterol Hepatol 27 Suppl 3:29-33

35. Verbeek FP, van der Vorst JR, Schaafsma BE, Swijnenburg RJ, Gaarenstroom KN, Elzevier HW, van de Velde CJ, Frangioni JV, Vahrmeijer AL (2013) Intraoperative near infrared fluorescence guided identification of the ureters using low dose methylene blue: a first in human experience. J Urol 190:574-579

36. Buckle T, Chin PT, van Leeuwen FW (2010) (Non-targeted) radioactive/fluorescent nanoparticles and their potential in combined pre- and intraoperative imaging during sentinel lymph node resection. Nanotechnology 21:482001

37. Choi HS, Gibbs SL, Lee JH, Kim SH, Ashitate Y, Liu F, Hyun H, Park G, Xie Y, Bae S, Henary M, Frangioni JV (2013) Targeted zwitterionic near-infrared fluorophores for improved optical imaging. Nat Biotechnol 31:148-153

38. Kosaka N, Mitsunaga M, Longmire MR, Choyke PL, Kobayashi H (2011) Near infrared fluorescenceguided real-time endoscopic detection of peritoneal ovarian cancer nodules using intravenously injected indocyanine green. Int J Cancer 129:1671-1677

39. Verbeek FP, Schaafsma BE, Tummers QR, van der Vorst JR, van der Made WJ, Baeten Cl, Bonsing BA, Frangioni JV, van de Velde CJ, Vahrmeijer AL, Swijnenburg RJ (2013) Optimization of near-infrared fluorescence cholangiography for open and laparoscopic surgery. Surg Endosc 28:1076-82 
40. Bydlon TM, Nachabe R, Ramanujam N, Sterenborg HJ, Hendriks BH (2014) Chromophore based analyses of steady-state diffuse reflectance spectroscopy: current status and perspectives for clinical adoption. Journal of biophotonics. In press

41. Cau R (2014) Design and realization of a master-slave system for reconstructive microsurgery. Eindhoven : Technische Universiteit Eindhoven 
Summary, discussion and future perspectives 
Nederlandse samenvatting 


\section{Nederlandse samenvatting}

Vele technologische innovaties hebben hun intrede gedaan in de operatiekamer gedurende de afgelopen decennia. In het bijzonder de minimaal-invasieve chirurgie is geassocieerd met een continue stroom van nieuwe technologische ontwikkelingen. "Beeld-geleide chirurgie" vormt een van de laatste innovaties die op de deur van de operatiekamer van de toekomst klopt.

De detectie van vitale anatomische structuren (bijv. zenuwen, ureteren, arteriën, galwegen) is van groot belang tijdens alle soorten chirurgische procedures, aangezien misidentificatie van deze anatomische structren kan leiden tot iatrogeen letsel. De verkenning van innovatieve optische technieken biedt mogelijkheden om de intraoperatieve identificatie en karakterisering van deze weefsels te verbeteren.

Op basis van een systematische review van de literatuur, beschrijft Hoofdstuk 2 zes optische technieken die mogelijk als intraoperatief hulpmiddel kunnen dienen voor rechtstreekse anatomische navigatie tijdens chirurgie: infrarood beeldvorming, fluorescentiebeeldvorming, optische coherentie tomografie, diffuse reflectie spectroscopie, hyperspectrale beeldvorming en opto-akoestische beeldvorming. In dit hoofdstuk wordt een overzicht gegeven van de meest recente ontwikkelingen betreffende deze optische technieken voor verbeterde anatomische identificatie en fysiologische karakterisering.

Voor de evaluatie van optische technieken gebaseerd op exogene of endogene contrasten, richt deze thesis zich op twee technieken: nabij-infrarode fluorescentie beeldvorming met gebruikmaking van exogene contrasten (Deel I) en diffuse reflectie spectroscopie op basis van endogene contrasten (Deel II).

\section{Nabij-infrarode fluorescentie laparoscopie (Deel I)}

De laparoscopische cholecystectomie betreft een van de meest uitgevoerde laparoscopische procedures. Galwegletsel is een zeldzame maar ernstige complicatie tijdens deze ingreep, veelal veroorzaakt door misidentificatie van de extra-hepatische galweganatomie. Conventionele intraoperatieve cholangiografie kan toegepast worden om het risicio op galwegletsel te reduceren; dit betreft echter geen standaard procedure wereldwijd. Hoofdstuk 3 beschrijft de eerste toepassing van een laparoscopisch fluorescentie beeldvorming systeem voor intermitterende nabijinfrarode fluorescentie cholangiografie (NIRFC) met gebruikmaking van jodiumvrij indocyanine groen (ICG) tijdens electieve laparoscopische cholecystectomie. Deze pilot studie demonstreert de verdienste van NIRFC als hulpmiddel om eerdere en duidelijkere herkenning van de extra-hepatische galweganatomie te verkrijgen, vergeleken met conventionele laparoscopische beeldvorming alleen. Hoofdstuk 4 
rapporteert de mogelijkheid van gelijktijdige vasculaire en biliaire beeldvorming op het moment van verkrijgen van Critical View of Safety (CVS). Herhaalde ICG injectie bij verkrijgen van CVS levert bevestiging van arteriële anatomie, in het bijzonder het verloop van de arteria cystica. De implementatie van zowel fluorescentie cholangiografie als angiografie kan ondersteunend zijn in gevallen waarin verkrijgen van CVS uitdagend is. Daarnaast kan het helpen bij intraoperatieve detectie van galwegletsel en mogelijk simultaan vasculobiliair letsel (bijv. van de arteria hepatica).

De observaties in Hoofdstuk $\mathbf{3}$ en $\mathbf{4}$ laten zien dat zowel biliaire als vasculaire fluorescentie beeldvorming gemakkelijk toepasbaar is tijdens laparoscopische cholecystectomie.

Ondanks veelbelovende resultaten is optimalisatie van deze nieuwe techniek met betrekking tot het beeldvormingssysteem én de gebruikte fluorescente contrastvloeistof wenselijk. Zo zou een grotere penetratiediepte waarop het beeldvormingssysteem een contrastvloeistof in weefsels kan detecteren, de toepasbaarheid van de techniek vergroten (huidig maximum tot 1 centimeter). Dit geldt ook voor een toename van de fluorescente karakteristieken van de contrastvloeistoffen (bijvoorbeeld toegenomen opname door het target-weefsel en betere contrast-ratio tussen het target-weefsel en achtergrondweefsel).

Hoofdstuk 5 vergelijkt de prestaties van een preklinische nabij-infrarode contrastvloeistof, CW800-CA met ICG voor nabij-infrarode fluorescentie laparoscopie van de ductus cysticus and arteria cystica in een varkensmodel. We demonstreren daarmee dat CW800-CA, evenals ICG, toegepast kan worden voor laparoscopische fluorescentie detectie van de arteria cystica and ductus cysticus met gebruikmaking van hetzelfde commercieel verkrijgbare beeldvormingssysteem. Laparoscopische fluorescentie identificatie van de ductus cysticus kan eerder verkregen worden na toediening van CW800-CA dan na injectie van ICG. Met de beschikbaarheid van een dergelijk fluorescent contrastmiddel (met sterkere fluorescente karakteristieken) nemen de mogelijkheden toe om de beeldvormingscapaciteiten van de huidig beschikbare fluorescentiesystemen verder te optimaliseren. Een klinische pilot studie met CW800-CA, voor onder andere "dosis bepaling", is de volgende stap.

Ureterletsel treedt zelden op tijdens laparoscopische colorectale chirurgie, maar het kan ernstige problemen tot gevolg hebben. Daarom is de vroege en eenvoudige detectie van ureteren en de preventie van ureterletsel klinisch relevant. Hoofdstuk 6 beschrijft nabij-infrarode fluorescentie visualisatie van de ureteren in een varkensmodel met gebruikmaking van een commercieel verkrijgbaar laparoscopisch fluorescentie beeldvorming systeem en CW800-CA. Een enkele dosis van CW800-CA (85 $\mu \mathrm{g}$ per kilogram lichaamsgewicht) levert een heldere visualizatie van het verloop van beide ureteren op, ongeveer tien minuten na intraveneuze toediening. Als een 
mogelijke volgende stap zien wij een klinische pilot studie, die de haalbaarheid van nabij-infrarode fluorescentiebeeldvorming (met CW800-CA) voor intraoperatieve detectie van het verloop van de ureteren onderzoekt. Een dergelijke toekomstige studie zou zich ook moeten richten op een meer gerichte "dosis bepaling" van de toegediende contrastvloeistof.

\section{Diffuse reflectie spectroscopie tijdens chirurgie (Deel II)}

Diffuse reflectie spectroscopie (DRS) is een non-invasieve techniek die het karakteristieke reflectiespectrum meet, dat geproduceerd wordt door verschillende weefsels. Het primaire mechanisme is gebaseerd op absorptie en verstrooiing van het licht, beide variërend met de golflengte van het invallende licht en de optische eigenschappen van het weefsel. Het reflectiespectrum wordt gebruikt om het type weefsel te karakteriseren, dat onderzocht wordt.

Menselijk "kleuren-zien" is trichromatisch: het oog heeft drie soorten kegels: voor blauw, groen en rood licht. Hyperspectrale beeldvorming technologie levert een overvloed aan spectrale banden en een bredere spectrale bandbreedte. Deze techniek beschikt over het potentieel om "beeld-geleide chirurgie" mogelijk te maken. Zo is het bijvoorbeeld onderzocht voor non-invasieve, intraoperatieve beoordeling van weefsel zuurstofsaturatie, verbeterde intraoperatieve anatomische beeldvorming en intraoperatieve beoordeling van snijranden voor residuaal tumorweefsel.

Arrays van Charge-Coupled Devices (zogenaamde CCD's) en Complementary Metal Oxide Semiconductors (CMOS) zijn de meest gebruikte detectoren (camera chips) in medische hyperspectrale beeldvorming systemen, die kunnen bestaan uit silicium (Si) en indium gallium arsenide (InGaAs) sensoren. Si sensoren bestrijken het golflengte gebied van $400-1000 \mathrm{~nm}$, terwijl InGaAs sensoren gevoelig zijn binnen de golflengten van $900-1700 \mathrm{~nm}$.

Als een eerste stap in de evaluatie van het potentieel van hyperspectrale beeldvorming in chirurgie, zijn de spectrale handtekeningen van diverse weefseltypen in kaart gebracht en verkend voor onderscheidende endogene contrasten middels DRS.

Momenteel komen hyperspectrale camera's met Si (detectiegebied: het zichtbare en nabij-infrarode lichtspectrum) en InGaAs (detectiegebied: het "verlengde" nabijinfrarode en infrarode lichtspectrum) sensor chips beschikbaar. Om die reden rapporteren we onze bevindingen betreffende onderscheidende spectrale kenmerken met inachtneming van deze twee sensor detectie gebieden.

Een eerste ex vivo verkenning van DRS wordt beschreven in Hoofdstuk 7. Van vers geëxtirpeerde humane colonpreparaten zijn de breedbandige spectrale kenmerken van verschillende weefseltypen onderzocht: normaal colonweefsel, tumorweefsel in de 
colonwand, mesenteriaal vetweefsel, arterie, vene en ureter. Vertaling van de verzamelde spectra naar klinisch bruikbare informatie met behulp van geautomatiseerde diagnostische algoritmen is gedemonstreerd voor "een-punts" data (verzameld met een optische fiber probe). De potentie van deze eerste (nog nietbeeldvormende) DRS ligt in de mogelijkheid om deze techniek in te bouwen in een hyperspectrale beeldvorming modaliteit.

Tijdens colorectale chirurgie is de detectie van ureteren en mesenteriale arteriën van groot belang om iatrogeen letsel te voorkomen en om intraoperatieve besluitvorming te vergemakkelijken. Een hulpmiddel dat ureter- en arterie-specifieke beeldverbetering ten opzichte van het omliggende vetweefsel mogelijk maakt, zou tegemoet komen aan deze behoefte, in het bijzonder tijdens laparoscopie. Hoofdstuk 8 beschrijft het gebruik van DRS tijdens open colorectale chirurgie voor de classificatie van ureter en arterie ten opzichte van omliggend vetweefsel. Om mogelijke onderscheidende kenmerken te identificeren voor weefselclassificatie, zijn 36 kenmerken (18 gradiënten en 18 amplitudeverschillen op vooraf gedefinieerde punten in de weefselspectra) geëxtraheerd op basis van bekende golflengten gerelateerd aan karakteristieke absorptiekenmerken voor bloed, water en vetweefsel. Gradiënten zijn "hellingen" tussen twee vooraf gedefinieerde punten in de weefselspectra: $\left(D R_{2}-D R_{1}\right) /\left(\lambda_{2}-\lambda_{1}\right)$. Amplitudeverschillen zijn "intensiteitsverschillen" tussen twee vooraf gedefinieerde spectrale punten: $\left(D R_{2}-D R_{1}\right)$. $D R=$ diffuse reflectance; $\lambda=$ wavelength. De kenmerken, gebruikt voor classificatie, zijn potenteel significant door verschillen in chemische compositie (bijvoorbeeld hemoglobine-, water- en vet-gehalte) van de onderzochte weefsels en structuren. Deze studie toont dat $\mathrm{Si}$ en InGaAs sensoren (in feite de spectrale detectie gebieden die zijn gehanteerd bij de spectrale data analyse, zoals hierboven uiteengezet) in gelijke mate geschikt zijn voor geautomatiseerde classificatie van ureter versus omliggend vetweefsel. Si sensoren lijken beter geschikt te zijn voor het classificeren van arterie ten opzichte van mesenteriaal vetweefsel.

Intraoperatieve zenuwdetectie kan tevens van groot belang zijn tijdens chirurgie. Bij bepaalde procedures, waarin zenuwen op het oog gelijkenis tonen met het omliggende vetweefsel, kan dit bijzonder uitdagend zijn voor het menselijk oog. Een camerasysteem dat zenuw-specifieke beeldversterking mogelijk maakt, zou nuttig zijn. Hoofdstuk 9 zet uiteen dat InGaAs sensoren beter geschikt zijn voor geautomatiseerd onderscheid tussen zenuwen en omliggend vetweefsel, dan Si sensoren. Dit is waarschijnlijk gebaseerd op een verschillende verhouding waarin de endogene chromoforen water en vet aanwezig zijn in respectievelijk zenuw en vetweefsel. Naar verwachting kan selectieve beeldversterking van zenuwen ten opzichte van omliggend vetweefsel gunstig zijn binnen alle chirurgische disciplines. 
Tot slot, tijdens schildklier- en bijschildklierchirurgie dient iatrogeen bijschildklierletsel voorkomen te worden. Het detecteren van de kleine bijschildkliertjes kan uitdagend en tijdrovend zijn. In Hoofdstuk $\mathbf{1 0}$ is geautomatiseerde bijschildklierdifferentiatie onderzocht. Si en InGaAs sensoren blijken redelijk accuraat voor geautomatiseerde classificatie van bijschildklierweefsel ten opzichte van omliggend vetweefsel of aangrenzend schildklierweefsel. Klinisch relevante nauwkeurigheid wordt echter niet bereikt voor de individueel onderzochte sensortypen. Combinatie van de twee sensortechnologiën verbetert de nauwkeurigheid, met name betreffende de classificatie van bijschildklier versus vetweefsel.

Met de resultaten van de verschillende verkennende studies met fiber-optische DRS in dit proefschrift, is het potentieel van geautomatiseerde weefselclassificatie onderstreept. Verder onderzoek van hyperspectrale chirurgische beeldvorming lijkt zodoende zeker de moeite waard. Het intraoperatieve visuele oordeel van een chirurg is niet alleen gebaseerd op spectrale (kleur) informatie, maar is ook afhankelijk van de herkenning van de ruimtelijke anatomische lokalisatie van een specifiek weefseltype. Om die reden moeten de "een-punts" metingen (in feite de "ground-truth" referentiespectra van specifieke weefseltypen), uitgevoerd in de verkennende studies in dit proefschrift, beschouwd worden als slechts een eerste stap richting de meer klinisch relevante techniek van hyperspectrale beeldvorming van het gehele chirurgische werkveld (hetgeen weefsel-specifieke contrastversterking oplevert).

\section{Conclusie}

Toekomstige implementatie van nieuwe intraoperatieve optische technieken, zoals nabij-infrarode fluorescentie beeldvorming (NIRF) of diffuse reflectie spectroscopie (DRS), kan de chirurg voorzien van een verbeterde, rechtstreekse identificatie en fysiologische weefsel karakterisering van essentiële anatomische structuren die van belang zijn tijdens een grote diversiteit aan chirurgische procedures. Dit kan een significante bijdrage leveren aan intraoperatieve anatomische navigatie en kritische besluitvorming vergemakkelijken. De NIRF techniek is momenteel het dichtst bij klinische implementatie. Technieken gebaseerd op endogene contrasten, zoals DRS, kunnen ook een sterk hulpmiddel tijdens chirurgie vormen wanneer verdere ontwikkeling plaatsvindt. Zowel NIRF als DRS hebben nog hun beperkingen, maar beschikken over potentieel om chirurgische zorg te verbeteren als aanvullende intraoperatieve hulpmiddelen. Dit kan uiteindelijk resulteren in een grotere procedurele veiligheid en efficiëntie. Zorgkosten kunnen gereduceerd worden door het voorkomen van kostbare heroperaties (en daarbijhorende heropname óf een langer verblijf in het ziekenhuis) voor bijvoorbeeld het herstel van een ureter- of galwegletsel. 
Wanneer bepaalde routinematige chirurgische procedures sneller uitgevoerd kunnen worden, als gevolg van een eerdere identificatie van vitale anatomische structuren, kan dit ook leiden tot een kostenreductie. 
Nederlandse samenvatting 


\section{Valorization addendum}

This chapter is intended to take a brief look upon the return of investment prospects for society from the knowledge gathered during this PhD-trajectory. For clarification, first a few terms will be defined that are frequently used in this chapter:

- Valorization is the use, for socio-economic purposes, of the results of research financed by public authorities. It represents society's direct and indirect return on the public sector's investment in research and development. More recently, the growing emphasis on open innovation has strengthened the cooperation between public research centers, universities and the business sector.

- Knowledge valorization refers to the utilization of scientific knowledge in practice. Examples include developing a product or a drug, or applying scientific knowledge to improve an existing system or process. The term knowledge valorization, in turn, is related to the term innovation.

- Innovation means converting new inventions to reality, in other words: applying inventions to create a product or process that indeed has a positive societal impact. Thus, in fact, an invention can only be considered an innovation if it is successfully applied and widely adopted in practice.

- History learns that many innovations were initiated by serendipity ${ }^{1}$ (valuable result by fortunate coincidence). One might argue that it would be worth thinking about how to increase the chance of indeed producing an innovation. Sheer luck itself cannot be forced, just like mankind cannot directly force a seed to sprout. But in both cases, optimizing the environmental preconditions increases the chance of success.

- An innovation eco-system is a research environment that helps to identify the right problems to work on, systematically looks for solutions, and once these are found then encourages and facilitates to complete the road to an actual product.

Hereafter the eco-system in which this thesis was constructed will be described, then the societal and economical relevance of introducing optical techniques in surgery will be addressed, and finally a perspective on knowledge utilization will be given.

\section{Description of the eco-system for the research conducted in this thesis}

This thesis focused on two optical techniques for application in surgery: near-infrared fluorescence imaging (using exogenous contrasts) and diffuse reflectance spectroscopy (based on endogenous contrasts). The focus of the research conducted on nearinfrared fluorescence laparoscopy was primarily guided by the researchers and medical 
specialists from the university medical center. With the resulting outcome of the various (pre)clinical studies and feedback from the end-users, the industrial endoscopic device partner is then able to further optimize the already commercially available laparoscopic fluorescence imaging apparatus (including both hardware and software), the industrial fluorescence contrast partner is helped with preclinical validation of its fluorophore towards future clinical application.

The investigations on diffuse reflectance spectroscopy form an early stage of discovering useful endogenous contrasts for selective tissue-enhancement. This work was conducted as part of the van 't Hoff Program for Medical Photonics. This shared research program, coordinated by TNO (Netherlands Organization for Applied Scientific Research), was named after Van 't Hoff, a famous Dutch chemist and winner of the first Nobel Prize for chemistry in 1901. The program is designed to be an innovation ecosystem in which multiple parties work together to make new knowledge applicable more quickly. It is focused upon Photonics in Medicine, because Photonics is regarded as a so-called Key Enabling Technology ${ }^{2}$. The European Union also regards developments in scanning, sensing and imaging of crucial importance for medical and healthcare activities to keep competitive and create new markets ${ }^{3}$.

For "discovery-phase" research the following issues applies:

- Complex and expensive research is needed to solve critical issues;

- Multiple applications by different parties can be expected (all based on the same knowledge base), especially if these parties also have comparable research questions;

- Simultaneous implementation of these applications increases the chance of success of the individual applications, and the synergetic effect is greater than the sum of its parts, thereby enhancing the societal impact and efficiency.

The aforementioned research program combines these points by bringing together key stakeholders to create an innovation ecosystem, ranging from research organizations to equipment and product manufacturers, from hospitals to foundations (see Figure 1).

The van 't Hoff Program: an innovation ecosystem consisting of research organizations, medical industry, key opinion clinicians from leading hospitals and foundations. This approach matches with the EU Council conclusions on innovation in the medical device sector: encourage better consideration of the needs of patients and healthcare professionals in the design process of medical devices and promote early dialogue between manufacturers, scientific and clinical experts, competent authorities and, where appropriate, notified bodies regarding 'new products' in particular, and their classification ${ }^{4}$. 


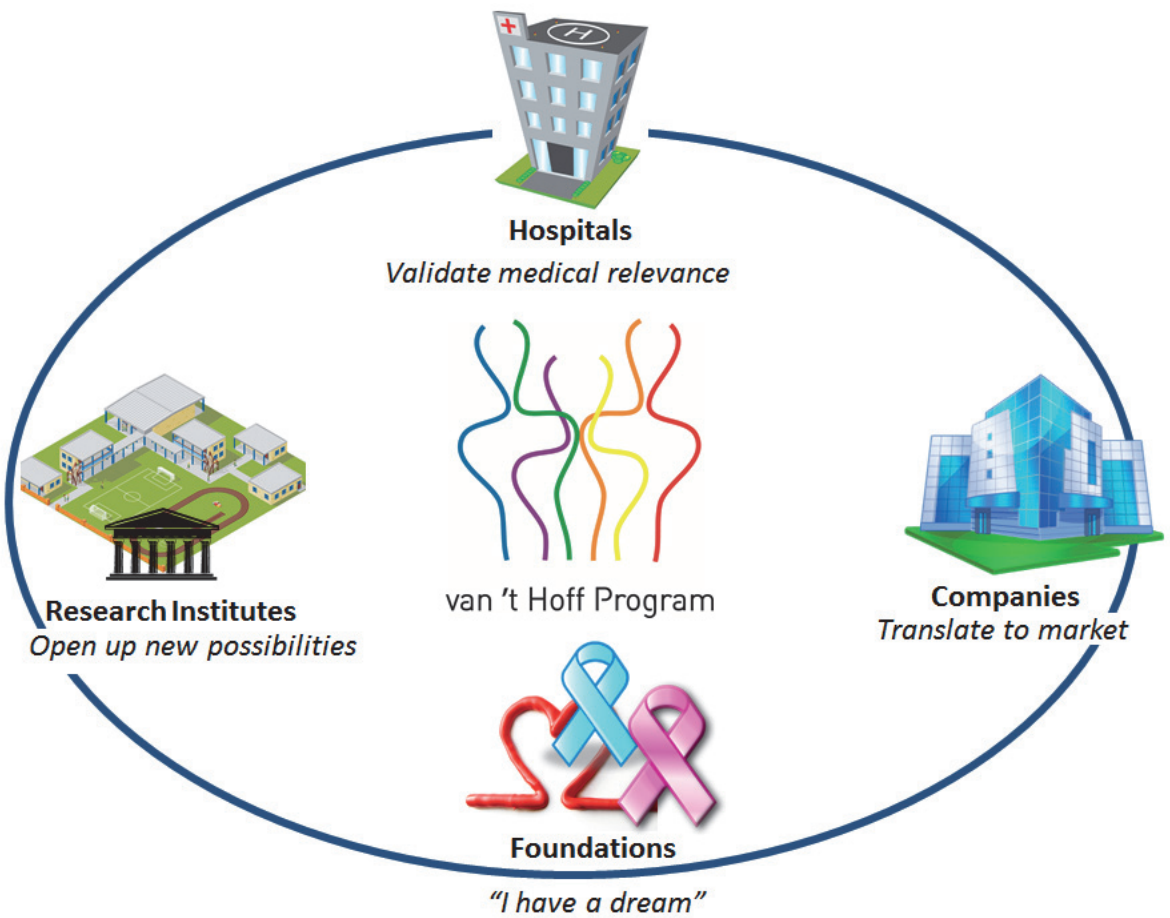

Figure 1 The aforementioned research program

This public-private collaboration is aimed at gathering knowledge and data that will help patients benefit from the potential advantages of optical spectroscopy. By examining the issues and addressing the unknowns together, the program shares the cost and risk factors associated with early phases of development. Each partner in this open innovation platform contributes specific knowledge and expertise to achieve a common goal: optimizing the use of optical spectroscopy in medicine. Risks, costs, facilities and data are shared between all participants, so that advancements can be made more effectively.

This approach provides a solid base that outlines the basic principles of how the technology works, and enables each individual industrial partner to use those principles for application in their product development process. This structure matches with the intention of the European Union to stimulate Responsible Research and Innovation that bridges the gap between science and society ${ }^{5}$. 


\section{Societal and economical relevance of introducing optical techniques in surgery}

As outlined in Chapter $\mathbf{1 1}$ of this thesis, it is likely that by developing and ultimately implementing innovative optical techniques (either near-infrared fluorescence imaging or diffuse reflectance spectroscopy) for intraoperative anatomical guidance, surgeons will benefit from improved (and perhaps even earlier) detection of vital anatomical structures.

In this context a visionary passage from Koninckx et al. ${ }^{6}$, describing a crave for such tools, can be cited: "Consider that on a separate screen side by side, or even better on the same screen, the vascularization pattern or the fluorescence of a cancer and its metastasis or of the smaller endometriosis lesions would be clearly visible. Consider what would happen to nerve sparing surgery when camera intelligence will show the difference between fibrosis and a nerve. Ureters today can be visualized with illuminated stents, but this is cumbersome and expensive; consider that the camera would recognize the ureter". At least two of these visions have come closer to becoming reality, with this thesis.

The developments described in this thesis can (over time) facilitate critical decisionmaking during surgery, which can result in safer and more efficient surgical dissection. With these projected developments a positive impact on the society - in the first place the patients undergoing surgery - and the economy is foreseen. Improved safety of the patient, in terms of a reduced risk of iatrogenic tissue injury, is in that perspective very relevant.

Enhanced intraoperative nerve detection (investigated in Chapter 9) could be beneficial for all kinds of surgical procedures. For example in abdominal surgical procedures preventing injury to autonomic pelvic nerves, improves functional outcome (decrease of the rate of sexual and urinary dysfunctions) ${ }^{7}$ and thereby the quality of life of the patient.

When higher procedural safety and efficiency can be achieved, health-care costs could be reduced by avoiding costly re-operations and thereby re-admission to or longer stay in the hospital, for e.g. repair of a ureteral injury or a common bile duct injury.

For example, Andersson et al conducted a cost-analysis regarding iatrogenic bile duct injury following cholecystectomy in a Scandinavian study population ${ }^{8}$. They conclude that the estimated overall costs for the society for the management of both minor and major bile duct injuries would be between 470,000 and 600,000 EURO per million inhabitants annually.

When certain routine surgical procedures can be performed faster, as a consequence of earlier identification of vital anatomical structures (e.g. as shown by the feasibility study 
on early biliary tract delineation using near-infrared fluorescence cholangiography, Chapter 3 ), this can also lead to a cost reduction. In a time of cut-backs on health-care costs, such cost-reduction is of great economical relevance and this can very well be achieved by implementation of innovative optical techniques in the operating room of the future.

Moreover, besides for technicians (medical technologists) and medical specialists (e.g. surgeons), the results of this thesis are also of interest for patients and patient societies. It can create awareness for the general public that there is a realistic hope for better intraoperative detection of vital tissue structures, which can result in safer and more efficient surgical procedures.

Another interesting fact: since 2002 the health care sector is the most important sector of employment in the Netherlands, and the proportion of health care in total employment is still growing. Altogether there are about 870,000 jobs in this sector. Although many highly educated people are working in health care, the number of jobs for highly educated persons itself is not increasing. An increase of highly technical jobs is mainly found in the development of drugs and medical devices. These categories are particularly interesting for the Netherlands, as these can also strengthen our export position $^{9}$.

\section{Perspective on knowledge utilization}

From the scope of this thesis, exploration of new intraoperative optical techniques and development of enhanced visualization chains for both open and endoscopic surgery is a goal of the project. As a matter of fact, the exploration of optical imaging/spectroscopy techniques might ultimately be interesting for all camera-linked interventions in medicine. In this way the entire medical community can benefit.

This thesis offers some new insights on medical photonics and hopefully there will follow next steps to make medical photonics contribute to patients' well-being. 


\section{References}

1. van Strien PJ (2011) Psychologie van de wetenschap: Creativiteit, serendipiteit, de persoonlijke factor en de sociale context

2. Aschhoff B, Crass D, Cremers K, Grimpe C, Rammer C, Brandes F, Diaz-Lopez F, Klein Woolthuis R, Mayer M, Montalvo C (2010) European Competitiveness in Key Enabling Technologies. ZEW (Centre for European Economic Research) and TNO (Netherlands Organization for Applied Scientific Research)

3. Butter M, Leis M, Sandtke M, McLean M, Lincoln J, Wilson A (2011) The Leverage Effect of Photonics Technologies: the European Perspective. European Commission

4. Council-of-the-European-Union (2011) Council conclusions on innovation in the medical device sector. Official Journal of the European Union

5. Geoghegan-Quinn M (2012) Responsible Research and Innovation: Europe's ability to respond to societal challenges. European Union, Publications Office, Odense, Denmark

6. Koninckx PR, Stepanian A, Adamyan L, Ussia A, Donnez J, Wattiez A (2013) The digital operating room and the surgeon. Gynecological Surgery 10:57-62

7. Grama FA, Burcos T, Bordea A, Cristian D (2014) Localisation and preservation of the autonomic nerves in rectal cancer surgery - technical details. Chirurgia 109:375-382

8. Andersson R, Eriksson K, Blind PJ, Tingstedt B (2008) latrogenic bile duct injury--a cost analysis. HPB : the official journal of the International Hepato Pancreato Biliary Association 10:416-419

9. Denktank-Omega (2011) Kruispunt van Wegen: 300.000+ banen in de Kenniseconomie. 
Valorization addendum 
List of publications 


\section{List of publications}

\section{Published articles}

Schols RM, Alic L, Beets GL, Breukink SO, Wieringa FP. Stassen LP. Automated spectroscopic tissue classification in colorectal surgery. Accepted for publication in Surgical Innovation.

Schols RM, ter Laan M, Stassen LP, Bouvy ND, Amelink A, Wieringa FP, Alic L. Differentiation between nerve and adipose tissue using wide-band ( $350-1830 \mathrm{~nm})$ in vivo diffuse reflectance spectroscopy. Lasers Surg Med. 2014 Sep;46(7):538-45.

Schols RM, Lodewick TM, Bouvy ND, van Dam DA, Meijerink WJHJ, van Dam GM, Dejong CHC, Stassen LPS. Near-infrared fluorescence laparoscopy of the cystic duct and artery in pigs: performance of a preclinical dye. J Laparoendosc Adv Surg Tech. 2014 May;24(5):318-22.

Schols RM, Lodewick TM, Bouvy ND, van Dam GM, Dejong CH, Stassen LP. Application of a new dye for near-infrared fluorescence laparoscopy of the ureters: demonstration in a pig model. Dis Colon Rectum. 2014 Mar;57(3):407-11.

Schipper RJ, Stassen LP, Smidt ML, Schols RM. A lady with history of colorectal carcinoma presenting with an abdominal mass. BMJ Case Reports. 2013 Nov 5.

Schols RM, Davies WL, Mudge EJ, Harding KG. Persistent plantar ulceration associated with mid-foot Charcot deformity. Wounds UK. 2013 Nov; 9(4):72-9.

Schols RM, Beets GL, Riedl RG, Schipper RJ. Oral pemphigus as first sign of an inflammatory myofibroblastic tumor in an 18-year old male. BMJ Case Reports. 2013 Oct 28.

Schols RM, Bouvy ND, van Dam RM, Masclee AA, Dejong CH, Stassen LP. Combined vascular and biliary fluorescence imaging in laparoscopic cholecystectomy. Surg Endosc. 2013 Dec;27(12):4511-7.

Schols RM, Stassen LP, Keymeulen KB, Bouvy ND. Dermoid cyst of the greater omentum: rare and innocent? BMJ Case Rep. 2013 Feb 28. 
Schols RM, Dunias P, Wieringa FP, Stassen LP. Multispectral characterization of tissues encountered during laparoscopic colorectal surgery. Med Eng Phys. 2013 Jul;35(7):1044-50.

Schols RM, Bouvy ND, van Dam RM, Stassen LP. Advanced intraoperative imaging methods for laparoscopic anatomy navigation: an overview. Surg Endosc. 2013 Jun;27(6):1851-9.

Schols RM, Bouvy ND, Masclee AA, van Dam RM, Dejong CH, Stassen LP. Fluorescence cholangiography during laparoscopic cholecystectomy: a feasibility study on early biliary tract delineation. Surg Endosc. 2013 May;27(5):1530-6.

Schols RM, Lauwers TM, Geskes GG, van der Hulst RR. Deep sternal wound infection after open heart surgery: current treatment insights. A retrospective study of 36 cases. Eur J Plast Surg. 2011 Dec; 34(6):487-492.

Schols RM, Schipper R, Brabers A, Schols JM. The Mini Suffering State Exam (MSSE) has been studied in a Dutch nursing home. Ned Tijdschr Verpleeghuisgeneesk. 2003; 27 (5): pp. 14-18.

\section{Submitted manuscripts}

Schols RM, Alic L, Wieringa FP, Bouvy ND, Stassen LP. Parathyroid differentiation during thyroid and parathyroid surgery by spectroscopy (350-1830 nm).

Schols RM, Connell NJ, Stassen LP. Near-infrared fluorescence imaging for real-time intraoperative anatomical guidance in minimally invasive surgery: a systematic review of the literature.

\section{Chapter in book}

Schols RM, Stassen LP (2014). Section II. Imaging Systems - Chapter 7: D-Light P System (Karl Storz). In: Dip F, Ishizawa T, eds. Concepts and Applications of Fluorescence Imaging for Surgeons. Springer Science and Business Media, New York, USA. In press. 
Publications 
Awards 


\section{Awards}

2014 NVEC Innovation Prize

$11^{\text {th }}$ National Congress of the Dutch Association for Endoscopic Surgery (NVEC), Amsterdam 25 March 2014

2013 Pélerin Science Prize

$18^{\text {th }}$ Pélerin arts-assistenten symposium Maastricht University Medical Center (MUMC), Maastricht 9 October 2013

2012 Clinical Science Travel Grant for Best Abstract

$20^{\text {th }}$ United European Gastroenterology Week (UEGW), Amsterdam 20-24 October 2012

2012 EAES Award for best Technology presentation

$20^{\text {th }}$ International Congress of the European Association for Endoscopic Surgery (EAES), Brussels 20-23 June 2012 
Dankwoord 


\section{Dankwoord}

Op de eerste plaats wil ik alle proefpersonen danken voor hun bereidwilligheid om mee te werken aan de intra-operatieve en postoperatieve onderzoeken, die zijn beschreven in de verschillende hoofdstukken. Voor deze studies, die grotendeels op de operatiekamers uitgevoerd werden, was ook de ondersteuning van de medewerkers van het MUMC OK-complex, de OK-assistenten, de medewerkers van de medisch technische dienst en de operateurs (chirurgen en arts-assistenten) onmisbaar.

De afdeling Heelkunde, het onderzoeksinstituut NUTRIM en het instituut voor Toegepast Natuurwetenschappelijk Onderzoek (TNO) wil ik hier graag danken voor het financieel mogelijk maken van mijn promotietraject, evenals hun support daarbij.

Tal van mensen hebben direct of indirect een waardevolle bijdrage geleverd aan de totstandkoming van dit proefschrift. Ik dank iedereen daarvoor!

Een aantal van hen wil ik in het bijzonder bedanken. Allereerst de drie (co-)promotoren.

Prof. dr. Stassen, beste Laurents, ik werd bij je geïntroduceerd door Nicole Bouvy. Je was kort daarvoor vanuit Delft in Maastricht gekomen en had grootse plannen voor diverse onderzoeksprojecten. De plannen die je mij als student schetste, spraken me direct aan en kort daarop begon ik, onder jouw toegewijde begeleiding, een gecombineerde klinische en wetenschappelijke stage gedurende het zesde jaar van mijn studie geneeskunde. Vanaf het begin kreeg ik alle vrijheid om ook mijn eigen ideeën en initiatieven te ontplooien. Het enthousiasme waarmee jij acteert op zowel klinisch, opleidings- als wetenschappelijk gebied werkt gewoonweg aanstekelijk. Ik ben je zeer dankbaar voor de mogelijkheid die ik heb gekregen om in een relatief rap tempo dit promotieonderzoek te voltooien en ook voor je steun bij mijn wens om de richting van de plastische chirurgie op te gaan.

Prof. dr. Bouvy, beste Nicole, jij was degene die me introduceerde bij Laurents. Gaandeweg werd jouw rol in de verschillende onderzoeken ook steeds nadrukkelijker. Je rol als copromotor was min of meer een logisch gevolg. Je grote betrokkenheid bij mijn activiteiten binnen de ziekenhuismuren, maar ook je interesse voor de persoonlijke kant van de arts-onderzoeker zorgden voor een plezierige samenwerking. Ondanks je drukke agenda was er altijd wel even tijd om bij te praten op je werkkamer. Je kordate en directe manier van werken heeft zeker bijgedragen aan het tempo waarmee dit proefschrift vorm heeft gekregen. Dat ik nu voor jou, als kersverse 
professor en daarmee tevens tweede promotor, ook de eerste officiële promovendus ben, maakt het nog extra bijzonder.

Dr. ing. Wieringa, beste Fokko, mijn medisch technologisch begeleider en eveneens copromotor vanuit TNO; vanaf onze eerste ontmoeting en daarmee het eerste experiment op de operatiekamer, was ik enorm onder de indruk van je bevlogenheid en tomeloos enthousiasme. Teksten als: "Rutger, jongen, we hebben hier werkelijk GOUD in handen", waren karakteristiek voor onze verdere samenwerking en voor het wederzijdse enthousiasme voor de activiteiten binnen het onderzoeksproject van TNO. Het is bewonderenswaardig hoe je je manifesteert op het snijvlak van de wereld van medisch specialisten en technologen. Daarnaast was je letterlijk elk moment van de dag bereid om mijn abstracts, manuscripten en presentaties van een kritische blik te voorzien; of dit nu op een vrije dag was als je het gras aan het maaien was bij je moeder, of dat je je een paar tijdzones verderop in de wereld bevond. Het is typerend voor jou als persoon.

Dr. Alic, beste Lejla; vanaf het moment dat de spectroscopie-data geanalyseerd en verwerkt moesten worden, heb jij, met jouw expertise op het gebied van imageprocessing, een essentiële rol gespeeld. Veel dank voor je hulp hierbij en je kritische beoordeling van de artikelen die hieruit zijn voortgekomen.

Drs. Lodewick, beste Toine; tijdens mijn afwezigheid vanwege een skivakantie sprong jij een dag voor mij in op het proefdierencentrum, hetgeen een perfecte score opleverde wat betreft output (2 manuscripten).

De hoofdstukken in dit proefschrift, die nu bijna allemaal zijn gepubliceerd, zouden kwalitatief niet van dit niveau zijn geweest zonder de inbreng van de co-auteurs. Hierbij wil ik dan ook alle co-auteurs danken die een bijdrage hebben geleverd aan een van deze hoofdstukken.

Graag wil ik ook het secretariaat Heelkunde, in het bijzonder Evelien, bedanken.

De leden van de beoordelingscommissie, prof. dr. J.G. Maessen, prof. dr. H.J. Bonjer, prof. dr. I.A.M.J. Broeders, prof. dr. J.P. Kooman en prof. dr. R.R.W.J. van der Hulst, wil ik hartelijk danken voor hun kostbare tijd en interesse om dit proefschrift te beoordelen en met mij te bediscussiëren tijdens mijn verdediging.

Ook dank ik de overige leden van de promotiecommissie, prof. dr. G.M. van Dam en dr. W.J.H.J. Meijerink, voor het optreden als opponent tijdens mijn verdediging. 
Tot slot wil ik nog enkele mensen noemen die niet direct een bijdrage hebben geleverd aan de wetenschappelijke inhoud van dit proefschrift, maar die wel belangrijk zijn geweest gedurende periode waarin dit proefschrift en de promotie tot stand zijn gekomen.

Oud-collega's van de onderzoeksafdeling Heelkunde in het MUMC.

Collega's van de afdeling Plastische Chirurgie in het MUMC, voor de leerzame periode tot dusver, de interesse voor mijn proefschrift en voor de collegialiteit.

Feest- en festivalgenoten, vrienden uit Amsterdam, Utrecht, Hilversum, Maastricht en elders. Vrienden van 't Oelbert, mooi dat we elkaar na al die jaren nog steeds af en toe zien. Laten we dat erin houden!

Vrienden van jaarclub Uitzonderring - Broos, Valentijn, Robert-Jan, Maarten, Wisse, Tom, Felix, Tim, Bart, Jeroen - maar ook Niels, als vaste aanwezige bij de jaarlijkse skivakantie; jullie zijn vrienden voor het leven, dat kan ik hier na ruim 9 jaar wel stellen!

Robert-Jan, Fust, klasgenoot vanaf de tweede klas van het gymnasium, allebei ingeloot voor de studie geneeskunde in dezelfde stad, dezelfde jaarclub, gelijktijdig gestart met promotieonderzoek bij de chirurgie en dan ook nog eens op dezelfde werkkamer terechtkomen. Wat hebben we een mooie tijd beleefd. De productie op de "office" werd in rap tempo gestimuleerd door de verse bonenkoffie die er dag in dag uit werd gemalen. Wat een prestatie dat je nu al in opleiding bent tot chirurg. Jouw promotie zal ook niet lang meer op zich laten wachten.

Ravi, Broertje, beste vrienden vanaf het moment dat we elkaar als eerstejaars studenten ontmoetten. Geweldig dat jij en Robert-Jan op deze bijzondere dag mijn paranimfen willen zijn.

Laurens, Floris, Myrthe en Emma, broers en zussen, wat hebben we het altijd gezellig samen. Ik ben ontzettend trots op wat jullie in jullie persoonlijke leven presteren.

Pa en ma, dankjewel voor de mogelijkheden en vrijheid die jullie me altijd hebben geboden en ook voor het feit dat jullie altijd voor ons klaar staan.

Last but not least, Mindy, lieve schat, bedankt voor je steun tijdens de laatste loodjes van de promotie en ook voor je creatieve inbreng bij de ontwikkeling van de cover van dit boekje. Ik ben gek op je! 
Curriculum Vitae 


\section{Curriculum Vitae}

Rutger Merlijn Schols werd geboren op 25 april 1987 in Maastricht. Na het behalen van het gymnasium diploma in 2005 aan het Sint-Oelbertgymnasium te Oosterhout (NoordBrabant), startte hij met de studie Geneeskunde aan de Universiteit van Maastricht. Reeds gedurende zijn studie verrichte hij onderzoek bij de afdeling Plastische Chirurgie van het Maastricht Universitair Medisch Centrum (MUMC). Hij volgde diverse keuzestages en coassistentschappen in het buitenland, onder andere in Italië (aan de Universiteit van Ferrara) en Suriname (in het Academisch Ziekenhuis en het Diakonessenhuis te Paramaribo). Ook volgde hij een klinische stage in Wales (UK) in de Wound Healing Research Unit te Cardiff en het Welsh Centre for Burns and Plastic Surgery te Swansea.

In 2011 studeerde hij af, na een gecombineerde kliniek- en wetenschapsstage bij de afdeling Heelkunde van het MUMC. Aansluitend startte hij op dezelfde afdeling zijn promotieonderzoek (promotores: prof. dr. L.P.S. Stassen, prof. dr. N.D. Bouvy; copromotor: dr. ing. F.P. Wieringa) waarvan de resultaten in dit proefschrift zijn beschreven. In het kader van dit promotieonderzoek was hij tevens aangesteld als promovendus binnen het van 't Hoff Programma, een zogenaamd "Shared Research Program" inzake Medische Fotonica, een samenwerkingsverband tussen ondermeer TNO (Nederlandse Organisatie voor Toegepast Natuurwetenschappelijk Onderzoek) en onderzoeksinstituut NUTRIM van de Universiteit Maastricht. Sinds 1 september 2014 werkt hij als arts-assistent (ANIOS) op de afdeling Plastische Chirurgie van het MUMC. 
